NBER WORKING PAPER SERIES

\title{
THE PRICE AIN'T RIGHT? HOSPITAL PRICES AND HEALTH SPENDING ON THE PRIVATELY INSURED
}

\author{
Zack Cooper \\ Stuart V. Craig \\ Martin Gaynor \\ John Van Reenen \\ Working Paper 21815 \\ http://www.nber.org/papers/w21815 \\ NATIONAL BUREAU OF ECONOMIC RESEARCH \\ 1050 Massachusetts Avenue \\ Cambridge, MA 02138 \\ December 2015, Revised May 2018
}

This paper drew inspiration from the work of Uwe Reinhardt. Professor Reinhardt passed away in December 2017 and we dedicate this paper to his memory. We are grateful for comments and suggestions that substantially improved the paper from the editors (Larry Katz and Andrei Shleifer), five anonymous referees, participants at multiple seminars, and Leemore Dafny, Matthew Fiedler, Joshua Gottlieb, Neale Mahoney, Fiona Scott Morton, Aviv Nevo, and Jonathan Skinner. This project received financial support from the Commonwealth Fund, the National Institute for Health Care Management Foundation, the Economic and Social Research Council, and the National Institute on Aging of the National Institutes of Health under Award Number P30AG012810. We acknowledge the assistance of the Health Care Cost Institute (HCCI) and its data contributors, Aetna, Humana, and United Healthcare, in providing the data analyzed in this study. The data used in this paper can be accessed with permission from HCCI. We thank Jennifer Wu, Nathan Shekita, Charles Gray, Austin Jaspers, Nina Russell, Darien Lee, Eugene Larsen-Hallock, and Christina Ramsay for outstanding research assistance. The opinions expressed in this paper and any errors are those of the authors alone, and do not necessarily reflect the views of the National Bureau of Economic Research. More details on our analysis can be found online at www.healthcarepricingproject.org.

NBER working papers are circulated for discussion and comment purposes. They have not been peer-reviewed or been subject to the review by the NBER Board of Directors that accompanies official NBER publications.

(C) 2015 by Zack Cooper, Stuart V. Craig, Martin Gaynor, and John Van Reenen. All rights reserved. Short sections of text, not to exceed two paragraphs, may be quoted without explicit permission provided that full credit, including $\odot$ notice, is given to the source. 
The Price Ain't Right? Hospital Prices and Health Spending on the Privately Insured Zack Cooper, Stuart V. Craig, Martin Gaynor, and John Van Reenen

NBER Working Paper No. 21815

December 2015, Revised May 2018

JEL No. I11,L10,L11

\begin{abstract}
$\underline{\text { ABSTRACT }}$
We use insurance claims data covering 28 percent of individuals with employer-sponsored health insurance in the US to study the variation in health spending on the privately insured, examine the structure of insurer-hospital contracts, and analyze the variation in hospital prices across the nation. Health spending per privately insured beneficiary differs by a factor of three across geographic areas and has a very low correlation with Medicare spending. For the privately insured, half of the spending variation is driven by price variation across regions and half is driven by quantity variation. Prices vary substantially across regions, across hospitals within regions, and even within hospitals. For example, even for a near homogenous service such as lower-limb MRIs, about a fifth of the total case-level price variation occurs within a hospital in the cross-section. Hospital market structure is strongly associated with price levels and contract structure. Prices at monopoly hospitals are 12 percent higher than those in markets with four or more rivals. Monopoly hospitals also have contracts that load more risk on insurers (e.g. they have more cases with prices set as a share of their charges). In concentrated insurer markets the opposite occurs - hospitals have lower prices and bear more financial risk. Examining the 366 merger and acquisitions that occurred between 2007 and 2011, we find that prices increased by over 6 percent when the merging hospitals were geographically close (e.g. 5 miles or less apart), but not when the hospitals were geographically distant (e.g. over 25 miles apart).
\end{abstract}

\section{Zack Cooper}

Yale ISPS

77 Prospect Street

New Haven, CT 06520

zack.cooper@yale.edu

Stuart V. Craig

The Wharton School

The University of Pennsylvania

stuart.v.craig@gmail.com

\author{
Martin Gaynor \\ Heinz College \\ Carnegie Mellon University \\ 4800 Forbes Avenue, Room 3008 \\ Pittsburgh, PA 15213-3890 \\ and NBER \\ mgaynor@cmu.edu \\ John Van Reenen \\ Department of Economics, E62-518 \\ MIT \\ 77 Massachusetts Avenue \\ Cambridge, MA 02139 \\ and NBER \\ vanreene@mit.edu
}




\section{Introduction}

Over 61 percent of the US population has private health insurance, which accounts for nearly 34 percent of total health spending (Hartman et al., 2017). In 2017, the average insurance premium for employer-sponsored health coverage for a family of four was $\$ 18,764$ and between 2007 and 2017, premiums increased by about 55 percent (Kaiser Family Foundation, 2017). However, because of data availability, most of our understanding of health care spending comes from the analysis of the Medicare program, which covers less than 17 percent of the population and represents 20 percent of total health spending. ${ }^{1}$ For the most part, Medicare pays hospitals using prospectively-set reimbursements that are formula-based. By contrast, hospital prices for the privately insured are set via negotiations between hospitals and insurers. Unfortunately, private health insurance claims data in general and the results of these hospital/insurer negotiations in particular - hospitals' transaction prices - have been treated as commercially sensitive and have been largely unavailable to researchers. In this study, we use newly accessible claims data from three of the five largest private insurers in the US to study the variation in health spending on the privately insured. Notably, the data we use includes hospitals' transaction prices. As a result, we are able to study the role that variation in hospitals' prices plays in influencing health spending variation for the privately insured; to describe the variation in hospital prices across regions, within regions, and within hospitals; and to analyze the extent to which hospital and insurer market structures are associated with hospital price levels and the design of insurer-hospital payments (henceforth, "contracts").

The main data we use in this analysis are claims from Aetna, Humana, and UnitedHealth, which were provided by the Health Care Cost Institute (HCCI). Our data capture the details of the health care delivered to 27.6 percent of individuals in the US with employer-sponsored coverage between 2007 and 2011. The data include more than 88 million unique individuals and capture over $\$ 125$ billion in health spending per year. The paper proceeds in three stages.

First, we present a national picture of the variation in health spending per privately insured beneficiary across all 306 hospital referral regions (HRRs) in the US. ${ }^{2}$ Risk-adjusted

\footnotetext{
${ }^{1}$ Our discussion of Medicare is focused on the traditional, publicly administered Medicare program. See Curtu, Einav, Finkelstein, Levin and Bhatacharya (2017) for a comparison of the traditional, public Medicare program and the privately administered Medicare Advantage program.

${ }^{2}$ Hospital referral regions are geographic regions created by researchers at the Dartmouth Institute for Health Care Policy to approximate markets for tertiary medical care in the US. Each HRR generally includes at least one major
} 
health spending per privately insured beneficiary age 18 to 64 varies by a factor of more than three across these regions. The HRR in the $90^{\text {th }}$ percentile of the spending distribution (Grand Junction, Colorado) spends 47 percent more than the HRR in the $10^{\text {th }}$ percentile of the spending distribution (Sarasota, Florida). Spending per privately insured beneficiary and spending per Medicare beneficiary have a correlation of only 0.044 across HRRs. For the Medicare program (where prices are set administratively), variation in hospital reimbursement rates account for only 13 percent of the variation in spending across regions, whereas the variation in the quantity of care delivered across regions accounts for 95 percent of the national variation in spending (these sum to more than 100 percent because a covariance term accounts for -8 percent). This fact has motivated research analyzing the factors that drive variation in the amount of care delivered across regions (e.g. Finkelstein et al. 2016 and Cutler et al. 2017). By contrast, for the privately insured, about half of the variation in spending is driven by price variation across regions and half is driven by quantity variation. This motivates us to focus on analyzing the drivers of hospital price variation.

The second stage of our analysis looks at the variation in hospital prices and the structure of hospital payment contracts. Hospital care represents nearly 6 percent of GDP (Centers for Disease Control and Prevention, 2017) and is expensive - the average price of an inpatient case in 2011 is $\$ 14,240$ in our data. Hospital prices vary significantly across the country and across hospitals within HRRs. For example, hospitals with risk-adjusted knee replacement prices in the $90^{\text {th }}$ percentile of the national distribution of hospitals are 2.3 times as expensive as hospitals in the $10^{\text {th }}$ percentile. Likewise, in one representative HRR (Philadelphia, PA), the hospital in the $90^{\text {th }}$ percentile of prices in the region is over twice as expensive as the hospital in the $10^{\text {th }}$ percentile. This variation is also present for plausibly undifferentiated services, such as lowerlimb MRIs, which suggests that the dispersion we observe is not simply a function of differences in hospital quality or patient severity across providers.

Our data allow us to extend beyond previous analysis and identify the variation in prices for health care services delivered within hospitals. ${ }^{3}$ We find that the variation in prices within

referral center and the US is divided into 306 HRRs.
www.dartmouthatlas.org/downloads/methods/geogappdx.pdf for more information.
A small number of studies of specific mergers, which involve only a few hospitals in a small geographic area, have
had such data, usually as the result of an antitrust merger investigation. Haas-Wilson and Garmon (2011) have data
from a merger in suburban Chicago, Thompson (2011) utilizes data from a merger in Wilmington, North Carolina,
and Tenn (2011) has data from a merger in the San Francisco Bay area. Gowrisankaran, Nevo, and Town (2015)


hospitals for services ranging from joint replacements to lower-limb MRIs is substantial. We find that over a fifth of the total price variation across cases in the average month-year occurs within hospitals for the same procedure, after controlling for hospital fixed effects, insurance plan characteristics, and patient characteristics. That there is such substantial variation in prices for plausibly undifferentiated procedures such as lower limb MRIs within hospitals suggests that the relative bargaining power of insurers with hospitals can strongly influence price levels.

We then analyze how hospitals are paid. While there has been recent work looking at how physicians set their negotiated prices with commercial insurers (Clemens et al. 2017), much less is known about insurer-hospital contracts. We find that about 23 percent of hospitals' inpatient cases have prices set as a share of hospitals' charges - a "cost plus" contract that loads idiosyncratic patient risk onto the insurers. ${ }^{4} \mathrm{We}$ estimate no more than 57 percent of cases are on contracts where prices are prospectively set as a percentage of Medicare payment rates. This implies that hospital prices are less closely linked to the Medicare fee schedule than the 75 percent of cases that Clemens and Gottlieb (2017) observed for physicians' prices.

In the third stage of our analysis, we look at whether there is a link between market structure, hospital prices, and contractual form. Hospital prices and contract form are determined by bargaining between hospitals and insurers. Market structure is related to bargaining power hospitals with fewer potential competitors are likely in a stronger negotiating position with insurers, and vice versa. Further motivating this analysis, as we illustrate in Figure 1, there has been significant consolidation in the hospital sector between 2001 and 2011. During that period, based on data we collected, there were, on average, 66 merger and acquisition (M\&A) transactions per year. ${ }^{5}$ This led the Herfindahl Hirschman index (HHI) in hospital markets where mergers occurred to increase by 19 percent over this period. ${ }^{6}$

In our cross-sectional analysis, we find that hospitals in monopoly markets (relative to hospitals in quadropoly or greater markets) have 12.5 percent higher prices, 10.5 percentage points more cases paid as a share of charges (over a mean of 18.6 percent), and 11.3 percentage

have data from a merger investigation in northern Virginia, but do not analyze within hospital price differences. Ho and Lee (2017) analyze data from the California Public Employees' Retirement System (CalPERS), which has information on insurer specific prices at hospitals.

${ }^{4}$ Hospital charges are the amount hospitals bill for care (i.e. their list prices). Individuals who self-fund their care are typically the only ones who pay hospitals their charges.

${ }^{5}$ We have made our roster of hospital mergers available at www.healthcarepricingproject.org.

${ }^{6}$ We measure a HHI for each hospital in our data within a circular area around each hospital defined by a 15-mile radius. We measure a hospital's market share as its share of total hospital beds in those areas. 
points fewer of their prospectively paid cases that have prices set as a share of Medicare payment rates (over a mean of 48.3 percent). ${ }^{7}$ By contrast, hospitals located in areas where the three insurers in our data had a high (collective) market share had significantly lower prices and participated in contracts that exposed insurers to less financial risk. A 10 percentage point increase in the insurers' market share is associated with 7 percent lower prices, 4 percentage points less cases paid as a share of charges, and 6 percentage points more prospectively paid cases that have prices set as a percentage of Medicare payments.

To look at events that shifted market structure over time, we use our comprehensive database of hospital mergers combined with the HCCI panel data to examine how hospital prices evolve before and after merger events using difference-in-difference analysis. After mergers occurred, we find that prices increase by over 6 percent if the merging hospitals were close neighbors (less than or equal to five miles apart). The size of the post-merger price increases decline as the distance between merging parties increases, and there are no significant merger coefficients once merging hospitals are located over 25 miles apart. We find no pre-merger differences in trends in prices between merging and non-merging hospitals and show that our results are robust when we use various procedures to match treated and control hospitals.

An important caveat to our paper is that it is fundamentally descriptive. While we find strong links between market structure, prices, and contract form, because market structure will be correlated with unobserved factors, these relationships should not be assumed to be causal.

Our paper builds on a sizable literature that has used Medicare claims data to document large variations in health spending per beneficiary across HRRs (Fisher et al. 2003a,b; Finkelstein et al. 2016). A smaller literature has documented similar variation in spending on privately insured individuals using limited data samples. Both Chernew et al. (2010) and Newhouse et al. (2013) have documented that there is a low correlation between Medicare spending per beneficiary and private spending per beneficiary across HRRs. We add to this literature by using a much larger and more comprehensive national dataset to analyze health spending on the privately insured, by analyzing hospitals' transaction prices, and by addressing the key question of why prices are so high in some regions, but not in others. Crucially, our data on hospitals' transaction prices allow us to probe more deeply the claim in Chernew et al. (2010)

\footnotetext{
${ }^{7}$ We measure hospital market structure by counting competitors within a circular area around each hospital defined by a radius of 15 miles. In the results section we show that our results are robust to many alternative measures of hospital market structure and different market definitions.
} 
and Philipson et al. (2010) that variation in health spending on the privately insured is driven by differences in hospital prices across regions.

We also add to an existing literature that has used limited datasets to analyze variation in hospital transaction prices. Most of this literature has focused on describing differences in prices across regions (e.g. Government Accountability Office 2005, Ginsburg 2010, Coakley 2011, White, Reschovsky, and Bond 2014). We add to this literature by using data that cover the majority of hospitals nationally. ${ }^{8}$ This allows us to look at national variation in hospitals' prices and compare hospital prices across and within geographic areas. Likewise, we risk-adjust prices, look at narrowly defined procedures (e.g. joint replacements without complications), and focus on plausibly homogenous services (e.g. lower-limb MRIs). Collectively, this allows us to more effectively compare prices across hospitals by reducing the potential bias created from differences in quality and patient characteristics across hospitals. In addition, this is one of the first papers we are aware of that has described and quantified variation in prices within hospitals. Analyzing price variation within hospitals for broadly undifferentiated services allows us to hold quality constant. That we observe significant variation in prices across contracts within the same hospital provides evidence that the bargaining leverage of insurers influences hospital prices.

Finally, we add to a large literature on hospital competition (see Gaynor, Ho, and Town 2015), which has generally found that hospital prices are higher in more concentrated markets. However, much of this literature has relied on estimates of transaction prices based on hospitals' charges (rather than actual data on transaction prices) or has focused on data from limited areas or single states (often California). Our analysis shows that there is a positive but rather low correlation (0.314) between hospital charges and hospitals' transaction prices. Moreover, we go beyond existing work by looking at the relationship between market structure and transaction prices using data from across the nation and by analyzing the relationship between market structure and the design of hospital-insurer contracts. Our findings are broadly consistent with models of insurer-hospital bargaining, such as Gowrisankaran, Nevo, and Town (2016) and Ho and Lee (2017). There is also an existing literature that has examined the effects of single mergers or small groups of mergers (Vita and Sacher 2001, Krishnan 2001, Gaynor and Vogt

\footnotetext{
${ }^{8}$ Our data contain transaction prices for 72 percent of non-critical access hospitals that are registered with the American Hospital Association (AHA). These 2,358 hospitals in our inpatient sample capture over 88 percent of total hospital admissions in the US (based on AHA data). Previous studies have generally relied on data from single states, a single employer, or a small set of urban areas.
} 
2003, Capps and Dranove 2004, Dafny 2009, Haas-Wilson and Garmon 2011, Tenn 2011, Thompson 2011, Gowrisankaran, Nevo, and Town 2015, Garmon and Kmitch 2017). ${ }^{9}$ We add to this literature by examining the post-merger price effects of all hospital mergers between 2007 and 2011.

This paper is structured as follows. In Section II we outline our data, describe how we measure prices, and present descriptive statistics. In Section III we describe the variation in health spending across HRRs and determine the share of the variation that is a function of price differences across regions and the share that is a function of quantity differences. In Section IV, we describe the variation in hospital prices across HRRs, within HRRs, and within hospitals. In Section V, we describe insurer-hospital contracts. We then analyze the cross-sectional correlates of hospital price levels and contracts in Section VI, analyze mergers and hospital prices in Section VII, and make some concluding comments in Section VIII. Our online Appendices give more details on data (A); how we construct risk-adjusted prices (B); our measures of market structure (C); how we identified mergers (D); econometric matching methods used in our merger analysis (E); and the robustness of our analysis in areas where Blue-Cross Blue Shield (BCBS) insurers had high and low market share (F).

\section{Data and Variables}

\section{II.A Health Care Cost Institute data}

The main data we use are from the Health Care Cost Institute (HCCI). ${ }^{10}$ We discuss the data in more detail in Appendix A, but outline some of the main features here. The HCCI database includes health insurance claims for individuals with coverage from three of the five largest insurance companies in the US: Aetna, Humana, and UnitedHealth. The data cover all health services paid for by the insurers from 2007 to 2011. We focus on individuals with employersponsored coverage who are aged between 18 and 64 and for whom an HCCI payer is their primary insurer. The raw data covers 2.92 billion claims that were delivered to an insured population in our data of 88.7 million unique individuals (Table 1). ${ }^{11}$

\footnotetext{
${ }^{9}$ The exception is Dafny (2009), which examines the effect of 97 mergers that occurred between 1989 and 1996.

${ }^{10} \mathrm{HCCI}$ is a nonprofit organization dedicated to advancing knowledge about US health care costs and utilization. See http://www.healthcostinstitute.org for more information.

11 The HCCI data are "de-identified" and do not include patient identifiers such as social security numbers, names, dates of birth, or addresses. Users of HCCI data are not allowed to publish results that identify patients, insurers, or
} 
Appendix Figure 1 shows the proportion of privately insured lives that the HCCI data cover by state. ${ }^{12}$ The HCCI database offers a significantly more comprehensive picture of private health spending across the US than other private health insurance claims databases. The most prominent alternative dataset of private health insurance claims is the MarketScan database. While MarketScan data includes individuals in 90 percent of HRRs in the US, some HRRs in the MarketScan data have very thin coverage and include fewer than 200 beneficiaries. By contrast, the HCCI data include individuals in all 306 HRRs and the smallest HRR in 2011 has 2,932 beneficiaries. Appendix A1 gives a more detailed comparison between the datasets.

Although we describe the most comprehensive picture to date of health spending on the privately insured, we do not have claims from every insurer and, in particular, from BCBS insurers. As a result, our analysis does not necessarily generalize to private health insurance spending in the US as a whole. BCBS plans covered 41 percent of covered lives across the small, medium, and large group markets in 2011. ${ }^{13}$ To address possible concerns about the generalizability of our results, in Appendix $\mathrm{F}$ we reproduce all our main results using data from areas where BCBS plans have a high share of privately insured lives and areas where BCBS plans have a low share of privately insured lives.

The HCCI data include a unique hospital identifier, a unique patient identifier, the date services were provided, hospitals' charges (for 2010 and 2011), hospitals' negotiated transaction prices (broken down by facility and physician fees), and payments to hospitals made by patients in the form of co-insurance payments, co-payments, and payments made before deductibles were met. As a result, we know the amounts paid to hospitals for all health care encounters recorded in our data. ${ }^{14}$ This allows us to analyze how prices vary within and across hospitals and study how insurers reimburse hospitals.

hospitals by name. Because our data is de-identified, our project was exempted by the Yale Institutional Review Board.

12 The data capture more than 30 percent of the privately insured population in Texas, Arizona, Colorado, Florida, Georgia, Kentucky, Ohio, Wisconsin, New Jersey, and Rhode Island. At the low end, the data capture between 1.9 percent and 10 percent of the privately insured in Vermont, Michigan, Alabama, Wyoming, Montana, South Dakota, and Hawaii.

${ }^{13}$ Blue Cross Blue Shield is an association of 36 for-profit and not-for-profit health insurance companies in the United States. The BCBS insurance companies are licensees, the largest of which, Anthem, is a for-profit publicly traded firm that has beneficiaries in fourteen states. For more information on Blue Cross Blue Shield, see http://www.bcbs.com. We identify BCBS market share using data from HealthLeaders Interstudy, which is described in more detail in Appendix A.

14 We present a sample hip replacement case constructed from claims data online at http://healthcarepricingproject.org/sites/default/files/papers/sample_hip_claims.xlsx. 
We use an encrypted version of hospitals' National Plan and Provider Identification System (NPI) code in the HCCI data to link to data on hospital characteristics from the American Hospital Association (AHA) annual survey, quality scores from Medicare's Hospital Compare webpage, Medicare activity data from the 100 percent sample of Medicare claims (accessed via the American Hospital Directory (AHD)), Medicare reimbursement information from the Centers for Medicare and Medicaid Services (CMS), and reputational quality scores from U.S. News \& World Report. We use hospitals' five-digit zip codes to link to local area characteristics from the Census. We use the system ID from the AHA data to identify multiple hospitals that are part of the same health system when we calculate our measures of hospital market structure. ${ }^{15}$ The AHA annual survey sometimes consolidates hospital IDs when two hospitals merge, even when those two hospitals each remain open. We use various data sources to continue tracking the original hospitals even after consolidation and to create a consistent longitudinal database of hospital sites. ${ }^{16}$

\section{II.B Sample Definitions}

To support our analysis, we create three broad sub-samples from the raw HCCI data: the "spending samples", the "inpatient price sample" and the "procedure samples".

The spending samples measure inpatient and overall spending per privately insured beneficiary. Our measure of total spending per beneficiary captures the sum of spending on inpatient, outpatient, and physician services, but excludes drug spending (we exclude prescription drug spending because it is not readily available for Medicare beneficiaries). Our measure of inpatient spending only captures inpatient hospital spending. We calculate spending per beneficiary by summing total or inpatient spending for each individual in our data in each HRR per year. To get the total number of private beneficiaries per HRR, we sum up the member months of coverage per HRR per year and divide by twelve. We use data from the Dartmouth Atlas for 2008 through 2011 to analyze variation in spending per Medicare beneficiary. ${ }^{17}$

\footnotetext{
${ }^{15}$ Hospitals that are part of the same health system are under common ownership (i.e. they are different establishments that are part of the same firm).

${ }^{16}$ A complete list of data sources is contained in Appendix A1 and our process for identifying hospitals using their NPI code is outlined in Appendix A2. In Appendix A3, we detail our method for maintaining a consistent hospitallevel panel database in the face of merger activity.

${ }^{17}$ Data from the Dartmouth Atlas can be downloaded at: http://www.dartmouthatlas.org/tools/downloads.aspx. Information on how Medicare spending per beneficiary is calculated is available in their Research Methods document, accessible at: http://www.dartmouthatlas.org/downloads/methods/research_methods.pdf.
} 
Following the approach taken by Dartmouth, we risk-adjust our HCCI spending samples for age and sex. ${ }^{18}$ In our decomposition of Medicare spending, we use data from the 100 percent sample of Medicare claims data that identifies how many cases in each diagnosis related group (DRG) case were provided by each hospital in the US in 2011. Our spending samples include claims for services that were delivered at all providers including, for example, care delivered at critical access hospitals.

The inpatient price sample is derived from hospital claims for all inpatient care provided to our covered population (age 18 to 64) in AHA registered facilities. ${ }^{19}$ In total, there are 3,272 non-critical access hospitals that are registered with the AHA during our sample period (see Appendix Table 1) and we have all but 70 of them in the HCCI data. We focus our analysis on general medical and surgical hospitals and do not include specialist hospitals (e.g. orthopedic specialty hospitals). We exclude three hospitals for which we do not have Medicare payment information and also drop data from 2007 because incomplete data (this leads to a loss of 10 hospitals). We also limit our analysis to providers that delivered 50 or more cases per year, so that we had sufficient data to calculate our inpatient price index. Although this means losing a further 831 hospitals, these hospitals only account for 1.5 percent of our inpatient cases. We are left with 2,358 hospitals in our inpatient sample, which account for 88.4 percent of the total inpatient cases from the original 3,272 AHA hospitals that were eligible to be included in our analysis (Appendix A4 gives more detail on our sample restrictions).

We also create seven procedure samples, which capture claims for hospital-based surgical or diagnostic inpatient and outpatient procedures. We create procedure samples for hip replacements, knee replacements, cesarean sections, vaginal deliveries, percutaneous transluminal coronary angioplasties (PTCAs), diagnostic colonoscopies, and magnetic resonance imaging (MRI) of lower-limb joints without contrast. These procedures occur with sufficient

\footnotetext{
${ }^{18}$ Because we do not have data on race, we risk-adjust using age and sex as opposed to Dartmouth who risk-adjust using age, sex, and race. Like Dartmouth, we also risk-adjust spending using indirect standardization. For a detailed discussion of the risk-adjustment methods, see: http://www.dartmouthatlas.org/downloads/methods/indirect_adjustment.pdf.

${ }^{19}$ Our inpatient data in Table 1 includes some incomplete records. We exclude the 0.1 percent of cases that have missing or negative prices. A further 8 percent of cases are excluded because they are missing a provider identifier or patient characteristics. We exclude cases that have length of stay in the top 1 percent of the distribution by DRG (these are cases with a length of stay of over six months in some cases). We then remove cases with prices in the top 1 percent and bottom 1 percent of the price distribution by DRG. Our results are robust to winsorizing these outliers instead of trimming them.
} 
frequency to support empirical analysis and are relatively homogeneous, thereby facilitating comparison across facilities and areas (Centers for Disease Control and Prevention 2010).

Each observation in the seven procedure samples includes all hospital claims from the time the patient entered the hospital until s/he exited the facility. We limit the observations included in our analysis to those without major medical complications and define the seven procedure samples narrowly using diagnosis and procedure codes to exclude atypical cases (see Appendix A4). We limit our observations to hospitals that deliver at least ten of a given procedure per year and applied the same cleaning rules we used to define our inpatient sample. ${ }^{20}$ In total, from 2008 to 2011, we capture 470 hospitals performing hip replacements, 932 performing knee replacements, 1,163 performing cesarean sections, 1,280 performing vaginal deliveries, 652 performing PTCAs, 1,237 performing colonoscopies, and 1,628 performing lower-limb MRIs who meet our sample restrictions.

Table 2 reports summary statistics for our inpatient sample. ${ }^{21}$ Our sample of hospitals in the inpatient and procedure samples are generally similar to the universe of AHA-registered hospitals, but there are some differences (Appendix Table 1). These differences are due in large part to our requirement that hospitals treat a minimum number of cases in our data annually, which means we are dropping some smaller hospitals. Relative to the universe of AHAregistered hospitals, hospitals in our inpatient sample are larger (an average of 270 beds versus 218 among all AHA hospitals), are located in less concentrated markets, and are more likely to be teaching facilities, non-profit facilities, and facilities ranked by the U.S. News \& World Report as top performers.

\section{II.C Measuring Hospital-level Prices}

Hospitals vary in the mix of services they offer and the patients they treat. As a result, a general concern when analyzing differences in prices across hospitals is that variation in prices could reflect observed and unobserved differences in the quality of care, mix of care, or the quantity of care provided per case at different facilities. For example, if patients with a given condition at a

\footnotetext{
${ }^{20}$ For MRI we also require a separate physician claim for the reading of the MRI, which we do not include in our main analyses of price. We do this so that the facility portion we analyze only captures the taking the MRI as opposed to the reading of the MRI. We also restrict our lower-limb MRI cases to those for which the MRI itself was the only intervention occurring during the individual's visit to the hospital,

${ }^{21}$ The descriptive statistics for the sub-samples for each of the seven procedures look qualitatively similar and are available online at www.healthcarepricingproject.org.
} 
hospital were more severely ill, they would require more care, which could potentially show up in our data as higher prices. Likewise, providing higher quality care could raise costs, so a hospital that had a higher quality of care could show up in our data as having higher prices.

We work to address these issues in a number of ways. First, we rely on risk-adjusted price measures, described in detail in Appendix B. Second, we show our results are stable when we control for hospital quality using a variety of measures. Third, we measure price variation across plausibly undifferentiated services (like lower-limb MRI) for which there is little variation in how these services are delivered across hospitals or across patients within a hospital. Since MRIs are plausibly homogeneous across patients, studying this procedure provides a reasonable benchmark for price variation that is uncontaminated by unobservable patient heterogeneity. Fourth, we define our procedures narrowly via our choice of clinical codes and exclude cases with complications. Finally, we limit the age of patients we analyze by procedure to fairly narrow age groups (since older patients or atypically young patients may raise costs). For knee and hip replacements, we limit our analysis to cases involving patients between 45 and 64 years old. For cesarean and vaginal delivery, we limit our analysis to mothers who are between 25 and 34 years old.

Our hospital price measures are generated from data on the actual payments patients and insurers make to hospitals. We construct three different measures of hospital prices based on these allowed amounts (i.e. the sum of the patient and insurer payments to hospitals). The first is a private payer overall inpatient price index that is adjusted for the mix of care that a hospital delivers (via DRG fixed effects) and the mix of patients that hospitals treat (we risk-adjust for patient age and sex). This hospital-level, regression-based measure is similar to those used previously in the literature (e.g. Gaynor and Vogt 2003 and Gowrisankaran, Nevo, and Town 2015). The second is a set of hospital-level and risk-adjusted price measures for each of our seven procedures. ${ }^{22}$ Third, we focus on contract-level prices within hospitals for the seven previously identified procedures. We also construct Medicare reimbursement rates for overall

\footnotetext{
${ }^{22}$ For inpatient procedures, the procedure price captures the combined price on all claims associated with services provided to the patient by hospitals from admission through discharge. For outpatient procedures (colonoscopies and MRIs), the price is the sum of all claims on the day the patient was in the hospital for the MRI or the colonoscopy. For colonoscopies and MRIs, we further limit our analysis to observations where no other medical care was provided to the patient on the day of the MRI or colonoscopy and exclude MRIs and colonoscopies that were performed within a wider hospital stay. As a robustness check, we also examine the sum of hospital and physician prices for inpatient and procedure prices.
} 
inpatient care and for the seven procedures in our analysis. More details on our price and Medicare reimbursement measures are in Appendix B.

\section{II.D Descriptive Statistics on Prices}

Table 3 presents the means, standard deviations, and within-hospital correlations of the inpatient hospital price index, the procedure prices, and the Medicare inpatient base payment rates. There is high correlation in prices within hospitals within service lines like orthopedics (e.g., the correlation of hip with knee replacements is 0.923) and a weaker (but still substantial) correlation across service lines (e.g., the correlation of knee replacement with vaginal delivery prices is 0.510). By contrast, there is a low correlation within hospitals between the Medicare base payment rate and the inpatient price index (0.203) and between Medicare procedure-specific reimbursements and private payment rates for the procedures we study (these range from -0.040 to 0.360 ). Medicare attempts to set administered prices to reflect hospitals' costs and therefore, the low correlation between Medicare and private prices suggests that private price variation is driven by more than simply differences in costs across hospitals.

The difference in the amounts that Medicare and private insurers pay for services is substantial. Figure 2 shows that in 2011, Medicare payments were 45 percent of private rates for inpatient care, 55 percent of private rates for hip and knee replacement, 62 percent for cesarean and vaginal delivery, 51 percent for PTCA, 37 percent for colonoscopy, and 25 percent for MRIs. As an illustration of the magnitude of this difference, we calculate that if private prices were set at 120 percent of Medicare rates rather than at their current levels, inpatient spending on the privately insured would drop by 19.7 percent. $^{23}$

There has also been significant recent interest in hospitals' charges - the list prices for hospital services (e.g. Brill 2013; Bai and Anderson 2015 and Hsia and Akosa Antwi 2014). Indeed, in 2013, the Department of Health and Human Services began releasing hospital charge information for all inpatient claims billed to Medicare (Department of Health and Human Services 2013). Figure 2 illustrates that charges are between 170 percent and 242 percent of the transaction prices. Figure 3 presents a scatterplot showing the relationship between hospital

\footnotetext{
${ }^{23}$ This thought experiment holds the quantities of care constant (i.e., it assumes no behavioral response). We also find that paying providers for inpatient care at 100 percent of Medicare rates, 110 percent of Medicare rates, 130 percent of Medicare rates, and 140 percent of Medicare rates would lower spending by 33.1 percent, 26.4 percent, 13 percent, and 6.3 percent, respectively.
} 
charges and transaction prices for knee replacements in 2011. There is a positive correlation, but it is only 0.31 . The other procedures also have similarly-scaled correlations between charges and transaction prices (Appendix Figure 2).

In the absence of available data on true transaction prices, a number of research papers have used transformations of hospital charges to produce proxies for hospitals' transaction prices. Unsurprisingly, we observe that transformations of charges are not very highly correlated with transaction prices. Using data kindly provided by Dafny, Ho, and Lee (2016), we find that the correlation between our main inpatient price index that is constructed using transaction prices and their price measure constructed using hospital charge data is 0.45. Although the Dafny et al (2016) measure contains useful information (Garmon 2017), the low correlation illustrates the advantage of using transaction prices if such data are available.

\section{Health Care Spending Variation}

\section{III.A Geographic Variation in Spending Per Privately Insured Beneficiary}

In Figure 4, we map total risk-adjusted spending per privately insured beneficiary across HRRs. In 2011, mean spending per beneficiary was \$4,197. Total spending per privately insured beneficiary in the highest spending HRR (Anchorage, Alaska) was \$6,366, more than three times as much as spending per beneficiary in the lowest spending HRR (Honolulu, Hawaii spent $\$ 2,110$ per person). Likewise, the HRR in the $90^{\text {th }}$ percentile of the spending distribution (Grand Junction, Colorado) spent 47.3 percent more than the HRR in the $10^{\text {th }}$ percentile of the spending distribution (Sarasota, Florida). ${ }^{24}$

Previous work has found that risk-adjusted Medicare spending per beneficiary also varies by a factor of more than three across HRRs (Fisher et al. 2003a,b). In Appendix Figure 4, we present maps of total and inpatient spending per Medicare beneficiary across HRRs using data made accessible by the Dartmouth Institute. The correlation between HRR-level total spending per Medicare beneficiary and spending per privately insured beneficiary is only 0.044 and the equivalent correlation for inpatient spending is 0.172. The correlation between HRR-level inpatient spending per privately insured beneficiary age 55 to 64 (i.e. a group with a more similar

\footnotetext{
${ }^{24} \mathrm{We}$ also present a map of inpatient spending per privately insured beneficiary in Appendix Figure 3 . Inpatient spending per privately insured beneficiary has a correlation with total spending per beneficiary of 0.774 . Total spending per privately insured beneficiary per HRR has a 0.468 correlation with spending per beneficiary on knee hip and knee replacements, 0.369 with cesarean sections, 0.335 with vaginal deliveries, and 0.393 with PTCA.
} 
demographic profile to the Medicare population) and spending per Medicare beneficiary across HRRs is still only $0.165 .^{25}$

\section{III.B The Contributions of Price vs. Quantity to Spending Variation}

To what extent is the geographic variation in health spending generated by the variation in the price of care versus the quantity of care delivered across regions? Because the Medicare program's administered hospital prices do not vary significantly across providers, it follows that most of the variation in Medicare spending is mainly driven by differences in the quantities of health care across HRRs. ${ }^{26}$ By contrast, variation in spending on the privately insured is likely to be a function of both variation in the quantities of care delivered across regions and variation in the market-determined prices that providers and insurers negotiate.

To analyze the relative contributions of price and quantity to spending variation for the 55 to 64 year old private patients from HCCI and Medicare, we decompose the variance of $\ln$ (inpatient spending per beneficiary) for each DRG $d$ into three components:

$$
\operatorname{Var}\left(\ln \left(p_{r} q_{r}\right)\right)=\operatorname{Var}\left(\ln \left(p_{r}\right)\right)+\operatorname{Var}\left(\ln \left(q_{r}\right)+2 \operatorname{Cov}\left(\ln \left(p_{r}\right), \ln \left(q_{r}\right)\right)\right.
$$

where $p_{r}$ is the average price in HRR $r$ and $q_{r}$ is the number of inpatient visits (quantity) divided by the number of beneficiaries in each HRR. The component $\frac{\operatorname{Var}\left(\ln \left(p_{r}\right)\right)}{\operatorname{Var}\left(\ln \left(p_{r} q_{r}\right)\right)}$ represents the share of the variance in spending attributable to differences in price across HRRs; the component $\frac{\operatorname{Var}\left(\ln \left(q_{r}\right)\right)}{\operatorname{Var}\left(\ln \left(p_{r} q_{r}\right)\right)}$ represents the share attributable to differences in quantity and $\frac{2 \operatorname{Cov}\left(\ln \left(p_{r}\right), \ln \left(q_{r}\right)\right)}{\operatorname{Var}\left(\ln \left(p_{r} q_{r}\right)\right)}$ is the share attributable to the covariance of price and quantity. ${ }^{27}$ We obtain each of these components per DRG.

In Table 4 we report results for the top 25 DRGs in the data individually and the final row in Table 4 presents the decomposition results for both spending samples averaged across all DRGs (where each DRG-observation is weighted by spending on that DRG in the private

\footnotetext{
${ }^{25}$ Chernew et al. (2010) find a correlation between private spending per beneficiary measured using MarketScan data and Medicare spending per beneficiary in 2006 of -0.17 .

${ }^{26}$ Finkelstein et al. (2016) find that 47 percent of the geographic variation in Medicare utilization is driven by patient characteristics. The remainder is driven by place-specific factors.

${ }^{27}$ We focus on inpatient spending because we do not have reimbursement and quantity measures for Medicare outpatient services.
} 
population in the first three columns and the Medicare population in the last three columns). ${ }^{28}$ The bottom row of Column (1) shows that averaged across DRGs, just under half of spending variation on the privately insured is due to price and almost the same is due to quantity in Column (2) with the covariance term accounting for essentially zero in Column (3). ${ }^{29}$ Columns (4) - (6) show that for Medicare spending, quantity differences across HRRs accounts for 95.3 percent of the variation whereas only 12.7 percent is attributable to price variation (the residual is a -8.1 percent covariance term). These results suggest that variation in health spending on the privately insured is a function of variation in both the price and quantity of care delivered across HRRs, while variation in spending on the Medicare population is driven almost exclusively by differences in the quantity of care delivered across regions. ${ }^{30}$

Overall, both populations have similar levels of quantity variation across HRRs where quantity is defined as spending with hospital prices fixed at the mean (we refer to this as "fixedprice spending", see Appendix Table 3). ${ }^{31}$ Further, although Medicare and private prices are only weakly correlated at the HRR level (recall that in Table 3 this correlation is only 0.203), the correlation is much stronger for quantities. The correlation of fixed-price spending (quantity) per private beneficiary and fixed-price spending (quantity) per Medicare beneficiary is 0.427 and rises to 0.536 when we restrict the private sample to 55 to 64 year olds. Similarly, we observe that the correlation in hip and knee replacements delivered per Medicare beneficiary and per privately insured beneficiary per HRR is correlated at 0.570 across HRRs. Finally, we observe that the correlation in hospitals' case-mix indexes - a measure of the average DRG weights at hospitals - across Medicare and privately insured beneficiaries is 0.659. All this suggests, perhaps unsurprisingly, that the quantities of care delivered to Medicare and privately insured beneficiaries are much more correlated than the payment rates from the two sets of payers.

\footnotetext{
28 There were 562 DRGs in the Medicare population and 735 DRGs in the private data. Because some DRGs are performed very infrequently, we limit our analysis in Table 4 to HRR-DRG pairs where at least one case was performed. We can extend this restriction and limit our analysis to HRR-DRG pairs where there was at least one case performed on Medicare beneficiaries and private patients. This did not qualitatively impact our results. Likewise, we observe qualitatively similar patterns in our decomposition results when we run it for other age bins.

${ }^{29}$ Later, we focus on two outpatient procedures (colonoscopy and lower-limb MRI) and five inpatient procedures (hip replacement, knee replacement, vaginal baby delivery, cesarean baby delivery, and PTCA). Price explains 29 percent of the variation in spending on hip and knee replacements, 42 percent for vaginal delivers, 40 percent on cesarean sections, and 34 percent on PTCAs. In contrast, price variation explains 12 percent and 10 percent variation in Medicare spending on hip and knee replacement and for PTCAs, respectively.

${ }^{30}$ The results are not driven by the particular weighting scheme used. For example, using the Medicare spending weights (by DRG) in the private spending decomposition generates an overall contribution of price of 52 percent instead of 50 percent in the final row of Column (1).

${ }^{31}$ Appendix A5 describes how these price-fixed and quantity-fixed measures of spending are constructed.
} 


\section{Variation in Hospital Prices}

Given the importance of prices for the privately insured, we turn now to describing the overall variation in hospital prices and then decompose the amount of variation that occurs in the crosssection (i) across HRRs, (ii) within HRRs across hospitals, and (iii) within hospitals.

\section{IV.A Quantifying How Much Hospital Prices Vary}

Previous research has shown substantial geographic variation in hospital prices for sub-national geographies. For example, the United States Government Accountability Office (2005) analyzed health care claims data from the Federal Employees Health Benefits Program and found that hospital prices varied by 259 percent across metropolitan areas. Likewise, the Massachusetts Attorney General's Office (Coakley, 2011) found that hospitals' prices varied by over 300 percent in the state. Ginsburg (2010) used insurance claims data to measure average hospital prices in six cities. Similarly, White, Reschovsky, and Bond (2014) used claims data from autoworkers to examine hospital prices in thirteen Midwestern markets. They found that the highest priced hospitals in a market were typically paid 60 percent more for inpatient care than the lowest priced hospitals. ${ }^{32}$ These analyses, while extremely valuable, do not rely on national data, often do not risk-adjust prices for patient case mix, and do not analyze within hospital price variation.

In Figure 5 we present the variation in hospital-specific, risk-adjusted private-payer prices for knee replacements across all hospitals in our sample (Panel A). We also include the corresponding hospital-specific Medicare reimbursement rates. Hospitals were paid \$24,059 on average for knee replacements in 2011 (Medicare reimbursed these same hospitals \$12,986 on average). Across the nation, the ratio of the commercial price for a knee replacement at hospitals

\footnotetext{
${ }^{32}$ While notable, this sort of variation is not unique to health care. Many other industries exhibit price variation. Pratt, Wise, and Zeckhauser (1979) find large price variation for a range of services in the Boston area. They find, for example, that prices in the markets for bicycles, mufflers, dry cleaning, pet cleaning, and vocal lessons have coefficients of variation of $0.044,0.174,0.168,0.128$, and 0.383 , respectively. Hortasçu and Syverson (2004) document extensive variation in mutual fund fees. Eizenberg, Lach, and Yiftach (2016) observe extensive price variation in retail prices at supermarkets in Jerusalem. Similarly, Kaplan and Menzio (2015) use data from the KiltsNielson Consumer panel data and find that the coefficient of variation for $36 \mathrm{oz}$. plastic bottles of Heinz ketchup is 0.23 in Minneapolis in 2007. Therefore, while we focus on health care in this study, price dispersion is a common phenomenon and understanding the determinants of price dispersion is a general problem.
} 
in the $90^{\text {th }}$ percentile of the price distribution relative to hospitals in the $10^{\text {th }}$ percentile is 2.29 and the coefficient of variation across hospitals is 0.32 .

It is possible that the variation in knee replacement prices across the US reflects differences in unobserved patient severity or quality across hospitals. Consequently we examine lower-limb MRIs as a plausibly homogeneous procedure free of any contamination due to unobserved heterogeneity. In Panel B of Figure 5, we present a histogram of risk-adjusted hospital transaction prices for lower-limb MRIs and show variation that is on a similar scale to knee replacements - the coefficient of variation for knee replacements is 0.32 and for lower-limb MRIs is 0.40 . The ratio of the price for a lower-limb MRI at the hospital in the $90^{\text {th }}$ percentile relative to the hospital in the $10^{\text {th }}$ percentile is 2.93 (similar figures for our other procedures are reported in Appendix Figure 5).

To determine whether the bulk of the price variation in the cross-section occurs across HRRs, within HRRs (across hospitals), or within hospitals, we use our case-level data for 2010 and 2011, add various combinations of control variables into a regression, and observe the subsequent changes in the $\mathrm{R}^{2}{ }^{33}$ In Table 5 the dependent variable is the price level, $p_{i, p, h, r, t}$, for a case (e.g. a knee replacement) delivered to patient $i$ with insurance characteristics $p$, at hospital $h$, located in HRR $r$, in month-year $t$. In all columns we include month-year dummies, which account for only a trivial fraction of the variance (less than 0.001). Column (1) introduces patient characteristics (sex and age). We then sequentially add in fully interacted insurance plan characteristics, HRR fixed effects, hospital fixed effects, and controls for the hospital charges for each case. ${ }^{34}$ We allow HRR fixed effects and hospital fixed effects to vary by month-year pair.

Table 5 shows that a substantial amount of variation in hospital prices exists across HRRs, within HRRs, and even within hospitals. In Column (1) we find that controlling for patient characteristics explains very little of the variation in hospital prices - the $\mathrm{R}^{2}$ falls by less than 2 percent across all procedures. In Column (2), introducing insurance plan characteristics explains no more than an additional 3 percent. In Column (3), including HRR fixed effects substantially increases the $\mathrm{R}^{2}$ to between 0.331 (lower-limb MRI) and 0.502 (hip replacements).

\footnotetext{
${ }^{33}$ We focus on these years as we do not have hospital charge information prior to 2010. Results are very similar for the first four columns of Table 5 for other years.

${ }^{34}$ Insurance plan characteristics include the product type (health maintenance organization (HMO), preferred provider organization (PPO), point of service (POS), exclusive provider organization (EPO), indemnity plan, and other), the funding type (administrative services only (ASO) or fully-insured plan), and market segment (large versus small group).
} 
Column (4) includes hospital fixed effects, which increase the $\mathrm{R}^{2}$ to between 0.647 (vaginal delivery) and 0.774 (lower-limb MRIs). Although this is a large increase, it still leaves between 22 percent and 34.3 percent of price variation unexplained. In Column (5) we include the total charge for each individual case. This is a further control for the patient-specific amount of care that was delivered within a case, since hospitals bill for each unit of service they deliver. Even in this demanding specification, between 18 to 30 percent of the cross-sectional variation still occurs within hospitals (Column (6)) implying that unobserved differences in the cost of providing care cannot account for the unexplained spread of within hospital prices in Column (5).

The sizable variation in prices that we observe within hospitals seems likely to be due to differential insurer bargaining leverage, but potentially it could also be due to measurement error or contract re-negotiations that occur within a hospital-month. To address these issues we focus on MRIs and identify specific hospital/insurer contracts (as described in more detail in Section IV.C). Limiting our analysis to identified contracts excludes cases that have unusually high or low prices due to pure measurement error. This lowers the unexplained variance only slightly (from 21.6 percent to 19.9 percent) which is unsurprising as this is administrative data. ${ }^{35}$ Furthermore, since we observe contracts, we also can drop the hospital-month observations when a contract renegotiation occurred. Doing this reduces the unexplained variation to 15.3 percent. Thus we conclude that over 70 percent $(=15.3 / 21.6)$ of the unexplained within hospital MRI price variation in Column (6) of Table 5 is due to cross-insurer price variation within hospitals, rather than measurement error or (within month) contract renegotiation. This is suggestive of the substantial degree to which differential insurer bargaining power affects hospital prices.

\section{IV.B Hospital-level Price Variation Within and Across HRRs}

Figure 6 presents a map of private-payer inpatient prices across HRRs. The map demonstrates that there is substantial variation in prices across geographic areas. Normalizing prices using the Medicare wage index, which captures local labor costs does not reduce this variation by much (Appendix Figure 6). To illustrate the extent of the price variation, Salinas, California has the highest average inpatient private-payer prices - more than four times as high as the least

\footnotetext{
${ }^{35}$ We can classify 97 percent of the 113,914 MRI cases in Table 5 to contracts in this way (a higher fraction than for the other procedures). Note that this 1.7 percentage points is an upper bound for measurement error as it also excludes singleton observations for which we cannot find two matching prices (see Appendix B3).
} 
expensive HRR (Lake Charles, Louisiana). Likewise, the HRR with average hospital inpatient prices in the $90^{\text {th }}$ percentile of the national distribution of HRRs (Eugene, Oregon) is 1.84 times as expensive as the average inpatient prices for the HRR in the $10^{\text {th }}$ percentile (Lafayette, Louisiana).

Appendix Table 6 presents the mean prices and coefficients of variation in private-payer prices for our inpatient price index and the seven procedures we analyze for the twenty-five HRRs with the greatest number of HCCI covered lives. The national averages of the within HRR coefficients of variation range from 0.162 (hip replacement) to 0.249 (MRI). To illustrate how large this variation is, consider the following thought experiment. If each patient paying above the median price in their HRR instead went to the hospital in their HRR with the median price, total inpatient spending for the privately insured would be reduced by 25.8 percent. $^{36}$

Figure 7 illustrates the extent of the variation in hospital prices within a single HRR (Philadelphia, Pennsylvania) for the seven procedures we analyze. The coefficients of variation across hospital-level prices within Philadelphia for hip replacement, knee replacement, cesarean section, vaginal delivery, PTCA, colonoscopy, and lower-limb MRI are 0.258, 0.308, 0.265, $0.235,0.282,0.383$ and 0.482 , respectively. There is a substantial amount of variation in prices for all of these procedures, including lower-limb MRI (note that there is virtually no variation in Medicare's administered payments across hospitals within HRRs). We find similar variation in hospital prices for all procedures within all HRRs and present the figures for every other HRR online. $^{37}$

\section{IV.C Within Hospital Variation in Prices}

Table 5 showed that the amount of within hospital price variation in the cross-section is substantial. Column (8) shows the within hospital coefficient of variation by procedure, averaged across every hospital- month which ranges from 0.157 (lower-limb MRIs) to 0.239 (PTCAs). For reference, the average within-HRR coefficient of variation in MRI prices across hospitals is 0.249 (Appendix Table 6).

\footnotetext{
${ }^{36}$ We calculated this number in the following way. Using data for 2011 , we identified the median price for every DRG in the data across all HRRs. For any patient who paid a price above the median for that DRG, we substituted the median price for the actual price and then recalculated average spending per beneficiary. This counterfactual ignores behavioral responses.

${ }^{37}$ Our data use agreement precludes us from publicly reporting information about HRRs with fewer than five providers in the data. Within market price variation graphs are available for all HRRs with five or more providers for all procedures at www.healthcarepricingproject.org.
} 
The HCCI data do not identify the specific insurer that covers each beneficiary. As a result, to delve into the patterns of contracts within hospitals, we developed an algorithm to identify ongoing hospital/insurer contracts (see Appendix B3 for details). To do so, we find repeated prices at hospitals over time (for a given DRG or procedure) and then pair claims into larger contracts by grouping those that have similar combinations of insurance product characteristics (e.g. HMO versus PPO, large group products versus small group products). To illustrate these matches, in Figure 8 we present within-hospital contracted prices for lower-limb MRIs from 2008 to 2011 at the two highest volume hospitals in our data. Each point is an exact price paid for a case; the size of the dots is proportional to the number of patient cases at that price (exactly to the cent). ${ }^{38}$ We highlight the three highest volume contracts at each hospital (these capture 92 percent and 98 percent of all lower-limb MRI cases at these hospitals, respectively). The figure clearly demonstrates that there is significant variation in MRI prices within hospitals at single points in time. For example, in January 2011, the ratio of the price of the highest volume contract (blue circles) to the price of the second highest volume contract (green triangles) is 1.39 at Hospital A and 1.65 at Hospital B. We also see that the main contract prices are stable for extended periods (usually one year) before being updated, although the updates occur at different times across contracts.

The analysis in this section provides the first national evidence that insurers pay substantially different prices for the same services at the same hospitals. This finding is consistent with insurer-hospital bargaining models of price determination where stronger insurers can negotiate lower prices. ${ }^{39}$

\section{Analysis of Insurer-Hospital Contracts}

\section{V.A What are the types of insurer-hospital contracts?}

When a hospital joins an insurer's network, the hospital signs a contract that stipulates how and what they will be paid. Unfortunately, because most of these contracts contain clauses that prohibit their terms from being released, little is known about precisely how insurers pay each hospital (Reinhardt, 2006; Gaynor and Town, 2011). However, in addition to analyzing price

\footnotetext{
${ }^{38} \mathrm{We}$ present these amounts as dollars from the hospital mean to remain consistent with publishing rules in our data use agreement. The hospital mean is fixed across all time periods so a flat line reflects an unchanging absolute price.

${ }^{39}$ See for example Town and Vistnes 2001; Capps, Dranove, and Satterthwaite 2003; Sorensen 2003; Farrell et al. 2011; Gowrisankaran, Nevo, and Town 2015; Ho and Lee 2017.
} 
levels, the richness of the HCCI data also enables us to estimate the types of insurer-hospital contracts that are being struck.

In general, there are two main ways hospitals are paid for inpatient services (Moody's Investors Service 2017). The first is using prospectively set prices that pay a fixed dollar amount based on the patient's DRG (or sometimes a more disaggregated coding framework like ICD-9 codes). The second method sets payments as a percent of hospital charges, which we call a "share of charges" contract. Note that there are also hybrid payments that blend elements of both payment types. These hybrid payments are prospective payment contracts that include "outlier adjustments" that allow hospitals to be paid more when costs for a particular case are significantly higher than average costs. ${ }^{40}$ Further, within the class of prospective payment contracts, some may have their payment levels set as a percentage of Medicare payments, while others will have payment levels independent of the Medicare fee schedule.

There are two main reasons why hospitals are likely to prefer share of charges contracts to prospective payments. ${ }^{41}$ First, hospitals bear less risk with share of charges contracts. With this type of contract, a hospital gets paid for every service they provide to a patient. As a consequence, if a patient (in a particular DRG for example) requires more care and is therefore more expensive, the hospital gets paid more and the insurer bears this additional cost. Of course, if the patient requires fewer services and is thus cheaper, then the hospital receives less payment. By contrast, under a prospective payment the amount a hospital will receive is fixed ex ante. As a consequence, the hospital bears the risk associated with uncertainty over the cost of treatment (Burns and Pauly 2018). With risk aversion, this uncertainty is unattractive (Ellis and McGuire 1988, Town et al. 2011). A second reason why hospitals prefer share of charge contracts is that it places them under less pressure to reduce costs, since they get paid for all the services provided (presuming that the prices at least cover hospitals' marginal costs of providing services). As a result, prospective payments give stronger incentives for the hospital to contain costs (Shleifer 1985).

From our discussions with insurers, it seems that when prospective payment contracts exist, insurers will often offer a simple standardized "boilerplate" contract tied to the Medicare

\footnotetext{
${ }^{40}$ There is another type of contract that has been used historically where some inpatient payments were made on a per diem basis. However, our data contributors report that virtually none of the cases in our data are paid on a per diem basis. They also report that they aim to have less than 5 percent of cases subject to outlier adjustments.

${ }^{41}$ See Newhouse (1996) for a more general discussion of contract form and trade-offs. Basically, share of charge contracts are like cost-plus contracts and prospective payments are like fixed price contracts.
} 
fee schedule (i.e. prospective payments at a fixed percentage of Medicare payments). This saves them the costs of negotiating with each hospital. The patient profile in a hospital may mean true costs depart significantly from Medicare reimbursement. However, it may be difficult for a hospital to credibly demonstrate this to an insurer due to asymmetric information, even if a deviation from the boilerplate contract were worthwhile for both parties (net of negotiating costs). Hence, whereas hospitals with high bargaining power may be able to move away from the insurer's standard Medicare related prospective scheme, it will be harder for a weaker hospital to persuade an insurer to do this.

These considerations suggest that the differential bargaining power of hospitals and insurers will affect not only the hospital price level, but also the form of the contract. In particular, we expect that hospitals with greater bargaining power will have more share of charge contracts and, if they have prospective contracts, a lower share of them will be tied to Medicare reimbursement. Before examining this hypothesis in the next section, we first turn to how we identify contract types and provide some basic descriptive statistics.

\section{V.B Estimating the Percentage of Cases Paid as a Share of Hospital Charges}

Appendix B3 details exactly how we classify contracts, but we sketch the method here. The HCCI data do not specify whether cases are paid prospectively, as a share of charges, or using a hybrid payment. As a result, we developed a strategy to identify how cases were paid. To do this, we group separate claims within hospitals for a procedure (e.g. knee replacement) into single contracts if cases are paid at identical dollar amounts (down to the cent) or paid at identical percentages of hospital charges (down to the hundredth of a percent). ${ }^{42}$ We categorize hospital payments as either (i) share of charges (contracts where two or more cases are paid at an identical percentage of hospital charges), (ii) prospective payments (two or more cases are paid at identical dollar amounts), or (iii) unclassified cases. Unclassified cases are a mix between those using one of the hybrid contracts (e.g. those involving outlier payments) and others which do fall under one of the main two contract classes, but where the data is not rich enough to identify which one. The latter occurs, for example, when we only observe one case under a contract so we cannot "price match" it to another case.

\footnotetext{
${ }^{42}$ Our approach to identifying contracts is similar to the bunching analysis that Clemens et al. (2017) use to study physician pricing. We identify cases that are paid as a repeated percentage of hospitals' charges or as a repeated dollar amount. For more discussion of how we identify contracts, see Appendix B3.
} 
We find evidence that even within a month a hospital can have prospective payments with one payer and share of charge contract with another for the same procedure. To illustrate this consider Figure 9. Here we group cases into contracts for vaginal delivery at a large hospital using the methods described above. Two insurer contracts are clearly visible - Contract \#1 is shown in blue circles and Contract \#2 in red triangles. ${ }^{43}$ In Panel A, we plot the contracted prices in dollars from the mean price at that hospital. As can be seen, there is one absolute dollar amount for Contract \#2, but there is significant heterogeneity in the dollar amounts paid for Contract \#1. Contract \#2 is paid using a prospective payment set at a fixed payment amount, where the payment amounts for Contract \#1 clearly vary. In Panel B, we plot all of these payments as a percent of the hospital's charges. What is clear is that Contract \#1 is paid at a constant percent of charges (60 percent). For Contract \#2, the percent of charges varies in this graph because, while the absolute price is constant, the precise charges vary for each case.

In Figure 10 we show the breakdown of cases for the inpatient sample (first two bars) and procedure sample (other bars). Among inpatient cases, about a third are on prospective payments contracts and 17 percent are share of charge contracts. Almost half were unclassified, but when we restrict our sample to hospital-DRG pairs in higher volumes, we see a big reduction in unclassified cases. For example, in the second bar, we restrict to DRG-hospital pairs that have at least 20 admissions and observe that 22 percent of cases are unclassified. That is because the more cases a hospital treats, the higher the likelihood we correctly identify two cases paid at the same constant rate. As Appendix Figure 7 details, as we alter count restrictions, we maintain a robust estimate of about 23 percent of all cases being share of charge payments. There is a little more uncertainty about the exact proportion of cases on prospective payments, but we know the upper bound is 77 percent $(=100-23)$, and Appendix B3 suggests that the true fraction is not far from this level. ${ }^{44}$

We also observe large variation in the fraction of share of charge contracts across hospitals and in Figure 11 we show this for vaginal deliveries (our highest volume service with

\footnotetext{
${ }^{43}$ To make it easier to visualize we only show the two highest volume contracts at this hospital.

${ }^{44}$ The proportion of cases classified as prospective payments rises (and the proportion unclassified falls) almost monotonically with the minimum case threshold. For example, the proportion of cases classified as prospective rises from 55 percent at a threshold of 20 cases to 72 percent at a threshold of 200 cases. Note that for the procedures (with zero minimum case threshold restrictions), estimates range from 18 percent of cases on a share of charge contract for PTCA up to 30 percent for colonoscopies. Since nearly all lower-limb MRIs in our data have identical charges inside facilities, we cannot differentiate between cases paid prospectively and those paid as a share of hospital charges.
} 
the lowest fraction of unclassified cases). ${ }^{45}$ The hospital in the $90^{\text {th }}$ percentile has 91 percent of cases paid as a share of charges, whereas the $10^{\text {th }}$ percentile has zero. It may seem surprising that a single hospital has multiple forms of contracts given their patient mix. The fact that they do so is consistent with the idea that different insurers have different degrees of bargaining power within a single hospital. ${ }^{46}$

There have been, to our knowledge, only two other attempts to identify hospital-insurer contracts, both trying to reverse engineer contracts from price (as we do here). Baker et al (2016) estimates that around three-quarters of inpatient payments were paid prospectively (see Appendix B3 for details). Gift et al. (2002) examined hospital contracts from a single insurer with hospitals in Washington State in financial year 1994/1995 and found only 41 percent of the contracts had prospective payment contracts. We are able to extend beyond these papers by having the ability to differentiate between cases paid prospectively and those paid as a share of charges and show the existence of different contracts within the same hospital. As we describe in the next subsection, we are also able to analyze whether prospectively paid cases have payments set as a percentage of Medicare payments. This allows us to extend work by Clemens et al. (2017) and Clemens and Gottlieb (2017) on physicians and analyze the relationship between hospitals' prices and Medicare payments.

\section{V.C Prospective Payment Contracts and Their Link to Medicare Hospital Payments}

To estimate the share of prospective cases tied to Medicare, we calculate each prospective price as a percentage of the Medicare PPS payment rates. We then identify other private cases with different DRGs at the same hospital that are paid at the same percentage of Medicare PPS rates. These cases are then grouped into contracts. We then calculate the share of a hospital's prospectively set inpatient cases that have another case of a different DRG that is paid at the same percentage of Medicare payment rates (down to the hundredth of a percent). We find that among all inpatient prospective payments, 74 percent are set as a share of Medicare rates. There

\footnotetext{
${ }^{45}$ We show these figures for our other procedures in Appendix Figure 8.

${ }^{46}$ In Appendix Figure 9, we plot $\ln$ (prices) on the $\mathrm{y}$-axis against $\ln$ (charges) on the $\mathrm{x}$-axis for the same DRG for cases paid as a share of charges at a large hospital in our data. It shows that there tend to be a single share of charge per contract applied across all DRGs. In other words, an insurer will tend to negotiate the same level of discount off charges for all DRGs in the same hospital.
} 
is significant heterogeneity across hospitals - the unweighted mean is 48 percent with a standard deviation of 32 .

To illustrate this heterogeneity, in Figure 12 we plot $\ln$ (prospective payments) on the yaxis against $\ln$ (Medicare payments) on the $\mathrm{x}$-axis for the same DRG at two large hospitals in our data. Each circle is a unique case that we have classified as being under a prospective payment contract for a specific DRG. If hospitals were paid a fixed percentage of Medicare payment rates, the points on the graph would have a slope of one. ${ }^{47}$ Indeed, we observe that the private payment rates for the hospital in Panel A, for example, are predominantly set as a percentage of Medicare rates (they parallel the 45 degree line). By contrast, the payment rates at the hospital in Panel B are not highly correlated with Medicare rates.

When we look across all inpatient cases in our data, our results suggest the share of hospitals' private prospective payments that are linked to Medicare is likely to be lower than the 75 percent estimate Clemens et al. (2017) observed among physicians. First, about 23 percent of cases are share of charge payments, which are therefore directly not linked to Medicare. Second, since no more than 77 percent of cases are paid prospectively and 74 percent of prospective cases are linked to Medicare, this implies that the upper bound for total cases linked to Medicare payment levels is 57 percent $(=77 * 0.74)$.

\section{Factors associated with Hospital Prices and Contract Types}

\section{VI.A Cross-Sectional Analysis of Hospital Prices and Contracting Type}

We have identified substantial differences across hospitals in their prices and contract structures and we now turn to identifying the factors associated with these differences. Prices and contract forms are determined by negotiations between hospitals and insurers and a number of factors may affect the outcomes of these negotiations. These include demand shifters (e.g. hospital quality), supply shifters (e.g. labor costs), and the respective bargaining leverage of insurers and hospitals.

We begin by examining the cross-sectional relationship between hospital and insurer market structure and hospital prices and contracts. To do so, we use the following estimating equation:

\footnotetext{
${ }^{47}$ To formalize this point, when the price $P$ paid at hospital $h$, for DRG $d$, for an admission that occurs at time $t$, is set as a percentage of the DRG-specific Medicare rate $M$, assume it takes the form of a percentage markup $\Theta_{\mathrm{h}, \mathrm{t}}$ over Medicare payments: $P_{h, d, t}=\Theta_{h, t} * M_{d, t}$. Thus, $\ln \left(P_{h, d, t}\right)$ is additively separable: $\ln \left(P_{h, d, t}\right)=\ln \left(\Theta_{h, t}\right)+\ln \left(M_{d, t}\right)$.
} 


$$
y_{h, t}=\alpha^{\prime} M_{h, t}+\gamma^{\prime} x_{h, t}+\tau_{t}+v_{h, t}
$$

where $M_{h, t}$ is a vector of measures of hospital and insurer market structure for hospital $h$ in year $t, x_{h, t}$ is a vector of control variables (described below), $\tau_{t}$ are year dummies and $v_{h, t}$ is the error term. The $y_{h, t}$ outcomes we consider are (i) the inpatient hospital price index $\left(\hat{p}_{h, t}\right)$ described above and in Appendix B1; (ii) our procedure-level prices described in Appendix B2; (iii) the percent of cases paid as a share of the hospital's charges described in Section V.B; and (iv) the percent of prospective payments that are linked to the Medicare fee schedule described in Section V.C.

We construct several measures of market structure. Our main measure of hospital market structure is made by drawing a circular area around each hospital with a radius of 15 miles. We label hospitals in these areas that do not have competitors as monopolies; those in areas with two hospitals as duopolies; and those in areas with three hospitals as triopolies. Our omitted base category is hospitals in areas with four or more hospitals (i.e. quadropolies or greater). We also show that our main results are robust to a large range of alternatively defined measures of hospital market structure, such as measures with alternative markets size definitions (e.g. fixeddistance radii of various distances) and alternative measures of market structure (e.g. counts of hospitals and Herfindahl-Hirschman indexes (HHIs)). Our main measure of insurer market structure is the HCCI data contributors' market share of privately insured lives at the county level. Further details of how our market structure measures are constructed are contained in Appendix C. We present correlates of our hospital concentration measures and key covariates in Appendix Figure 10. These concentration measures are not strongly associated with other covariates, such as hospital quality or average population characteristics, although we do find that rural areas have more concentrated hospital markets.

We begin by examining the bivariate correlations between our hospital inpatient price index and other key variables in Figure 13. Relative to hospitals in markets with four or more competitors, hospitals in markets with fewer competitors have significantly higher prices. By contrast, prices are considerably lower at hospitals in counties where HCCI insurers have a higher market share. Apart from market structure, the other covariates are generally of the expected signs. Hospitals using more technologies, teaching hospitals, and larger hospitals have higher prices. Non-profit and government hospitals have slightly lower prices than for-profit 
hospitals. Hospitals with higher quality measured either by a mention in U.S. News \& World Report or via process scores tend to have higher prices. ${ }^{48}$ Hospitals with higher Medicare base payment rates or those located in high-income counties have higher prices, consistent with these being high cost areas. The higher the share of Medicare patients a hospital treats, the lower its private prices. ${ }^{49}$

\section{VI.B Cross-Sectional Analysis of Hospital Prices and Contract Form}

In Table 6, we present estimates of Equation (2) and report the coefficients on the market structure variables where an observation is a hospital-year (full results with coefficients on the other covariates are reported in Appendix Tables 7 through 9). In Panel A the dependent variable is the inpatient price index, in Panel B it is the percent of each hospitals' inpatient cases paid as a share of charges, and in Panel $\mathrm{C}$ it is the percent of prospective payments that are paid as a percentage of Medicare payments.

Panel A of Table 6 shows that there is a significant and positive association between hospital price and whether a hospital is located in a monopoly, duopoly, or triopoly market. Conversely, hospital prices fall as the HCCI insurers' market share increases. Column (1) presents the simplest specification, Column (2) adds insurer market share, and Column (3) further adds HRR fixed effects, so the coefficients are identified from the variation in market structure within HRRs. Introducing HRR fixed effects reduces all the hospital concentration coefficients, but with the exception of the triopoly dummy, all coefficients remain significant at conventional levels. The coefficients in Column (3) indicate that monopoly hospitals are associated with prices that are 12.5 percent $\left(=e^{0.118}-1\right)$ higher than places where there are four or more hospitals. Duopolies are associated with 7.6 percent higher prices. Further, a tenpercentage point increase in the market share of the HCCI insurers (e.g. from the mean of 18 percent to 28 percent) is associated with a statistically significant 7 percent fall in hospital prices. Note that the hospital market structure indicators are quantitatively the most important variables in our cross-sectional price analysis. Our hospital market structure indicators capture 19.6

\footnotetext{
${ }^{48}$ These are the percentage of AMI patients given aspirin at arrival, the percentage of patients given an antibiotic before surgery, and the percentage of patients treated to prevent blood clots. The sole exception is hospitals' 30-day AMI survival rate, which is negatively correlated with hospital prices.

${ }^{49}$ By contrast, the higher the percentage of Medicaid patients a hospital treats, the higher its prices. However, this is the only coefficient which is significantly reversed in our multivariate regression estimates of Equation (2) - see Appendix Table 7.
} 
percent of the explained variance from estimates presented in Column (2) of Panel A in Table 6 (when we exclude these measures, the $\mathrm{R}^{2}$ drops from 0.170 to 0.137 ). The market share of the HCCI insurers captures the second highest share of the explained variance, with an associated decrease in $\mathrm{R}^{2}$ of 16.1 percent (from 0.170 to 0.143 ). No other variables in the analysis capture more that 10 percent of the explained price variance.

The results in Panel A of Table 6 are robust to measuring prices in a multitude of ways such as (i) risk-adjusting our inpatient price measure with patients' Charlson score; (ii) riskadjusting our inpatient price using International Classification of Disease (ICD-9) diagnosis codes instead of DRG fixed effects (about 9,235 ICD-9 codes vs. 746 DRG codes), and measuring price in levels instead of logarithms. ${ }^{50}$ Our results are consistent with earlier, single state studies of hospital prices and market structure (mostly using data from California), which have found strong positive and statistically significant effects of hospital market concentration on prices (see Vogt and Town, 2006; Gaynor and Town, 2012).

Panel B of Table 6 has the same specification as we used in Panel A, but changes the dependent variable to the percent of cases paid as a share of hospital charges ${ }^{51}$ Since data on charges are only available in 2010 and 2011, the sample size roughly halves. Across the various specifications, we consistently find that the share of inpatient cases paid as a share of charges declines monotonically as the number of potential rival hospitals per market increases. Focusing on the estimates from Column (3), we find that a monopoly hospital has 10.5 percentage points more cases paid as a percent of charges than do hospitals in areas with four or more hospitals. Hospitals in counties where the HCCI insurers have a larger market share have significantly lower rates of cases paid as a share of charges (a 10 percentage point increase in the HCCI share is associated with a 4 percent lower share of cases on these contracts).

One might be concerned that the coefficient on monopoly in the price regressions of Panel A of Table 6 reflects some form of prospective contract where the hospital obtains a higher price because it is bearing more risk than the insurer. For example, perhaps there are more patients with unobservable idiosyncratic costs in places with concentrated hospital markets

\footnotetext{
${ }^{50}$ For example, when we use prices in levels as the dependent variable instead of logarithms in Table 6 Panel A, we obtain a coefficient on the monopoly indicator of 1,605 in the equivalent of Column (3). Since the average inpatient case is $\$ 14,020$, this estimate implies an effect of 12 percent, nearly identical to the baseline estimate. This is reported in Appendix Table 10.

${ }^{51}$ The bivariate correlations are illustrated in Appendix Figure 11. Note that the alternative to this payment form is that cases are paid based on a prospective payments basis as well as the unclassified cases we could not identify. Our results are robust to dropping these unclassified cases.
} 
which (under a prospective pay contract) would leave hospitals bearing more financial risk. The fact that monopoly hospitals receive both higher prices and have disproportionately more share of price contracts (where insurers bear more of the risk) is inconsistent with this explanation. ${ }^{52}$

Panel $\mathrm{C}$ of Table 6 uses the share of prospective payments that are tied to Medicare payment levels as the dependent variable. ${ }^{53}$ The pattern is a familiar one: hospitals in markets with fewer potential competitors have significantly fewer cases paid as a percent of the Medicare payments. In Column (3), monopoly hospitals are associated with having 11.3 percentage points fewer cases on contracts of this type (over a baseline mean of 48 percent). We also find that hospitals in areas where the HCCI insurers have bigger market shares have a higher share of their cases paid based on the Medicare fee schedule (a ten percentage point increase in insurer share is associated with 6 percent more Medicare-linked contracts).

The results in Table 6 paint a consistent picture of bargaining power. At least descriptively, when hospital markets are concentrated (and/or insurer markets are fragmented), hospital prices are higher and hospitals are able to obtain contracts that shift more risk on to insurers.

\section{VI.C Results for Individual Procedures}

A concern with the regressions in Table 6 is that because we aggregate over many different procedures, we may fail to account for unobserved heterogeneity in hospitals' care. For example, prices in monopoly hospitals may be higher because their procedures are more complex and costly, even after we risk-adjust. Consequently, in Table 7 we re-estimated the models of Table 6 using our seven procedures. ${ }^{54}$ In Column (1) we reproduce the baseline inpatient estimates in the final column of Table 6. Looking across the different procedures, it is striking that despite the smaller sample sizes, the results are qualitatively very consistent with the overall inpatient results. For all procedures, we find that areas with a monopoly hospital have higher prices than

\footnotetext{
${ }^{52}$ If we control for contract type on the right hand side of the price regressions the coefficient on monopoly falls by about a tenth which implies that monopolies have higher prices even on the same type of contract. To investigate this we ran a case-level price regression in 2010 and 2011 data (where we have charge data) analogously to Column (3) of Table 6 Panel A where we include a dummy reflecting whether the case is paid as a share of charges or not. Without this control the coefficient on monopoly was 0.137 , but with the control the coefficient falls to 0.125 .

${ }_{53}^{53}$ Bivariate correlations are in Appendix Figure 12.

${ }^{54}$ See Appendix B2 for construction of these prices. Note that we cannot perform an analysis of the share of prospective payments tied to Medicare at the procedure level, because the variable is constructed by linking payment rates across procedures (DRGs), and hence does not exist for any specific procedure.
} 
those with four or more hospitals. This positive association is significant at the 5 percent level for all procedures except hip replacements and PTCA (which have our smallest sample size) and colonoscopy (significant at the 10 percent level). The coefficients imply that a hospital located in a monopoly market has prices that are between 5.5 percent (hip replacements in Column (3)) and 23.4 percent (lower-limb MRIs in Column (9)) higher than hospitals in markets with four or more hospitals. The coefficient on the HCCI insurer market share is less precisely estimated, but it is negative for all procedures except cesarean sections and hip replacements. Column (2) summarizes the effects by pooling across all the procedures in Columns (3) through (9) and adding a dummy variable for each procedure. The pooled results confirm that hospitals facing fewer potential competitors have significantly higher prices. ${ }^{55}$

In Panel B of Table 7, we perform the same exercise for each procedure sample, but use the percent of cases paid as a share of charges as the dependent variable. We again find that hospitals with fewer potential competitors have a higher proportion of their cases paid as a share of charges. As with price, we find that hospital concentration is positively associated with the percentage of cases paid as a share of charges for all procedures and is significant for all procedures except hip replacements and PTCA (which have the smallest samples). The coefficient on HCCI insurer share is negative for five of the six procedures. There is almost no variation in hospital charges for MRIs within a facility, so we cannot estimate the structure of contracts for this procedure. When we pool our procedures into a single estimate (Column (2)), we confirm that there is a positive association between hospital market concentration and the fraction of cases paid as a share of charges. We also find that HCCI insurer market share is negatively and significantly associated with the fraction of cases paid as a share of charges.

\section{VI.D Robustness of cross sectional analysis}

We conducted a large number of robustness tests on the results in Tables 6 and 7, some of which we describe here. First, the main cross-sectional estimates are robust when we use alternatively constructed measures of hospital market structure, such as continuous or binned HHIs, allowing many alternatively sized radii to define markets, and/or allowing differential market definitions

\footnotetext{
${ }^{55}$ As hospitals increasingly purchase physician groups, there may be concerns that some portion of physician fees show up in facility prices. Consequently, we re-estimate our analysis using prices measured as the sum of hospital and physician prices in each claim (see Appendix Table 11). The results are qualitatively similar to what we observe in our main specifications.
} 
in rural and urban areas. Likewise, our results are also robust to different measures of insurance market structure. ${ }^{56}$ Second, our pricing analysis could be sensitive to omitted quality if, in particular, quality is correlated with market structure. Consequently, we include four additional measures of clinical quality to the price regression. Consistent with Figure 13, three of the four measures are correctly signed, but the coefficients on market structure were largely unchanged. We also included all 41 measures of quality published by Medicare Hospital Compare into crosssectional regression, which again did not meaningfully shift the hospital market structure coefficients. Third, we show that our results are not driven exclusively by extremes by dropping observations from monopolies or hospitals in markets with six or more providers. Fourth, we show that our results are not sensitive to the exact sample size cutoffs we use (e.g. hospitals must perform at least 50 cases per year to be in the inpatient sample) by showing results where we use many alternative cutoffs from between zero to 100 cases per year. ${ }^{57}$

Finally, as we discussed previously, we do not have data from Blue Cross Blue Shield (BCBS) plans. If hospital market structure is correlated with omitted BCBS presence, this could present a problem. Appendix F conducts an extensive analysis of this and does not find it to be a major issue. First, note that the correlation between hospital HHI and county-level BCBS market share is only 0.222. Second, we estimated all our models solely in areas with high (above median) and low (below median) BCBS market shares. While the exact magnitudes of some of our coefficients differ in areas where BCBS have high and low market share, our main finding that having fewer hospitals in a market is associated with higher prices, a higher proportion of cases paid as a share of hospital charges, and a lower fraction of prospectively paid cases paid as a share of Medicare rates remains robust. ${ }^{58}$

\section{Hospital Mergers}

\section{VII.A Introduction to merger analysis}

\footnotetext{
${ }^{56}$ For example, the coefficients on our main hospital market structure measures are broadly unchanged when we include cubic polynomials of the market shares of the three HCCI contributors and/or individual shares of the top ten insurers in each market.

${ }^{57}$ The analysis of alternative market structure is in Appendix Tables 12- 14; quality in Appendix Table 15; extreme market structures in Appendix Table 16 and alternative cut-offs in Appendix Table 17.

${ }^{58}$ As we discuss in more detail in Appendix F, it becomes difficult to precisely estimate the impacts of the market structure variables in areas with high BCBS share when HRR fixed effects are included because very few of those HRRs have monopoly hospitals and hospitals facing four or more competitors that meet our sample restrictions.
} 
Our cross-sectional regressions in the previous section suggest that hospital market structure is strongly associated with hospital prices. In this section, we analyze mergers and hospital prices using the panel aspect of our data. Over the last few decades, there have been hundreds of mergers between hospitals across the US (recall Figure 1). Economic models of competition in the hospital sector predict that mergers between hospitals that are close geographic competitors will lead to price increases making mergers of direct interest (see the Gaynor et al. 2015 review). Further, examining the impact of mergers on hospital prices provides us with another lens through which to view the relationship between market structure and prices, and complements our cross-sectional analysis.

A number of papers have estimated the impacts of specific mergers that were suspected to be anticompetitive. One strand of this literature uses estimates from structural (or semistructural) models and ex ante simulation methods to generate estimates of predicted price changes from a single or a small number of transactions. ${ }^{59}$ Although these models allow for a more sophisticated modeling approach to competition and bargaining between insurers and hospitals, they would be difficult to estimate for the hundreds of mergers we have in our data. Instead, we follow a second strand of the literature that uses ex post econometric methodologies to analyze the effects of consummated mergers. ${ }^{60}$ This kind of modeling is coarser, but does have the advantage of looking at what happens after mergers occur. Historically, this strand of the literature has also focused on analyzing individual mergers or small numbers of mergers. We extend the literature by examining the impact of hospital mergers that occurred in the US during the five years covered by our data (which is also a more recent time period than covered in previous studies).

\section{VII.B Hospital Merger Data}

We created a database of nearly all US hospital mergers between 2007 and 2011 (see Appendix D for details) and found 366 transactions involving over 2,000 hospitals. For example, as Appendix Table 18 shows, there were 55 transactions involving 84 hospitals where the merging parties were less than 5 miles apart and 121 transactions involving 260 hospitals within 15 miles of each other.

\footnotetext{
${ }^{59}$ See Town and Vistnes 2001; Capps et al. 2003; Gaynor and Vogt 2003; Gowrisankaran et al. 2015.

${ }^{60}$ See Vita and Sacher 2001; Krishnan 2001; Capps and Dranove 2004; Dafny 2009; Kemp, Kersten, and Severijnen 2012; Haas-Wilson and Garmon 2011; Tenn 2011; Thompson 2011.
} 


\section{VII.C Modeling Hospital Mergers}

To estimate the effects of mergers on hospital prices, we employ the following specification:

$$
\ln \left(\hat{p}_{h, t}\right)=\beta M E R G E_{h, t}^{D}+\eta_{h}+\delta_{t}+v_{h, t}
$$

where $\hat{p}_{h, t}$ is the usual risk-adjusted hospital inpatient price for hospital $h$ in year $t$. We include hospital fixed effects $\left(\eta_{h}\right)$ and year dummies $\left(\delta_{t}\right)$. The key variable of interest is the binary indicator, $M E R G E_{h, t}^{D}$. In our baseline specification this indicator is zero until the year a hospital becomes involved in a merger, when it then takes a value of one and retains a value of one for the remainder of our sample period. We categorize mergers based on the physical distance (superscript $D$ ) between the merging entities (e.g. whether the merging parties were separated by five miles or less, ten miles or less, etc.). Since hospital location is a key factor determining demand (and hence potential patient substitutability between hospitals), we expect mergers between hospitals that are geographically closer to result in larger increases in prices than mergers between hospitals separated by large distances. ${ }^{61} \mathrm{We}$ use a variety of different control groups, including all hospitals not involved in mergers and matched controls using a number of different matching methods. In some specifications we also include the same set of control variables included in our cross-sectional regressions in Table $6 .{ }^{62}$

There are differences in the characteristics of the merging vs. non-merging hospitals (see Appendix Table 19). Merging hospitals tend to be located in less concentrated markets (this is unsurprising due to antitrust scrutiny and a mechanical limit to how concentrated a market can get), are more likely to be non-profit and teaching hospitals, are larger (more beds), and have higher reputational average quality (U.S. News \& World Report quality rankings). However, merging and non-merging hospitals look broadly comparable in terms of their share of Medicare and Medicaid admissions, the technologies they possess, and their area characteristics (county uninsured and median income). Most of these characteristics vary little over time so the hospital

\footnotetext{
${ }^{61}$ We recognize that mergers between hospitals farther apart may have impacts on prices through more subtle forms of multi-market conduct behavior. Our specification flexibly allows for mergers to have impacts at any distance, although we are not testing specifically for cross-market merger effects like those analyzed by Dafny et al. 2016 and Lewis and Pflum 2017.

${ }^{62}$ Because DOJ and FTC occasionally allow failing or "flailing" firms to merge, we want to exclude these firms from our analysis. To do that, we exclude 53 hospitals that have the largest share of unused capacity defined as the average daily census divided by the total number of hospital beds (e.g. those in the $99^{\text {th }}$ percentile of unused capacity). Our results are robust to including these 53 hospitals in our analysis.
} 
fixed effects in Equation (3) will largely control for them. More importantly, as we demonstrate below, we do not find any evidence that merging hospitals have different pre-merger trends in prices relative to non-merging hospitals.

\section{VII.D Results on Mergers and Hospital Prices}

Panel A of Table 8 contains the baseline specifications where we vary the distance between merging hospitals from 5 to 50 miles. There are positive coefficients on the merger dummies at every distance and these are almost all significant for mergers between hospitals up to 25 miles apart. The magnitude of the merger coefficient declines as the distance between the merging parties increases. Mergers within 5 miles are associated with price increases of 6 percent whereas the coefficients decline to 2 percent for mergers involving hospitals located up to 25 miles apart. In Figure 14, we present the estimates of merger effects by one-mile bins for all mergers up to those 50 miles apart. The estimates are noisy for very close mergers (because there are few such events) but the coefficient on mergers is broadly monotonically decreasing as the distance between the merging parties increases.

In Panel B of Table 8, we add the control variables we included in our cross-sectional

analysis, which makes almost no difference to the results. It is also possible that non-merging neighboring hospitals may be affected by mergers (Dafny 2009). We test for this by adding a dummy for neighboring hospitals, which switches on after a neighboring hospital is exposed to a nearby merger (in the relevant distance bin). As we illustrate in Panel $\mathrm{C}$, although the coefficients on neighboring mergers are usually positive, they are generally statistically insignificant.

It is possible that our estimates are capturing intertemporal factors other than the mergers themselves. Given the short time series in our panel, we examine price trends for two years before and after the merger event in Panel D of Table 8 and in Figure 15. Reassuringly, there does not appear to be evidence of pre-trends prior to the merger, as prices in the year before the merger are not significantly different from two years before (or earlier) in any of the columns. By contrast there are significant post-merger price increases, with higher prices in all columns two years after mergers occurred. The coefficients seem to generally build up from the year of the merger, but given the size of the standard errors, it is hard to be certain. 
The merger coefficients we observe are economically significant. ${ }^{63} \mathrm{~A}$ horizontal merger price effect of five percent is often used as an indicator of (enhanced) market power (U.S. Department of Justice and Federal Trade Commission 2010). Further, this estimate represents the average effects of all mergers, not just those thought to be anticompetitive (as in previous ex ante studies). In addition, since we examine the impacts of consummated mergers, we are looking only at transactions that passed antitrust scrutiny. Since it is likely that the mergers with the largest potential effects on price are not attempted due to concerns over antitrust litigation or are blocked by enforcement authorities, those that we observe should be expected to have a smaller impact on price.

\section{VII.E Robustness of Merger Results}

We subject our merger analysis to a large number of other robustness tests, some of which we discuss here ${ }^{64}$ First, instead of using the simple merger dummy, we estimate the cumulative merger effects by hospital for all mergers that hospitals were exposed to from 2007 to $2011 .{ }^{65}$ Our post-merger price coefficients remain similarly scaled. Second, we used various matching procedures to identify alternative control groups for our analysis (see Appendix E), such as Mahalanobis distance matching between hospitals, the Dranove and Lindrooth (2003) procedure, and K-nearest neighbor matching. These tend to show slightly larger price effects for mergers within five miles than we observe in our baseline estimates. Third, we varied the 50 patients per year sample cutoff. This does not alter our main results. Fourth, it is possible that the price increases we observe following a merger could be due to improvements in management (e.g. hospitals doing a better job at price setting) rather than increased bargaining leverage. To test for this, we allow the merger coefficient to be different for targets and the acquirers and do not find statistically significant differences between the two. Finally, we also attempted to estimate merger effects for the seven procedures used in Table 7. Unfortunately, because those samples have fewer hospitals, there are fewer treated hospitals, so we cannot estimate merger effects with precision.

\footnotetext{
${ }^{63} \mathrm{We}$ note that our estimates are of the same or similar order of magnitude to the bulk of studies of merger price effects in other industries (Ashenfelter, Hosken, Weinberg, 2014).

${ }^{64}$ The tests discussed here are contained in Appendix Table 20 where Panel A reproduces the baseline results from Table 8.

${ }^{65}$ For example, of the 514 hospitals involved in at least one merger involving hospitals located less than 30 miles apartment, 47 were involved in more than one merger from 2007 to 2011.
} 


\section{Conclusions}

Using insurance claims from three of the five largest commercial insurers in the US, we find that health spending on the privately insured varies by a factor of three across the nation. Approximately half of the variation in private spending across HRRs is driven by differences in hospitals' prices and half by quantity (Medicare spending variation is almost all accounted for by quantity variation). Since previous research has focused on understanding the drivers of differences in the quantity of health care delivered across regions (Cutler et al. 2017, Finkelstein et al. 2016), we focus on analyzing the variance in hospital prices.

Historically, the prices hospitals negotiate with insurers have been treated as commercially sensitive and have been largely unavailable to researchers on a national basis. Our data includes hospitals' transaction prices and we are able to observe substantial variation in prices across hospitals, even for plausibly undifferentiated services like lower-limb MRIs. Moreover, a significant amount of the national variation in prices occurs within hospitals. This suggests that insurers' bargaining leverage influences the prices they negotiate with hospitals

We also use our data to characterize insurer-hospital contracts. When prices are set as a share of charges (rather than prospectively paid), it offers hospitals weak incentives to lower costs and it transfers the financial risk from idiosyncratically expensive cases to insurers. We find that approximately 23 percent of inpatient cases are paid as a share of charges and estimate that no more than 57 percent of inpatient cases are set as a percentage of Medicare rates.

Market structure appears strongly associated with hospitals' price levels and contract structure. Monopoly hospitals are associated with 12 percent higher prices, 10 percentage points more cases paid as a share of charges, and 11 percentage points less of their prospectively paid cases set as a percentage of Medicare payments compared to hospitals located in quadropoly or greater markets. In concentrated insurer markets we find the opposite correlations - hospitals have lower transaction prices and operate under contracts where they bear more risk. We also analyze the 366 hospital mergers that occurred between 2007 and 2011 and find that after mergers involving hospitals located less than five miles apart, prices at the merging parties increased by over 6 percent. As the distance between the merging parties' increases, the size of the post-merger price increases is attenuated. This set of results around market structure suggests 
that bargaining leverage is an important component of the dispersion we see in transaction prices.

Collectively, our research highlights the importance of studying hospital pricing and contracts when analyzing health spending on the privately insured. While our analysis is not causal, it does suggest that policy-makers should continue to analyze whether potential hospital mergers could harm consumer welfare. Likewise, while we cannot draw strong normative conclusions, quantifying the scale of the variation in prices is nevertheless important. Given the variation in prices that we observe (particularly for undifferentiated procedures), our results suggest that patients and payers could save significant amounts of money if patients attended lower-priced providers. This suggests that policies aimed at steering patients towards low cost providers (e.g. reference pricing, incentivizing referring physicians, etc.) could lower spending. Finally, there is widespread agreement that payment reform (shifting to contracts where providers bear more risk) is crucial to increasing hospital productivity (McClellan et al. 2017). Our analysis suggests that providers who have fewer potential competitors will be more able to resist attempts at such payment reform.

Further research should be focused on understanding the economic forces behind the patterns and correlations we have identified in the data. Given the growing availability of insurance claims data, there is scope for a rich and broad variety of research that takes on these important tasks.

\section{References}

Ashenfelter, Orley, Daniel Hosken, and Matthew Weinberg, "Did Robert Bork Understate the Competitive Impact of Mergers? Evidence from Consummated Mergers," The Journal of Law and Economics, 57 (2014), S67-100.

Bai, Ge, and Gerard F. Anderson, "Extreme Markup: The Fifty US Hospitals with the Highest Charge-To-Cost Ratios," Health Affairs, 34 (2015), 922-928.

Baker, Laurence, M. Kate Bundorf, Aileen Devlin, and Daniel P. Kessler, "Why Don't Commercial Health Plans Use Prospective Payment?" NBER Working Paper Series, No. 22709 (2016).

Bresnahan, Timothy, "Empirical Studies of Industries with Market Power", in Handbook of Industrial Organization, Volume 2 (1989): 1011-1057.

Brill, Steven, "Bitter Pill: Why Medical Bills Are Killing Us," in Time, (New York: Time Incorporated, 2013).

Burns, Lawton R., Pauly, Mark V., "Transformation of the Health Care Industry: Curb Your Enthusiasm," Milbank Quarterly, 96(2018): 57-109. 
Capps, Cory, and David Dranove, "Hospital Consolidation and Negotiated PPO Prices," Health Affairs, 23 (2004), 175-181.

Capps, Cory, David Dranove, and Mark Satterthwaite, "Competition and Market Power in Option Demand Markets," The Rand Journal of Economics, 34 (2003), 737-763.

Centers for Disease Control and Prevention, "Number of All-Listed Procedures for Discharges from Short-Stay Hospitals, by Procedure Category and Age: United States, 2010," (2010).

Centers for Disease Control and Prevention, "National Center for Health Statistics - Health Insurance Coverage," (2017).

Chernew, Michael E., Lindsay M. Sabik, Amitabh Chandra, Teresa B. Gibson, and Joseph P. Newhouse, "Geographic Correlation Between Large-Firm Commercial Spending and Medicare Spending," The American Journal of Managed Care, 16 (2010), 131-138.

Clemens, Jeffrey, and Joshua D. Gottlieb, "In the Shadow of a Giant: Medicare's Influence on Private Physician Payments," Journal of Political Economy, 125 (2017), 1-39.

Clemens, Jeffrey, Joshua D. Gottlieb, and Timea Laura Molnar, "Do Health Insurers Innovate? Evidence from the Anatomy of Physician Payments," Journal of Health Economics, 55 (2017), 153-167.

Coakley, Martha, "Examination of Health Care Cost Trends and Cost Drivers - Report for Annual Public Hearing," edited by Massachusetts Attorney General's Office. Boston, Massachusetts (2011).

Curtu, Vilsa, Liran Einav, Amy Finkelstein, Jonathan Levin and Jay Bhatacharya (2017) "Health Care Spending Utilization in Public and Private Medicare", NBER Working Paper No. 23090.

Cutler, David, Jonathan Skinner, Ariel Dora Stern, and David Wennberg, "Physician Beliefs and Patient Preferences: A New Look at Regional Variation in Health Care Spending," Harvard Business School Working Paper, No. 15-090 (May 2015). Revised December 2017.

Dafny, Leemore, "Estimation and Identification of Merger Effects: An Application to Hospital Mergers," The Journal of Law and Economics, 52 (2009), 523-550.

Dafny, Leemore, Kate Ho, and Robin S. Lee, "The Price Effects of Cross-Market Hospital Mergers," NBER Working Paper Series, No. 22106 (2016).

Department of Health and Human Services, "Administration Offers Consumers an Unprecedented Look at Hospital Charges," (Centers for Medicare \& Medicaid Services, 2013).

Dranove, David, and Richard Lindrooth, "Hospital Consolidation and Costs: Another Look at the Evidence," Journal of Health Economics, 22 (2003), 983-997.

Eizenberg, Alon, Saul Lach, and Merav Yiftach, "Retail Prices in a City," (CEPR Discussion Papers: 11590, 2016).

Ellis, Randall P., and Thomas G. McGuire, "Insurance Principles and the Design of Prospective Payment Systems," Journal of Health Economics, 7 (1988), 215-237.

FastStats - Health Expenditures (https://www.cdc.gov/nchs/fastats/health-expenditures.htm, Center for Disease Control and Prevention).

Farrell, Joseph, David J. Balan, Keith Brand, and Brett W. Wendling, "Economics at the FTC: Hospital Mergers, Authorized Generic Drugs, and Consumer Credit Markets," Review of Industrial Organization, 39 (2011), 271-296. 
Finkelstein, Amy, Matthew Gentzkow, and Heidi Williams, "Sources of Geographic Variation in Health Care: Evidence from Patient Migration," Quarterly Journal of Economics, 131 (2016), 1681-1726.

Fisher, Elliott S., David E. Wennberg, Therese A. Stukel, Daniel J. Gottlieb, F. L. Lucas, and Etoile L. Pinder, "The Implications of Regional Variations in Medicare Spending. Part 1: The Content, Quality, and Accessibility of Care," Ann Intern Med, 138 (2003a), 273-287.

---, "The Implications of Regional Variations in Medicare Spending. Part 2: Health Outcomes and Satisfaction with Care," Ann Internal Medicine, 138 (2003b), 288-298.

Garmon, Christopher, "The Accuracy of Hospital Merger Screening Methods," The Rand Journal of Economics, 48 (2017), 1068-1102.

Garmon, Christopher, Kmitch, Laura, "Health Care Competition or Regulation: The Unusual Case of Albany Georgia," Mimeo (2017).

Gaynor, Martin, Kate Ho, and Robert J. Town, “The Industrial Organization of Health-Care Markets," Journal of Economic Literature, 53 (2015), 235-284.

Gaynor, Martin, and Robert J. Town, "Competition in Health Care Markets," in Handbook of Health Economics, Mark V. Pauly, Thomas G. McGuire, and Pedro P. Barros, eds. (Elsevier, 2011).

---, "The Impact of Hospital Consolidation-Update," in The Synthesis Project, (Robert Wood Johnson Foundation, 2012).

Gaynor, Martin, and William B. Vogt, "Competition among Hospitals," The Rand Journal of Economics, 34 (2003), 764-785.

Gift, Thomas L., Richard Arnould, and Larry DeBrock, "Is Healthy Competition Healthy? New Evidence of the Impact of Hospital Competition," Inquiry, 39 (2002), 45-55.

Ginsburg, Paul B., "Wide Variation in Hospital and Physician Payment Rates Evidence of Provider Market Power," in HSC Research Brief No. 16, Center for Studying Health System Change, ed. (2010).

Government Accountability Office, "Report to the Honorable Paul Ryan, House of Representatives: Competition and Other Factors Linked to Wide Variation in Health Care Prices," United States Government Accountability Office, ed. (Washington, DC, 2005).

Gowrisankaran, Gautam, Aviv Nevo, and Robert Town, "Mergers When Prices Are Negotiated: Evidence from the Hospital Industry," American Economic Review, 105 (2015), 172-203.

Haas-Wilson, Deborah, and Christopher Garmon, "Hospital Mergers and Competitive Effects: Two Retrospective Analyses," International Journal of the Economics of Business, 18 (2011), 17-32.

Hartman, Micah, Anne B. Martin, Nathan Espinosa, Aaron, Caitlin, "National Health Care Spending in 2016," Health Affairs, 37(2017): 1299 - 1305.

Ho, Kate, and Robin S. Lee, "Insurer Competition in Health Care Markets," Econometrica, 85 (2017), 379-417.

Hortaçsu, Ali, and Chad Syverson, "Product Differentiation, Search Costs, and Competition in the Mutual Fund Industry: A Case Study of S\&P 500 Index Funds," Quarterly Journal of Economics, 119 (2004), 403-456.

Hsia, R. Y., and Y. Akosa Antwi, "Variation in Charges for Emergency Department Visits Across California," Ann Emergency Medicine, 64 (2014), 120-126, 126.e121-124.

Kaiser Family Foundation, "2017 Employer Health Benefits Survey,” Kaiser Family Foundation, Washington, D.C. 
Kaplan, Greg, and Guido Menzio, "The Morphology of Price Dispersion," International Economic Review, 56 (2015), 1165-1205.

Kemp, Ron G. M., Nikki Kersten, and Astrid M. Severijnen, "Price Effects of Dutch Hospital Mergers: An Ex-Post Assessment of Hip Surgery," De Economist, 160 (2012), 237-255.

Krishnan, Ranjani, "Market Restructuring and Pricing in the Hospital Industry," Journal of Health Economics, 20 (2001), 213-237.

Lewis, Matthew S., and Kevin E. Pflum, "Hospital Systems and Bargaining Power: Evidence From Out-of-Market Acquisitions," The Rand Journal of Economics, 48 (2017), 579-610.

McClellan, Mark, Feinberg, David, Bach, Peter et al., "Payment Reform for Better Value and Medical Innovation", National Academy of Sciences (2017).

Moody's Investors Service, "Sector In-Depth: Not-For-Profit and Public Healthcare - US," Moody's, New York, NY.

Newhouse, Joseph P., "Reimbursing Health Plans and Health Providers: Efficiency in Production versus Selection," Journal of Economic Literature, 34(1996), 1236-63.

Newhouse, Joseph P., Alan M. Garber, Robin P. Graham, Margaret A. McCoy, Michelle Mancher, and Ashna Kibria, Variation in Health Care Spending: Target Decision Making, Not Geography (Washington, DC: The National Academies Press, 2013).

Philipson, Tomas J., Seth A. Seabury, Lee M. Lockwood, Dana P. Goldman, and Darius N. Lakdawalla, "Geographic Variation in Health Care: The Role of Private Markets," Brookings Papers on Economic Activity, (2010), 325-355.

Pratt, John, David A. Wise, and Richard Zeckhauser, "Price Differences in Almost Competitive Markets," Quarterly Journal of Economics, 93 (1979), 189-211.

Reinhardt, Uwe E., "The Pricing of U.S. Hospital Services: Chaos Behind A Veil of Secrecy," Health Affairs, 25 (2006), 57-69.

Shleifer, Andrei, "A Theory of Yardstick Competition," Rand Journal of Economics, 16(1985): 319-327.

Sorensen, Alan T., "Insurer-Hospital Bargaining: Negotiated Discounts in Post-Deregulation Connecticut," The Journal of Industrial Economics, 51 (2003), 469-490.

Tenn, Steven, "The Price Effects of Hospital Mergers: A Case Study of the Sutter-Summit Transaction," International Journal of the Economics of Business, 18 (2011), 65-82.

Thompson, Aileen, "The Effect of Hospital Mergers on Inpatient Prices: A Case Study of the New Hanover-Cape Fear Transaction," International Journal of the Economics of Business, 18 (2011), 91-101.

Town, Robert, and Gregory Vistnes, "Hospital Competition in HMO Networks," Journal of Health Economics, 20 (2001), 733-753.

Town, Robert, Roger Feldman, and John Kralewski, "Market Power and Contract Form: Evidence from Physician Group Practices," International Journal of Health Care Finance Economics, 11(2011): 115-132.

United States Department of Justice and the Federal Trade Commission, "Horizontal Merger Guidelines," (2010).

United States Government Accountability Office, "Report to the Honorable Paul Ryan, House of Representatives: Competition and Other Factors Linked to Wide Variation in Health Care Prices," United States Government Accountability Office, ed. (Washington, DC, 2005).

Vita, Michael G., and Seth Sacher, "The Competitive Effects of Not-for-Profit Hospital Mergers: A Case Study," The Journal of Industrial Economics, XLIX (2001), 63-84. 
Vogt, William B, and Robert Town, "How Has Hospital Consolidation Affected the Price and Quality of Hospital Care?" in The Synthesis Project, (Robert Wood Johnson Foundation, 2006).

White, Chapin, James D. Reschovsky, and Amelia M. Bond, "Understanding Differences Between High- And Low-Price Hospitals: Implications For Efforts To Rein In Costs," Health Affairs, 33 (2014), 324-331. 
Table 1: Annual Patients, Claims, and Spending From HCCI Data, 2007 - 2011

\begin{tabular}{lccc}
\hline \hline & & & \\
\cline { 2 - 4 } & Distinct Members & Inpatient Spending $(\$)$ & Total Spending $(\$)$ \\
\cline { 2 - 4 } 2007 & $44,869,397$ & $28,703,216,810$ & $126,439,637,925$ \\
2008 & $45,064,977$ & $29,796,787,559$ & $131,711,103,920$ \\
2009 & $44,780,736$ & $32,288,419,203$ & $141,932,049,143$ \\
2010 & $43,642,097$ & $31,829,518,213$ & $140,894,344,384$ \\
2011 & $42,976,359$ & $31,829,841,920$ & $141,110,226,944$ \\
Total & $88,680,441$ & $154,447,783,705$ & $682,087,362,316$ \\
& & & \\
\hline \hline
\end{tabular}

Notes: This table is based on claims from the entire HCCI database. All spending values have been inflation adjusted to 2011 dollars using the BLS All Items Consumer Price Index. 
Table 2: Hospital and Patient Characteristics

\begin{tabular}{|c|c|c|c|c|}
\hline Market Characteristics & Mean & SD & Min & Max \\
\hline Hospital in Monopoly Market, 15 Mile Radius & 0.163 & 0.370 & 0 & 1 \\
\hline Hospital in Duopoly Market, 15 Mile Radius & 0.194 & 0.395 & 0 & 1 \\
\hline Hospital in Triopoly Market, 15 Mile Radius & 0.123 & 0.328 & 0 & 1 \\
\hline Hospital in Quadropoly+ & 0.520 & 0.500 & 0 & 1 \\
\hline Hospital HHI Defined by Beds in a 15 Mile Radius & 0.461 & 0.295 & 0.043 & 1 \\
\hline HCCI Market Share Measured at the County Level & 0.178 & 0.101 & 0.017 & 0.571 \\
\hline Blue Cross Blue Shield Market Share Measured at the County Level & 0.403 & 0.218 & 0.001 & 0.958 \\
\hline \multicolumn{5}{|l|}{ Hospital Characteristics } \\
\hline Number of Technologies & 59 & 30 & 0 & 138 \\
\hline Ranked in US News \& World Reports & 0.053 & 0.225 & 0 & 1 \\
\hline Beds & 270 & 203 & 10 & 2,264 \\
\hline Teaching Hospital & 0.380 & 0.485 & 0 & 1 \\
\hline Government Owned & 0.122 & 0.327 & 0 & 1 \\
\hline Non-Profit & 0.693 & 0.461 & 0 & 1 \\
\hline For-Profit & 0.185 & 0.388 & 0 & 1 \\
\hline \multicolumn{5}{|l|}{ Local Area Characteristics } \\
\hline Percent of County Uninsured & 0.171 & 0.058 & 0.031 & 0.389 \\
\hline Median Income & 51,516 & 13,153 & 22,255 & 119,525 \\
\hline Rural & 0.162 & 0.369 & 0 & 1 \\
\hline \multicolumn{5}{|l|}{ Other Payers } \\
\hline Medicare Payment Rate & 6,437 & 1,288 & 4,590 & 14,292 \\
\hline Share Medicare & 0.446 & 0.101 & 0 & 0.833 \\
\hline Share Medicaid & 0.188 & 0.096 & 0 & 0.777 \\
\hline \multicolumn{5}{|l|}{ Quality Scores } \\
\hline 30-Day AMI Survival Rate & 0.840 & 0.016 & 0.751 & 0.898 \\
\hline$\%$ of AMI Patients Given Aspirin at Arrival & 0.975 & 0.049 & 0.330 & 1 \\
\hline$\%$ of Patients Given Antibiotics Pre Surgery & 0.934 & 0.082 & 0.140 & 1 \\
\hline$\%$ of Surgery Patients Given Treatment to Prevent Blood Clots & 0.881 & 0.106 & 0.030 & 1 \\
\hline \multicolumn{5}{|l|}{ Patient Characteristics } \\
\hline Age $18-24$ & 0.074 & 0.262 & 0 & 1 \\
\hline Age $25-35$ & 0.248 & 0.432 & 0 & 1 \\
\hline Age $35-44$ & 0.196 & 0.397 & 0 & 1 \\
\hline Age $45-54$ & 0.219 & 0.414 & 0 & 1 \\
\hline Age $55-64$ & 0.262 & 0.440 & 0 & 1 \\
\hline Female & 0.672 & 0.470 & 0 & 1 \\
\hline Charlson Comorbidity Index & 0.707 & 1.442 & 0 & 6 \\
\hline
\end{tabular}

Notes: These are descriptive statistics for the Inpatient Pricing sample from the HCCI database. There are 8,772 hospital-year observations representing 2,358 unique hospitals and 4,964,774 unique patients. 


\section{Table 3: Private Prices and Medicare Base Payment Rate at the Hospital Level, 2011}

\begin{tabular}{|c|c|c|c|c|c|c|c|c|c|c|c|c|}
\hline & \multicolumn{3}{|c|}{ Summary Statistics } & \multicolumn{9}{|c|}{ Correlation } \\
\hline & Mean & $\begin{array}{c}\text { Standard } \\
\text { Deviation }\end{array}$ & $\begin{array}{c}\# \\
\text { Hospitals }\end{array}$ & 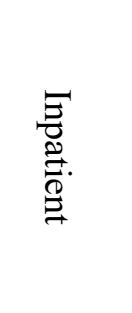 & 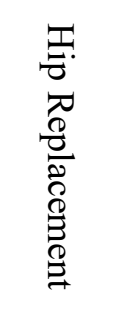 & 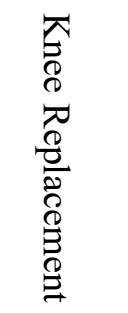 & 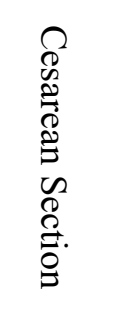 & 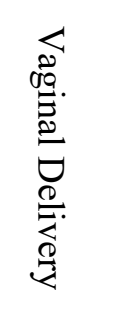 & $\vec{\beta}$ & $\begin{array}{l}\delta \\
\frac{0}{2} \\
0 \\
0 \\
\delta \\
\delta\end{array}$ & 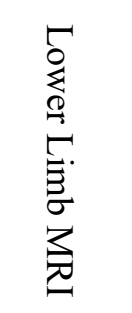 & 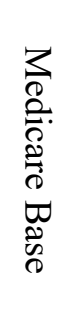 \\
\hline Inpatient & 14,020 & 4,782 & 2,139 & 1 & & & & & & & & \\
\hline Hip Replacement & 24,565 & 7,209 & 341 & 0.724 & 1 & & & & & & & \\
\hline Knee Replacement & 24,059 & 7,677 & 664 & 0.761 & 0.923 & 1 & & & & & & \\
\hline Cesarean Section & 8,258 & 2,758 & 926 & 0.794 & 0.535 & 0.574 & 1 & & & & & \\
\hline Vaginal Delivery & 5,465 & 1,727 & 1,022 & 0.693 & 0.544 & 0.510 & 0.879 & 1 & & & & \\
\hline PTCA & 25,395 & 8,577 & 375 & 0.678 & 0.580 & 0.573 & 0.440 & 0.349 & 1 & & & \\
\hline Colonoscopy & 1,834 & 685 & 844 & 0.342 & 0.285 & 0.273 & 0.303 & 0.322 & 0.156 & 1 & & \\
\hline Lower Limb MRI & 1,343 & 533 & 1,304 & 0.350 & 0.224 & 0.264 & 0.276 & 0.232 & 0.255 & 0.252 & 1 & \\
\hline Medicare Base & 6,494 & 1,291 & 2,139 & 0.203 & 0.283 & 0.203 & 0.258 & 0.360 & 0.093 & 0.087 & -0.040 & 1 \\
\hline
\end{tabular}


Table 4: Price/Quantity Decomposition of Medicare and Private Health Spending, 2011

Intracranial hemorrhage or cerebral infarction w CC

Pulmonary edema $\&$ respiratory failure

Simple pneumonia \& pleurisy w CC

Respiratory system diagnosis w ventilator support 96+ hours

Respiratory system diagnosis w ventilator support $<96$ hours

Cardiac valve \& oth maj cardiothoracic proc w/o card cath w MCC

Cardiac valve \& oth maj cardiothoracic proc w/o card cath w CC

Cardiac defibrillator implant w/o cardiac cath w/o MCC

Coronary bypass w cardiac cath w/o MCC

Coronary bypass w/o cardiac cath w/o MCC

Major cardiovasc proc w MCC or thoracic aortic aneurysm repair

Major cardiovascular proc w/o MCC

Perc cardiovasc proc w drug-eluting stent w MCC or 4+ vessels/stents

Perc cardiovasc proc $\mathrm{w}$ drug-eluting stent w/o MCC

Circulatory disorders except AMI, w card cath w/o MCC

Major small \& large bowel proc w MCC

Major small \& large bowel proc w CC

Esophagitis, gastroent \& misc digest disorders w/o MCC

Spinal fusion except cervical w/o MCC

Major joint replacement or reattachment of lower extremity w/o MCC

Cellulitis w/o MCC

Infectious \& parasitic diseases w O.R. proc w MCC

Septicemia w MV 96+ hours

Septicemia w/o MV 96+ hours w MCC

Rehabilitation w CC/MCC

\section{Average Shares (weighted by spending)}

\begin{tabular}{|c|c|c|}
\hline $\begin{array}{c}(1) \\
\text { Share } \\
\text { Price }\end{array}$ & $\begin{array}{c}\text { Private } \\
\text { (2) } \\
\text { Share } \\
\text { Quantity }\end{array}$ & $\begin{array}{c}\text { (3) } \\
\text { Share } \\
\text { Covariance }\end{array}$ \\
\hline 0.484 & 0.466 & 0.050 \\
\hline 0.594 & 0.402 & 0.004 \\
\hline 0.475 & 0.514 & 0.011 \\
\hline 0.650 & 0.415 & -0.064 \\
\hline 0.655 & 0.321 & 0.024 \\
\hline 0.468 & 0.410 & 0.122 \\
\hline 0.389 & 0.498 & 0.113 \\
\hline 0.713 & 0.377 & -0.090 \\
\hline 0.277 & 0.746 & -0.023 \\
\hline 0.381 & 0.699 & -0.079 \\
\hline 0.555 & 0.308 & 0.138 \\
\hline 0.518 & 0.547 & -0.065 \\
\hline 0.371 & 0.564 & 0.065 \\
\hline 0.465 & 0.681 & -0.146 \\
\hline 0.435 & 0.756 & -0.191 \\
\hline 0.676 & 0.299 & 0.025 \\
\hline 0.474 & 0.453 & 0.073 \\
\hline 0.387 & 0.637 & -0.024 \\
\hline 0.334 & 0.512 & 0.154 \\
\hline 0.381 & 0.645 & -0.026 \\
\hline 0.425 & 0.583 & -0.008 \\
\hline 0.701 & 0.360 & -0.061 \\
\hline 0.759 & 0.305 & -0.065 \\
\hline 0.536 & 0.365 & 0.099 \\
\hline 0.460 & 0.430 & 0.109 \\
\hline 0.496 & 0.495 & 0.009 \\
\hline
\end{tabular}

\begin{tabular}{|c|c|c|}
\hline $\begin{array}{l}(4) \\
\text { Share } \\
\text { Price }\end{array}$ & $\begin{array}{c}\text { Medicare } \\
\text { (5) } \\
\text { Share } \\
\text { Quantity }\end{array}$ & $\begin{array}{c}\text { (6) } \\
\text { Share } \\
\text { Covariance }\end{array}$ \\
\hline 0.256 & 0.662 & 0.082 \\
\hline 0.213 & 0.770 & 0.017 \\
\hline 0.221 & 0.989 & -0.210 \\
\hline 0.102 & 0.771 & 0.127 \\
\hline 0.155 & 0.987 & -0.143 \\
\hline 0.086 & 0.840 & 0.074 \\
\hline 0.069 & 0.846 & 0.085 \\
\hline 0.061 & 0.956 & -0.017 \\
\hline 0.074 & 1.168 & -0.242 \\
\hline 0.108 & 1.058 & -0.166 \\
\hline 0.166 & 0.871 & -0.037 \\
\hline 0.163 & 1.059 & -0.222 \\
\hline 0.089 & 1.004 & -0.094 \\
\hline 0.153 & 1.113 & -0.265 \\
\hline 0.112 & 1.110 & -0.222 \\
\hline 0.213 & 0.888 & -0.101 \\
\hline 0.193 & 0.811 & -0.005 \\
\hline 0.164 & 1.028 & -0.192 \\
\hline 0.085 & 1.067 & -0.152 \\
\hline 0.213 & 0.973 & -0.186 \\
\hline 0.128 & 0.923 & -0.051 \\
\hline 0.112 & 0.769 & 0.119 \\
\hline 0.072 & 0.860 & 0.067 \\
\hline 0.120 & 0.815 & 0.064 \\
\hline 0.056 & 1.164 & -0.219 \\
\hline 0.127 & 0.953 & -0.081 \\
\hline
\end{tabular}
based on the $100 \%$ sample of Medicare claims accessed via the AHD. HCCI data includes all inpatient claims from our spending sample for those aged 55-64. "CC" is short for with "complication or comorbidity"; "MCC" is short for with "major complication or comorbidity"; "proc"="procedure"; "cath" = "catheter"; "w"=With"; "w/o"="without". Because of space constraints, we show only the top 25 highest spending DRGs in the HCCI data; the "Average Shares" in the final row are the average decomposition results by DRG (weighted by spending, i.e. first three columns use spending weights for private and last three use weights based on Medicare) across the 735 DRGs (HCCI) 562 DRGs (Medicare). 
Table 5: Decomposition of Hospitals' Transaction Price Variation

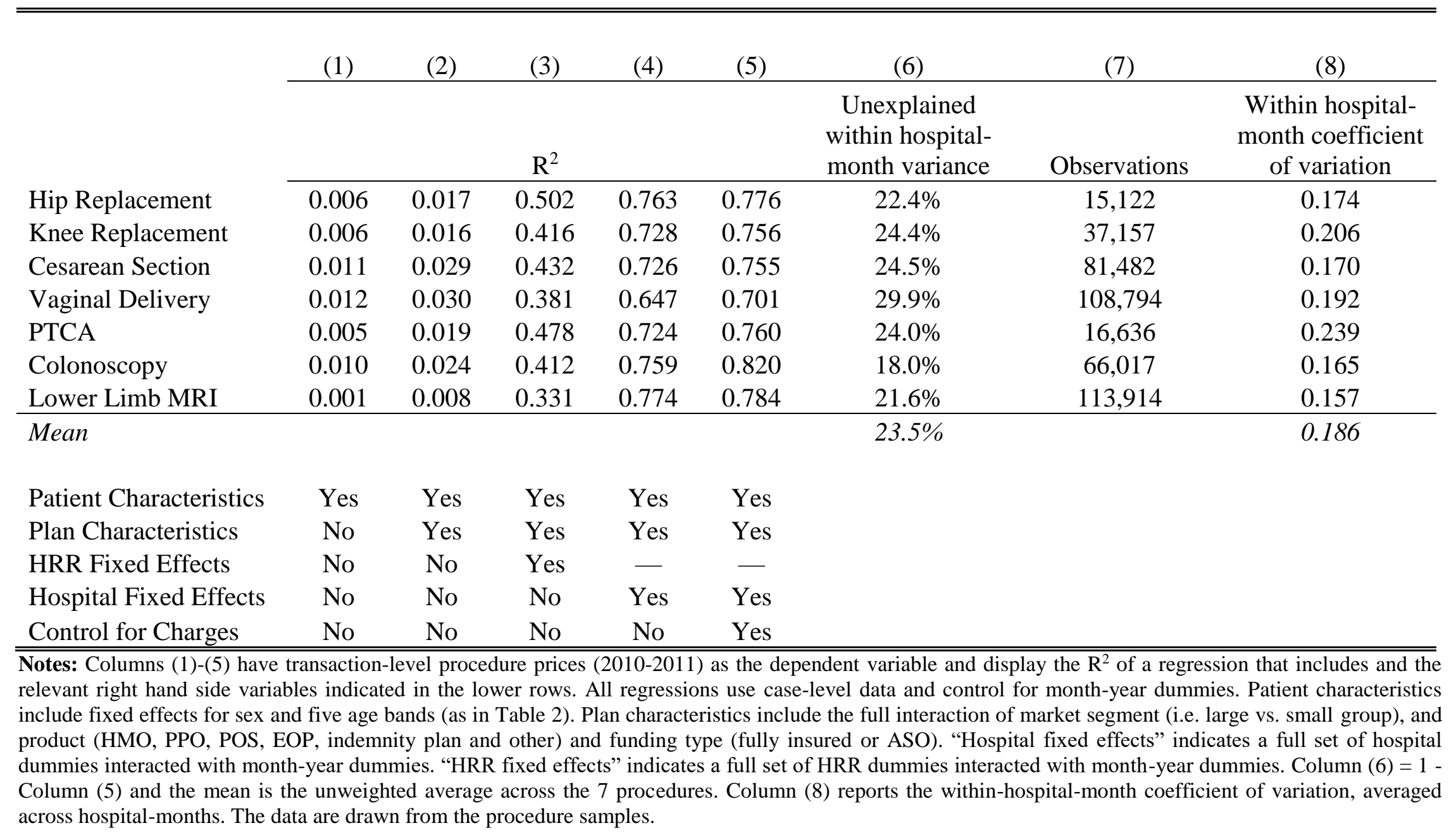


Table 6: Hospital Concentration, Prices and Contract Form, 2008-2011

\begin{tabular}{|c|c|c|c|}
\hline & $(1)$ & $(2)$ & (3) \\
\hline \multicolumn{4}{|c|}{ Panel A: $\ln ($ Hospital Price), Mean=9.42, Obs=8,772, Number of Hospitals=2,358 } \\
\hline Monopoly & $\begin{array}{c}0.234 * * * \\
(0.024)\end{array}$ & $\begin{array}{c}0.190 * * * \\
(0.024)\end{array}$ & $\begin{array}{c}0.118 * * * \\
(0.024)\end{array}$ \\
\hline Duopoly & $\begin{array}{c}0.161 * * * \\
(0.021)\end{array}$ & $\begin{array}{c}0.130 * * * \\
(0.020)\end{array}$ & $\begin{array}{c}0.073 * * * \\
(0.024)\end{array}$ \\
\hline Triopoly & $\begin{array}{c}0.115^{* * *} \\
(0.023)\end{array}$ & $\begin{array}{c}0.083 * * * \\
(0.023)\end{array}$ & $\begin{array}{c}0.036 \\
(0.023)\end{array}$ \\
\hline \multicolumn{4}{|c|}{ Hospitals in quadropoly or greater markets are the omitted category } \\
\hline HCCI Market Share & & $\begin{array}{c}-0.006^{* * *} \\
(0.002)\end{array}$ & $\begin{array}{c}-0.007 * * * \\
(0.002)\end{array}$ \\
\hline \multicolumn{4}{|c|}{$\begin{array}{l}\text { Panel B: Percent of Cases Paid as Share of Charges; Mean=18.6\%, Obs=4,344, Number of } \\
\text { Hospitals=2,253 }\end{array}$} \\
\hline Monopoly & $\begin{array}{c}17.335 * * * \\
(1.828)\end{array}$ & $\begin{array}{c}15.241 * * * \\
(1.823)\end{array}$ & $\begin{array}{c}10.455 * * * \\
(1.778)\end{array}$ \\
\hline Duopoly & $\begin{array}{c}9.979 * * * \\
(1.760)\end{array}$ & $\begin{array}{c}8.424 * * * \\
(1.740)\end{array}$ & $\begin{array}{c}5.702 * * * \\
(1.596)\end{array}$ \\
\hline Triopoly & $\begin{array}{l}7.804 * * * \\
(1.909)\end{array}$ & $\begin{array}{c}6.235^{* *} \\
(1.938)\end{array}$ & $\begin{array}{c}4.909 * * \\
(1.608)\end{array}$ \\
\hline \multicolumn{4}{|c|}{ Hospitals in quadropoly or greater markets are the omitted category } \\
\hline HCCI Market Share & & $\begin{array}{c}-0.288^{* * * *} \\
(0.077)\end{array}$ & $\begin{array}{c}-0.403 * * * \\
(0.120)\end{array}$ \\
\hline \multicolumn{4}{|c|}{$\begin{array}{l}\text { Panel C: Percent of Cases of Prospective Payments Tied to Medicare; Mean=48.3\%, Obs=3,669, } \\
\text { Number of Hospitals=1,936 }\end{array}$} \\
\hline Monopoly & $\begin{array}{c}-16.849 * * * \\
(2.882)\end{array}$ & $\begin{array}{c}-11.275^{* * *} * \\
(2.696)\end{array}$ & $\begin{array}{c}-11.293 * * * \\
(3.160)\end{array}$ \\
\hline Duopoly & $\begin{array}{c}-8.791 * * * \\
(2.441)\end{array}$ & $\begin{array}{c}-4.272 * \\
(2.443)\end{array}$ & $\begin{array}{c}-5.595 * * \\
(2.316)\end{array}$ \\
\hline Triopoly & $\begin{array}{c}-7.111^{* *} \\
(2.866)\end{array}$ & $\begin{array}{l}-2.422 \\
(2.727)\end{array}$ & $\begin{array}{c}-5.747 * * \\
(2.790)\end{array}$ \\
\hline \multicolumn{4}{|c|}{ Hospitals in quadropoly or greater markets are the omitted category } \\
\hline HCCI Market Share & & $\begin{array}{c}0.890 * * * \\
(0.091) \\
\end{array}$ & $\begin{array}{c}0.616^{* * * *} \\
(0.174) \\
\end{array}$ \\
\hline HRR Fixed Effects & No & No & Yes \\
\hline
\end{tabular}

Notes: $* \mathrm{p}<0.10, * * \mathrm{p}<0.05, * * * \mathrm{p}<0.01$. OLS estimates of Equation (2) with standard errors clustered at the HRRlevel in parentheses. Market structure variables described in Appendix C. The dependent variable in Panel A is $\ln$ (Hospital inpatient prices) that are regression risk-adjusted for DRG, age, and sex; in Panel B the dependent variable is the percent of cases paid as share of charges (i.e. non-prospective payments); in Panel C the dependent variable is the percent of cases tied to the Medicare reimbursement rate. An observation is a hospital-year. In Panel A, the data covers 2008 to 2011; Panels B and C it covers 2010 to 2011 because charge data is unavailable for earlier years. All regressions include controls for the number of technologies, dummy for being ranked in US News \& World Reports, size (number of beds), hospital ownership (government, non-profit or for-profit), whether a teaching hospital, $\%$ of county uninsured, county median income, the Medicare payment rate, share of Medicare, share of Medicaid, and year dummies. Appendix Tables 7-9 reports full set of results. 
Table 7: Prices and Contractual Form at the Procedure level

\begin{tabular}{|c|c|c|c|c|c|c|c|c|c|}
\hline & $(1)$ & $(2)$ & $(3)$ & $(4)$ & $(5)$ & $(6)$ & $(7)$ & $(8)$ & $(9)$ \\
\hline Sample: & Inpatient & $\begin{array}{c}\text { Pooled } \\
\text { Procedures }\end{array}$ & $\begin{array}{c}\text { Hip } \\
\text { Replacement }\end{array}$ & $\begin{array}{c}\text { Knee } \\
\text { Replacement }\end{array}$ & $\begin{array}{c}\text { Cesarean } \\
\text { Section }\end{array}$ & $\begin{array}{l}\text { Vaginal } \\
\text { Delivery }\end{array}$ & PTCA & Colonoscopy & $\begin{array}{c}\text { Lower } \\
\text { Limb } \\
\text { MRI }\end{array}$ \\
\hline \multicolumn{10}{|c|}{ Panel A: $\ln ($ Hospital Price $)$} \\
\hline Monopoly & $\begin{array}{c}0.118 * * * \\
(0.024)\end{array}$ & $\begin{array}{c}0.139 * * * \\
(0.026)\end{array}$ & $\begin{array}{c}0.054 \\
(0.102)\end{array}$ & $\begin{array}{c}0.152 * * * \\
(0.057)\end{array}$ & $\begin{array}{l}0.140 * * \\
(0.059)\end{array}$ & $\begin{array}{l}0.100 * * \\
(0.040)\end{array}$ & $\begin{array}{c}0.150 \\
(0.100)\end{array}$ & $\begin{array}{l}0.080^{*} \\
(0.043)\end{array}$ & $\begin{array}{c}0.210 * * * \\
(0.036)\end{array}$ \\
\hline Duopoly & $\begin{array}{c}0.073 * * * \\
(0.024)\end{array}$ & $\begin{array}{c}0.095 * * * \\
(0.018)\end{array}$ & $\begin{array}{c}0.016 \\
(0.069)\end{array}$ & $\begin{array}{c}0.019 \\
(0.046)\end{array}$ & $\begin{array}{c}0.092 * * * \\
(0.030)\end{array}$ & $\begin{array}{c}0.072 * * * \\
(0.024)\end{array}$ & $\begin{array}{c}0.153 * * \\
(0.071)\end{array}$ & $\begin{array}{c}0.064 \\
(0.039)\end{array}$ & $\begin{array}{c}0.141 * * * \\
(0.031)\end{array}$ \\
\hline Triopoly & $\begin{array}{c}0.036 \\
(0.023)\end{array}$ & $\begin{array}{c}0.055 * * \\
(0.021)\end{array}$ & $\begin{array}{c}0.068 \\
(0.084)\end{array}$ & $\begin{array}{c}-0.011 \\
(0.048)\end{array}$ & $\begin{array}{c}0.040 \\
(0.038)\end{array}$ & $\begin{array}{c}-0.001 \\
(0.031)\end{array}$ & $\begin{array}{c}0.086 \\
(0.052)\end{array}$ & $\begin{array}{c}0.037 \\
(0.041)\end{array}$ & $\begin{array}{c}0.126 * * * \\
(0.035)\end{array}$ \\
\hline HCCI Market Share & $\begin{array}{c}-0.007 * * * \\
(0.002)\end{array}$ & $\begin{array}{c}-0.003 \\
(0.002)\end{array}$ & $\begin{array}{c}0.001 \\
(0.004)\end{array}$ & $\begin{array}{l}-0.002 \\
(0.003)\end{array}$ & $\begin{array}{l}<0.001 \\
(0.003)\end{array}$ & $\begin{array}{c}-0.001 \\
(0.002)\end{array}$ & $\begin{array}{l}-0.003 \\
(0.004)\end{array}$ & $\begin{array}{c}-0.003 \\
(0.003)\end{array}$ & $\begin{array}{c}-0.004 \\
(0.002)\end{array}$ \\
\hline Observations & 8,772 & 22,167 & 1,259 & 2,660 & 3,794 & 4,096 & 1,764 & 3,512 & 5,082 \\
\hline \multicolumn{10}{|c|}{ Panel B: (Percent of Cases Paid As a Share of Charges)*100 } \\
\hline Monopoly & $\begin{array}{c}10.455 * * * \\
(1.778)\end{array}$ & $\begin{array}{c}22.264 * * * \\
(3.226)\end{array}$ & $\begin{array}{c}6.655 \\
(6.425)\end{array}$ & $\begin{array}{c}19.596 * * * \\
(4.832)\end{array}$ & $\begin{array}{c}22.228 * * * \\
(5.540)\end{array}$ & $\begin{array}{c}24.937 * * * \\
(4.488)\end{array}$ & $\begin{array}{l}10.504 \\
(8.583)\end{array}$ & $\begin{array}{c}22.628 * * * \\
(4.299)\end{array}$ & \\
\hline Duopoly & $\begin{array}{c}5.702 * * * \\
(1.596)\end{array}$ & $\begin{array}{c}12.678 * * * \\
(2.908)\end{array}$ & $\begin{array}{c}-2.558 \\
(7.533)\end{array}$ & $\begin{array}{c}13.366 * * \\
(4.824)\end{array}$ & $\begin{array}{c}14.932 * * * \\
(4.087)\end{array}$ & $\begin{array}{c}18.528 * * * \\
(3.683)\end{array}$ & $\begin{array}{l}13.160 \\
(6.797)\end{array}$ & $\begin{array}{l}8.166 * \\
(3.868)\end{array}$ & \\
\hline Triopoly & $\begin{array}{l}4.909 * * \\
(1.608)\end{array}$ & $\begin{array}{l}7.942 * * \\
(2.604)\end{array}$ & $\begin{array}{l}16.634 * \\
(7.943)\end{array}$ & $\begin{array}{c}9.208 \\
(5.447)\end{array}$ & $\begin{array}{c}5.471 \\
(3.980)\end{array}$ & $\begin{array}{c}10.256^{* *} \\
(3.576)\end{array}$ & $\begin{array}{c}0.049 \\
(3.949)\end{array}$ & $\begin{array}{l}9.607 * \\
(3.869)\end{array}$ & \\
\hline HCCI Market Share & $\begin{array}{c}-0.403 * * * \\
(0.120)\end{array}$ & $\begin{array}{c}-0.579 * * \\
(0.218)\end{array}$ & $\begin{array}{c}0.500 \\
(0.331)\end{array}$ & $\begin{array}{c}-0.434 \\
(0.327)\end{array}$ & $\begin{array}{l}-0.510 \\
(0.331)\end{array}$ & $\begin{array}{l}-0.510 \\
(0.272)\end{array}$ & $\begin{array}{l}-0.259 \\
(0.314)\end{array}$ & $\begin{array}{c}-0.801 * * \\
(0.252)\end{array}$ & \\
\hline Observations & 4,344 & 8,463 & 661 & 1,362 & 1,870 & 2,056 & 807 & 1,707 & \\
\hline
\end{tabular}

Notes: $* \mathrm{p}<0.10, * * \mathrm{p}<0.05, * * * \mathrm{p}<0.01$. OLS estimates of Equation (2) with standard errors clustered at the HRR-level in parentheses. Column (1) reproduces the results in Column (3) of Table 6. The dependent variables in Panel A are the ln(Inpatient hospital prices), risk-adjusted for age and sex. In Panel B, they are the Percent of cases paid as a share of hospital charges. In both panels these are for the specific procedures noted at the head of the column. Charges for MRIs do not generally vary across cases within hospitals so it is not possible to split into contract type. All regressions include controls for the number of technologies, dummy for being ranked in US News \& World Reports, size as measured by number of beds, hospital ownership (government, non-profit or for-profit), whether a teaching hospital, percent of county uninsured, county median income, the Medicare payment rate, share of Medicare, share of Medicaid, year dummies and HRR fixed-effects. The pooled sample reported in Column (2) stacks all the regressions for the specific procedures in the later columns and includes a set of procedure dummies. 
Table 8: Hospital Prices and Mergers

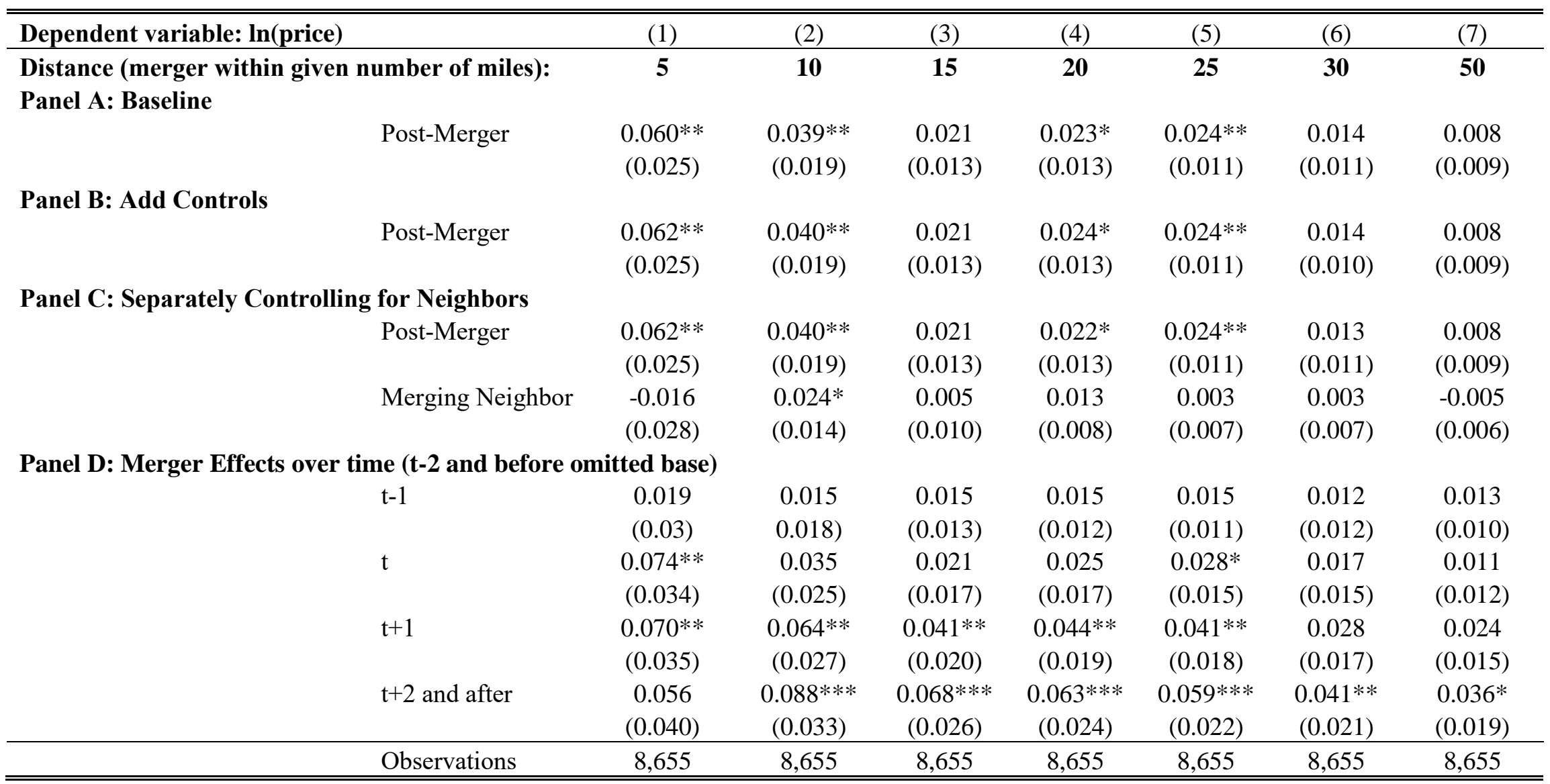

Notes: $* \mathrm{p}<0.10, * * \mathrm{p}<0.05, * * * \mathrm{p}<0.01$. OLS estimates of Equation (3) with standard errors in parentheses (clustered by hospital and system). All regressions include hospital fixed effects and year dummies. The dependent variable is our risk-adjusted inpatient price index. Controls: share of the privately insured covered by the HCCI insurers, number of technologies, dummy for being ranked in US News \& World Reports, size as measured by number of beds, hospital ownership (government, non-profit or for-profit), whether a teaching hospital, percent of county uninsured, county median income, the Medicare payment rate, share of Medicare, share of Medicaid, year dummies and HRR fixed-effects. Post-merger is dummy equal to 1 in the year a hospital merges and in all years afterwards and zero otherwise. "Neighbor" = 1 if a hospital was not involved in the merger, but within the distance indicated in the column head of a hospital where a merger took place (and zero otherwise). 


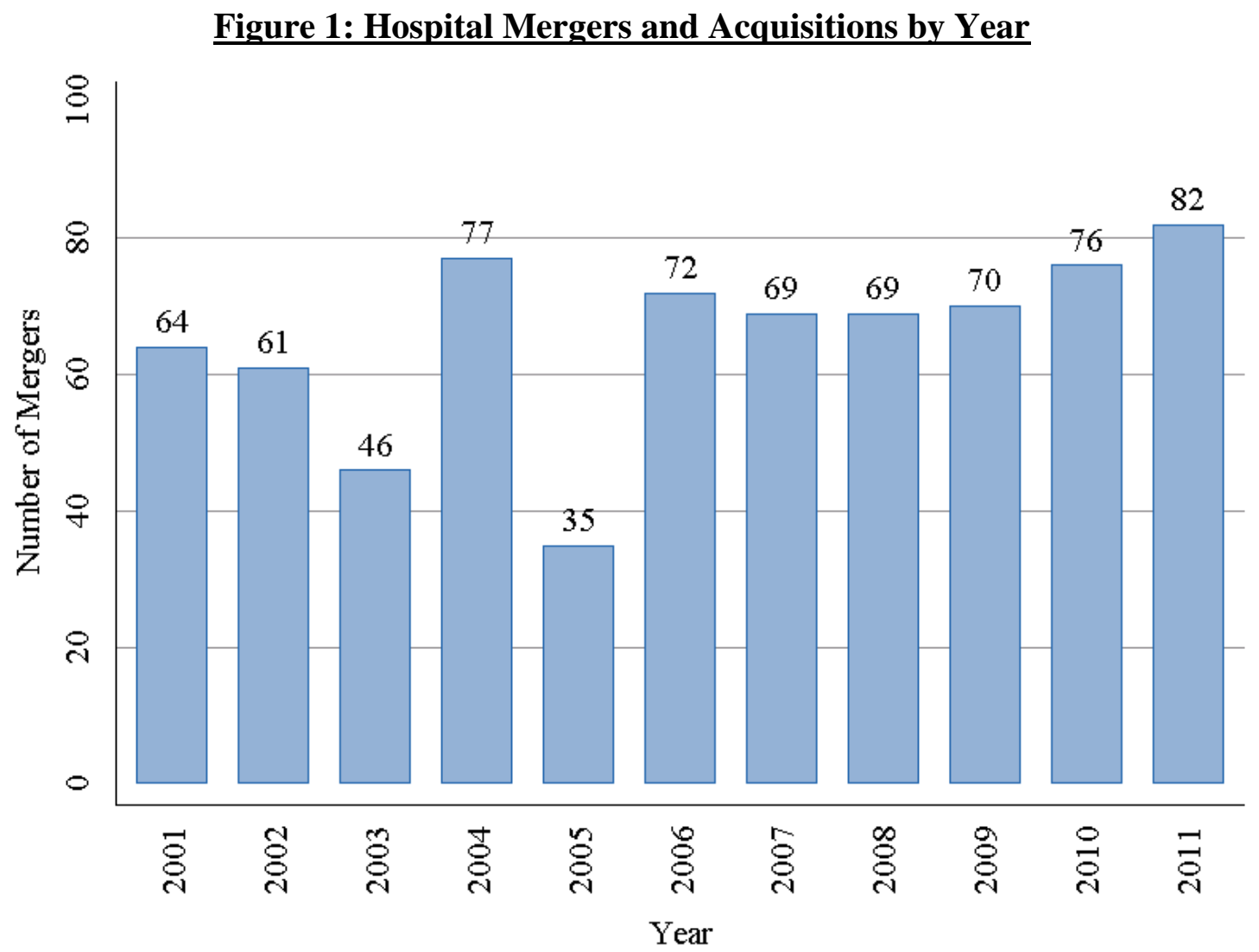

Notes: This figure shows the number of unique hospital merger and acquisition transactions by year. Authors' calculations based on data from the AHA, Irving-Levin Associates, Factset, and SDC Platinum databases. See Appendices A and D for details. 
Figure 2: Average Hospital Facilities Charges, Negotiated Prices, and Medicare Reimbursements, 2011

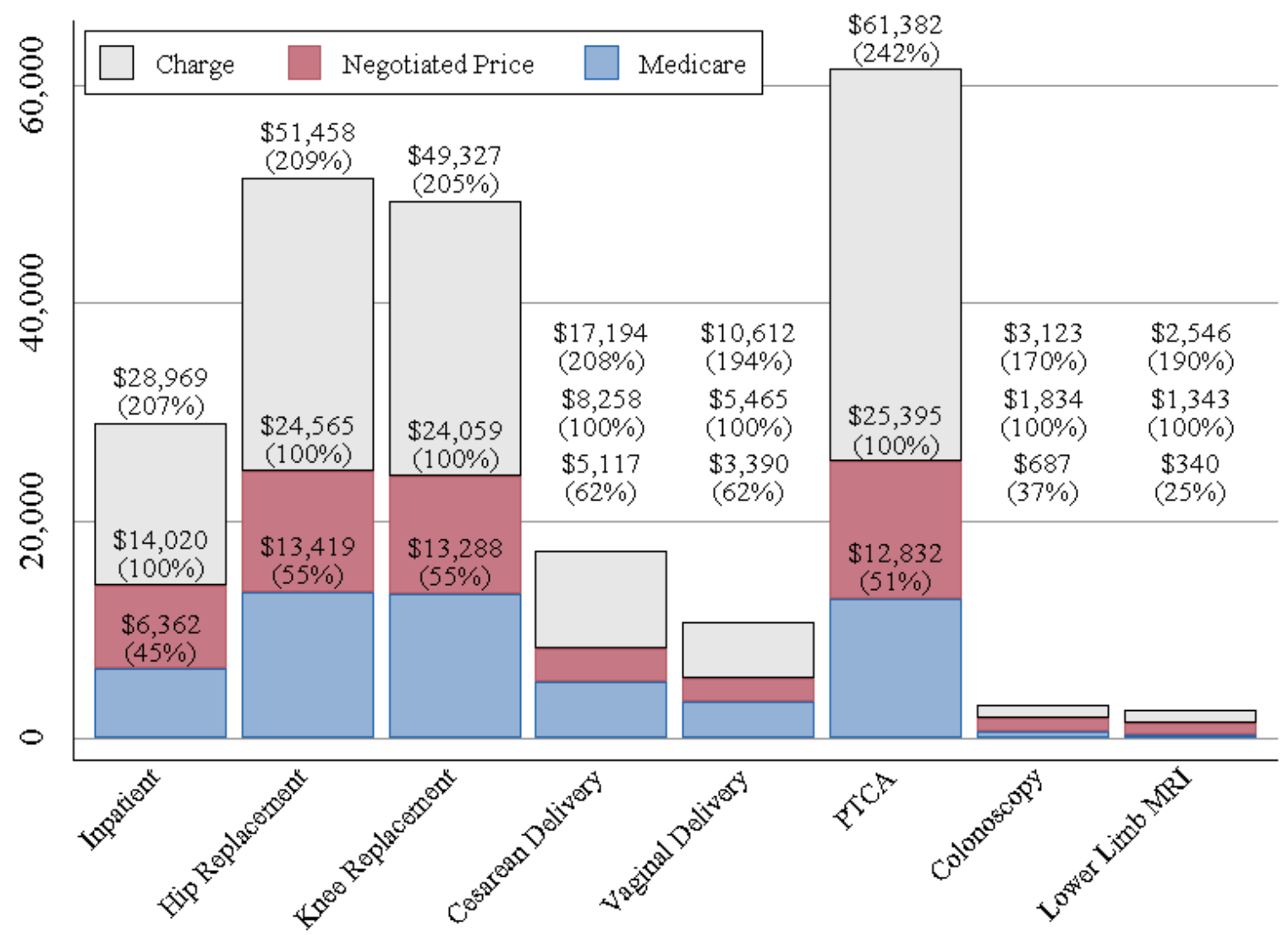

Notes: Data drawn from the inpatient and procedures samples. The height of the pale grey bars (top) are the average hospital charges. The height of the darker red shaded bars (middle) red the transaction prices. Both are risk-adjusted as described in Appendices B1 and B2. The blue bars (bottom) are the Medicare reimbursements as described in Appendix B4. Prices are given in 2011 dollar amounts and as a percentage of the transaction prices (in parentheses). 
Figure 3: Relationship between Charges and Negotiated Prices for Knee Replacements, 2011

Correlation: 0.314

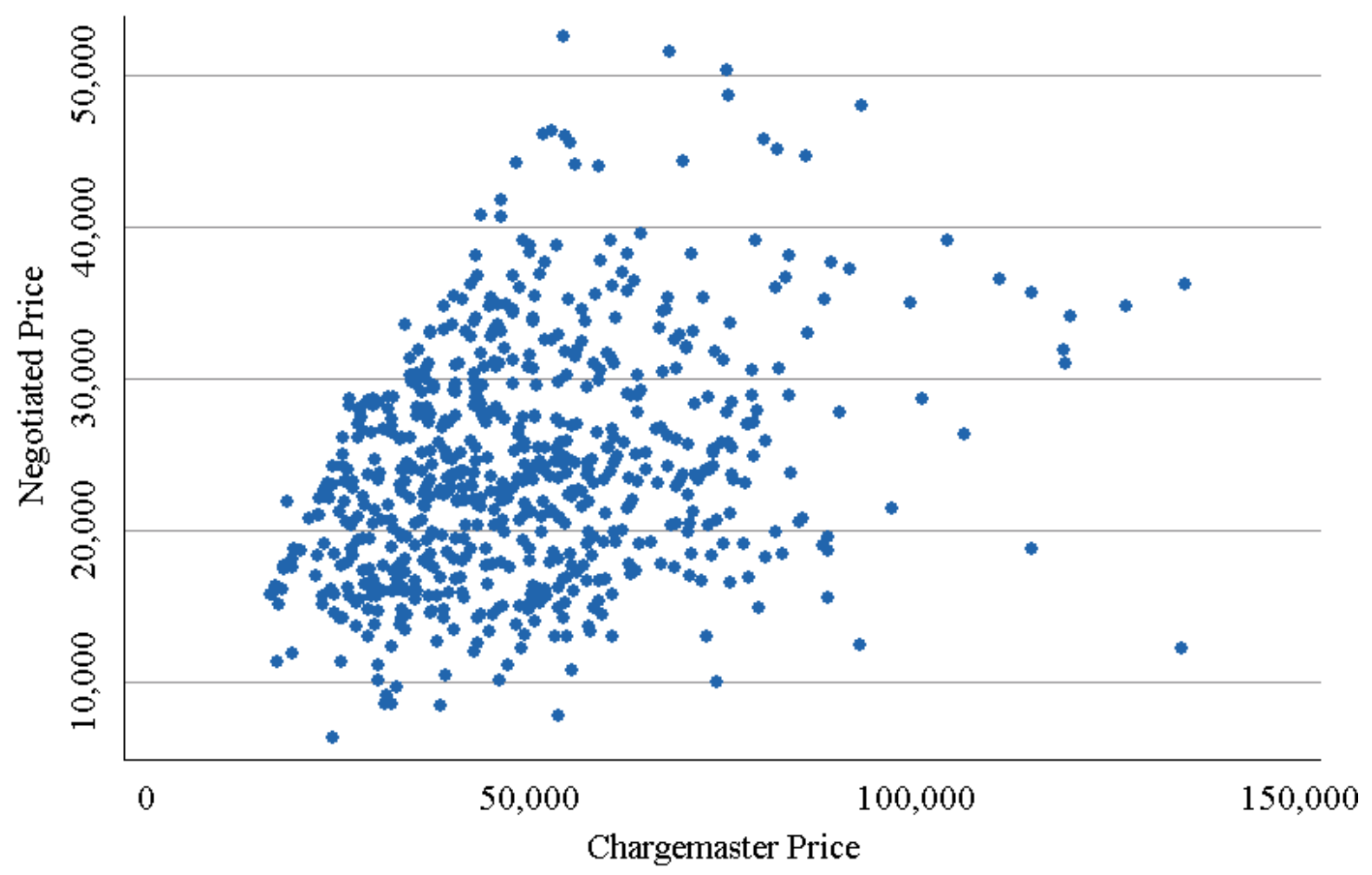

Notes: This is a scatter plot of hospital-level, risk-adjusted charges for knee replacements and risk-adjusted transaction prices. There are 696 unique providers included in this analysis who delivered 10 or more knee replacements to HCCI funded patients in 2011. 


\section{Figure 4: Total Private Spending by HRR, 2011}

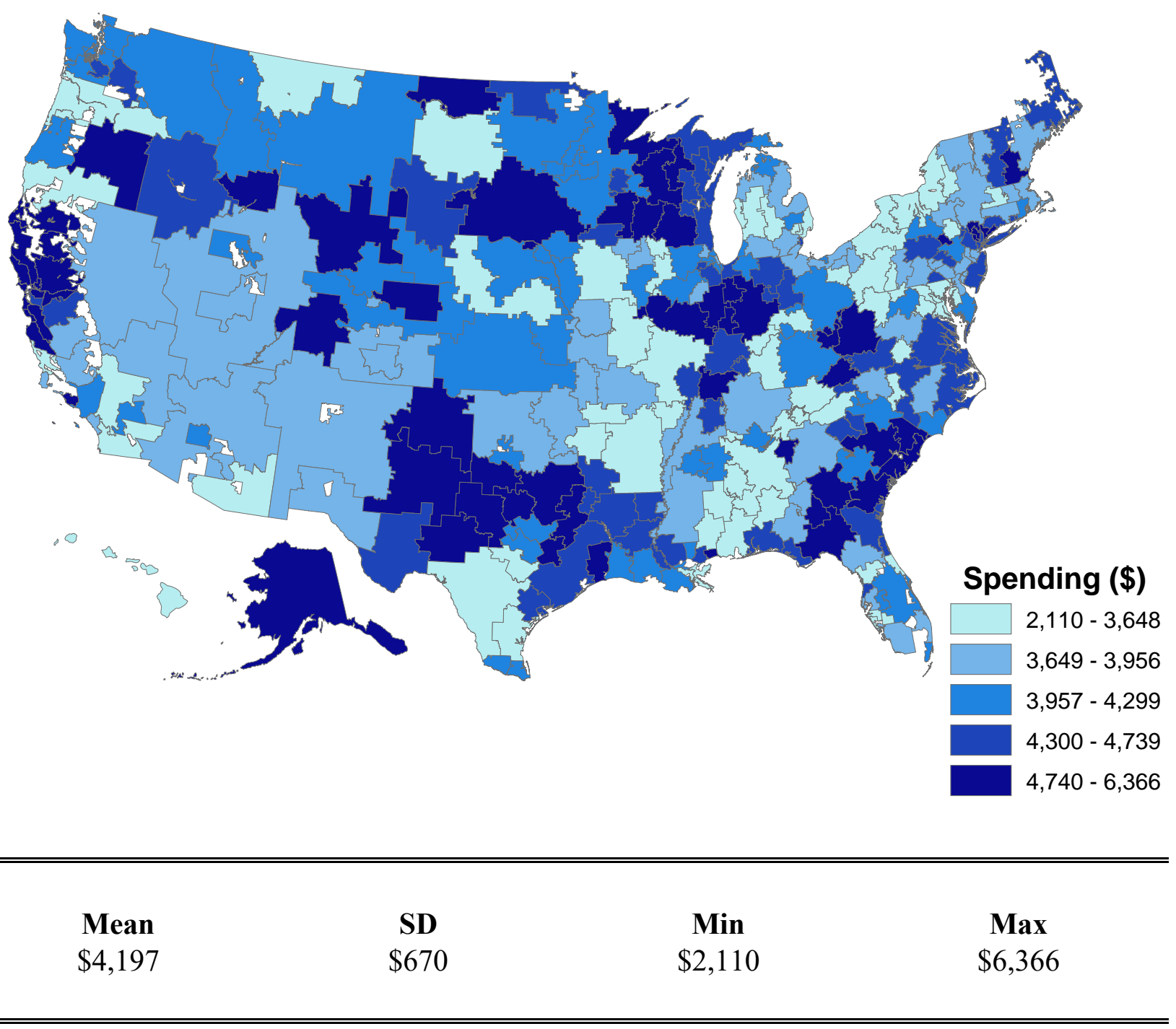

Notes: This figure captures risk-adjusted spending per beneficiary by HRR using data from 2011. Each bin captures a quintile of spending per beneficiary. The data are drawn from the spending sample. Spending per beneficiary is risk-adjusted for age and sex. 
Figure 5: National Variation in Hospital Prices for Knee Replacement and Lower Limb MRIs, 2011

Panel A: Knee Replacement Prices

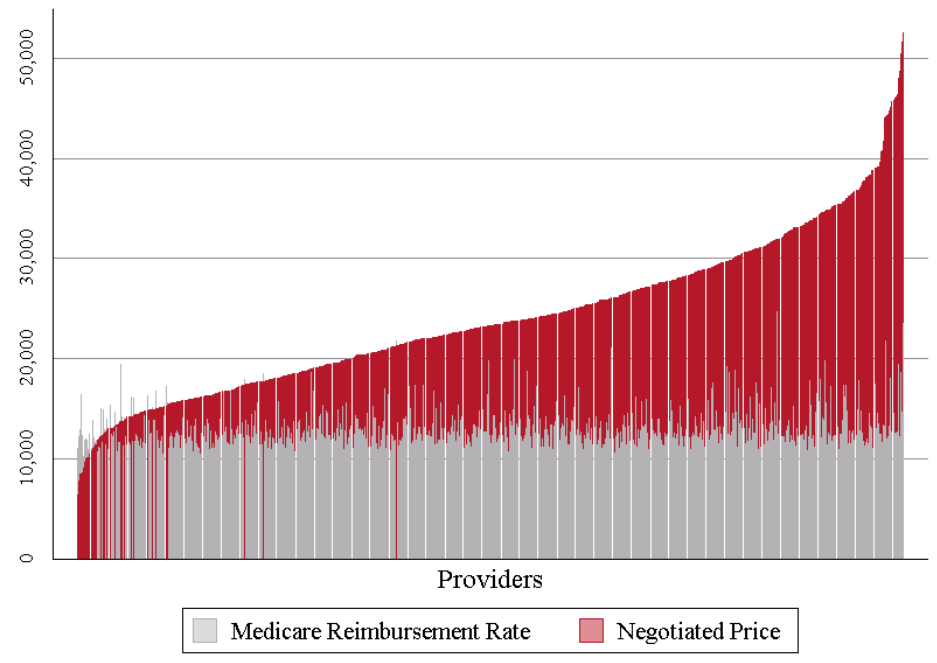

Panel B: Lower Limb MRI Prices

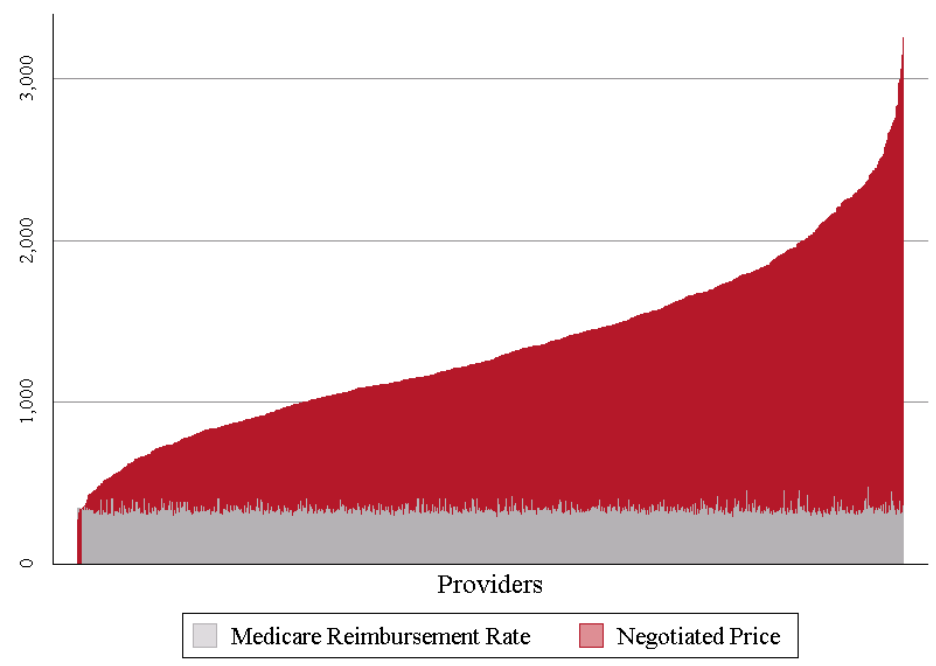

Summary Statistics for Negotiated Prices

$\$ 24,059$
$\$ 6,404-\$ 52,503$
$\$ 15,115-\$ 34,554$
$\$ 18,260-\$ 28,698$
2.29
0.32
0.18
664

Mean
Min - Max
p10 - p90
Inter Quartile Range (IQR)
p90/10 ratio
Coefficient of Variation
Gini Coefficient
Number of Hospitals

$\$ 1,343$

$\$ 270-\$ 3,251$

$\$ 719-\$ 2,104$

$\$ 965-\$ 1,671$

2.93

0.40

0.22

1,304

Notes: Each red bar represents a single hospital's regression-adjusted transaction price based on 2011 cases. The Medicare payment (gray) is based on the PPS fee schedule described in Appendix B4. The bars are ordered by private price. 


\section{Figure 6: Regression Adjusted HRR-Level Inpatient Hospital Prices, 2011}

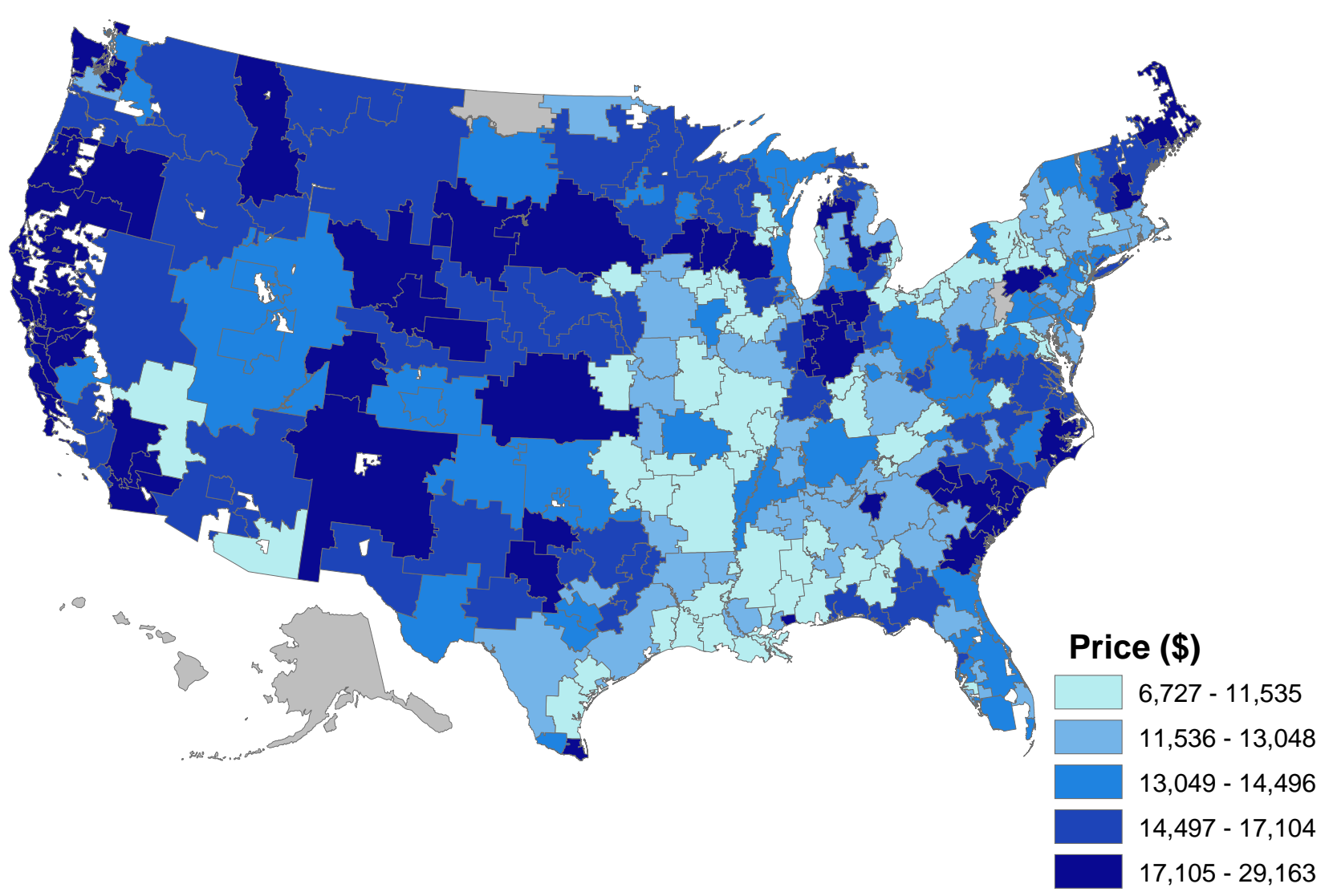

Notes: This figure captures HRR-level average hospital regression-adjusted inpatient prices that are risk-adjusted for DRG, age, and sex, and weighted by hospital activity. In Appendix Figure A6, we present this map normalized using the Medicare wage-index in order to control for local wage costs across the US. Gray regions are areas where we do not have sufficient data to calculate prices. 
Figure 7: Within Market Hospital Price Variation for Philadelphia, PA, 2011

Panel A: Hip Replacement

部 Mean: $\$ 29,289$

p90/p10 Ratio: 2.07

高

Max/Min Ratio: 2.50

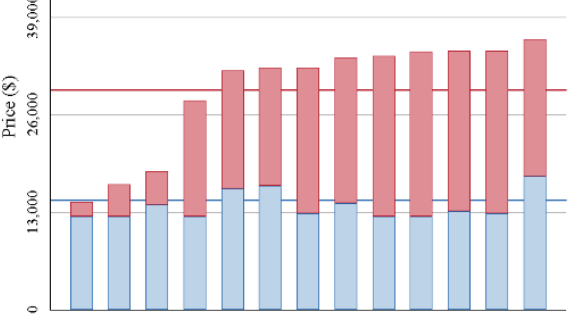

Panel D: Vaginal Delivery

Mean: $\$ 7,147$

CoV: 0.235

p90/p10 Ratio: 1.86

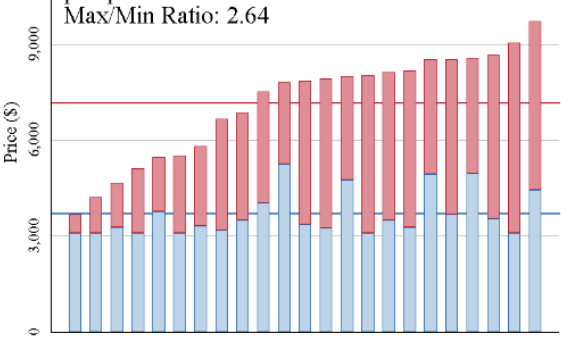

Panel G: Lower Limb MRI

\& Mean: $\$ 1,502$

CoV: 0.482

p90/p10 Ratio: 3.95

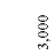

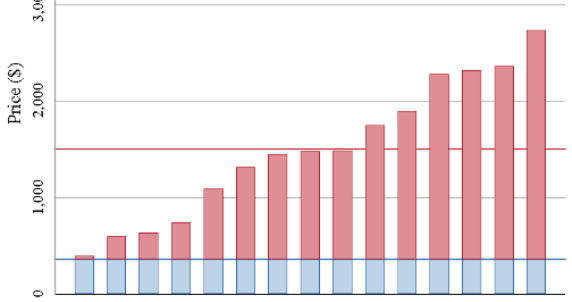

Panel B: Knee Replacement

高 Mean: \$27,129

Max/Min Ratio: 3.00

总

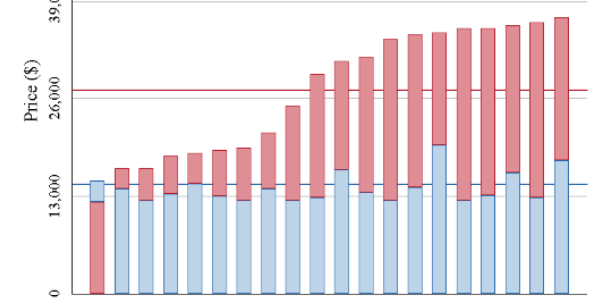

Panel E: PTCA

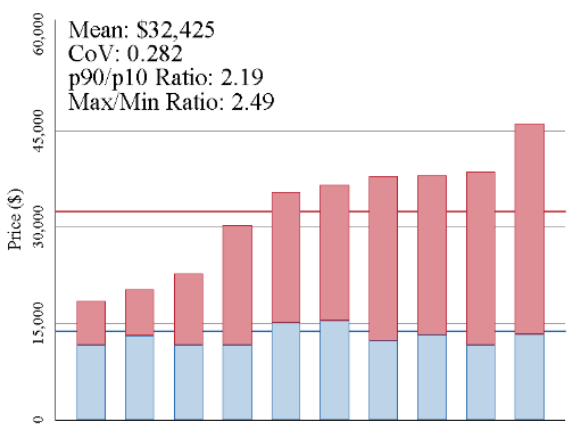

Panel C: Cesarean Section

: Mean: $\$ 10,425$

p90/p10 Ratio: 1.95

Max/Min Ratio: 2.50

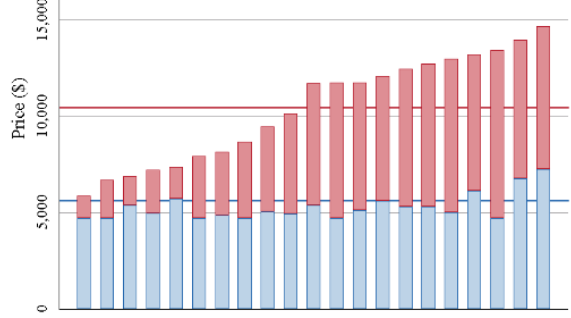

Panel F: Colonoscopy

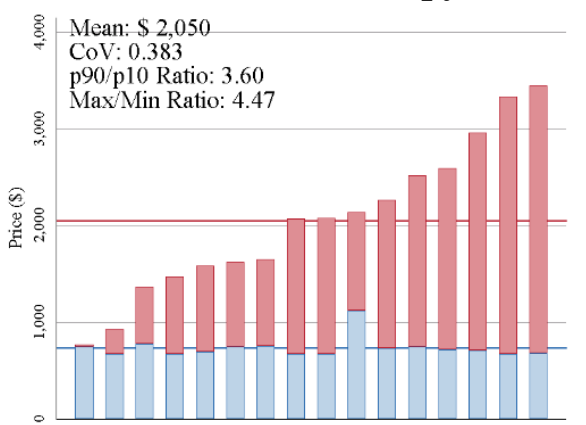

Notes: These panels present average hospital-level regression-adjusted private-payer prices for our seven hospital procedures using data from 2011. Each column captures a hospital in the Philadelphia, PA HRR. We include similar graphs for all HRRs that include five or more providers at www.hospitalpricingproject.org

\section{Negotiated Price \\ Medicare Reimbursement Rate}




\section{Figure 8: Within Hospital Prices for Lower Limb MRI at Two High Volume Hospitals,}

\section{8-2011}

Panel A: Hospital 1

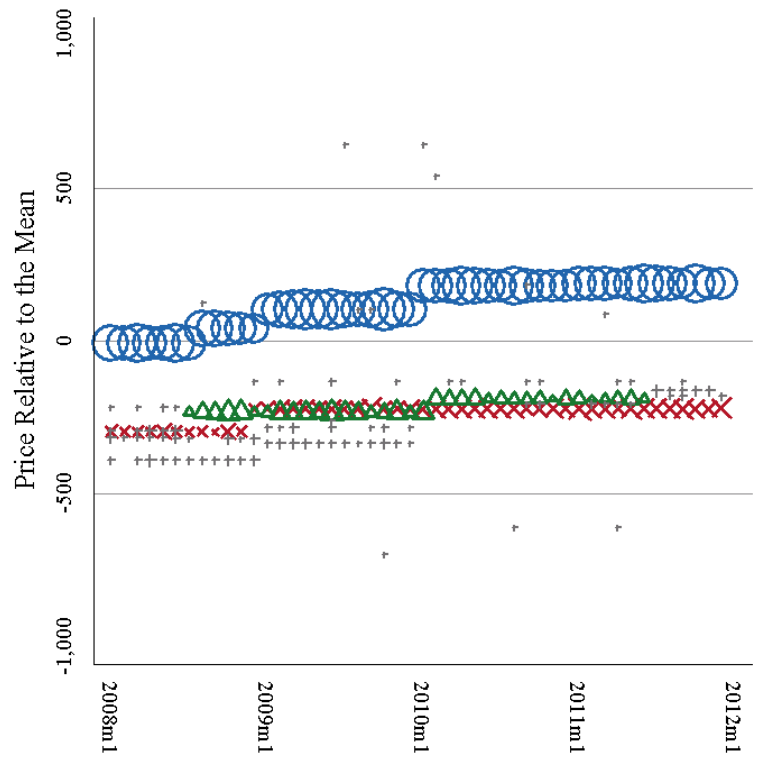

Panel B: Hospital 2

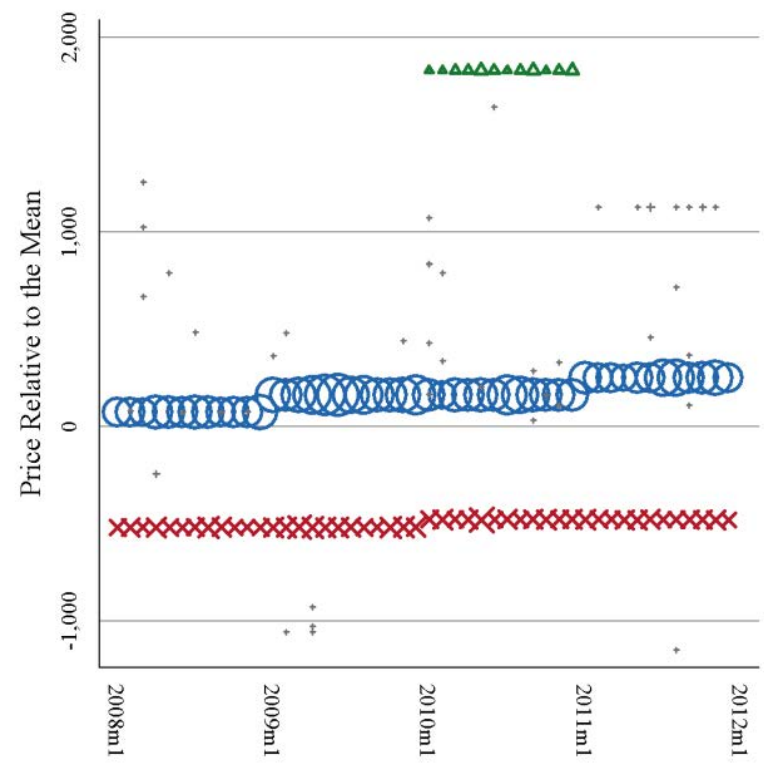

\section{Contract: $\circ 1 \times 2 \quad 3+$ Other}

Notes: These figures highlight the top three linked contracts (circles, crosses and triangles) within the two highest volume hospitals in our data in 2008-2011. Each point represents a unique price paid for lower limb MRI in a given hospital-month, where the size of the point corresponds to the volume of MRIs paid at that price. Repeated prices are linked across renegotiation events using information on the plan characteristics of the patients whose episodes were paid at that price. For more information on the methods used to link contracted prices see Appendix B3. 


\section{Figure 9: Repeated Price and Share of Charge Agreements at a Hospital}

for Vaginal Delivery, 2010-2011

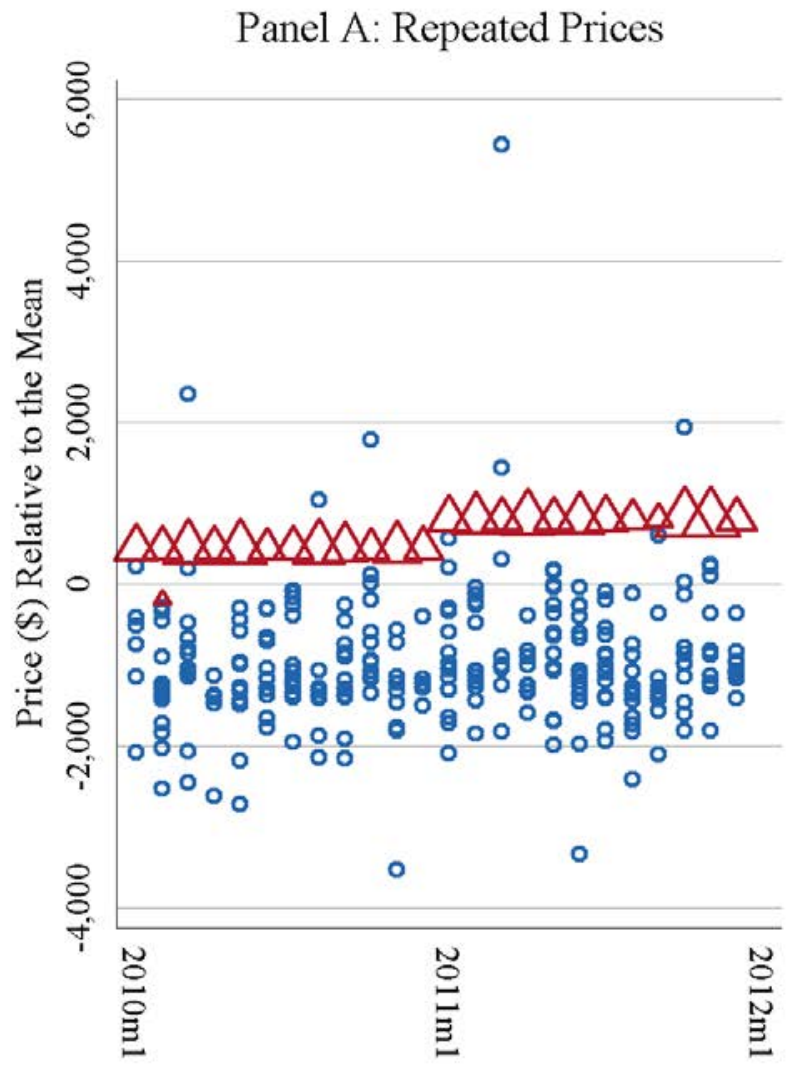

Month
Panel B: Repeated Share of Charges

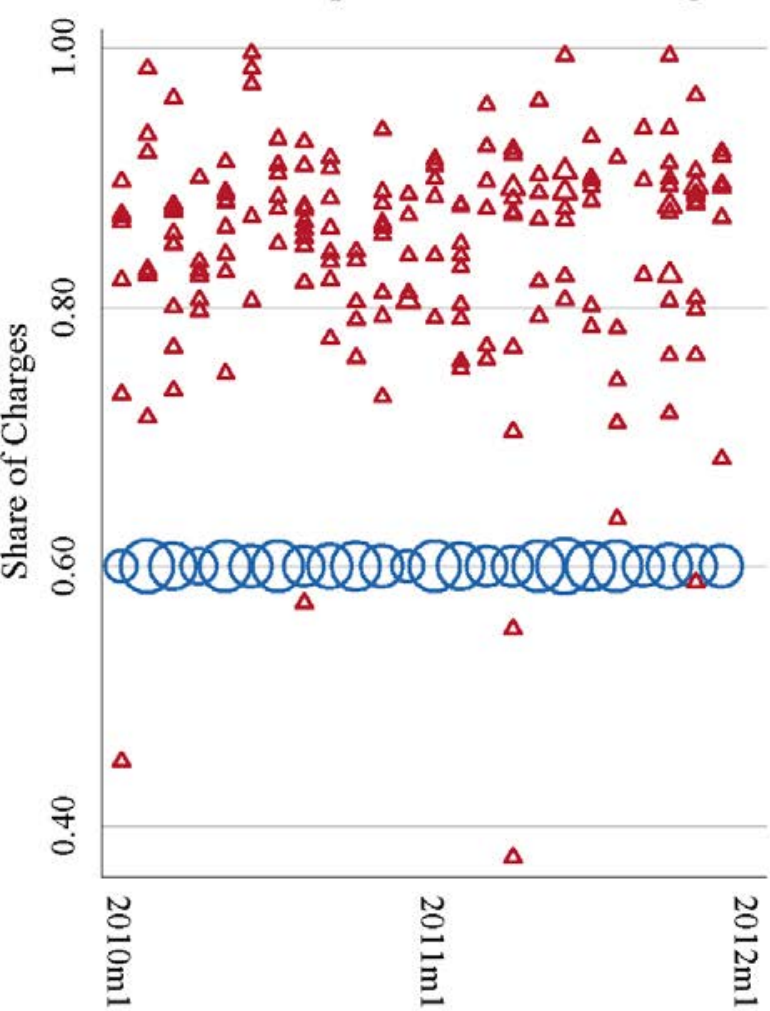

Month

\section{- Contract \#1 $\Delta$ Contract \#2}

Notes: These figures highlight the top two linked contracts within a high volume hospital for 2010-2011. Blue circles represent Contract \#1; red triangles represent Contract \#2. The size of the point corresponds to the volume of cases at that price. Repeated prices and price-to-charge ratios are linked across renegotiation events using information on the plan characteristics of the patients whose episodes were paid at that price or rate. For more information on the methods used to link contracted prices see Appendix B3. 
Figure 10: Contract Classifications overall and by Procedure, 2010-2011

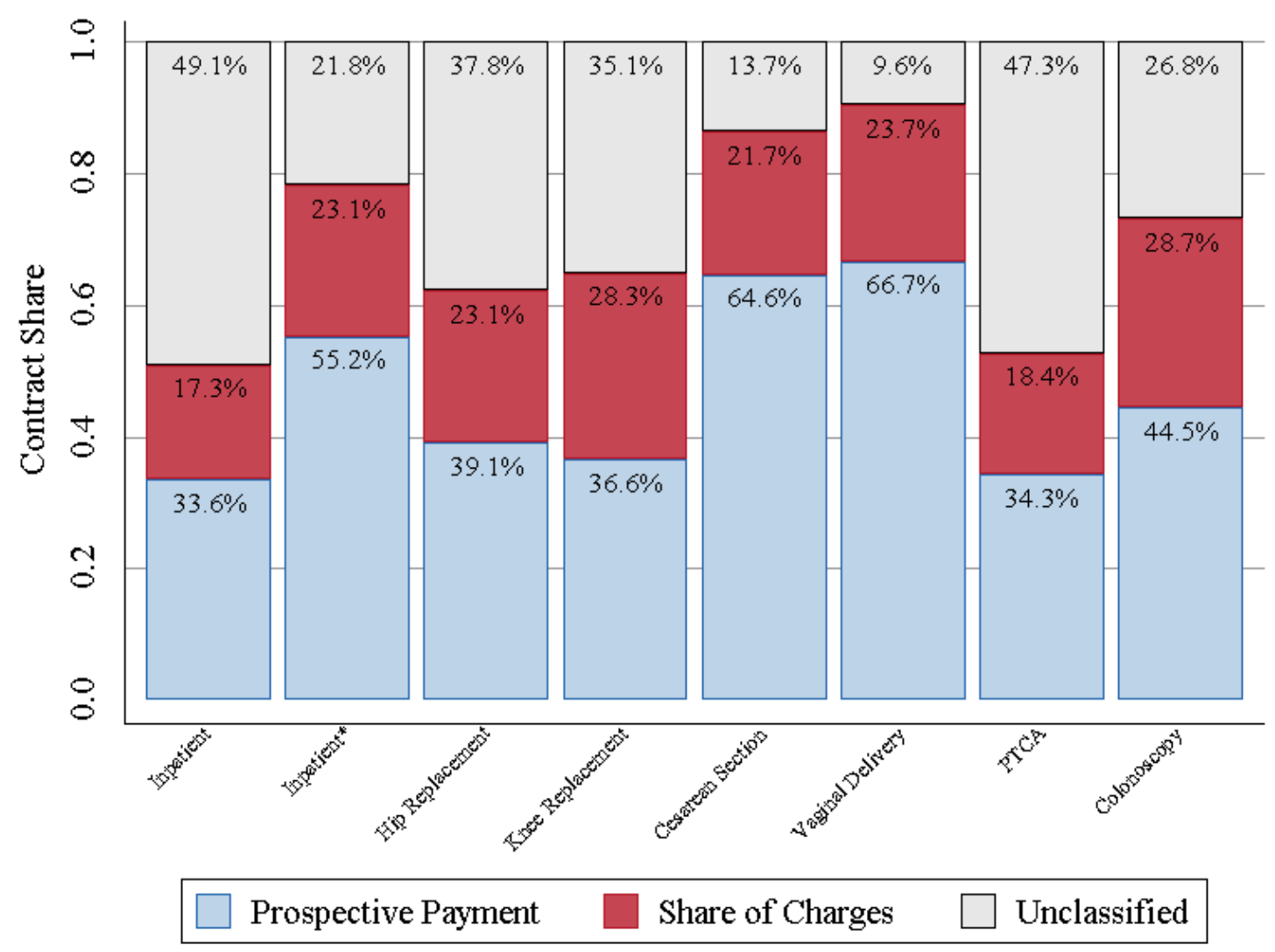

Notes: The bars present the share of the claims by procedure (or inpatient sample) classified into each type of contract using case-level data from 2010-2011. The numbers of hospitals (cases) underlying each bar are 2,253 $(2,288,907)$ for inpatient sample, $404(15,122)$ for Hip Replacement, $809(37,157)$ for Knee Replacement, 1,041 $(81,482)$ for Cesarean Section, $1,136(108,794)$ for Vaginal Delivery, $501(16,636)$ for PTCA, and 1,008 $(66,018)$ for Colonoscopy. Inpatient* presents a restricted sub-sample of the inpatient cases for hospital-DRG pairs that represent at least 20 admissions from 2010-2011. This sample represents 1,841 hospitals and 1,078,697 admissions and eliminates approximately 63.7 percent of spending. 
Figure 11: The Fraction of Each Hospital's Vaginal Delivery Cases Paid as a Share of Charges, 2011

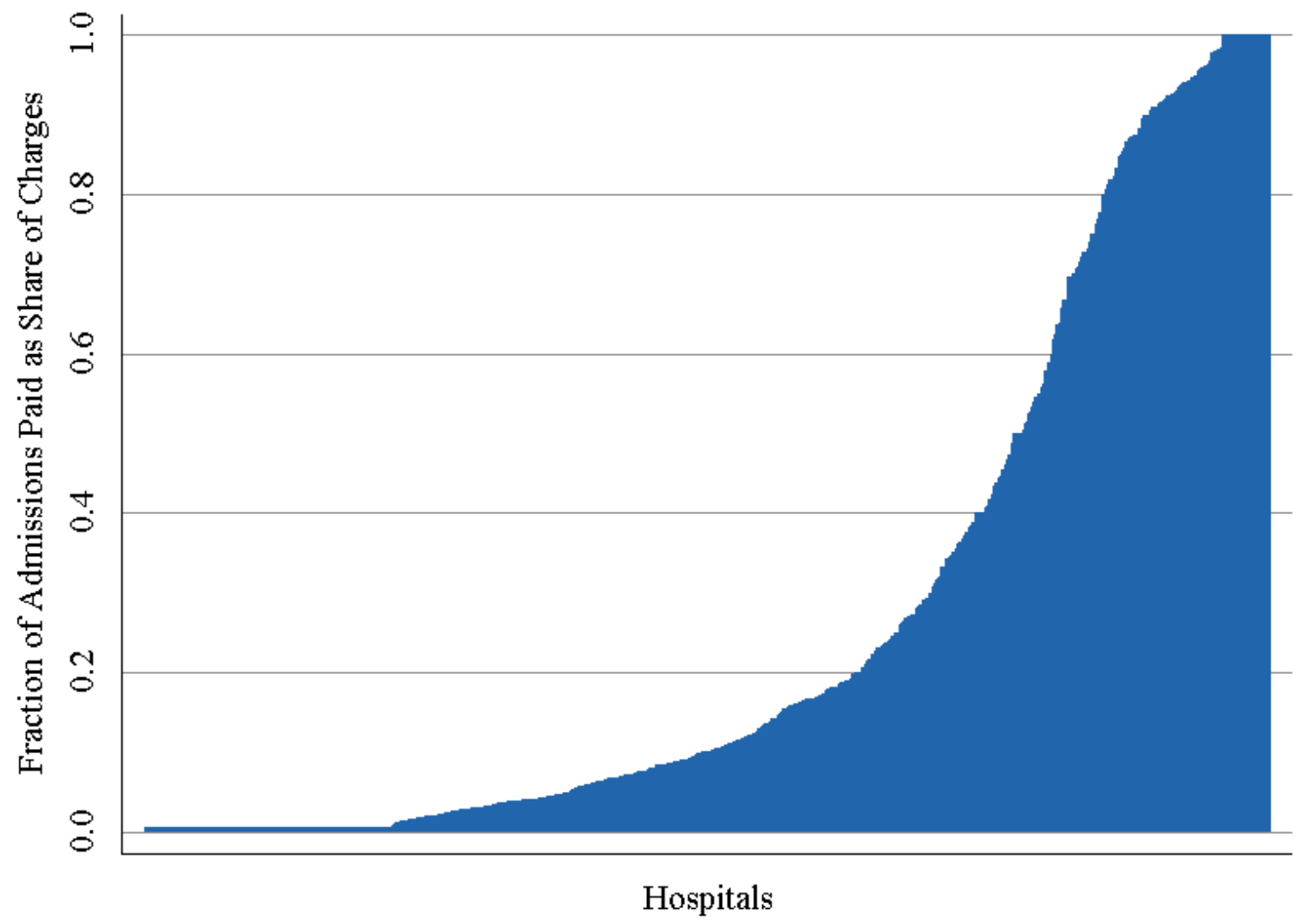

Notes: Each bar represents a hospital ordered by the fraction of vaginal deliveries paid as a share of the charges. 


\section{Figure 12: Medicare Reimbursements and Negotiated Prices at Four High Volume}

Hospitals, 2011

\section{Panel A}
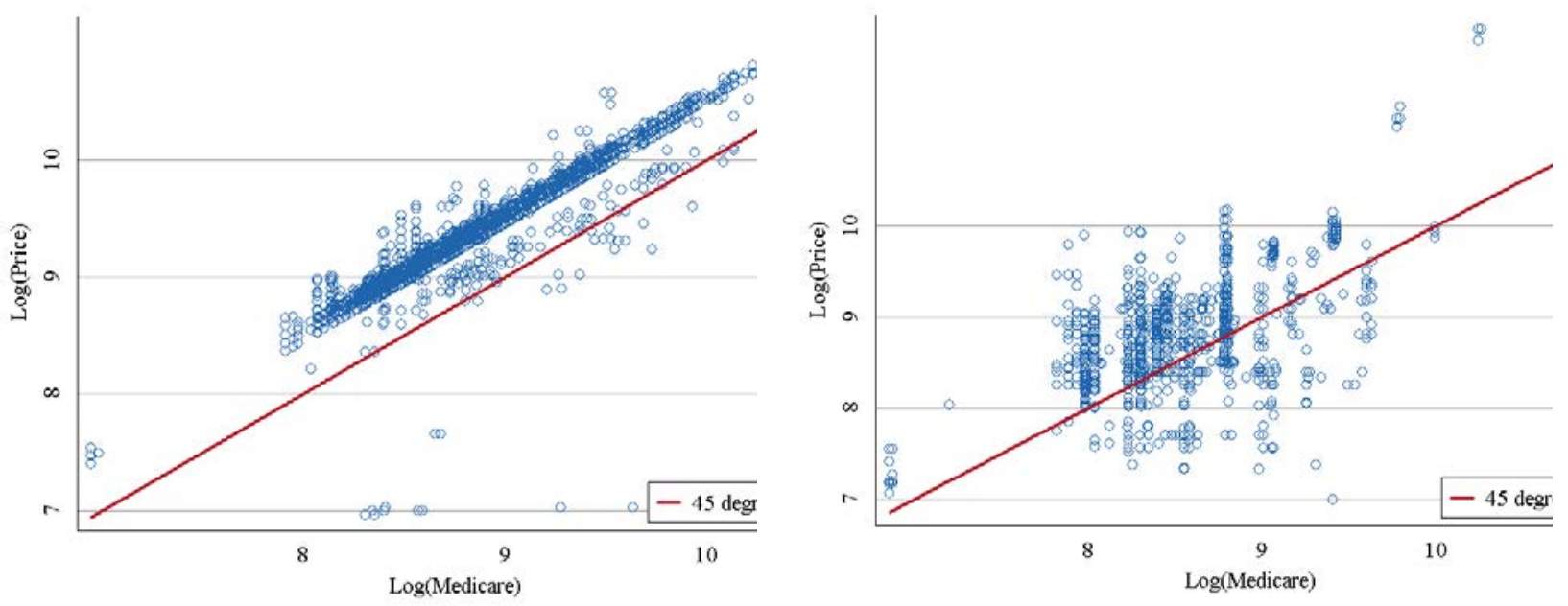

Notes: The panels represent two large hospitals in the data. Each circle is a unique, privately-paid prospectivepayment amount for a DRG The $\mathrm{x}$-axis is the corresponding logged Medicare reimbursement rates based on 2011 data. The red line is the $45^{0}$ line. 


\section{Figure 13: Bivariate Correlations of Hospital Price with Observable Factors, 2008-2011}

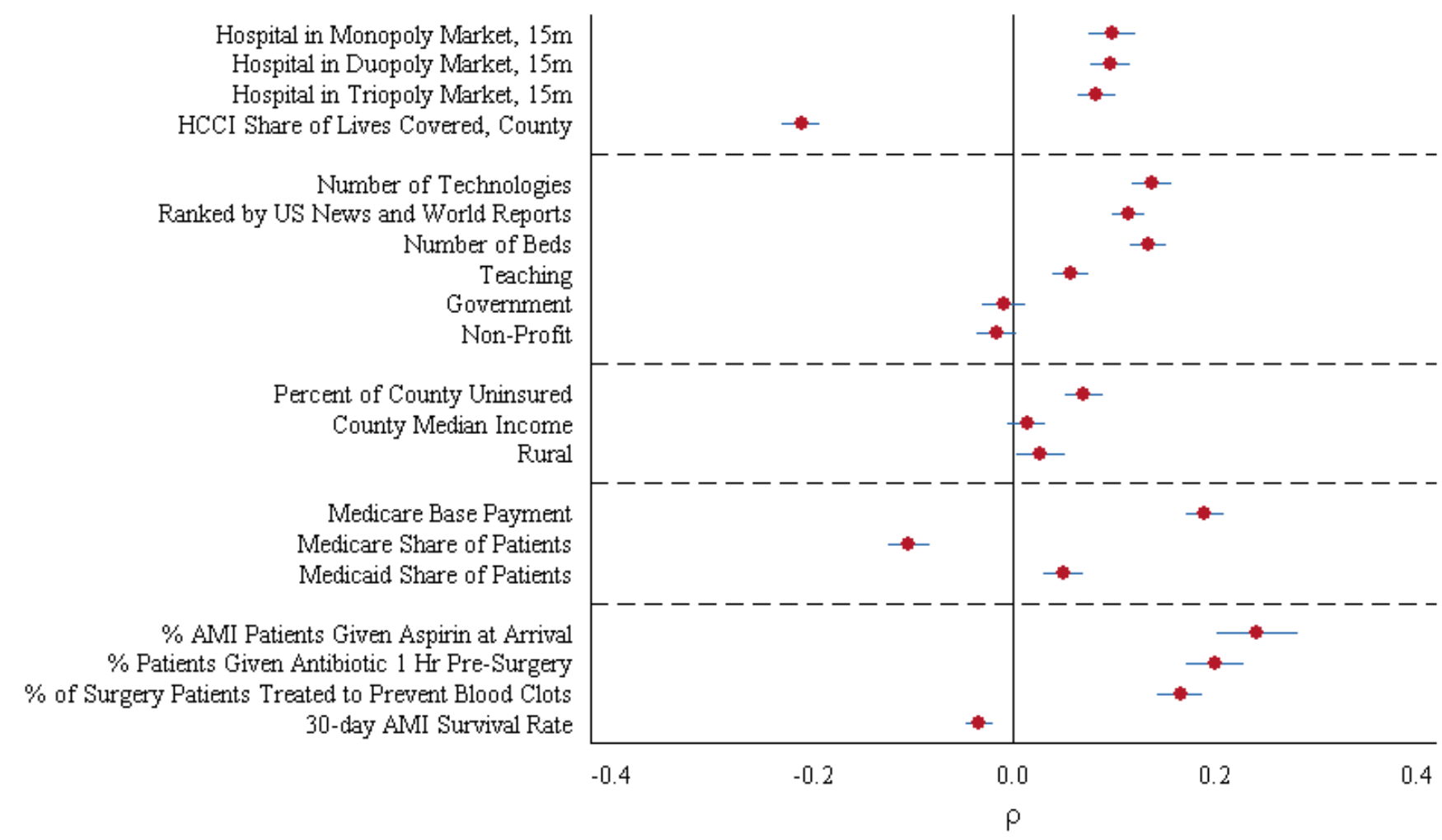

Notes: The $\mathrm{x}$-axis reflects the level of the bivariate correlations between key variables featured in our regressions and hospitals' regression-adjusted inpatient prices that are risk-adjusted for DRG, age, and sex. The bars show the $95 \%$ confidence intervals surrounding the correlations. Since these are bivariate correlations "Duopoly" is duopoly or monopoly and the implicit omitted category is triopoly or greater. "Triopoly" is triopoly, duopoly or monopoly. For government and non-profit, the omitted category is private for-profit hospital. 


\section{Figure 14: How merger coefficient changes for mergers between hospitals of different geographical proximity}

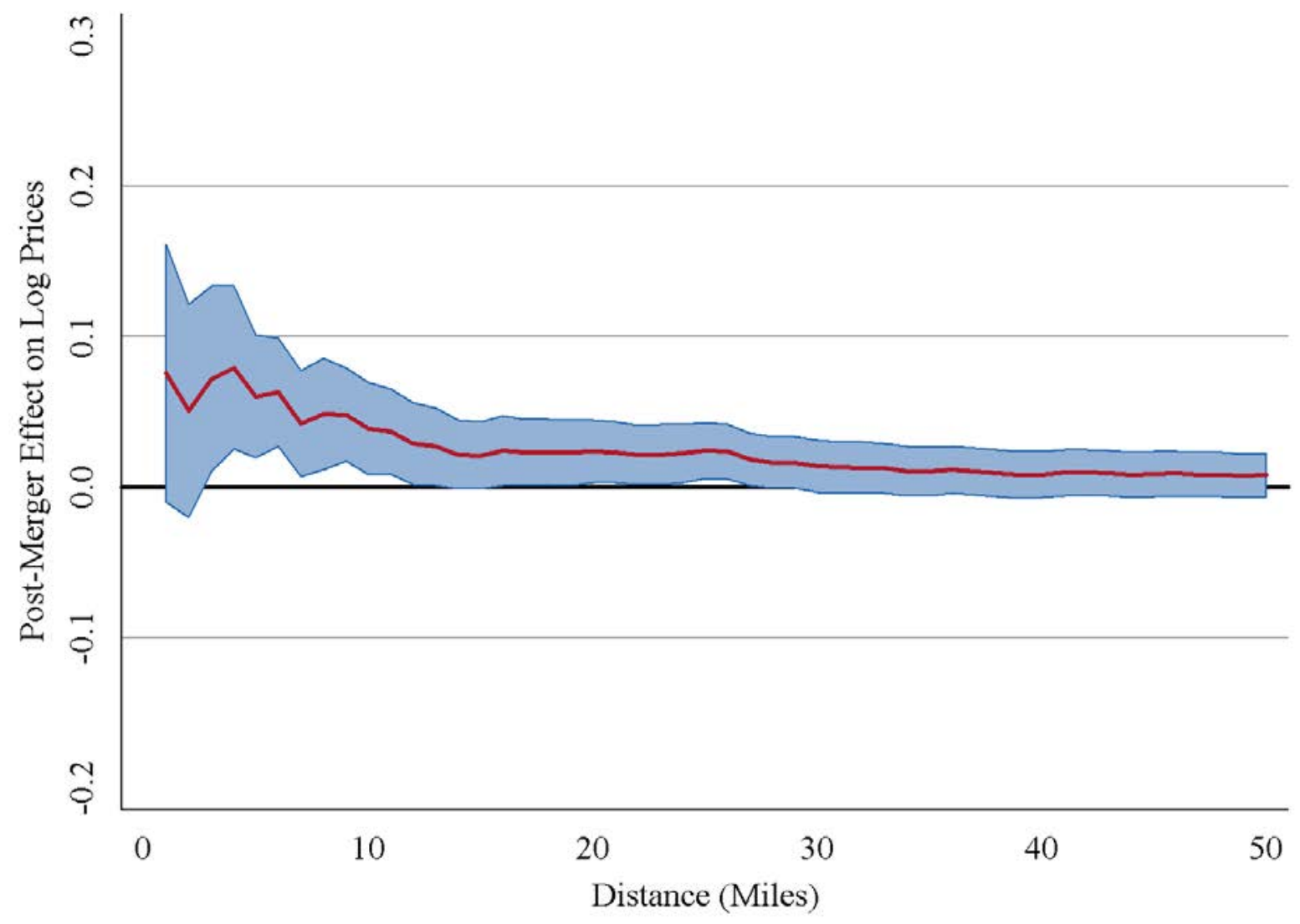

Notes: These are the regression coefficients from Equation (3) of post-merger effects on the log of regression-adjusted price for the sample of inpatient admission. These prices are risk-adjusted for DRG, age, and sex. We estimate the model separately for 50 specifications identical to that of Panel A in Table 8 . We allow the merger definition to vary in including merging hospitals within the distances shown on the $\mathrm{x}$-axis. So a value of 10 corresponds to a merger of hospitals within 10 miles of each other. The shaded area presents the 90 percent confidence interval for each estimate. 


\section{Figure 15: Merger event studies, 2008-2011}

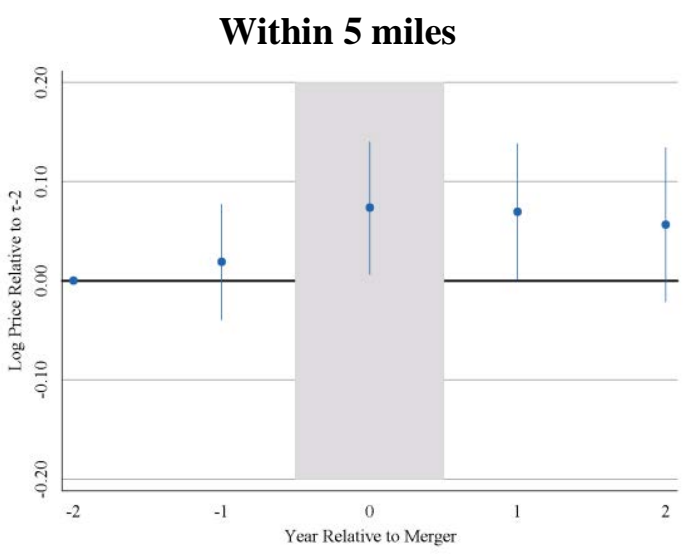

Within 20 miles

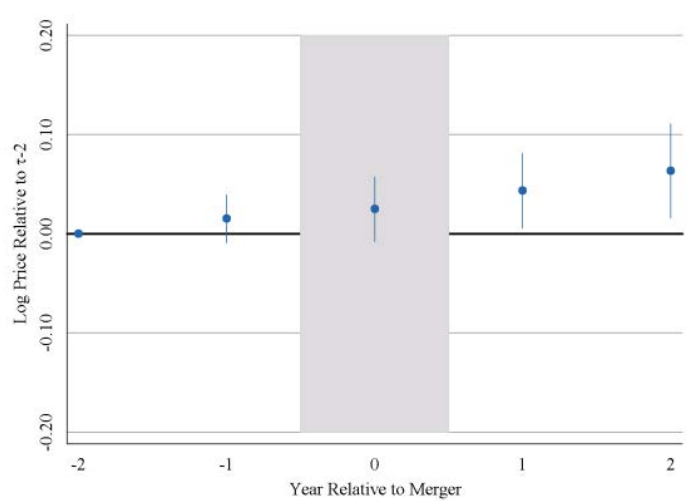

Within 10 miles

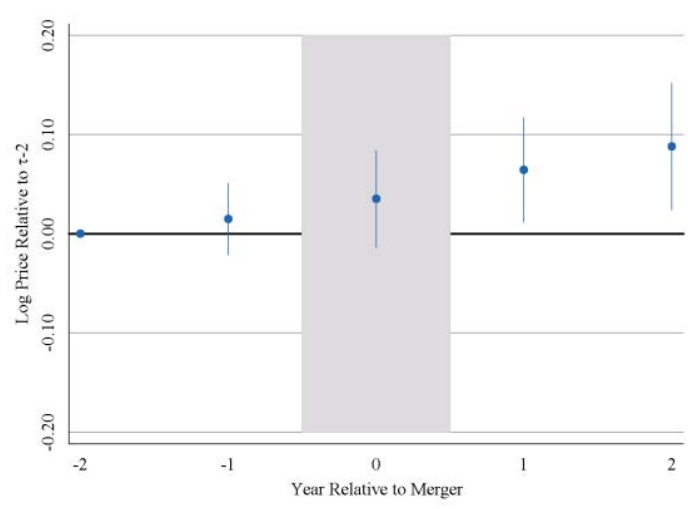

Within 30 miles

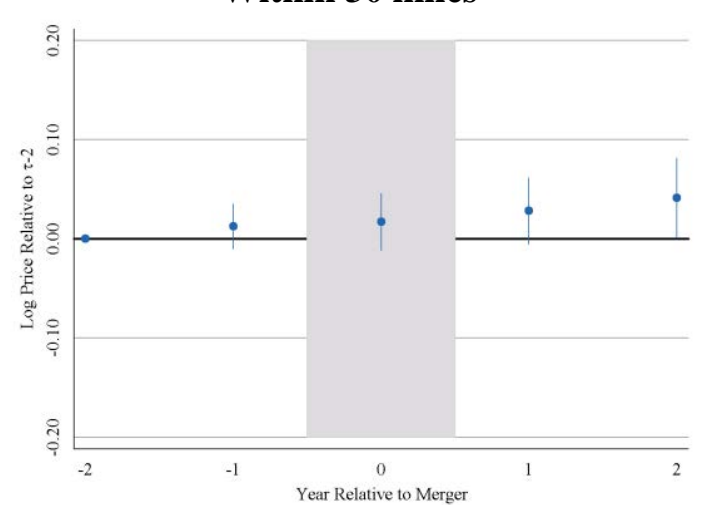

Within 15 miles

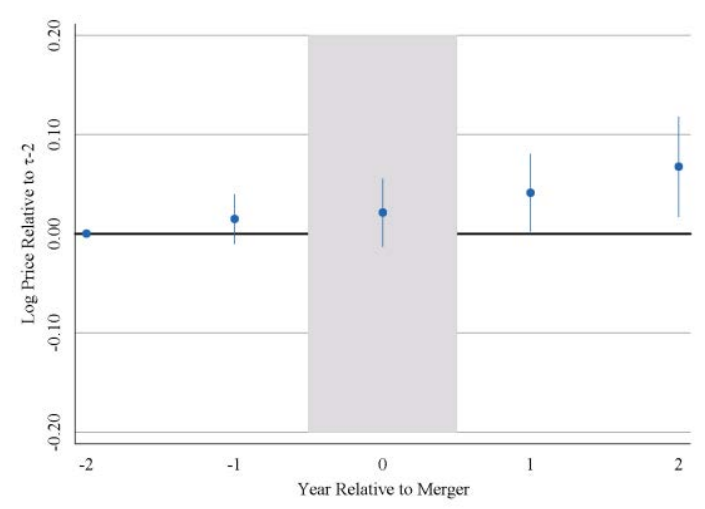

Within 50 miles

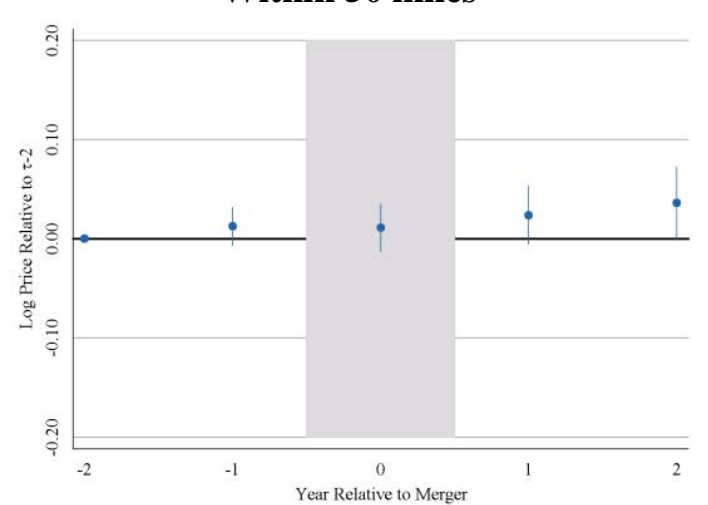

Notes: These are the regression coefficients of price differences across merging and non-merging hospitals estimated separately by year. The dependent variable is $\log$ of our regression adjusted inpatient price that is risk-adjusted for DRG, age, and sex. All regressions include hospital and year fixed effects. 95 percent confidence intervals shown. The merger year (" 0 ") is shaded. The omitted category is 2 or more years before the merger. 


\section{Appendices: For Online Publication Only}




\section{APPENDIX A: Description of Data and Data Cleaning}

\section{Appendix A1: Datasets and Sources}

Health Care Cost Institute (HCCI) Data: Our paper draws on data from the Health Care Cost Institute (HCCI). The HCCI data include claims from beneficiaries with employer-sponsored coverage from Aetna, Humana, and UnitedHealthcare. More details on HCCI can be found at www.healthcostinstitute.org.

The data include claims for individuals with fully-insured and self-insured plans that receive employer-sponsored insurance. ${ }^{1}$ This includes insurance products in the national, large, and small group markets. The data cover 27.6 percent of individuals in the US with employer-sponsored insurance. The data begin with sheets of membership data, inpatient facilities data, outpatient data, physician data, and pharmacy data. We use these to construct our inpatient and procedure samples. A sample hip replacement case constructed from these claims is posted online at http://healthcarepricingproject.org/sites/default/files/papers/sample_hip_claims.xlsx. This illustrates how we aggregate claims up to the case level and calculate a price.

While the HCCI data include more than forty million covered lives per year (see Table 1 in the body of the paper), the data are from health insurance claims for individuals with health care coverage from Aetna, Humana, or UnitedHealthcare. While these are three of the largest five health insurers in the US, we do not have claims from Blue Cross Blue Shield (BCBS) health insurers. BCBS is an association of 38 for-profit and not-for-profit health insurers in the US who purchase a license to use the BCBS name. We use membership data from our database and compare it to coverage rates in the American Community Survey and the Census Bureau's Small Area Health Insurance Estimates (SAHIE) to estimate the coverage of our three insurers at the state and county level. We also use data from the HealthLeaders Interstudy database to estimate the share of lives BCBS insurers cover by county. We use this information to show that our results are robust to areas with different levels of HCCI and BCBS coverage (See Appendix F).

The most prominent alternative source of private health insurance claims data is the MarketScan database from Truven Health Analytics. MarketScan data include claims for individuals with health insurance from a number of large employers and also some smaller employers (although it seems that the MarketScan coverage for smaller employers is substantially lower than their coverage for larger employers). Most previous research using the MarketScan data to analyze health spending has relied on only the claims for individuals employed by large firms. We use the HCCI data to analyze claims for individuals employed in small, medium, and large firms. Using the HCCI data allows us to look at a substantially larger population than has been analyzed using the MarketScan data. Chernew et al. (2010) report that the MarketScan data contain between 16.9 million and 22.9 million covered lives per year between 1996 through 2006. By contrast, the HCCI data contain between 42 and 46 million lives per year (see Table 1).

While the MarketScan database is useful for many research applications, it has drawbacks for the type of analysis we undertake in this project. First, the MarketScan database does not contain hospital IDs and sub-three digit geographic identifiers. A unique hospital identifier is necessary

\footnotetext{
${ }^{1}$ With fully-insured plans, the insurer pools and bears risk. With self-insured plans, the firm pays all insurance claims themselves and relies on insurance companies for administrative services.
} 
so that we can merge in hospital characteristics and, more importantly, analyze price variation within and between providers. With HCCI, we can merge on hospital characteristics, identify individual hospitals, and merge in local characteristics at the zip code level. Second, MarketScan has very thin coverage in a number of markets. For example, while the smallest HRR in the HCCI data has 2,932 unique individuals, MarketScan includes HRRs with fewer than two hundred individuals.

In addition to the core HCCI data, we merge on a number of other datasets listed below.

American Hospital Association Annual Survey: We obtain data on hospital characteristics from the American Hospital Association (AHA) annual survey. More information on the AHA survey data can be obtained from: http://www.ahadataviewer.com/book-cd-products/AHA-Survey/. The survey polls hospitals on characteristics, staffing, technology, finances, and other information and has been running since 1946. We use the AHA data to create our technology measures and measures of hospital market structure.

American Community Survey Data: We use data on the percentage of working age (18-64) adults with employer-based health insurance coverage by county from the American Community Survey conducted by the US Census Bureau, https://usa.ipums.org/usa/acs_healthins.shtml.

American Hospital Directory Data: We use data on hospitals' Medicare activity that we obtained from the American Hospital Directory (AHD). The AHD is a for-profit data vendor that sells cleaned Medicare claims data derived from the Medicare Provider Analysis and Review limited access database. This includes claims records for $100 \%$ of Medicare fee-for-service inpatient claims. Details on the AHD data can be found at www.ahd.com.

Census Data: Data on the number of uninsured lives by county, lives privately insured per county, and median household income come from the US census. See: http://www.census.gov/did/www/sahie/ and http://www.census.gov/did/www/saipe/index.html.

Dartmouth Data: We use data on Medicare spending per HRR that we downloaded from the Dartmouth Atlas. Full details on the Dartmouth Atlas Medicare data can be obtained from: http://www.dartmouthatlas.org.

FactSet Research Systems: These reports provide a roster of merger and acquisition (M\&A) activity across industries and include the names of firms involved in transactions and the date of transactions. We used the database to find hospital mergers. The data are accessible with a subscription at: https://www.factset.com/data/company_data/mergers_acq

HealthLeaders Interstudy Data: The HealthLeaders Interstudy database, available for purchase from the Decision Resources Group, includes the count of individuals enrolled, by county, by insurer in the small, medium, and large group markets. The data include coverage of the selfinsured and fully-insured market. See: decisionresourcesgroup.com.

Irving Levin Associates' Health Care Services Acquisition Reports: These reports provide a roster of M\&A activity in hospitals, managed care companies, physician medical groups, rehabilitation centers, labs, and behavioral health groups. We used reports for 2007 to 2011 to identify the hospital mergers that we include in this analysis. The reports can be purchased from: https://products.levinassociates.com/downloads/har-2017/ 
Medicare Quality Scores: We use data on hospital quality obtained from data.medicare.gov. The data include quality scores drawn from both Medicare and private claims data. The data can be downloaded from: https://data.medicare.gov/data/hospital-compare. The quality scores used were developed by the Agency for Health Care Research and Quality (AHRQ).

Securities Data Company (SDC) Platinum: This database provides a historical transaction database including a roster of hospital mergers. The data are accessible with a subscription via: https://financial.thomsonreuters.com/en/products/data-analytics/market-data/sdc-platinumfinancial-securities.html.

U.S. News \& World Report Rankings: We obtained rankings of hospitals printed in the US News and World Report from 2007 - 2011. Some data were obtained from online rankings. For some years, we obtained the physical copy of the printed magazine issues.

Appendix A2: Identifying Hospitals Using National Plan and Provider Enumeration System Identifiers

Single hospitals can be assigned multiple National Plan and Provider Enumeration System Identifiers (NPI) because different wings of the hospitals and different units can each have their own NPI (e.g. a hospital's radiology service could have a separate NPI to its Emergency Room). To address this issue, we made a crosswalk that consolidates providers' multiple NPIs into a single, master NPI. We use the master NPI to merge on data from the AHA and Medicare. To consolidate NPIs, we undertake the following steps:

1. Compile all variations of AHA ID/hospital name/address/city/state/ZIP Code in the 20002011 AHA survey data, retaining the row for the latest year.

2. Add NPI from the AHA survey files, beginning with the most recent year.

3. Make sure there is only one NPI per AHA ID. If more than one AHA ID have the same NPI, look up in the CMS NPI Registry to resolve the discrepancy.

4. Check all NPIs in the CMS NPI Registry to make sure they are valid and accurate. Remove invalid NPIs.

5. Look up hospitals in the NPI Registry that do not have an NPI in AHA by name and address. Attach NPI to the AHA file when a match is found.

6. Extract all organizational rows from the CMS NPI Registry where primary taxonomy code is for a hospital $(287300000 \mathrm{X}, 281 \mathrm{P} 00000 \mathrm{X}, 281 \mathrm{PC} 2000 \mathrm{X}, 282 \mathrm{~N} 00000 \mathrm{X}, 282 \mathrm{NC} 2000 \mathrm{X}$, 282NC0060X, 282NR1301X, 282NW0100X, 282E00000X, 286500000X, 2865C1500X, 2865M2000X, 2865X1600X, 283Q00000X, 283X00000X, 283X00000X, 283XC2000X, 282J00000X, 284300000X) or hospital unit (273100000X, 275N00000X, 273R00000X, 273Y00000X, 276400000X).

7. Match AHA compiled address file to the hospital NPI file on NPI. Add AHA number to the hospital NPI file and mark the NPI as 'PRIMARY' NPI for that hospital.

8. Match remaining rows in the hospital NPI file according to the following hierarchy:

1. Organization name, address1, city, state, ZIP Code

2. Address1, city, state, ZIP Code, similar organization name

3. Other organization name, address1, city, state, ZIP Code

4. Address1, city, state, ZIP Code, similar other organization name 
5. Address, city, state, ZIP Code, different name (validated name changes via web search $)^{2}$

6. Organization name, similar address1, city, state, ZIP Code ${ }^{3}$

7. Other organization name, similar address1, city, state, ZIP Code

8. Similar organization name, similar address 1, city, state, ZIP Code

9. Similar other organization name, similar address1, state, ZIP Code

10. Medicare number, city, state, ZIP Code

9. When a match is found, append AHA ID and 'PRIMARY' NPI.

10. Some hospitals in the NPI Registry were not in the AHA survey data files. For these hospitals, we pick one NPI as 'PRIMARY' and, using the match steps outlined above, add an ' $\mathrm{X}$ ' to the AHA ID column and append the 'PRIMARY' NPI to all matched rows.

11. We also consolidated NPIs to ZIP codes. To do so, we:

1. Sort file by ZIP Code, primary taxonomy code, address 1

2. Where more than one 'PRIMARY' NPI exists within a ZIP Code for the same organization name and primary taxonomy, change all rows to the 'PRIMARY' NPI associated with the AHA ID.

3. Where more than one 'PRIMARY' NPI exists within a ZIP Code for the same organization name and primary taxonomy but none of the rows is associated with an AHA ID, double check against the AHA file. If no match is found, consolidate the rows to one single 'PRIMARY' NPI.

\section{Appendix A3: Constructing a consistent hospital-level panel from the AHA Data}

When hospitals merge, the AHA Survey will often consolidate two hospital IDs into a new single ID. While this does not affect our measure of hospital prices (since those are generated from the HCCI data), it does delete observations from the AHA data. This creates two issues. First, according to the AHA data, the count of AHA hospital sites (as opposed to systems) decreases over time. This is caused mechanically by mergers, which reduce the numbers of IDs. Second, because we measure prices for hospital sites, AHA characteristics that we use as control variables are only available at the more aggregated level of the consolidated sites. While most of our control variables are categorical (e.g. whether a hospital is a teaching facility), some are continuous measures (e.g. hospital beds, the count of Medicare discharges per year, and the count of Medicaid discharges per year).

A good example of this issue is that after their merger, the IDs for New Britain General Hospital in New Britain, CT and Bradley Memorial Hospital in Southington, CT are consolidated into a new ID number for the Hospital of Central Connecticut in 2006. In the AHA Survey data the IDs for "New Britain General" and "Bradley Memorial" vanish from the survey in 2006 and a new hospital ID for "Hospital of Central CT" appears in the same year.

This is a standard problem in firm-level analysis. A firm is composed of a number of establishments and often data are only available at the higher firm-level (e.g. Compustat). When

\footnotetext{
${ }^{2}$ Because there can be hospitals within hospitals (e.g., specialty or children's hospital on one floor of a general hospital), all of these occurrences were manually validated to ensure that the correct hospital was identified.

${ }^{3}$ Suburb names are occasionally used in addresses (e.g., Brentwood vs. Los Angeles). If the address1, state, and ZIP Code matched but the city name differed, this was still considered a valid match at each level.
} 
two firms merge information is often only available at the aggregate consolidated level and not for the individual firms (even when they are still run as separate businesses). A standard approach to this problem is to freeze the organizational structure at a point of time, so the researcher can analyze a consistent set of firm sub-units (or at least until they exit). We perform an analogous exercise for hospital sites.

In order to maintain the information at the more disaggregated level we "undo" the site-level consolidation in AHA after 2001 by (i) maintaining the original (vanished) ID at the site level in the year the consolidation occurs and for all years afterwards; (ii) remove the new consolidated ID from the data in all years after it occurs. ${ }^{4}$ We then construct a new master hospital system ID. The challenge that arises from "undoing" this consolidation of IDs is we do not know the correct bed count (and other observables) at the hospital site-level after consolidation.

We address this by imputing the information at the consolidated level to the site level for all continuous variables for these hospitals in the following manner. Consider the following example of imputing hospital beds. Let two separate hospitals have distinct IDs $A$ and $B$ at time $T$ - 1 . Assume that hospitals $A$ and $B$ merge at time $T$ and become hospital $\mathrm{C}$ (hospital $\mathrm{C}$ may have already been in existence at T-1 or may be a new hospital created from the merger of $\mathrm{A}$ and $\mathrm{B}$ at time T). The merged hospital is given the ID $C$ and the IDs for A and B cease to exist. Let $b_{t}^{h}$ be the number of beds at hospital $h$ at time $t$ where $h \in\{A, B, C\}$ and $t \in\{2001,2002, \ldots, 2014\}$. Let $w^{h}=\frac{b_{T-1}^{h}}{\sum_{h \in\{A, B\}} b_{T-1}^{h}} \cdot w^{h}$ is hospital $h$ 's share of the total number of beds between hospitals $A$ and $B$ at time $T-1$. If $\frac{\left|b_{T}^{C}-\sum_{h \in\{A, B\}} b_{T-1}^{h}\right|}{\frac{b_{T}^{C}+\sum_{h \in\{A, B\}} b_{T-1}^{h}}{2}} \leq 0.2$, then we assume hospital $h$ 's bed total is $w^{h} b_{t}^{C}$ for all $t$ in which hospital $C$ exists in the AHA Survey. Otherwise, we assume hospital $h$ 's bed total is $b_{T-1}^{h}$ for all $t$ in which hospital $C$ exists.

In other words, if the percentage difference between the total number of beds at $A$ and $B$ in $T-1$ and the number of beds of the consolidated hospital ID in time $T$ is less than or equal to 20 percent, then we impute hospital $A$ 's bed count to be its share of the total beds at $A$ and $B$ at time $T-1\left(w^{A}\right)$, multiplied by the consolidated hospital's total number of beds $\left(b_{t}^{C}\right)$ for all years that hospital $C$ exists in the AHA Survey. If this percentage difference is greater than 20 percent, then we assign hospital $A$ the bed total it has at time $T-1$ to all the years in which hospital $C$ exists (from time T forward). ${ }^{5}$

We carry out this same imputation procedure for the share of Medicare and Medicaid discharges using the above methodology.

\section{Appendix A4: Defining the Inpatient and Procedure Pricing Samples}

The inpatient sample in our data includes all inpatient claims aggregated to the level of a single hospital admission (which we call a case), each of which has a unique DRG. The procedures we

\footnotetext{
${ }^{4}$ In some cases, the merger is recorded using the aggregation of an acquired hospital into an existing AHA ID. In these cases, the procedure is the same except we do not delete observations for the acquiring hospital.

${ }^{5}$ We choose a threshold because if the difference is large then it indicates that the merged hospital is undergoing a large restructuring, so this casts doubt on the assumption that the relative size of original entities is stable. 20 percent is an arbitrary threshold, of course, but the results are robust to other reasonable thresholds.
} 
use are defined using combinations of ICD9 codes and DRGs. In the case of MRIs, we identify cases using CPT-4 codes. The specific codes we use to define samples include:

\section{Coding Definitions for the Seven Procedure Samples}

\begin{tabular}{|c|c|c|c|c|c|}
\hline Procedure & ICD9 & and & MS-DRG & or & CPT-4 \\
\hline Hip Replacement & 8151 & & 470 & & \\
\hline Knee Replacement & 8154 & & 470 & & \\
\hline Cesarean Section & 741 & & 766 & & \\
\hline Vaginal Delivery & 7359 & & 775 & & \\
\hline PTCA & 0066 & & 247 & & \\
\hline Colonoscopy & V7651 (CM) & & & & \\
\hline MRI & & & & & 73721 \\
\hline
\end{tabular}

For hip and knee replacements, we limit our analysis to individuals between forty-five and sixtyfour years of age. For vaginal deliveries and cesarean sections, we limit our analysis to delivering mothers who are between the ages of twenty-five and thirty-four. In order to be included, an MRI case must be a single-line facility claim and we must observe a separate physician payment for the reading of the MRI. We do this to ensure that we are isolating the professional component (reading of the MRI) from the technical component (administering the scan). We also limit MRIs to those carried out on individuals who had no other hospital claims on the day that the MRI was provided and for whom the hospitalization was exclusively for the MRI. Similarly, for colonoscopies, we limit our analysis to individuals aged forty-five through sixty-four and only include hospital-based cases where nothing else was done to the patient that day and for which the colonoscopy was the reason for the trip to the hospital. We exclude colonoscopies where a biopsy was taken.

In order to minimize the impact of unusually complicated cases or clerical billing errors, we exclude cases above the $99^{\text {th }}$ percentile of length-of-stay as well as cases where the price is below the $1^{\text {st }}$ percentile or above the $99^{\text {th }}$ percentile. In the inpatient sample, these restrictions are implemented by DRG.

Appendix Table 2 shows the impact on the number of hospitals and cases of the main selection criteria we use to derive our inpatient sample. After conditioning our data to cases delivered at hospitals that are registered with the AHA, we have 5,865,727 inpatient cases delivered at 4,326 facilities between 2008 and 2011. Excluding critical access hospitals drops our number of providers by 1,124 (26 percent), but only lowers the number of cases we observe by 51,349 (less than one percent). We further exclude three hospitals where we do not have data on Medicare activity. We then exclude all cases from 2007. This lowers our cases by 769,104 (13 percent) and number of hospitals by 10 (less than one percent). In order to have sufficient data at each hospital to calculate an inpatient price index, we exclude providers that had fewer than 50 cases per year. This drops 74,705 cases (1.5 percent) and 831 hospitals (26 percent). 


\section{Appendix A5: Construction of Price Fixed Spending and Quantity Fixed Spending Used in Section III.B.}

We calculate Medicare and private spending per beneficiary where we fix quantities nationally (and only allow price variation to drive variation in spending) and fix prices (and only allow quantity variation to drive spending variation).

To do so, we first calculate inpatient spending per beneficiary for the privately insured and for Medicare recipients. Inpatient spending per beneficiary in $\operatorname{HRR} r\left(y_{r}\right)$ is a function of the quantity $\left(q_{r}\right)$ of care provided and the price of care $\left(p_{r}\right)$ :

$$
y_{r}=\frac{\sum_{h, d}\left(p_{h, d} q_{h, d}\right)}{B_{r}},
$$

where the price of DRG $d$ at hospital $h$ in HRR $r$ is represented by $p_{h, d}$ and quantity is $q_{h, d}$ (we suppress the subscript $r$ for economy of notation), $B_{r}$ is the number of beneficiaries in HRR $r$, and $\sum_{h, d}$ indicates summing across all DRGs in a hospital and the all hospitals in an HRR.

We compute counterfactuals to calculate the relative contributions of price and quantity to variation in inpatient spending. The first counterfactual we create is to fix all prices per DRG to be the same as the national average $\left(\bar{p}_{d}\right)$ and then analyze spending variation. This allows us to identify the relative contribution that differences in the quantity of care provided across regions make to variation in spending per beneficiary. Spending per beneficiary calculated with national average prices is (where $\sim$ indicates a counterfactual calculation):

$$
\tilde{y}_{r}^{\bar{p}_{d}}=\frac{\sum_{h, d}\left(\bar{p}_{d} q_{h, d}\right)}{B_{r}} .
$$

The second counterfactual is to fix the quantity and mix of inpatient care delivered in each HRR to be the same as the national average mix and quantity of care $\left(\bar{q}_{d}\right)$ and then analyze spending variation. ${ }^{6}$ To do so, we calculate:

$$
\tilde{y}_{r}^{\bar{q}_{d}}=\frac{\sum_{h, d}\left(\bar{q}_{d} p_{h, d}\right)}{B_{r}} .
$$

This allows us to identify the relative contribution that differences in price make to variation in spending per beneficiary across HRRs. These are, of course, purely accounting decompositions to gauge rough magnitudes, as quantity and price are both endogenously determined in the private sector.

Appendix Tables 3 and 4 contain the results of these counterfactual calculations for individuals age 55 to 64 (Appendix Table 3) and individuals age 18 to 64 (Appendix Table 4).

\section{Appendix A6: Construction of Control Variables for Sections VI and VII}

\footnotetext{
${ }^{6}$ To do so, we identify the mix of DRGs at a national level and set every HRR to have that mix of DRGs.
} 
In our estimates of the relationship between market structure, mergers, and hospital prices in Sections VI and VII, we also include a range of additional hospital and local area controls. Below are descriptions of these additional measures.

Hospital Characteristics and Hospitals' Local Area Characteristics: In our cross-sectional and merger analysis, we include controls for hospital characteristics drawn from the AHA annual survey. These include: the number of hospital beds, ownership type (not-for-profit, for-profit, government), teaching status, and indicators for the technologies available at a hospital in a specific year. In addition, we link hospitals' zip codes to local area characteristics from the Census Bureau's Small Area Health Insurance Estimates and Small Area Income and Poverty Estimates, including the proportions of the population who are uninsured and the median income in the county where the hospital is located.

Technology Index: We follow Acemoglu and Finkelstein (2008) in using a count of hospital technologies offered by a hospital as recorded in the AHA survey data. The AHA data include binary indicators for whether a hospital has various technologies and services, such as computertomography (CT) scanners, electron beam computed tomography, or proton beam therapy. We sum the number of these technologies available at each hospital in each year.

Hospital Quality: To capture reputational quality, we include a yearly indicator for whether or not a hospital was ranked by the U.S. News \& World Report as a top hospital. We indicate a hospital was ranked in the U.S. News and World Report if it was ranked as an overall top hospital or received a ranking as a top hospital for cancer care; gastrointestinal care; ear nose and throat; geriatric care; gynecology; cardiology; orthopedics; rheumatology; or urology. In total, from 2008 through 2011, the U.S. News \& World Report ranked 192 hospitals in our sample in their annual 'Best Hospital' rankings across clinical specialties and the overall ranking.

To measure clinical performance, we merge in data on hospital quality from https://data.medicare.gov/, which includes the hospital quality scores reported publicly on the CMS Hospital Compare webpage (https://medicare.gov/hospitalcompare). These include measures of patient safety, patient outcomes, and process measures of care captured from public and private claims data. We included quality scores for 2008 through 2011 for four measures: the percentage of heart attack patients given aspirin upon arrival to the hospital; the percentage of surgery patients given an antibiotic prior to surgery; the percentage of patients treated within twenty-four hours of surgery to prevent blood clots; and the 30-day risk adjusted mortality from heart attacks. ${ }^{7}$ These are widely acknowledged measures of the quality of care and they are all available for hospitals in our sample from 2008 through 2011 (Yale Center for Outcomes Research and Evaluation 2013). We focus on these four clinical quality measures in the robustness analysis, but we also examine the effect of conditioning on all 41 quality measures. Note that we do not have CMS quality measures for 168 hospitals (7.5 percent) from our inpatient sample. As a result, we present analysis of these measures separately from our main analysis.

Medicare and Medicaid Activity: We include the Medicare base payment rate for hospitals, since this may proxy for hospital costs. This comes from annual Medicare Impact Files. We also include

7 For the technical descriptions of the measures of performance we used in this analysis, see http://www.medicare.gov/hospitalcompare/Data/Measures.html. 
data from the AHA on the share of hospitals' inpatient cases paid by Medicare and Medicaid each year. 


\section{APPENDIX B: Measures of Providers Private Prices and Medicare Reimbursements}

Appendix B1: Inpatient Private-Payer Hospital Price Index: Our private-payer inpatient price index captures the combined amount paid by patients and insurers for patient case $i$ in DRG $d$ delivered in hospital $h$, and provided in year $t$. Following Gaynor and Vogt (2003) and Gowrisankaran, Nevo, and Town (2015), we regress hospital payments $\left(p_{i, h, d, t}\right)$ on year-specific hospital fixed effects $\left(\alpha_{h, t}\right)$, a vector of patient characteristics $\left(X_{i, h, d, t}\right)$ comprised of indicators for patient age (measured in ten-year age bands), a dummy for the patient's sex, and a vector of DRG fixed effects $\left(\gamma_{d}\right)$. The regression to produce our inpatient prices has the form:

$$
p_{i, h, d, t}=\alpha_{h, t}+X_{i, h, d, t} \beta+\gamma_{d}+u_{i, h, d, t}
$$

where $u_{i, h, d, t}$ is the stochastic error term. We recover the vector of hospital fixed effects $\hat{\alpha}_{h, t}$ and calculate a hospital price index for each year at the sample means of the patient characteristics $(\bar{X})$ and the DRG indicators, $\bar{d}$ (i.e., the sample mean basket of DRGs).

$$
\hat{p}_{h, t}=\hat{\alpha}_{h, t}+\bar{X} \widehat{\beta}+\bar{d} \hat{\gamma}_{d}
$$

This yields the hospital's price, adjusted for its mix of treatments and mix of patients (note the fixed effect $\hat{\alpha}_{h, t}$ is the key output: $\bar{X} \hat{\beta}+\bar{d} \hat{\gamma}_{d}$ is just a constant across all hospitals to match the mean in the data).

For robustness, we also created alternate price indexes using many different functional forms. For example, in Appendix Table 10 we show robustness of the estimates reported in Table 6 in the paper to alternative approaches. Panel A has the baseline results which are the same as Panel A of Table 6, i.e. using $\ln \left(\hat{p}_{h, t}\right)$ as the dependent variable. Panel B constructs the risk-adjusted inpatient price by estimating Equation (A1) but using $\ln \left(p_{i, h, d, t}\right)$ instead of $p_{i, h, d, t}$. We then implement the analog of Equation (A2) to obtain an alternative $\ln$ (price) that we use as the dependent variable in Panel B. In Panel C of Appendix Table 10, we use the level of price $\left(\hat{p}_{h, t}\right)$ instead of the logarithm of price. In Panel D we include the Charlson Score of co-morbidities to the $X_{i, h, d, t}$ vector in Equation (A1). In Panel E we include a full set of ICD9 dummies instead of DRG dummies.

In addition, we also looked at many other approaches. For example, we calculated regressions where DRG complexity was parameterized using CMS's MS-DRG weights as right hand side control variables, rather than as fixed-effects for each DRG. We also calculated a price index where we regressed the DRG price divided by the DRG weight against patient characteristics and hospital fixed effects. These price measures are all highly correlated with each other (correlation coefficients greater than 0.95), and using alternative price measures does not materially affect our baseline results.

\section{Appendix B2: Procedure-Level Private-Payer Hospital Price Index:}

In addition to creating an inpatient price index, we also create risk-adjusted prices for the specific procedures we study. We adjust prices for differences in patient characteristics, just as we did in the inpatient price index. These regressions take the form: 


$$
p_{i, h, d, t}^{P}=\alpha_{h, d, t}^{P}+X_{i, h, d, t} \beta_{d}^{P}+e_{i, h, d, t}^{P}
$$

Superscript $P$ indicates one of our seven procedures. We then recover our estimates of the hospitalyear-procedure fixed effects as we did when we constructed our inpatient price index.

\section{Appendix B3: Constructing Hospital-Insurer Contracts}

\section{Determining between Share of Charge and Prospective Payment contracts}

Unfortunately we do not directly observe the contracts struck between insurers and hospitals. In order to classify cases into contracts we "reverse engineer" our data using an ex post algorithmic method from observations of prices, charges, and case characteristics. We did this after extensive discussions with insurers on a sensible way to back out contracts.

The first step is to search for repeated absolute prices and repeated price-to-charge ratios within a hospital for our narrowly defined procedures sample (or within DRGs in the inpatient sample). For each hospital and procedure, we look at all cases $i$ over the two year period for which we observe hospital charge data (i.e. January $1^{\text {st }} 2010$ to December $31^{\text {st }} 2011$ ). Prices are considered repeated if for all cases $i$ and $i$ ' (i) their prices match to the cent (\$0.01) or (ii) their price-to-charge ratios match within 0.1 percent (0.001). Type (i) contracts are likely to be prospective (say tied to a DRG) whereas type (ii) will be share of charge contracts.

If there is only ever one charge for a procedure, we cannot distinguish whether a case falls into one of these two categories. For example, if cases $i$ and $i$, have the same payment for a knee replacement (e.g. $\$ 1,000)$, then we will suspect them of being on prospectively paid contracts. But, if their charges are identical (e.g. $\$ 2,000$ ), the price to charge is also at 50 percent for both. This is usually the case for lower limb MRIs, for example, which is why we cannot successfully implement our algorithm on this procedure. We can, however, identify the payment type if there exists a third hospital case $i$ "' which has the same price level but a different charge (or vice versa). For example if knee replacement case $i$ " was also $\$ 1,000$, but had a charge of $\$ 4,000$ we would classify all three cases as falling under a prospective pay contract as although its price was always $\$ 1,000$, its price-to-charge ratio differed (i.e. was 25 percent for contract $i$ ' ' and 50 percent for $i$ and $i^{\prime}$ ).

There are, of course, a number of cases that cannot be classified in this manner, since they are singleton prices or singleton price-to-charge ratios. This may be because they are on a "hybrid" contract, which is prospective but with outlier payments. Or it may be that they are on one of the two standard contracts (share of charge or prospective payments) but there has only been one case over our period so we cannot distinguish the contract. We denote these "unclassified cases."

\section{Repeated contracts}

Repeated price-to-charges and repeated absolute prices define a "primitive contract," which we can then use to construct a more persistent set of payment agreements over time by observing whether the classifications hold sequentially over time. We define primitive contracts not only by their price, but also by the first and last date at which that agreement is executed. We calculate characteristics of these contracts, measuring the average monthly volume of patients who are paid under those agreements and measuring the plan characteristics of those contracts (percent of 
patients on ASO or fully insured plans; the percent of patients by market segment: large group or small group; and the percent of patients by product type: health maintenance organization (HMO), preferred provider organization (PPO), point of service plan, exclusive provider organization, indemnity, and other). We use all of this information to find contracts that precede or follow each other in order to match primitive contracts over time. Matching contracts are those which begin/end within 45 days of the end/beginning of the candidate contract, and minimize the Euclidean distance of characteristics (patient volume and plan characteristics):

$$
d(\vec{x}, \vec{y})=\sqrt{\sum_{i=1}^{k} \frac{\left(x_{i}-y_{i}\right)^{2}}{s_{i}^{2}}}
$$

where $x$ and $y$ are vectors of contract characteristics, and $s_{i}$ is the standard deviation of the $i^{\text {th }}$ characteristic across contracts. We recognize "valid" matches to be two contracts that mutually minimize this distance for each other.

While we can determine the type of contract without this matching procedure, the fact that matches are well determined by plan characteristics gives us confidence that distinct contracts reflect distinct agreements across insurers at the same hospital. As we illustrate in Figure 8 in the paper, we are able to link primitive contracts over renegotiations. For example, we can link two primitive contracts if, before and after a price increase, both have 60 percent of cases where the beneficiary is on an ASO product and 80 percent are part of a PPO plan.

\section{Illustrative Examples and Descriptive Statistics}

To illustrate this, re-consider Figure 9 in the paper for vaginal deliveries in one of the hospitals in our sample. This hospital had between 500 and 600 cases overall in 2010 and $2011 .^{8}$ We were able to identify that 59.5 percent of these fall under a share of charge contract (the circles) and 38.0 percent of these fall under a prospective pay contract (the triangles). The remaining 2.5 percent were unclassified. In one month in 2011, for example, we had 24 cases of which 10 were the same absolute price of $\$ 1000$ and 14 were all on a 60 percent price-to-charge ratio. This means that for this hospital-month, 41.7 percent of cases were prospective payment contracts, 58.3 percent were price-to charge contracts and zero cases were unclassified.

Figure 10 shows how the contracts are split by the inpatient sample and for each procedure (these are all in terms of fractions of cases). The fraction unclassified is related to the sparsity of the data. As we noted above, the unclassifieds are a mixture of truly hybrid contracts and those we cannot classify, due to the fact we may only observe one case under a particular contract so do not have any other cases we can "match prices" with. This is particularly an issue for the inpatient sample where we are seeking to assign cases to contracts to every one of the approximately 750 DRGs for every hospital. Many hospitals (especially the smaller ones) will only have one case in a particular DRG over this time period. Recall that the only threshold the cases data have is that a hospital must have at least 50 inpatient cases over all DRGs in a year.

Appendix Figure 7 illustrates this issue by showing what is the impact on contract classification (across cases in the inpatient sample) of introducing more stringent cut-offs over the minimum number of cases per DRG in the hospital. We start with our baseline of zero on the far left of the

\footnotetext{
${ }^{8}$ To keep the figure anonymous, we are providing a range of the count of vaginal deliveries performed each year.
} 
$\mathrm{X}$-axis, i.e. we do not insist on any minimum number of cases per DRG in a hospital. At this point we reproduce the first bar chart in Figure 10 for the inpatient sample: 33.6 percent of cases are on prospective contracts; 17.3 percent are share of charges and 49.1 percent are unclassified. As we move to the right we see the fraction of unclassified cases shrink. This is because we are reducing the number of "singleton" prices by focusing on DRGs where we have more chance of identifying contracts. Importantly, the fraction of cases under share of charge contracts asymptotes after we condition on having only about 20 cases per DRG. This suggests, that the true fraction of cases which are on share of charge contracts are genuinely around 23 percent in our sample.

By contrast, the fraction on perspective payments contracts is still rising over the whole range of the $\mathrm{x}$-axis. By the time we restrict attention to DRGs with at least 100 cases in a hospital, we have shrunk the fraction of unclassifieds to under 10 percent and when we reach a 200 cases threshold, it is 4.2 percent.

It is tempting to conclude from this that all the remaining unclassified cases are prospective, so the "true" breakdown of cases is 23 percent on share of charges and 77 percent on prospective contracts. An important caveat to this reading of Appendix Figure 7 is that the sample is changing as we move along the $\mathrm{x}$-axis. We are effectively conditioning on larger and larger hospitals. Hence, the increasing incidence of prospective payment contracts may be due to selection if prospective contracts are more prevalent in the larger volume hospitals. One might have reason to doubt this selection-based explanation of the Figure however, as share of charge contracts are more commonly associated with larger hospitals in the cross sectional regressions on the full inpatient sample. Appendix Table 8 (the full results of Table 6 Panel B) shows that there is a positive coefficient on hospital size (as measured by number of beds) in the regressions where the percentage of cases on share of charge is the dependent variable (and this is significant in our preferred Column (3)). Hence, our view is that Appendix Figure 7 shows that the unclassifieds are mainly prospective contracts (rather than hybrids) and this is simply disguised by the fact we only have finite samples of patients with many singleton observations.

This selection effect is very unlikely to be an explanation for our estimate of the percent of cases under share of charge contracts, as the fraction does not change much after a threshold of 5 cases per DRG. Hence we feel confident that the true share of charge incidence is really around 23 percent. The breakdown of the remaining 77 percent of cases between prospectives and hybrids has a bit more uncertainty. An upper bound for prospectives is 77 percent, but in principle a lower bound could be the 33.6 percent in the first column in Figure 10. As argued in the previous paragraph, however, our view is that the true incidence of prospective contracts is closer to 77 percent given the evidence in Appendix Figure 7.

\section{Share of Prospective Payment contracts that are Medicare Related}

As discussed in the text, we divide the prospective payments contracts into those that appear to be linked to the Medicare fee schedule and those that are not. Figure 12 in the paper illustrates the methodology for four hospitals.

In the inpatient sample as a whole, 74 percent of prospective payment contracts were linked to Medicare. This fraction was reasonably stable throughout the support of Appendix Figure 7. At baseline, when we do not require a minimum DRG-hospital count restriction, we observed that 72 percent of cases paid prospectively were linked to Medicare. This rose to 75 percent when we 
limited our analysis to DRG-hospital pairs with more than 100 cases. In order to estimate the overall fraction of cases that paid prospectively and linked to Medicare, we have to make an assumption about how the unclassifieds are split. Appendix Figure 7 strongly suggests that the share of charge contracts are about 23 percent across all sample restrictions. If all of the remaining 77 percent of claims were under prospective contracts (which we have argued is not a bad assumption), the upper bound of the share of claims on Medicare related contracts would be 57 percent $\left(=77^{*} 0.74\right)$. Even this upper bound is considerably below the share of physician cases under prospective payment contracts linked to Medicare, which is estimated by Clemens and Gottlieb (2017) to be around 75 percent.

\section{Appendix B4: Medicare Reimbursements}

We also construct hospital Medicare reimbursement rates for the services we observe from the HCCI data. Medicare reimburses providers for inpatient care on the basis of DRGs; these are set in an attempt to compensate hospitals slightly above their costs of treating Medicare patients. To calculate the payment for specific cases of care, Federal regulations stipulate that a hospital's base payment is multiplied by a DRG weight that is set by CMS to capture the complexity of treating a particular type of case. Using data obtained from the CMS webpage, we follow the regulations and calculate the base payment rate for every hospital for every year from 2008 through 2011, including adjustments for wage index reclassifications, indirect medical education payments, and disproportionate share payments. The base payment rate is the hospital's Medicare price before any adjustment for its specific mix of DRGs. This is analogous to the risk-adjusted private price. In addition, we also obtain DRG weights from CMS that allow us to know the rates CMS paid hospitals for every DRG per year from 2008 through 2011. We also create Medicare reimbursement rates for our outpatient services using the relevant ambulatory payment classification weights. 


\section{APPENDIX C: Measuring Hospital Market and Insurer Market Structure}

\section{Appendix C1: Hospital Market Structure:}

We construct our measures of hospital market structure in a two-step process. The first step is to define a hospital's market area. ${ }^{9}$ We define both fixed- and variable-radius markets. For our fixedradius markets, we draw a radius around each hospital, which places hospitals in the center of circular markets of radius $z$. We construct hospital markets using five-mile, ten-mile, fifteen-mile, and thirty-mile radii extending outwards from hospitals' locations. ${ }^{10}$ Previous analysis of Medicare beneficiaries found that 80 percent of patients were admitted to hospitals within ten miles of their home (Tay 2003). We generally report statistics for markets with a radius $z$ of fifteen-miles drawn around each hospital, so that we capture the travel distance of most patients. We illustrate our results are robust to using radii of longer and shorter distances.

The second step is to measure market structure within our defined market areas. We do so in two ways. First, we identify whether the geographically defined markets are monopolies, duopolies, triopolies, or include four or more providers. Second, we calculate either counts of hospitals or Herfindahl-Hirschman Indexes (HHIs) within our various market definitions.

The HHI for each hospital-centered market containing $H$ hospitals is:

$$
\text { Hospital } H_{m, t}=\sum_{h=1}^{H}\left(s_{h, t}^{m}\right)^{2} \text {, }
$$

where Hospital $\mathrm{HHI}_{m, t}$ is concentration in market $m$ at time $t$, where $s_{h, t}^{m}$ is the market share of hospital $h$ in market $m$ at time $t$, calculated using hospital bed count. ${ }^{11}$

There are well-known endogeneity concerns about the use of concentration measures in pricing equations (e.g., Bresnahan 1989). For example, higher quality hospitals may attract more patients and have higher market shares, resulting in a higher HHI for their market. Since they will likely also have higher prices, this can lead to an estimated positive relationship between price and concentration driven by omitted quality rather than by market power. It is also possible that hospitals with higher shares may be lower cost, which could create a negative association between price and concentration, again due to an omitted variable. This may be less of a problem in our paper, since we have a number of observable measures of quality and of cost. Nonetheless, the estimates should be interpreted as associations, not causal effects. ${ }^{12}$

\footnotetext{
${ }^{9}$ These are approximations to hospitals' geographic markets, not precise antitrust markets. Since these are not precise markets, we test the robustness of our results to various market delineations.

${ }^{10} \mathrm{We}$ also calculate a variable radius market where the radius that defines a hospitals' market is a function of the urban-rural classification defined by the US census. Hospitals located in 'large urban' areas are assigned a market defined by a ten-mile radius; hospitals located in 'urban' have a market defined around them using a fifteen-mile radius; and hospitals located in 'rural' areas have a market defined around them using a twenty-mile radius. For details on the Census definitions, see: https://www.census.gov/geo/reference/ua/uafaq.html.

${ }^{11}$ We also compute HHIs using hospital discharges and total days of care delivered. All measures have correlations of over 0.98 .

${ }^{12}$ Kessler and McClellan (2000) propose one strategy to mitigate endogeneity by using a choice model to predict patient flows and then calculate market concentrations using predicted rather than actual patient flows. We cannot use this strategy because we do not see every patient treated at each hospital; we only see patients at a hospital who are insured by one of the three payers in our dataset. Moreover, as Cooper et al. (2011) note, fixed-radius HHIs measured
} 
Appendix Figure 10 shows the relationship between hospital HHI, measured with our 15 mile radius market boundary, and our set of observable covariates. Unsurprisingly, rural areas have a higher hospital HHI. We also observe that higher hospital HHI is associated with hospitals having fewer technologies, lower rankings from the U.S. News and World reports, fewer beds, and lower quality scores. We also observe that hospitals with higher HHIs have lower Medicare payment levels and treat more Medicare patients.

\section{Appendix C2: Insurance Market Structure:}

There are few reliable sources of information on market structure in the health insurance industry (Dafny et al. 2011). We measure insurance market structure in the following way. We measure, by county, the share of privately insured lives per county that are covered in our data. To do so, we use data from the Census Bureau's Small Area Health Insurance Estimates to identify total covered lives per county. We then use the count of covered lives per county from the HCCI data; the fraction of HCCI covered lives over total covered lives provides the share of county covered lives that received insurance coverage from the HCCI payers annually. Although this does not capture the market share across all private insurers, the measure is both county specific and is most relevant for the prices negotiated with the HCCI insurers (our dependent variable).

using actual patient flows are correlated at over 0.90 with Kessler and McClellan (2000) style predicted flow HHIs. Instead, we measure hospital market size and hospital market share based on the total number of beds within a market and a facility, respectively. We also note that the number of hospital beds is a measure potentially less subject to endogeneity than patient flows because it is costly for hospitals to alter the number of beds. 


\section{APPENDIX D: Identifying Hospital Mergers}

The American Hospital Association Annual Survey contains data on respondent hospitals in the United States. While the AHA data are an invaluable source of information regarding hospital characteristics and geography, they provide an incomplete picture of hospital ownership transitions for multiple reasons. As a result, we have implemented several corrections in order to create more comprehensive and accurate roster of hospital mergers.

First, the AHA reports data for a reference period preceding the year of the survey. As a result, system information in the AHA typically refers to the year following the reference year. In general, we deal with this issue by utilizing the lagged system information.

Second, the AHA sometimes deals with mergers and acquisitions in a way that complicates our analysis. In a case where one hospital merges with another, the AHA contains a single observation for the merged entity. However, when a system acquires a hospital, it sometimes retains its unique AHA ID and experiences a change in its system ID. In order to obtain a complete picture of hospital geography and ownership, we generate imputed observations for those hospitals, which are deleted from the data as a result of a merger, while noting the change in ownership structure through the system information.

We also incorporate several additional changes, which are motivated by validations with external data sources. We used data from the following databases to track mergers and acquisitions of hospitals: Irving-Levin Associates, Factset, and SDC Platinum. Each database contains detailed information (e.g. parties involved, announcement and closing dates) on both completed and failed M\&A deals. To incorporate this merger information into the AHA survey, we aggregated the 2006 to 2011 AHA surveys to create a panel dataset of hospital IDs where the time unit is year. We then created a new health system ID for each hospital (called sysid2). If a hospital's health system ID (sysid in the AHA survey) was non-missing, we assigned this health system ID to sysid2. For those hospitals where the value was missing, we "filled-down" sysid 2 with the health system ID of the first non-missing year before it. That is, if hospital $h$ had health system ID $A$ in 2007, but the sysid was blank in 2008 and 2009, we assigned health system $A$ to $h$ in 2008 and 2009. ${ }^{13}$ If a hospital had a missing sysid for all years, then we assigned the hospital's unique hospital ID number to the sysid 2 to denote that the hospital was an independent hospital in all years.

Next, we reviewed each merger description in the three M\&A databases and determined which AHA hospital IDs were parties to a merger, which health system IDs corresponded to the parties involved, and the date the merger closed. We then recorded the system ID of the acquiring party in a new variable called ilsysid for the target hospital in the year the merger closed. ${ }^{14}$ After completing this for every hospital merger in the three M\&A databases, we then "filled-down" the blank values of the ilsysid variable in a similar manner to sysid 2 (i.e. the years where a hospital did not experience a merger). If the hospital was not involved in any mergers (according to our

\footnotetext{
13 "Fill-down" in this context assumes the panel data are sorted by AHA hospital ID number and in ascending order by year.

${ }^{14}$ If the closing date was not populated in one of the M\&A databases and we could not find a news article or report that documented the closing of the deal, we used the announcement date as an estimate of when the deal was completed.
} 
three databases), then we assigned the hospital's unique ID number to the ilsysid variable to denote it was an independent hospital.

We then flagged all instances where sysid 2 did not equal ilsysid and reviewed each instance on a case-by-case basis to determine why there were discrepancies between the two health system IDs. We used resources such as Becker's Hospital Review and local newspapers to determine if sysid2 or ilsysid (or neither) were the correct health system ID. We then created a consolidated health system ID variable (called $m$ sysid) to account for this new information; msysid is the variable we use to identify mergers. If the msysid of hospital $h$ switched from $s_{1}$ to $s_{2}$ between year $T-1$ and year $T$, then we say hospital $h$ experienced a merger in year $T$.

We have created a database of hospital mergers that are available at www.healthcarepricingproject.org. 


\section{Appendix E: Matching Estimators for our Merger Analysis}

In order to demonstrate the robustness of our result to choices of control hospitals, we implement several matching procedures. First, we follow Dranove and Lindrooth (2003) in generating propensity score matches using a probit regression including controls for the share of hospital admissions covered by Medicare and Medicaid, whether the hospital was located in an urban area, HMO penetration, number of hospitals in the market, miles to the closest hospital, teaching status, ownership type, and the number of beds in the hospital.

We perform K-Nearest Neighbor (KNN) matching to select the 20 closest matches for each hospital using the propensity score generated from a probit regression. Specifically, we predict the probability of merger using lagged controls for monopoly, duopoly, and triopoly indicators, combined county market share of HCCI insurers, county level insurer HHI, technologies, whether the hospital was ranked by US News and World Reports, number of beds, teaching status, ownership type, median income and un-insurance rate of the county, Medicare base payment rate, and share of hospital admissions paid by Medicare or Medicaid. We then use the predicted values from the probit to select the 20 closest matches for each hospital as control observations.

We also match based on Mahalanobis distance nationally and within state using the same controls used in the KNN matching (which rely on the hospital controls we use in our main analysis - i.e. in Table 8 Panel B). 
APPENDIX F: Robustness of Key Results in Markets Where Blue Cross and Blue Shield Insurance Plans Have High and Low Market Share

Although we provide the most comprehensive picture of privately insured spending and prices to date, we do not have claims from every insurer and, in particular, from the Blue Cross Blue Shield (BCBS) insurers. In this Appendix, we analyze the robustness of our results to focusing on segments of the data with high and low BCBS market share. The areas where the BCBS plans have high market share correspond to areas where we have low HCCI insurer market share.

We use data from HealthLeaders Interstudy to compute the BCBS market share by county (see Appendix Figure 13). The map in this figure shows the national distribution of BCBS market share. We estimate that BCBS plans account for approximately 41 percent of the privately insured market. The median county has BCBS market share of 51 percent. We use this measure directly in our hospital-level regression analyses, restricting attention to hospitals located in counties above and below the median.

In order to analyze the impact BCBS has on our spending results, we need a measure of BCBS market share by HRR. While there is not a one-to-one mapping between counties and HRRs (or even counties and zip codes), we estimate HRR level market share in the following way:

(1) We generate an estimate of zip code level market share using the counties which overlap it, weighting them by the share of residents in the zip code who live in each county;

(2) We then aggregate these zip code level market shares to the HRR level using the Dartmouth Atlas zip code to HRR crosswalk, again weighting by the fraction of the HRR who live in each zip code. We estimate the median HRR to have a BCBS market share of 47 percent, and present our spending results separately for HRRs above and below the median.

\section{Appendix F1: Correlation of Private Health Spending Per Beneficiary and Medicare Spending Per Beneficiary}

BCBS market share is not strongly correlated with private health spending per beneficiary on the HCCI beneficiaries. There is a -0.064 correlation between total private spending per beneficiary in our HCCI data and BCBS county-level market share. There is a -0.026 correlation between private inpatient spending per beneficiary in our HCCI data and BCBS county-level market share. In Section III.A, we show that there is a 0.044 correlation across all HRRs in total spending per Medicare beneficiary per HRR and total spending per privately insured beneficiary per HRR. We also find a 0.172 correlation across all HRRs in inpatient spending per Medicare beneficiary per HRR and inpatient spending per privately insured beneficiary per HRR. In Appendix Table 21, we segment our sample into HRRs in which we estimate BCBS to have market share above and below 47 percent. As can be seen, the correlations differ little between high and low BCBS areas.

\section{Appendix F2: Decomposing the Drivers of Spending Per Beneficiary into the Contributions of Price and Quantity}

In Section III.B, we decompose the drivers of inpatient spending variation on the privately insured into the relative contributions of price variation and quantity variation across HRRs in the US. We find that across the nation, variation in hospital prices drives 49.6 percent of the variation in inpatient spending and variation in the quantity of each DRG provided across HRRs accounts for 
49.5 percent of the variation (the remainder is captured by a covariance term). In Appendix Table 22 we redo this analysis on the 153 HRRs with BCBS market share above 47 percent and the half of HRRs with BCBS below 47 percent.

As these results demonstrate, we see a similar role for prices and quantities to drive spending variation in HRRs where BCBS plans have above and below median market shares.

\section{Appendix F3: Variation in Hospital Prices}

We find significant variation in hospital prices across HRRs, within HRRs, and within hospitals. In Table 5, we identify the share of the variation explained by a combination of HRR fixed effects, hospital fixed effects, and controls for plan characteristics. We found that including HRR fixed effects capture 33.5 percent of the national variation in hospitals' MRI prices and introducing hospital fixed effects captures 78.0 percent of price variation, which implies that roughly 22 percent of the variation in MRI prices across the nation occurs within hospitals. In Appendix Table 23 we recreate Table 5 for the half of counties with BCBS market share below 51 percent and the half of counties with BCBS market share above 51 percent.

These results are nearly identical to our main results and the key findings do not differ as a function of the BCBS market share.

In addition, we report the national coefficient of variation across our main procedures across HRRs, within HRRs, and within hospitals by month. For lower limb MRIs, the coefficient of variation across hospitals in the US is 0.40 , the average within HRR coefficient of variation across hospitals is 0.31 , and the average within hospital, within month coefficient of variation for lowerlimb MRIs is 0.17. In Appendix Table 24, we replicate those numbers for all our procedures using hospitals in counties where BCBS market share is above 51 percent and in counties where BCBS market share is below 51 percent.

These results illustrate that we observe similar variation in procedure-level prices in counties with above and below average BCBS plan market share.

\section{Appendix F4: Cross-Sectional Analysis of Hospital Prices}

In our cross-sectional results in Section VI (Column (3) in Table 6), we show that monopoly hospitals have prices that are 12.5 percent higher than hospitals in markets with four or more competitors, have 10.5 percentage points more of their cases paid as a share of charges and have 11.3 percent less of their prospectively set payment rates pegged to Medicare payment rates. In Appendix Table 25 Panels A and B, we replicate these results for hospitals in counties where BCBS has market share above and below 51 percent. These specifications include HRR, year fixed effects, and the same controls we use in the above mentioned analysis.

Our cross-sectional pricing results are similar in areas with high and low BCBS coverage when we do not include HRR fixed effects. When we include HRR fixed effects, we lose precision on our hospital market structure point estimates in HRRs with high BCBS market share. This is because while there are 70 low BCBS-share HRRs with both a monopoly hospital and a hospital facing three or more competitors, there are only 42 high BCBS-share HRRs with both a monopoly hospital and a hospital facing three or more competitors. As a result, we lose the variation we need to estimate these cross-sectional results with precision. 
Another approach to testing the sensitivity of our results to insurer composition is to control for BCBS market share directly as a covariate in the regressions. We have also run specifications using a high order polynomial on HCCI insurers, as well as versions where we control for the top 10 insurers in each market, allowing their effects to differ based on whether they are HCCI insurers or not. In all of these exercises, the results are qualitatively unchanged. Likewise, as we illustrate in Appendix Table 25, introducing the county-level BCBS insurer share as a control variable does not change our main monopoly/duopoly/triopoly point estimates (see Column (2) of Appendix Table 25).

Appendix Table 25 Panel $\mathrm{C}$ examines whether hospital market structure is associated with the share of cases at a hospital paid as a share of hospital charges is robust in areas with high and low BCBS coverage with and without the inclusion of hospital fixed effects. Panel D shows that in markets where BCBS insurers have high and low market share, hospitals in markets with fewer other hospitals have a lower share of prospective payments that are linked to the Medicare fee schedule.

\section{Appendix F5: Merger Analysis}

In our merger analysis in Section VII, we show that mergers of two hospitals that are located less than 5 miles apart raise prices by over 6 percent. In Appendix Table 26 we analyze mergers that occurred in counties with BCBS market shares above and below the median BCBS market share. As these results illustrate, while we observe that mergers raise prices in areas where the BCBS plans have low market share, we do not observe a price effect in areas where the BCBS plans have high market share. In part, this reflects that we observe considerably more mergers in areas where BCBS have low market share. For instance, we have 188 hospitals that are exposed to mergers where the merging parties are less than 15 miles apart. However, only 56 of them are in markets where BCBS payers have high market share. Likewise, for mergers involving hospitals located less than 5-miles apart, we have 34 hospitals within the support of our treatment effect estimation. However, only 6 of these are in high BCBS HRRs. 


\section{References Used in the Appendix}

Acemoglu, Daron and Amy Finkelstein "Input and Technology Choices in Regulated Industries: Evidence from the Health Care Sector" Journal of Political Economy, $116: 5$ (2008) 837879

Bresnahan, Timothy, "Empirical Studies of Industries with Market Power", in Handbook of Industrial Organization, Volume 2 (1989): 1011-1057.

Chernew, Michael E., Lindsay M. Sabik, Amitabh Chandra, Teresa B. Gibson, and Joseph P. Newhouse, "Geographic Correlation Between Large-Firm Commercial Spending and Medicare Spending," The American Journal of Managed Care, 16 (2010), 131-138.

Clemens, Jeffrey, and Joshua D. Gottlieb, "In the Shadow of a Giant: Medicare's Influence on Private Physician Payments," Journal of Political Economy, 125 (2017), 1-39.

Cooper, Zack, Gibbons, Stephen, Jones, Simon, McGuire, Alistair, "Does Hospital Competition Save Lives? Evidence from the English NHS Patient Choice Reforms," The Economic Journal, 121(2011): 228-260.

Dafny, Leemore, Dranove, David, Limbrock, Frank, Scott Morton, Fiona, "Data Impediments to Empirical Work on Health Insurance Markets," B.E. Journal of Economic Analysis and Policy, 11(2011): 1-24.

Dranove, David, and Richard Lindrooth, "Hospital Consolidation and Costs: Another Look at the Evidence," Journal of Health Economics, 22 (2003), 983-997.

Gaynor, Martin, and William B. Vogt, "Competition among Hospitals," The Rand Journal of Economics, 34 (2003), 764-785.

Gowrisankaran, Gautam, Aviv Nevo, and Robert Town, "Mergers When Prices Are Negotiated: Evidence from the Hospital Industry," American Economic Review, 105 (2015), 172-203.

Kessler, Daniel, McClellan, Mark, "Is Hospital Competition Socially Wasteful?," Quarterly Journal of Economics, 115(2000): 577-615.

Tay, Abigail, "Assessing Competition in Hospital Care Markets: The Importance of Accounting for Quality Differentiation" Rand Journal of Economics, 34(2003): 786-814.

Yale Center for Outcomes Research, "Medicare Hospital Quality Chartbook: Performance Report on Outcomes Measures. Centers for Medicare and Medicaid Services, 2013. 
Appendix Table 1: Comparison of AHA Hospitals, the Inpatient Sub-sample and the Procedure Sub-samples

\begin{tabular}{|c|c|c|c|c|c|c|c|c|c|}
\hline & $\begin{array}{l}\text { All AHA } \\
\text { Hospitals } \\
\end{array}$ & Inpatient & $\begin{array}{c}\text { Hip } \\
\text { Replacement }\end{array}$ & $\begin{array}{c}\text { Knee } \\
\text { Replacement }\end{array}$ & $\begin{array}{l}\text { Cesarean } \\
\text { Section }\end{array}$ & $\begin{array}{l}\text { Vaginal } \\
\text { Delivery }\end{array}$ & PTCA & Colonoscopy & MRI \\
\hline \multicolumn{10}{|l|}{ Market Characteristics } \\
\hline Monopoly & 0.275 & 0.163 & 0.028 & 0.073 & 0.07 & 0.105 & 0.04 & 0.129 & 0.168 \\
\hline Duopoly & 0.194 & 0.194 & 0.087 & 0.153 & 0.153 & 0.161 & 0.125 & 0.185 & 0.198 \\
\hline Triopoly & 0.108 & 0.123 & 0.06 & 0.099 & 0.102 & 0.096 & 0.09 & 0.099 & 0.125 \\
\hline Hospital HHI & 0.541 & 0.461 & 0.314 & 0.38 & 0.374 & 0.402 & 0.338 & 0.425 & 0.472 \\
\hline HCCI Market Share, County & 15.3 & 17.8 & 25.3 & 23.6 & 21.1 & 20.5 & 24.1 & 20.6 & 19.3 \\
\hline \multicolumn{10}{|l|}{ Hospital Characteristics } \\
\hline Number of Technologies & 51.1 & 59.3 & 74.3 & 68.3 & 67.7 & 66.2 & 71.8 & 65.1 & 62.7 \\
\hline Ranked in US News \& World Reports & 0.037 & 0.053 & 0.137 & 0.08 & 0.076 & 0.072 & 0.124 & 0.081 & 0.063 \\
\hline Beds & 218.4 & 269.7 & 420.5 & 345.6 & 342.1 & 327.1 & 417.3 & 290.3 & 267.8 \\
\hline Teaching Hospital & 0.306 & 0.38 & 0.622 & 0.503 & 0.478 & 0.455 & 0.555 & 0.428 & 0.389 \\
\hline Government Owned & 0.167 & 0.122 & 0.068 & 0.074 & 0.088 & 0.101 & 0.074 & 0.108 & 0.117 \\
\hline Non-Profit & 0.64 & 0.693 & 0.83 & 0.785 & 0.754 & 0.744 & 0.75 & 0.75 & 0.735 \\
\hline \multicolumn{10}{|l|}{ Local Area Characteristics } \\
\hline Percent of County Uninsured & 17.5 & 17.1 & 16.3 & 16.8 & 16.9 & 17.1 & 17.3 & 16.3 & 16.5 \\
\hline Median Income & 49,019 & 51,516 & 55,663 & 53,892 & 55,116 & 54,566 & 52,968 & 53,691 & 51,745 \\
\hline Rural & 0.292 & 0.162 & 0.01 & 0.042 & 0.048 & 0.068 & 0.029 & 0.124 & 0.164 \\
\hline \multicolumn{10}{|l|}{ Other Payers } \\
\hline Medicare Payment Rate & 6,295 & 6,437 & 6,339 & 6,207 & 6,464 & 6,482 & 6,400 & 6,381 & 6,208 \\
\hline Share Medicare & 46.2 & 44.6 & 42.8 & 43.9 & 41.9 & 42 & 43.6 & 44.3 & 45.2 \\
\hline Share Medicaid & 18.7 & 18.8 & 15.2 & 16.2 & 17.9 & 18.3 & 16.7 & 17.4 & 17.7 \\
\hline \multicolumn{10}{|l|}{ Quality Scores } \\
\hline 30-Day AMI Survival Rate & 16.1 & 16 & 15.5 & 15.8 & 15.8 & 15.9 & 15.6 & 15.9 & 16 \\
\hline $\begin{array}{l}\% \text { of AMI Patients Given Aspirin at } \\
\text { Arrival }\end{array}$ & 95.7 & 97.3 & 98.5 & 98.1 & 98.2 & 98.1 & 98.5 & 97.6 & 97.4 \\
\hline $\begin{array}{l}\% \text { of Patients Given Antibiotics Pre } \\
\text { Surgery }\end{array}$ & 91.5 & 93.3 & 94.4 & 94.4 & 94.1 & 94.1 & 94 & 94 & 93.9 \\
\hline $\begin{array}{l}\% \text { of Surgery Patients Given } \\
\text { Treatment to Prevent Blood Clots }\end{array}$ & 85.9 & 88 & 89.8 & 89.3 & 88.8 & 88.7 & 88.7 & 88.8 & 88.9 \\
\hline Number of Observations & 12,847 & 8,772 & 1,259 & 2,660 & 3,794 & 4,096 & 1,764 & 3,512 & 5,082 \\
\hline Number of Hospitals & 3,272 & 2,358 & 470 & 932 & 1,163 & 1,280 & 652 & 1,237 & 1,628 \\
\hline$\%$ of Inpatient Cases Represented & 100 & 88.4 & 23.4 & 38.4 & 54.3 & 55.1 & 31.1 & 40.9 & 52.4 \\
\hline
\end{tabular}

Notes: The inpatient data is derived from the inpatient sample. The procedure files are drawn from the procedure samples. MRIs include only lower-limb scans. 
Appendix Table 2: Effect of Sample Restrictions on Number of Cases and Hospitals

\begin{tabular}{lll}
\hline \hline & & \\
\cline { 2 - 3 } & & Cases \\
\cline { 2 - 3 } 1. Condition on match to AHA & & Facilities \\
2. Exclude critical access hospitals & $5,865,727$ & 4,326 \\
3. Condition on match to Medicare payment data & $5,814,378$ & 3,202 \\
4. Exclude 2007 data & $5,808,583$ & 3,199 \\
5. Exclude hospitals with fewer than 50 cases per year & $5,039,479$ & 3,189 \\
\end{tabular}

Notes: This table tracks the impact of each of our successive cleaning rules on the inpatient data used in our main analyses. The data contains cases drawn from all claims in the HCCI database from 2007 to 2011. 


\section{Appendix Table 3: Counterfactual Spending Holding Price or Quantity Fixed, 2011}

\section{All Medicare vs Private Ages 55-64}

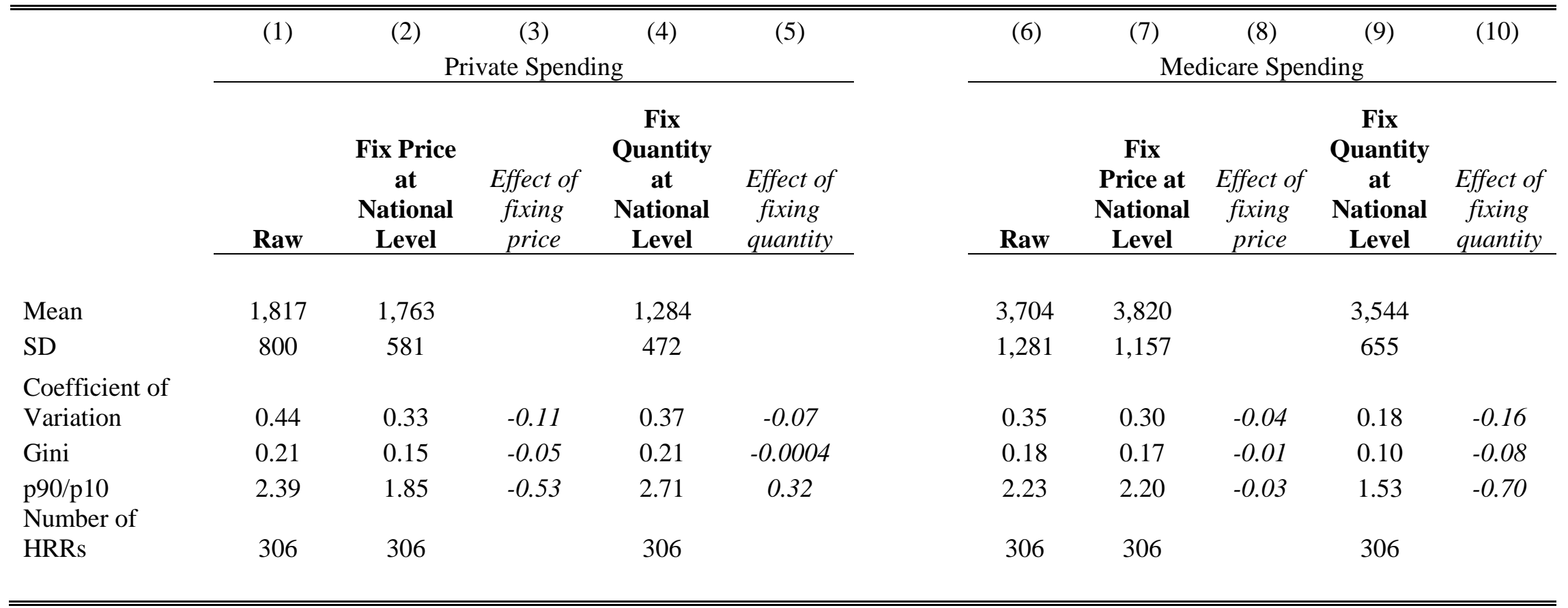

Notes: Counterfactual spending measures are calculated at the HRR level using 2011 spending data. Columns (1) and (6) present raw inpatient spending per beneficiary for the privately insured and Medicare populations, respectively. Columns (2) and (7) present the spending per privately insured and Medicare beneficiary when DRG-level prices are fixed to be the national average in all regions. Columns (3) and (8) report the reduction in measures of spe nding variation that result from fixing price. Columns (4) and (9) present spending per privately insured and Medicare beneficiary when the quantity of care (i.e. mix of DRGs as well as the rate at which beneficiaries are admitted across DRGs) is fixed to the national average. Columns (5) and (10) report the reductions in measures of spending variation that result from fixing quantity. 


\section{Appendix Table 4: Counterfactual Spending for Holding Price and Quantity Fixed, 2011}

\section{All Medicare vs Private, Ages 18-64}

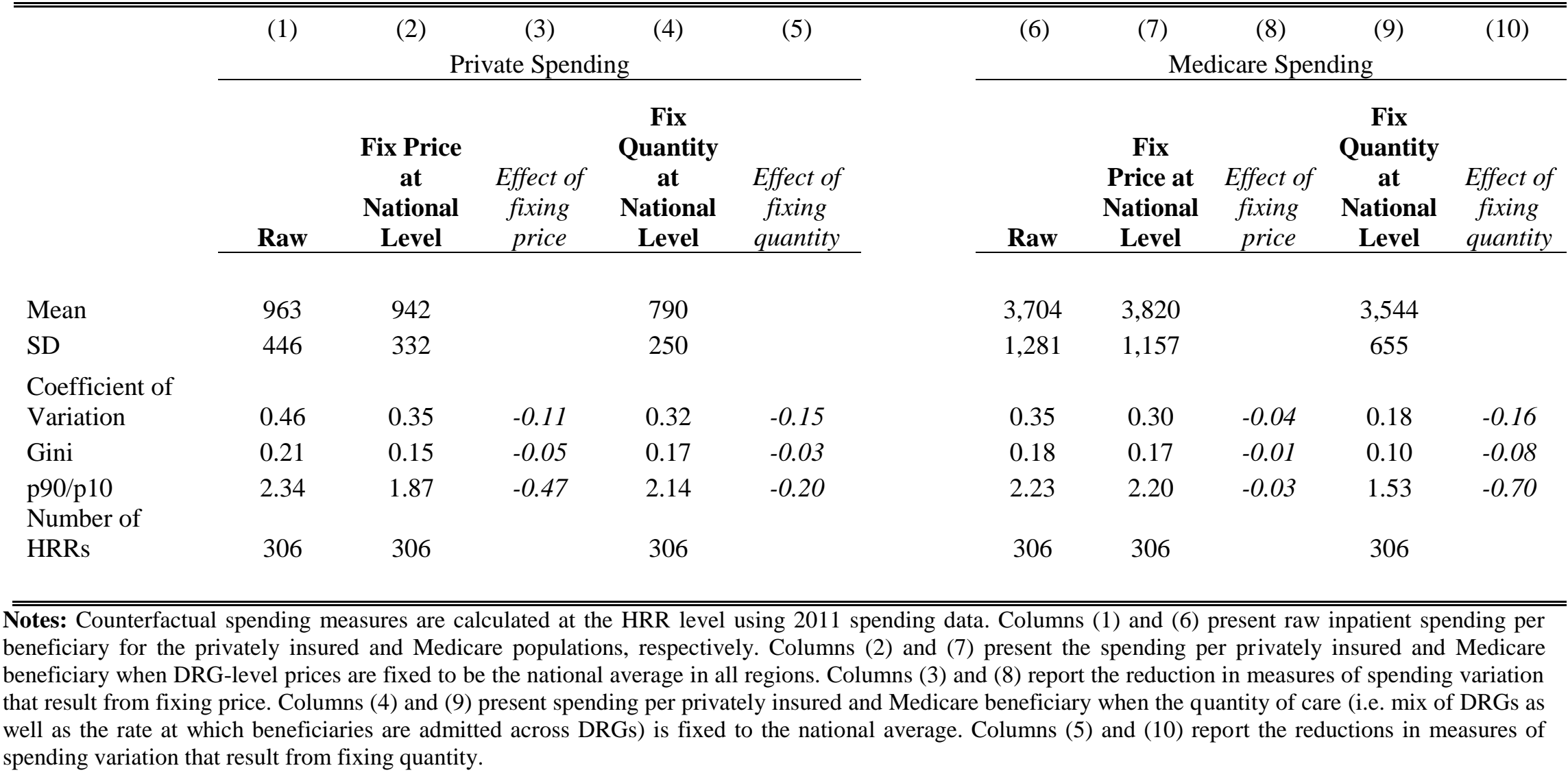




\section{Appendix Table 5: Results of Formal Price/Quantity Decomposition}

\section{of Medicare and Private Health Spending, 2011, Ages 18-64}

\begin{tabular}{|c|c|c|c|c|c|c|}
\hline & $\begin{array}{c}\text { (1) } \\
\text { Share } \\
\text { Price }\end{array}$ & $\begin{array}{c}\text { Private } \\
\text { (2) } \\
\text { Share } \\
\text { Quantity } \\
\end{array}$ & $\begin{array}{c}(3) \\
\text { Share } \\
\text { Covariance }\end{array}$ & $\begin{array}{c}(4) \\
\text { Share } \\
\text { Price }\end{array}$ & $\begin{array}{c}\text { Medicare } \\
\text { (5) } \\
\text { Share } \\
\text { Quantity } \\
\end{array}$ & $\begin{array}{c}(6) \\
\text { Share } \\
\text { Covariance }\end{array}$ \\
\hline Craniotomy \& endovascular intracranial procedures w MCC & 0.386 & 0.535 & 0.079 & 0.120 & 0.860 & 0.020 \\
\hline Pulmonary edema $\&$ respiratory failure & 0.488 & 0.437 & 0.075 & 0.213 & 0.770 & 0.017 \\
\hline Simple pneumonia \& pleurisy w MCC & 0.546 & 0.482 & -0.028 & 0.160 & 1.073 & -0.233 \\
\hline Simple pneumonia \& pleurisy w CC & 0.493 & 0.747 & -0.240 & 0.221 & 0.989 & -0.210 \\
\hline Respiratory system diagnosis w ventilator support $96+$ hours & 0.609 & 0.540 & -0.150 & 0.102 & 0.771 & 0.127 \\
\hline Respiratory system diagnosis $w$ ventilator support $<96$ hours & 0.571 & 0.484 & -0.055 & 0.155 & 0.987 & -0.143 \\
\hline Cardiac valve \& oth maj cardiothoracic proc w/o card cath w MCC & 0.396 & 0.617 & -0.013 & 0.086 & 0.840 & 0.074 \\
\hline Cardiac valve \& oth maj cardiothoracic proc w/o card cath w CC & 0.312 & 0.618 & 0.071 & 0.069 & 0.846 & 0.085 \\
\hline Coronary bypass w cardiac cath w/o MCC & 0.238 & 0.852 & -0.090 & 0.074 & 1.168 & -0.242 \\
\hline Major cardiovasc procedures $\mathrm{w}$ MCC or thoracic aortic anuerysm repair & 0.478 & 0.447 & 0.075 & 0.166 & 0.871 & -0.037 \\
\hline Major cardiovascular procedures w/o MCC & 0.360 & 0.760 & -0.120 & 0.163 & 1.059 & -0.222 \\
\hline Perc cardiovasc proc $\mathrm{w}$ drug-eluting stent $\mathrm{w}$ MCC or $4+$ vessels/stents & 0.329 & 0.722 & -0.052 & 0.089 & 1.004 & -0.094 \\
\hline Perc cardiovasc proc w drug-eluting stent w/o MCC & 0.463 & 0.889 & -0.352 & 0.153 & 1.113 & -0.265 \\
\hline Circulatory disorders except AMI, w card cath w/o MCC & 0.339 & 0.877 & -0.216 & 0.112 & 1.110 & -0.222 \\
\hline Major small \& large bowel procedures w MCC & 0.584 & 0.421 & -0.005 & 0.213 & 0.888 & -0.101 \\
\hline Major small \& large bowel procedures w CC & 0.387 & 0.564 & 0.049 & 0.193 & 0.811 & -0.005 \\
\hline Esophagitis, gastroent \& misc digest disorders w/o MCC & 0.372 & 0.835 & -0.208 & 0.164 & 1.028 & -0.192 \\
\hline Spinal fusion except cervical w/o MCC & 0.280 & 0.571 & 0.149 & 0.085 & 1.067 & -0.152 \\
\hline Major joint replacement or reattachment of lower extremity w/o MCC & 0.331 & 0.724 & -0.055 & 0.213 & 0.973 & -0.186 \\
\hline Cellulitis w/o MCC & 0.406 & 0.995 & -0.401 & 0.128 & 0.923 & -0.051 \\
\hline Kidney \& urinary tract infections w/o MCC & 0.372 & 0.750 & -0.122 & 0.151 & 1.062 & -0.212 \\
\hline Infectious \& parasitic diseases w O.R. procedure w MCC & 0.590 & 0.306 & 0.104 & 0.112 & 0.769 & 0.119 \\
\hline Septicemia w MV 96+ hours & 0.768 & 0.269 & -0.038 & 0.072 & 0.860 & 0.067 \\
\hline Septicemia w/o MV 96+ hours w MCC & 0.508 & 0.457 & 0.035 & 0.120 & 0.815 & 0.064 \\
\hline Rehabilitation w CC/MCC & 0.420 & 0.507 & 0.074 & 0.056 & 1.164 & -0.219 \\
\hline Average Shares (weighted by spending) & 0.438 & 0.567 & -0.005 & 0.127 & 0.953 & -0.081 \\
\hline
\end{tabular}

Notes: The decomposition of ln(spending per beneficiary) is carried out on the 2011 Medicare and HCCI inpatient spending samples. The Medicare analysis is based on data drawn from the $100 \%$ sample of Medicare claims that we accessed via the AHD. The HCCI data includes all inpatient claims and is drawn from our spending sample. "CC" is short for with "complication or comorbidity"; "MCC" is short for with "major complication or comorbidity"; "proc"="procedure"; "cath" = "catheter"; "w"=With"; "w/o"="without". Because of space constraints, we show the top 25 highest spending DRGs in the HCCI data; the "Average Shares" in the final row are the average decomposition results by DRG (weighted by spending) across the 735 DRGs (HCCI) 562 DRGs (Medicare). 
Appendix Table 6: Hospital Procedure Prices (Mean and Coefficient of Variation) for the 25 Most Populated HRRs, 2011

\begin{tabular}{|c|c|c|c|c|c|c|c|c|c|c|c|c|c|c|c|c|}
\hline & \multicolumn{2}{|c|}{ Inpatient } & \multicolumn{2}{|c|}{$\begin{array}{c}\text { Hip } \\
\text { Replacement }\end{array}$} & \multicolumn{2}{|c|}{$\begin{array}{c}\text { Knee } \\
\text { Replacement }\end{array}$} & \multicolumn{2}{|c|}{$\begin{array}{c}\text { Cesarean } \\
\text { Section }\end{array}$} & \multicolumn{2}{|c|}{$\begin{array}{l}\text { Vaginal } \\
\text { Delivery }\end{array}$} & \multicolumn{2}{|c|}{ PTCA } & \multicolumn{2}{|c|}{ Colonoscopy } & \multicolumn{2}{|c|}{$\begin{array}{c}\text { Lower Limb } \\
\text { MRI }\end{array}$} \\
\hline & Mean & $\mathrm{CoV}$ & Mean & $\mathrm{CoV}$ & Mean & $\mathrm{CoV}$ & Mean & $\mathrm{CoV}$ & Mean & $\mathrm{CoV}$ & Mean & $\mathrm{CoV}$ & Mean & $\mathrm{CoV}$ & Mean & $\mathrm{CoV}$ \\
\hline Phoenix, AZ & 15,710 & 0.427 & 16,350 & 0.195 & 20,376 & 0.471 & 7,378 & 0.262 & 4,982 & 0.297 & 15,236 & 0.298 & 1,724 & 0.522 & 1,326 & 0.6 \\
\hline Los Angeles, CA & 14,836 & 0.355 & 25,658 & 0.387 & 22,447 & 0.465 & 9,205 & 0.342 & 5,998 & 0.317 & 20,773 & 0.52 & 2,459 & 0.325 & 1,453 & 0.281 \\
\hline Denver, CO & 15,876 & 0.291 & 20,475 & 0.287 & 22,849 & 0.38 & 8,471 & 0.229 & 4,912 & 0.237 & 25,423 & 0.22 & 2,127 & 0.356 & 1,306 & 0.335 \\
\hline Washington, DC & 10,830 & 0.204 & 19,669 & 0.183 & 18,521 & 0.302 & 7,532 & 0.216 & 5,603 & 0.143 & 21,855 & 0.297 & 1,302 & 0.394 & 1,010 & 0.378 \\
\hline Ft Lauderdale, FL & 12,329 & 0.288 & 21,230 & 0.278 & 22,008 & 0.365 & 6,349 & 0.247 & 4,471 & 0.205 & 23,574 & 0.287 & 1,639 & 0.309 & 753 & 0.405 \\
\hline Miami, FL & 12,983 & 0.257 & 22,418 & 0.34 & 25,454 & 0.287 & 6,439 & 0.165 & 4,827 & 0.189 & 23,942 & 0.41 & 1,855 & 0.422 & 1,213 & 0.654 \\
\hline Orlando, FL & 13,902 & 0.28 & 24,987 & 0.3 & 23,137 & 0.288 & 7,800 & 0.21 & 4,685 & 0.276 & 23,779 & 0.336 & 2,142 & 0.287 & 1,219 & 0.309 \\
\hline Atlanta, GA & 11,368 & 0.253 & 20,617 & 0.266 & 20,105 & 0.319 & 5,905 & 0.281 & 4,303 & 0.261 & 19,038 & 0.28 & 1,653 & 0.408 & 1,040 & 0.377 \\
\hline Louisville, KY & 9,509 & 0.241 & 18,508 & 0.207 & 15,628 & 0.173 & 5,611 & 0.278 & 4,138 & 0.341 & 14,680 & 0.193 & 1,343 & 0.273 & 1,206 & 0.386 \\
\hline Minneapolis, MN & 14,225 & 0.177 & 23,613 & 0.192 & 22,542 & 0.167 & 8,488 & 0.19 & 4,953 & 0.137 & 24,412 & 0.179 & 1,499 & 0.165 & 1,299 & 0.395 \\
\hline Kansas City, MO & 11,240 & 0.222 & 19,441 & 0.252 & 18,499 & 0.239 & 5,935 & 0.251 & 4,012 & 0.206 & 20,567 & 0.297 & 1,448 & 0.181 & 1,182 & 0.295 \\
\hline St. Louis, MO & 10,091 & 0.317 & 15,225 & 0.117 & 14,415 & 0.155 & 5,070 & 0.236 & 3,922 & 0.317 & 18,401 & 0.2 & 1,227 & 0.238 & 1,188 & 0.298 \\
\hline Camden, NJ & 13,131 & 0.487 & 20,351 & 0.237 & 20,142 & 0.262 & 9,144 & 0.295 & 6,542 & 0.249 & 21,064 & 0.39 & 1,548 & 0.362 & 1,006 & 0.265 \\
\hline E Long Island, NY & 13,664 & 0.216 & 40,049 & 0.135 & 31,567 & 0.201 & 8,905 & 0.136 & 6,279 & 0.142 & 32,862 & 0.174 & 2,154 & 0.232 & 1,294 & 0.4 \\
\hline Manhattan, NY & 13,529 & 0.229 & 30,464 & 0.082 & 28,323 & 0.214 & 8,337 & 0.26 & 5,715 & 0.201 & 28,654 & 0.292 & 1,745 & 0.287 & 1,050 & 0.241 \\
\hline Cincinnati, $\mathrm{OH}$ & 11,749 & 0.156 & 25,085 & 0.091 & 23,153 & 0.12 & 6,381 & 0.079 & 4,465 & 0.134 & 21,641 & 0.125 & 1,794 & 0.154 & 1,259 & 0.455 \\
\hline Columbus, $\mathrm{OH}$ & 13,638 & 0.171 & 30,246 & 0.198 & 27,439 & 0.288 & 7,783 & 0.304 & 5,265 & 0.224 & 25,401 & 0.287 & 1,506 & 0.402 & 1,446 & 0.307 \\
\hline Philadelphia, PA & 12,236 & 0.257 & 27,697 & 0.231 & 26,173 & 0.287 & 9,464 & 0.274 & 6,402 & 0.247 & 29,369 & 0.302 & 1,945 & 0.387 & 1,512 & 0.515 \\
\hline Austin, TX & 11,957 & 0.216 & 24,713 & 0.183 & 23,964 & 0.172 & 6,435 & 0.099 & 4,523 & 0.087 & 27,261 & 0.21 & 1,349 & 0.211 & 1,069 & 0.296 \\
\hline Dallas, TX & 13,691 & 0.244 & 32,427 & 0.186 & 31,826 & 0.209 & 6,992 & 0.207 & 5,070 & 0.164 & 29,935 & 0.2 & 1,627 & 0.169 & 1,277 & 0.312 \\
\hline Fort Worth, TX & 13,632 & 0.248 & 39,709 & 0.115 & 34,626 & 0.24 & 7,001 & 0.185 & 5,220 & 0.173 & 29,917 & 0.232 & 1,617 & 0.222 & 1,191 & 0.375 \\
\hline Houston, TX & 12,643 & 0.434 & 26,855 & 0.341 & 22,642 & 0.31 & 6,319 & 0.218 & 4,308 & 0.302 & 29,663 & 0.299 & 1,409 & 0.338 & 1,178 & 0.402 \\
\hline San Antonio, TX & 12,770 & 0.288 & 24,733 & 0.138 & 22,621 & 0.205 & 6,247 & 0.291 & 3,608 & 0.34 & 26,139 & 0.125 & 1,179 & 0.289 & 1,082 & 0.319 \\
\hline Arlington, VA & 12,987 & 0.126 & 24,672 & 0.137 & 24,428 & 0.136 & 7,868 & 0.129 & 5,420 & 0.135 & 22,984 & 0.201 & 1,707 & 0.155 & 1,460 & 0.177 \\
\hline Milwaukee, WI & 14,084 & 0.159 & 25,284 & 0.167 & 24,491 & 0.169 & 8,585 & 0.165 & 5,103 & 0.126 & 26,266 & 0.251 & 2,450 & 0.213 & 1,561 & 0.248 \\
\hline National Average & 13,815 & 0.218 & 24,658 & 0.162 & 23,567 & 0.182 & 7,825 & 0.184 & 4,957 & 0.183 & 25,992 & 0.196 & 1,719 & 0.228 & 1,373 & 0.249 \\
\hline Medicare Average & 6,461 & 0.087 & 13,389 & 0.064 & 13,039 & 0.068 & 4,954 & 0.067 & 3,175 & 0.096 & 12,907 & 0.072 & 656 & 0.073 & 354 & 0.033 \\
\hline
\end{tabular}

Notes: Prices are regression adjusted transaction prices for 2011. CoV = coefficient of variation. The national averages present the mean within HRR Coefficient of Variation (CoV) and the average within HRR price. The data are drawn from the pricing samples and include prices that are risk-adjusted for age and sex. The inpatient analysis uses our risk-adjusted inpatient price index. 
Appendix Table 7: Inpatient Cross-Sectional Price Regressions with All Controls, 2008$\underline{\text { 2011; Full Results }}$

\begin{tabular}{|c|c|c|c|}
\hline \multirow{3}{*}{$\begin{array}{c}\text { Dependent Variable: } \\
\text { Market Characteristics } \\
\text { Monopoly }\end{array}$} & \multicolumn{3}{|c|}{ In(Facilities Price) } \\
\hline & & & \\
\hline & $\begin{array}{c}0.234 * * * \\
(0.024)\end{array}$ & $\begin{array}{c}0.190 * * * \\
(0.024)\end{array}$ & $\begin{array}{c}0.118 * * * \\
(0.024)\end{array}$ \\
\hline Duopoly & $\begin{array}{c}0.161 * * * \\
(0.021)\end{array}$ & $\begin{array}{c}0.130 * * * \\
(0.020)\end{array}$ & $\begin{array}{c}0.073^{* * *} * \\
(0.024)\end{array}$ \\
\hline Triopoly & $\begin{array}{c}0.115^{* * *} * \\
(0.023)\end{array}$ & $\begin{array}{c}0.083 * * * \\
(0.023)\end{array}$ & $\begin{array}{c}0.036 \\
(0.023)\end{array}$ \\
\hline Share HCCI & & $\begin{array}{c}-0.006^{* * * *} \\
(0.002)\end{array}$ & $\begin{array}{c}-0.007 * * * * \\
(0.002)\end{array}$ \\
\hline \multicolumn{4}{|l|}{ Hospital Characteristics } \\
\hline $\ln$ (Technologies) & $\begin{array}{c}0.012 * * \\
(0.005)\end{array}$ & $\begin{array}{c}0.011 * * \\
(0.005)\end{array}$ & $\begin{array}{c}0.010^{* *} \\
(0.004)\end{array}$ \\
\hline Ranked by US News and World Reports & $\begin{array}{c}0.118^{* * *} \\
(0.031)\end{array}$ & $\begin{array}{c}0.138^{* * *} \\
(0.031)\end{array}$ & $\begin{array}{c}0.134 * * * \\
(0.033)\end{array}$ \\
\hline $\ln ($ Number of Beds) & $\begin{array}{c}0.046 * * * \\
(0.012)\end{array}$ & $\begin{array}{c}0.040 * * * \\
(0.011)\end{array}$ & $\begin{array}{c}0.067 * * * \\
(0.010)\end{array}$ \\
\hline Teaching Hospital & $\begin{array}{c}-0.006 \\
(0.018)\end{array}$ & $\begin{array}{c}0.001 \\
(0.018)\end{array}$ & $\begin{array}{c}0.020 \\
(0.014)\end{array}$ \\
\hline Government Owned & $\begin{array}{c}-0.129 * * * \\
(0.031)\end{array}$ & $\begin{array}{c}-0.133 * * * \\
(0.031)\end{array}$ & $\begin{array}{c}-0.148 * * * \\
(0.030)\end{array}$ \\
\hline Non-Profit & $\begin{array}{c}-0.049 * * \\
(0.022)\end{array}$ & $\begin{array}{c}-0.053 * * \\
(0.022)\end{array}$ & $\begin{array}{c}-0.074 * * * \\
(0.023)\end{array}$ \\
\hline \multicolumn{4}{|l|}{ County Characteristics } \\
\hline Percent Uninsured & $\begin{array}{c}0.006^{* *} \\
(0.002)\end{array}$ & $\begin{array}{c}0.009 * * * \\
(0.002)\end{array}$ & $\begin{array}{l}-0.002 \\
(0.003)\end{array}$ \\
\hline $\ln ($ Median Income $)$ & $\begin{array}{c}0.137 * * * \\
(0.047)\end{array}$ & $\begin{array}{c}0.236 * * * \\
(0.050)\end{array}$ & $\begin{array}{c}0.048 \\
(0.056)\end{array}$ \\
\hline \multicolumn{4}{|l|}{ Other Payers } \\
\hline $\ln ($ Medicare Base Payment Rate) & $\begin{array}{c}0.430 * * * \\
(0.083)\end{array}$ & $\begin{array}{c}0.299 * * * \\
(0.085)\end{array}$ & $\begin{array}{c}0.088 \\
(0.078)\end{array}$ \\
\hline Share Medicare & $\begin{array}{c}-0.003 * * * \\
(0.001)\end{array}$ & $\begin{array}{c}-0.004 * * * \\
(0.001)\end{array}$ & $\begin{array}{c}-0.002 * * * \\
(0.001)\end{array}$ \\
\hline Share Medicaid & $\begin{array}{c}-0.004 * * * \\
(0.001)\end{array}$ & $\begin{array}{c}-0.004 * * * \\
(0.001)\end{array}$ & $\begin{array}{c}-0.002 * * \\
(0.001)\end{array}$ \\
\hline R-square & 0.143 & 0.170 & 0.453 \\
\hline Year Fixed Effects & Yes & Yes & Yes \\
\hline HRR Fixed Effects & No & Yes & Yes \\
\hline Observations & 8,772 & 8,772 & 8,772 \\
\hline
\end{tabular}

Notes: $* \mathrm{p}<0.10, * * \mathrm{p}<0.05, * * * \mathrm{p}<0.01$. OLS estimates with standard errors clustered at the HRR-level in parentheses. We use hospital price data from 2008 to 2011. Facilities prices are regression adjusted transaction prices that are riskadjusted for DRG, age, and sex. All regressions include yearly fixed effects. The omitted hospital market structure is quadropoly or greater and the omitted ownership category is private hospitals. 


\begin{tabular}{|c|c|c|c|}
\hline \multirow{2}{*}{$\begin{array}{l}\text { Dependent Variable: } \\
\text { Market Characteristics } \\
\text { Monopoly }\end{array}$} & \multicolumn{3}{|c|}{ Percent of Cases Paid as Share of Charges } \\
\hline & $\begin{array}{c}17.335^{* * * *} \\
(1.828)\end{array}$ & $\begin{array}{c}15.241^{* * * *} \\
(1.823)\end{array}$ & $\begin{array}{c}10.455^{* * * *} \\
(1.778)\end{array}$ \\
\hline Duopoly & $\begin{array}{c}9.979 * * * \\
(1.760)\end{array}$ & $\begin{array}{c}8.424 * * * \\
(1.740)\end{array}$ & $\begin{array}{c}5.702 * * * \\
(1.596)\end{array}$ \\
\hline Triopoly & $\begin{array}{c}7.804 * * * \\
(1.909)\end{array}$ & $\begin{array}{c}6.235 * * \\
(1.938)\end{array}$ & $\begin{array}{c}4.909 * * \\
(1.608)\end{array}$ \\
\hline Share HCCI & & $\begin{array}{c}-0.288^{* * *} \\
(0.077)\end{array}$ & $\begin{array}{c}-0.403 * * * \\
(0.120)\end{array}$ \\
\hline \multicolumn{4}{|l|}{ Hospital Characteristics } \\
\hline $\ln$ (Technologies) & $\begin{array}{c}0.733 * * \\
(0.271)\end{array}$ & $\begin{array}{c}0.750^{* *} \\
(0.270)\end{array}$ & $\begin{array}{c}0.462 \\
(0.249)\end{array}$ \\
\hline Ranked by US News and World Reports & $\begin{array}{c}3.860 \\
(2.299)\end{array}$ & $\begin{array}{l}4.807 * \\
(2.284)\end{array}$ & $\begin{array}{c}1.728 \\
(1.501)\end{array}$ \\
\hline $\ln$ (Number of Beds) & $\begin{array}{c}1.099 \\
(0.791)\end{array}$ & $\begin{array}{c}0.809 \\
(0.776)\end{array}$ & $\begin{array}{c}2.905 * * * \\
(0.601)\end{array}$ \\
\hline Teaching Hospital & $\begin{array}{c}1.343 \\
(0.934)\end{array}$ & $\begin{array}{c}1.615 \\
(0.949)\end{array}$ & $\begin{array}{c}0.528 \\
(0.784)\end{array}$ \\
\hline Government Owned & $\begin{array}{c}3.265 \\
(1.847)\end{array}$ & $\begin{array}{c}3.048 \\
(1.842)\end{array}$ & $\begin{array}{l}4.407^{*} \\
(1.828)\end{array}$ \\
\hline Non-Profit & $\begin{array}{c}6.651^{* * * *} \\
(1.188)\end{array}$ & $\begin{array}{c}6.514 * * * \\
(1.219)\end{array}$ & $\begin{array}{c}4.532 * * * \\
(1.103)\end{array}$ \\
\hline \multicolumn{4}{|l|}{ County Characteristics } \\
\hline Percent Uninsured & $\begin{array}{c}-0.338^{*} \\
(0.136)\end{array}$ & $\begin{array}{l}-0.215 \\
(0.141)\end{array}$ & $\begin{array}{c}0.248 \\
(0.347)\end{array}$ \\
\hline $\ln ($ Median Income $)$ & $\begin{array}{l}-2.637 \\
(3.961)\end{array}$ & $\begin{array}{c}1.934 \\
(4.205)\end{array}$ & $\begin{array}{c}3.761 \\
(5.049)\end{array}$ \\
\hline \multicolumn{4}{|l|}{ Other Payers } \\
\hline In(Medicare Base Payment Rate) & $\begin{array}{c}-18.993 * * * \\
(4.833)\end{array}$ & $\begin{array}{c}-25.057 * * * \\
(5.367)\end{array}$ & $\begin{array}{c}-16.714 * * * \\
(4.679)\end{array}$ \\
\hline Share Medicare & $\begin{array}{c}-0.377 * * * \\
(0.079)\end{array}$ & $\begin{array}{c}-0.388 * * * \\
(0.077)\end{array}$ & $\begin{array}{c}-0.206 * * * \\
(0.050)\end{array}$ \\
\hline Share Medicaid & $\begin{array}{l}-0.032 \\
(0.068)\end{array}$ & $\begin{array}{c}-0.015 \\
(0.069)\end{array}$ & $\begin{array}{l}-0.086 \\
(0.045)\end{array}$ \\
\hline R-square & 0.166 & 0.179 & 0.557 \\
\hline Yearly FE & Yes & Yes & Yes \\
\hline HRR FE & No & Yes & Yes \\
\hline Observations & 4,344 & 4,344 & 4,344 \\
\hline
\end{tabular}

Notes: $* \mathrm{p}<0.10, * * \mathrm{p}<0.05, * * * \mathrm{p}<0.01$. OLS estimates of Equation (2) with standard errors clustered at the HRRlevel in parentheses. We measure percent of inpatient cases paid as share of charges for 2010-2011. The omitted hospital market structure is quadropoly or greater and the omitted ownership category is private hospitals. 
Appendix Table 9: Inpatient Regressions for Share of Linked to Medicare, 2010-2011; Full $\underline{\text { Results }}$

\begin{tabular}{|c|c|c|c|}
\hline \multirow{3}{*}{$\begin{array}{l}\text { Dependent Variable: } \\
\text { Market Characteristics } \\
\text { Monopoly }\end{array}$} & \multicolumn{3}{|c|}{ Share of Prospective Payments Linked to Medicare } \\
\hline & & & \\
\hline & $\begin{array}{c}-16.849 * * * \\
(2.882)\end{array}$ & $\begin{array}{c}-11.275 * * * \\
(2.696)\end{array}$ & $\begin{array}{c}-11.293 * * * \\
(3.160)\end{array}$ \\
\hline Duopoly & $\begin{array}{c}-8.791 * * * \\
(2.441)\end{array}$ & $\begin{array}{c}-4.272 * \\
(2.443)\end{array}$ & $\begin{array}{c}-5.595 * * \\
(2.316)\end{array}$ \\
\hline \multirow[t]{2}{*}{ Triopoly } & $-7.111 * *$ & -2.422 & $-5.747 * *$ \\
\hline & $(2.866)$ & $(2.727)$ & $(2.790)$ \\
\hline HCCI Market Share & & $\begin{array}{c}0.890 * * * \\
(0.091)\end{array}$ & $\begin{array}{c}0.616 * * * \\
(0.174)\end{array}$ \\
\hline \multicolumn{4}{|l|}{ Hospital Characteristics } \\
\hline $\ln ($ Technologies $)$ & $\begin{array}{c}0.465 \\
(0.511)\end{array}$ & $\begin{array}{c}0.453 \\
(0.461)\end{array}$ & $\begin{array}{l}0.809^{*} \\
(0.459)\end{array}$ \\
\hline Ranked in US News \& World Reports & $\begin{array}{l}7.662 * * \\
(3.390)\end{array}$ & $\begin{array}{c}4.591 \\
(3.266)\end{array}$ & $\begin{array}{l}5.339^{*} \\
(2.722)\end{array}$ \\
\hline $\ln ($ Beds $)$ & $\begin{array}{c}7.998 * * * \\
(1.317)\end{array}$ & $\begin{array}{c}9.138 * * * \\
(1.209)\end{array}$ & $\begin{array}{c}9.320 * * * \\
(1.239)\end{array}$ \\
\hline Teaching & $\begin{array}{c}4.402 * * * \\
(1.511)\end{array}$ & $\begin{array}{c}3.405 * * \\
(1.429)\end{array}$ & $\begin{array}{l}2.504^{*} \\
(1.472)\end{array}$ \\
\hline Government & $\begin{array}{c}-0.859 \\
(2.588)\end{array}$ & $\begin{array}{l}-0.481 \\
(2.535)\end{array}$ & $\begin{array}{l}-3.377 \\
(2.638)\end{array}$ \\
\hline Non-Profit & $\begin{array}{l}2.781 \\
(2.022)\end{array}$ & $\begin{array}{c}3.031 \\
(1.881)\end{array}$ & $\begin{array}{l}1.485 \\
(2.084)\end{array}$ \\
\hline \multicolumn{4}{|l|}{ County Characteristics } \\
\hline Percent Uninsured & $\begin{array}{l}-0.024 \\
(0.264)\end{array}$ & $\begin{array}{c}-0.394 * * \\
(0.186)\end{array}$ & $\begin{array}{l}-0.118 \\
(0.483)\end{array}$ \\
\hline $\ln ($ Median Income) & $\begin{array}{l}-0.747 \\
(5.510)\end{array}$ & $\begin{array}{c}-14.915^{* * * *} \\
(4.781)\end{array}$ & $\begin{array}{l}-3.349 \\
(7.177)\end{array}$ \\
\hline \multicolumn{4}{|l|}{ Other Payers } \\
\hline $\ln$ (Medicare Base Payment Rate) & $\begin{array}{c}-34.805 * * * \\
(8.942)\end{array}$ & $\begin{array}{c}-14.562^{*} \\
(7.824)\end{array}$ & $\begin{array}{c}-18.145^{* * *} \\
(8.960)\end{array}$ \\
\hline Share Medicare & $\begin{array}{c}-0.210 * * \\
(0.087)\end{array}$ & $\begin{array}{c}-0.140 * \\
(0.081)\end{array}$ & $\begin{array}{c}-0.231 * * * \\
(0.080)\end{array}$ \\
\hline Share Medicaid & $\begin{array}{l}-0.071 \\
(0.091)\end{array}$ & $\begin{array}{l}-0.126 \\
(0.086)\end{array}$ & $\begin{array}{c}-0.185 * * \\
(0.086)\end{array}$ \\
\hline R-Squared & 0.115 & 0.172 & 0.380 \\
\hline Yearly-FE & Yes & Yes & Yes \\
\hline HRR-FE & No & Yes & Yes \\
\hline Observations & 3,669 & 3,669 & 3,669 \\
\hline
\end{tabular}

Notes: $* \mathrm{p}<0.10, * * \mathrm{p}<0.05, * * * \mathrm{p}<0.01$. OLS estimates of Equation (2) with standard errors clustered at the HRRlevel in parentheses. We measure share of inpatient cases linked to Medicare from 2010 to 2011. All regressions include yearly fixed effects. The omitted hospital market structure is quadropoly or greater and the omitted ownership category is private hospitals. 
Appendix Table 10: Cross-sectional Pricing Regressions Using Alternative Price Measures

\begin{tabular}{|c|c|c|c|}
\hline \multicolumn{4}{|c|}{ Panel A: Baseline Result, Observations = 8,772 } \\
\hline Monopoly & $\begin{array}{c}0.234 * * * \\
(0.024)\end{array}$ & $\begin{array}{c}0.190 * * * \\
(0.024)\end{array}$ & $\begin{array}{c}0.118 * * * \\
(0.024)\end{array}$ \\
\hline Duopoly & $\begin{array}{c}0.161 * * * \\
(0.021)\end{array}$ & $\begin{array}{c}0.130 * * * \\
(0.020)\end{array}$ & $\begin{array}{c}0.073 * * * \\
(0.024)\end{array}$ \\
\hline Triopoly & $\begin{array}{c}0.115 * * * \\
(0.023)\end{array}$ & $\begin{array}{c}0.083 * * * \\
(0.023)\end{array}$ & $\begin{array}{c}0.036 \\
(0.023)\end{array}$ \\
\hline HCCI Market Share & & $\begin{array}{c}-0.006^{* * * *} \\
(0.002) \\
\end{array}$ & $\begin{array}{c}-0.007 * * * \\
(0.002)\end{array}$ \\
\hline \multicolumn{4}{|c|}{ Panel B: $\ln ($ Price) Before Risk-Adjustment, Observations = 8,772 } \\
\hline Monopoly & $\begin{array}{c}0.222 * * * \\
(0.027)\end{array}$ & $\begin{array}{c}0.182 * * * \\
(0.028)\end{array}$ & $\begin{array}{c}0.096 * * * \\
(0.026)\end{array}$ \\
\hline Duopoly & $\begin{array}{c}0.148 * * * \\
(0.023)\end{array}$ & $\begin{array}{c}0.119 * * * \\
(0.022)\end{array}$ & $\begin{array}{l}0.047^{*} \\
(0.024)\end{array}$ \\
\hline Triopoly & $\begin{array}{c}0.095 * * * \\
(0.025)\end{array}$ & $\begin{array}{c}0.066 * * * \\
(0.025)\end{array}$ & $\begin{array}{c}0.002 \\
(0.023)\end{array}$ \\
\hline HCCI Market Share & & $\begin{array}{c}-0.006 * * * * \\
(0.002)\end{array}$ & $\begin{array}{c}-0.007 * * * \\
(0.002)\end{array}$ \\
\hline \multicolumn{4}{|c|}{ Panel C: Levels of Price, Observations = 8,772 } \\
\hline Monopoly & $\begin{array}{c}3080.604 * * * \\
(350.922)\end{array}$ & $\begin{array}{c}2402.447 * * * \\
(343.335)\end{array}$ & $\begin{array}{c}1604.775 * * * \\
(339.422)\end{array}$ \\
\hline Duopoly & $\begin{array}{c}2168.105^{* * * *} \\
(290.420)\end{array}$ & $\begin{array}{c}1685.231 * * * \\
(266.204)\end{array}$ & $\begin{array}{c}1006.571 * * * \\
(319.430)\end{array}$ \\
\hline Triopoly & $\begin{array}{c}1545.485^{* * * *} \\
(303.488)\end{array}$ & $\begin{array}{c}1055.851 * * * \\
(300.250)\end{array}$ & $\begin{array}{c}470.042 \\
(314.683)\end{array}$ \\
\hline HCCI Market Share & & $\begin{array}{c}-96.276^{* * *} \\
(19.530)\end{array}$ & $\begin{array}{c}-116.731^{* * *} \\
(23.029) \\
\end{array}$ \\
\hline \multicolumn{4}{|c|}{ Panel D: Adding Charlson Score to Risk Adjustment, Observations = 8,491 } \\
\hline Monopoly & $\begin{array}{c}0.230 * * * \\
(0.024)\end{array}$ & $\begin{array}{c}0.188^{* * * *} \\
(0.025)\end{array}$ & $\begin{array}{c}0.115 * * * \\
(0.024)\end{array}$ \\
\hline Duopoly & $\begin{array}{c}0.159 * * * \\
(0.021)\end{array}$ & $\begin{array}{c}0.129 * * * \\
(0.020)\end{array}$ & $\begin{array}{c}0.070 * * * \\
(0.024)\end{array}$ \\
\hline Triopoly & $\begin{array}{c}0.119 * * * \\
(0.023)\end{array}$ & $\begin{array}{c}0.088 * * * \\
(0.023)\end{array}$ & $\begin{array}{l}0.038^{*} \\
(0.023)\end{array}$ \\
\hline HCCI Market Share & & $\begin{array}{c}-0.006^{* * * *} \\
(0.002) \\
\end{array}$ & $\begin{array}{c}-0.008^{* * * *} \\
(0.002)\end{array}$ \\
\hline \multicolumn{4}{|c|}{ Panel E: Risk-Adjustment Using ICD9 Codes, Observations = 8,772 } \\
\hline Monopoly & $\begin{array}{c}0.205^{* * * *} \\
(0.027)\end{array}$ & $\begin{array}{c}0.158 * * * \\
(0.027)\end{array}$ & $\begin{array}{c}0.076 * * * \\
(0.026)\end{array}$ \\
\hline Duopoly & $\begin{array}{c}0.156 * * * \\
(0.024)\end{array}$ & $\begin{array}{c}0.123 * * * \\
(0.022)\end{array}$ & $\begin{array}{c}0.055^{* *} \\
(0.026)\end{array}$ \\
\hline Triopoly & $\begin{array}{c}0.107 * * * \\
(0.024)\end{array}$ & $\begin{array}{c}0.073 * * * \\
(0.025)\end{array}$ & $\begin{array}{c}0.012 \\
(0.024)\end{array}$ \\
\hline HCCI Market Share & & $\begin{array}{c}-0.007 * * * \\
(0.002)\end{array}$ & $\begin{array}{c}-0.008 * * * \\
(0.002)\end{array}$ \\
\hline HRR FE & No & No & Yes \\
\hline
\end{tabular}

Notes: $* \mathrm{p}<0.10, * * \mathrm{p}<0.05, * * * \mathrm{p}<0.01$. OLS estimates with standard errors clustered at the HRR-level in parentheses. All regressions include controls in Table 6 notes. In Panel B $\ln$ (prices) rather than levels are used in Equation (A1). Panel C uses level instead of logs of prices. In Panels A, B, and C, prices are risk-adjusted for DRG, age, and sex. In Panel D, they are risk-adjusted for DRG, Charlson Score, age, and sex. In Panel E, we risk-adjust using ICD-9 codes, age, and sex. 
Appendix Table 11: Procedure-Level Regressions Measured as the Sum of Facility and Physician Prices, 2008-2011

\begin{tabular}{|c|c|c|c|c|c|c|c|c|c|}
\hline & (1) & (2) & (3) & (4) & (5) & (6) & (7) & (8) & (9) \\
\hline Sample: & Inpatient & $\begin{array}{c}\text { Pooled } \\
\text { Procedure } \\
\text { s }\end{array}$ & $\begin{array}{c}\text { Hip } \\
\text { Replacement }\end{array}$ & $\begin{array}{c}\text { Knee } \\
\text { Replacement }\end{array}$ & $\begin{array}{c}\text { Cesarean } \\
\text { Section }\end{array}$ & $\begin{array}{l}\text { Vaginal } \\
\text { Delivery }\end{array}$ & PTCA & Colonoscopy & MRI \\
\hline Dependent Variable: & \multicolumn{9}{|c|}{$\ln ($ Facilities Price + Physician Price $)$} \\
\hline Market Characteristics & & & & & & & & & \\
\hline Monopoly & $\begin{array}{c}0.093 * * * \\
(0.019)\end{array}$ & $\begin{array}{c}0.110 * * * \\
(0.022)\end{array}$ & $\begin{array}{c}0.026 \\
(0.089)\end{array}$ & $\begin{array}{c}0.120 * * \\
(0.048)\end{array}$ & $\begin{array}{c}0.084 * * \\
(0.038)\end{array}$ & $\begin{array}{c}0.053 * * \\
(0.027)\end{array}$ & $\begin{array}{c}0.135 \\
(0.091)\end{array}$ & $\begin{array}{c}0.077 * * \\
(0.037)\end{array}$ & $\begin{array}{c}0.189 * * * \\
(0.032)\end{array}$ \\
\hline Duopoly & $\begin{array}{c}0.058 * * * \\
(0.018)\end{array}$ & $\begin{array}{c}0.078 * * * \\
(0.016)\end{array}$ & $\begin{array}{c}0.004 \\
(0.061)\end{array}$ & $\begin{array}{c}0.012 \\
(0.038)\end{array}$ & $\begin{array}{c}0.053 * * \\
(0.022)\end{array}$ & $\begin{array}{c}0.044 * * * \\
(0.017)\end{array}$ & $\begin{array}{c}0.137 * * \\
(0.064)\end{array}$ & $\begin{array}{c}0.083 * * \\
(0.035)\end{array}$ & $\begin{array}{c}0.125 * * * \\
(0.028)\end{array}$ \\
\hline Triopoly & $\begin{array}{c}0.028 \\
(0.018)\end{array}$ & $\begin{array}{c}0.046 * * * \\
(0.017)\end{array}$ & $\begin{array}{c}0.070 \\
(0.071)\end{array}$ & $\begin{array}{l}-0.006 \\
(0.039)\end{array}$ & $\begin{array}{c}0.026 \\
(0.027)\end{array}$ & $\begin{array}{c}0.002 \\
(0.021)\end{array}$ & $\begin{array}{c}0.071 \\
(0.047)\end{array}$ & $\begin{array}{c}0.043 \\
(0.034)\end{array}$ & $\begin{array}{c}0.115 * * * \\
(0.031)\end{array}$ \\
\hline HCCI Market Share & $\begin{array}{c}-0.006 * * * \\
(0.001)\end{array}$ & $\begin{array}{c}-0.003 * * \\
(0.001)\end{array}$ & $\begin{array}{c}0.000 \\
(0.003)\end{array}$ & $\begin{array}{c}-0.003 \\
(0.003)\end{array}$ & $\begin{array}{l}-0.000 \\
(0.002)\end{array}$ & $\begin{array}{l}-0.002 \\
(0.001)\end{array}$ & $\begin{array}{c}-0.002 \\
(0.003)\end{array}$ & $\begin{array}{l}-0.003 \\
(0.002)\end{array}$ & $\begin{array}{c}-0.004 * \\
(0.002)\end{array}$ \\
\hline \multicolumn{10}{|l|}{ Hospital Characteristics } \\
\hline $\ln ($ Technologies $)$ & $\begin{array}{c}0.008 * * \\
(0.003)\end{array}$ & $\begin{array}{c}0.006 * * \\
(0.003)\end{array}$ & $\begin{array}{l}-0.003 \\
(0.008)\end{array}$ & $\begin{array}{c}-0.004 \\
(0.006)\end{array}$ & $\begin{array}{c}0.004 \\
(0.004)\end{array}$ & $\begin{array}{c}0.001 \\
(0.003)\end{array}$ & $\begin{array}{c}0.014 * \\
(0.008)\end{array}$ & $\begin{array}{c}0.013 * * \\
(0.006)\end{array}$ & $\begin{array}{c}0.009 \\
(0.007)\end{array}$ \\
\hline Ranked in US News & $0.107 * * *$ & $0.063 * * *$ & 0.032 & $0.073 * *$ & $0.072 * * *$ & $0.067 * * *$ & 0.052 & $0.081 * *$ & 0.053 \\
\hline \& World Reports & $(0.027)$ & $(0.021)$ & $(0.033)$ & $(0.031)$ & $(0.022)$ & $(0.020)$ & $(0.040)$ & $(0.032)$ & $(0.034)$ \\
\hline $\ln ($ Beds $)$ & $\begin{array}{c}0.052 * * * \\
(0.008)\end{array}$ & $\begin{array}{c}0.010 \\
(0.006)\end{array}$ & $\begin{array}{l}-0.005 \\
(0.025)\end{array}$ & $\begin{array}{c}-0.002 \\
(0.017)\end{array}$ & $\begin{array}{c}0.024 * * \\
(0.010)\end{array}$ & $\begin{array}{c}0.025^{*} * * \\
(0.007)\end{array}$ & $\begin{array}{c}0.079 * * * \\
(0.028)\end{array}$ & $\begin{array}{l}-0.021 \\
(0.014)\end{array}$ & $\begin{array}{c}0.006 \\
(0.012)\end{array}$ \\
\hline Teaching & $\begin{array}{c}0.017 \\
(0.011)\end{array}$ & $\begin{array}{c}0.006 \\
(0.010)\end{array}$ & $\begin{array}{c}0.030 \\
(0.027)\end{array}$ & $\begin{array}{c}0.010 \\
(0.019)\end{array}$ & $\begin{array}{c}0.010 \\
(0.012)\end{array}$ & $\begin{array}{c}0.008 \\
(0.013)\end{array}$ & $\begin{array}{c}-0.036 \\
(0.029)\end{array}$ & $\begin{array}{c}0.019 \\
(0.025)\end{array}$ & $\begin{array}{l}-0.001 \\
(0.017)\end{array}$ \\
\hline Government & $\begin{array}{c}-0.113 * * * \\
(0.023)\end{array}$ & $\begin{array}{c}-0.049 * \\
(0.026)\end{array}$ & $\begin{array}{l}-0.107 \\
(0.072)\end{array}$ & $\begin{array}{c}-0.086 \\
(0.056)\end{array}$ & $\begin{array}{c}-0.069 * * \\
(0.031)\end{array}$ & $\begin{array}{c}-0.077 * * * \\
(0.027)\end{array}$ & $\begin{array}{c}-0.177 * * * \\
(0.061)\end{array}$ & $\begin{array}{c}-0.141 * * * \\
(0.041)\end{array}$ & $\begin{array}{c}0.059 \\
(0.049)\end{array}$ \\
\hline Non-Profit & $\begin{array}{c}-0.058 * * * \\
(0.018)\end{array}$ & $\begin{array}{l}-0.009 \\
(0.016)\end{array}$ & $\begin{array}{l}-0.006 \\
(0.037)\end{array}$ & $\begin{array}{c}0.022 \\
(0.036)\end{array}$ & $\begin{array}{l}-0.001 \\
(0.018)\end{array}$ & $\begin{array}{c}0.004 \\
(0.016)\end{array}$ & $\begin{array}{c}-0.078 \\
(0.048)\end{array}$ & $\begin{array}{c}-0.104 * * * \\
(0.026)\end{array}$ & $\begin{array}{c}0.046 \\
(0.044)\end{array}$ \\
\hline \multicolumn{10}{|l|}{ County Characteristics } \\
\hline Percent Uninsured & $\begin{array}{l}-0.002 \\
(0.002)\end{array}$ & $\begin{array}{l}-0.003 \\
(0.002)\end{array}$ & $\begin{array}{l}-0.011^{*} \\
(0.006)\end{array}$ & $\begin{array}{l}-0.003 \\
(0.006)\end{array}$ & $\begin{array}{c}-0.009 * * * \\
(0.004)\end{array}$ & $\begin{array}{l}-0.006 * \\
(0.003)\end{array}$ & $\begin{array}{l}-0.004 \\
(0.008)\end{array}$ & $\begin{array}{c}0.000 \\
(0.005)\end{array}$ & $\begin{array}{l}-0.002 \\
(0.005)\end{array}$ \\
\hline $\ln ($ Median Income) & $\begin{array}{c}0.039 \\
(0.044)\end{array}$ & $\begin{array}{c}-0.067 \\
(0.045)\end{array}$ & $\begin{array}{c}-0.315 * * * \\
(0.094)\end{array}$ & $\begin{array}{l}-0.097 \\
(0.106)\end{array}$ & $\begin{array}{c}-0.171 * * * \\
(0.065)\end{array}$ & $\begin{array}{l}-0.051 \\
(0.056)\end{array}$ & $\begin{array}{c}-0.179 \\
(0.160)\end{array}$ & $\begin{array}{c}0.080 \\
(0.096)\end{array}$ & $\begin{array}{l}-0.033 \\
(0.097)\end{array}$ \\
\hline \multicolumn{10}{|l|}{ Other Payers } \\
\hline $\ln ($ Medicare Base & 0.088 & -0.043 & 0.185 & 0.143 & -0.089 & -0.043 & -0.075 & -0.038 & 0.003 \\
\hline Payment Rate) & $(0.063)$ & $(0.051)$ & $(0.136)$ & $(0.108)$ & $(0.075)$ & $(0.070)$ & $(0.125)$ & $(0.104)$ & $(0.105)$ \\
\hline $\ln ($ Share Medicare) & $-0.002 * * *$ & -0.001 & -0.001 & -0.002 & $-0.003 * * *$ & $-0.002 * * *$ & -0.001 & 0.000 & 0.000 \\
\hline
\end{tabular}




\begin{tabular}{|c|c|c|c|c|c|c|c|c|c|}
\hline & $(0.001)$ & $(0.000)$ & $(0.001)$ & $(0.001)$ & $(0.001)$ & $(0.001)$ & $(0.001)$ & $(0.001)$ & $(0.001)$ \\
\hline $\ln ($ Share Medicaid) & $-0.002 * * *$ & $-0.002 * * *$ & $-0.004 * *$ & $-0.003 * * *$ & $-0.002 * * *$ & $-0.002 * * *$ & 0.001 & -0.002 & -0.001 \\
\hline & $(0.001)$ & $(0.001)$ & $(0.002)$ & $(0.001)$ & $(0.001)$ & $(0.001)$ & $(0.002)$ & $(0.001)$ & $(0.001)$ \\
\hline Yearly-FE & Yes & Yes & Yes & Yes & Yes & Yes & Yes & Yes & Yes \\
\hline HRR-FE & Yes & Yes & Yes & Yes & Yes & Yes & Yes & Yes & Yes \\
\hline R-Squared & 0.456 & 0.955 & 0.627 & 0.548 & 0.613 & 0.614 & 0.582 & 0.513 & 0.398 \\
\hline Observations & 8,772 & 22,167 & 1,259 & 2,660 & 3,794 & 4,096 & 1,764 & 3,512 & 5,082 \\
\hline
\end{tabular}

Notes: $* \mathrm{p}<0.10, * * \mathrm{p}<0.05, * * * \mathrm{p}<0.01$. OLS estimates of Equation (2) with standard errors clustered at the HRR-level in parentheses. We rely on data from 2008 2011. Procedure prices are regression-adjusted transaction prices where we risk-adjust for age and sex (plus DRGs for the inpatient index). All regressions include yearly fixed effects. The omitted ownership category is private hospitals. MRIs include only lower limb scans. 


\section{Appendix Table 12: Inpatient Cross-Sectional Price Results Using Different Measures of Hospital Market Concentration}

\begin{tabular}{|c|c|c|c|c|c|c|c|}
\hline \multirow[b]{3}{*}{ Market Characteristics } & $(1)$ & $(2)$ & (3) & $(4)$ & $(5)$ & $(6)$ & $(7)$ \\
\hline & \multicolumn{7}{|c|}{ Dependent Variable: $\ln ($ Facilities Price) } \\
\hline & & & & & & & \\
\hline $\ln (\mathrm{HHI})$ & $\begin{array}{c}0.053 * * * \\
(0.015)\end{array}$ & $\begin{array}{c}0.076^{* * *} \\
(0.014)\end{array}$ & $\begin{array}{c}0.100 * * * \\
(0.021)\end{array}$ & $\begin{array}{c}0.047 * * * \\
(0.014)\end{array}$ & & & \\
\hline Hospital Count & & & & & $\begin{array}{c}-0.005 * * * \\
(0.001)\end{array}$ & & \\
\hline Q4 HHI & & & & & & $\begin{array}{c}0.117 * * * \\
(0.026)\end{array}$ & $\begin{array}{c}0.077 * * * \\
(0.014)\end{array}$ \\
\hline Q3 HHI & & & & & & $\begin{array}{c}0.055^{* *} \\
(0.027)\end{array}$ & \\
\hline Q2 HHI & & & & & & $\begin{array}{c}0.023 \\
(0.020)\end{array}$ & \\
\hline Market Radius & 5 Miles & 15 Miles & 30 Miles & Variable & 15 Miles & 15 Miles & 15 Miles \\
\hline HCCI Market Share & $\begin{array}{c}-0.009 * * * \\
(0.002)\end{array}$ & $\begin{array}{c}-0.008 * * * \\
(0.002)\end{array}$ & $\begin{array}{c}-0.008 * * * \\
(0.001)\end{array}$ & $\begin{array}{c}-0.009 * * * \\
(0.002)\end{array}$ & $\begin{array}{c}-0.009 * * * \\
(0.002)\end{array}$ & $\begin{array}{c}-0.008 * * * \\
(0.002)\end{array}$ & $\begin{array}{c}-0.008 * * * \\
(0.002)\end{array}$ \\
\hline Observations & 8,772 & 8,772 & 8,772 & 8,772 & 8,772 & 8,772 & 8,772 \\
\hline
\end{tabular}

Notes: $* \mathrm{p}<0.10, * * \mathrm{p}<0.05, * * * \mathrm{p}<0.01$. OLS estimates with standard errors clustered at the HRR-level in parentheses. 8,772 observations. The dependent variable is our regression-based inpatient price index that is risk-adjusted for DRG, age and sex. All regressions have the same set of controls in the notes to Table 6 Panel A Column (3). We use multiple measures of hospital market concentration. Column (1) includes hospital HHIs where the market is defined using a five-mile fixed radius drawn around each hospital. Column (2) includes hospital HHIs where the market is defined using a fifteen-mile fixed radius drawn around each hospital. Column (3) includes hospital HHIs where the market is defined using a thirty-mile fixed radius drawn around each hospital. In Column (4), we measure hospital HHIs in variable radii markets. Hospitals located in 'large urban' areas are assigned a market defined by a 10-mile radius; hospitals located in 'urban' have a market defined around them using a 15-mile radius; and hospitals located in 'rural' areas have a market defined around them using a 20-mile radius. In Column (5), we measure market concentration using counts of hospitals within a fifteen-mile radius drawn around each hospital. In Column (6), we use dummy variables to capture the quartiles of our hospital HHIs measured within hospital markets defined using fixed radii extending fifteen-miles around each hospital. The omitted category, quartile 1, is the least concentrated quartile. In Column (7), we measure the effect of being in the most concentrated quartile of hospital HHI within a market defined by a fifteen-mile fixed radius market drawn around each hospital. The reference categories are the other three quartiles of hospital HHI. Facilities prices are regression-adjusted transaction prices. All regressions include yearly fixed effects and controls for number of beds, teaching status, government ownership, non-profit status, county insurance rate and median income, Medicare payment rate, and share of hospital activity covered by Medicare and Medicaid. The omitted ownership category is private hospitals. 


\section{Appendix Table 13: Determinants of Share of Cases Paid Percentage of Hospital Charges, Alternative Concentration}

Measures

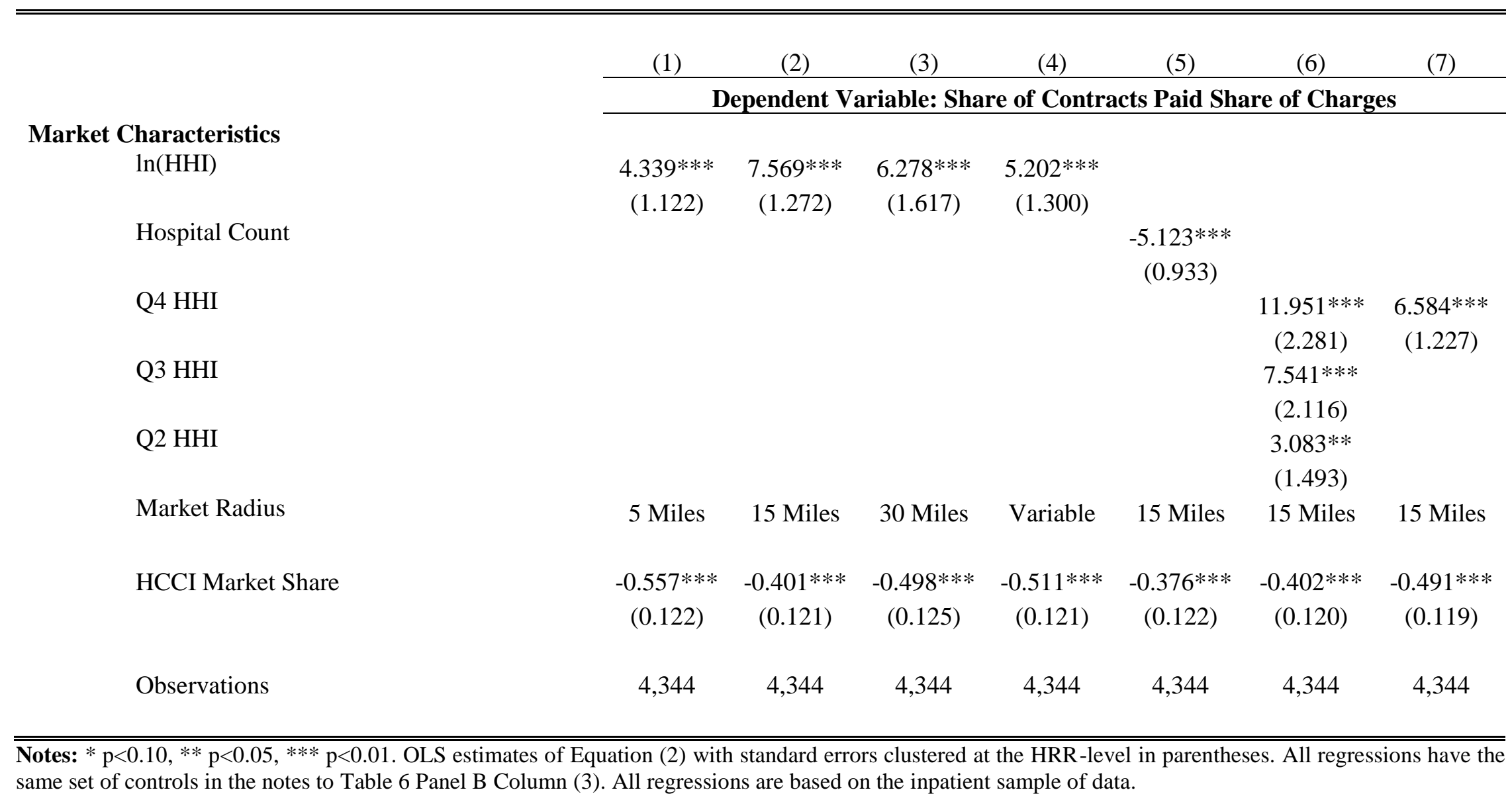


Appendix Table 14: Determinates of the Linkage between Private and Medicare Payments Estimated with Alternative Measures of Concentration, 2010-2011

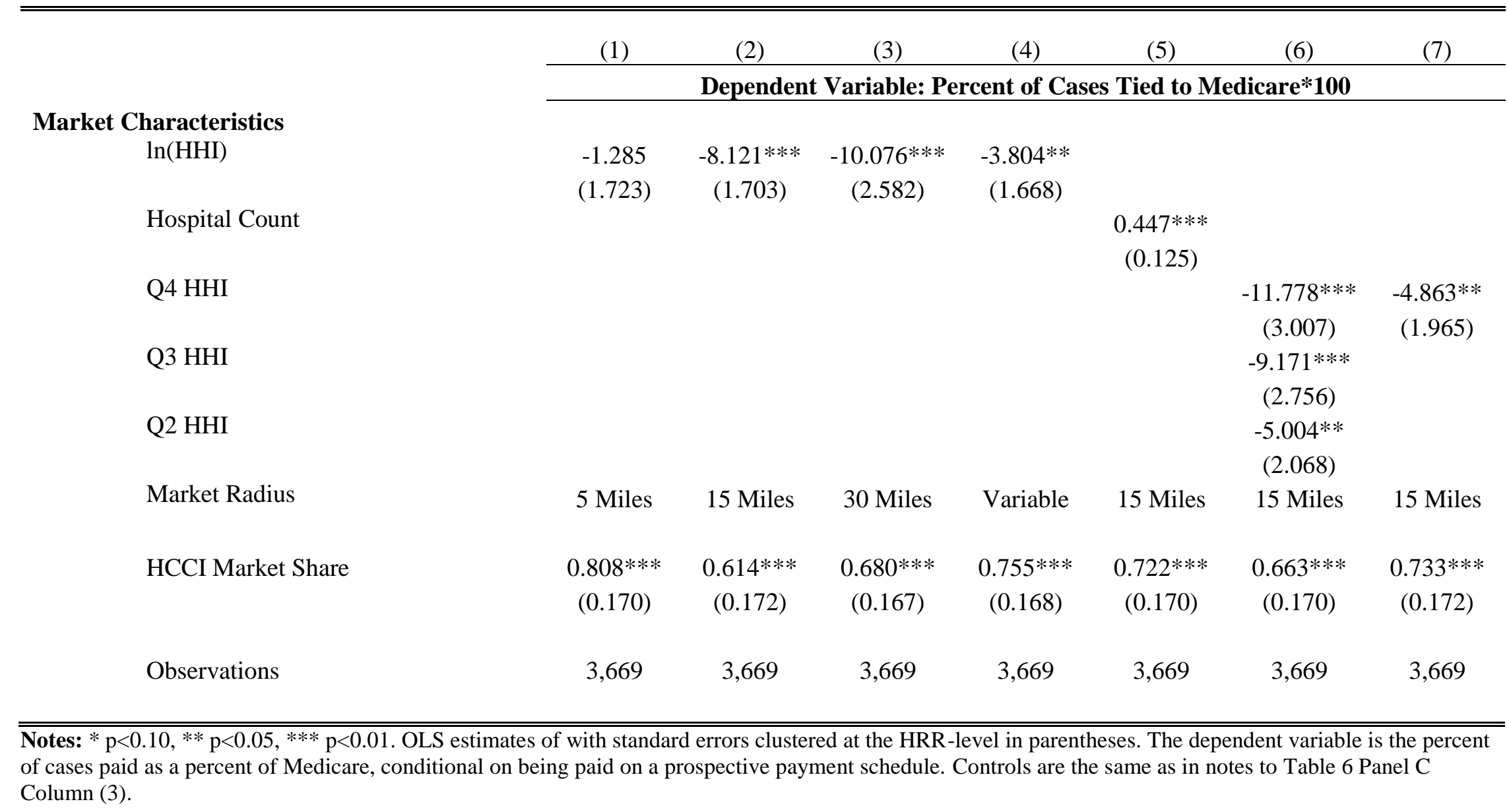




\section{Appendix Table 15: Inpatient Cross-Sectional Price Results with Multiple Measures of Quality}

\section{Dependent Variable:}

A standard deviation increase in quality by:

$\%$ AMI pats. given aspirin at arrival

$\%$ of surgery pats. given antibiotic 1 hour before surgery

$\%$ of surgery pats. given treatment to prevent blood clots within 24 hours

30-day death rate for heart attack patients

Full set of 41 quality controls?

\section{Other Characteristics}

Monopoly

Duopoly

Triopoly

Share HCCI

\begin{tabular}{|c|c|c|c|c|c|c|}
\hline$(1)$ & (2) & (3) & (4) & $(5)$ & (6) & (7) \\
\hline \multicolumn{7}{|c|}{$\ln ($ Facilities Price $)$} \\
\hline No & $\begin{array}{c}0.022 * * \\
(0.009)\end{array}$ & $\begin{array}{c}0.010 \\
(0.009)\end{array}$ & $\begin{array}{c}0.025^{* * * *} \\
(0.007)\end{array}$ & $\begin{array}{c}0.005^{*} \\
(0.003) \\
\text { No }\end{array}$ & $\begin{array}{c}0.018 * * \\
(0.009) \\
-0.002 \\
(0.009) \\
0.023 * * * \\
(0.007) \\
0.005 \\
(0.003) \\
\text { No }\end{array}$ & Yes \\
\hline $\begin{array}{c}0.118 * * * \\
(0.024)\end{array}$ & $\begin{array}{c}0.119 * * * \\
(0.024)\end{array}$ & $\begin{array}{c}0.117 * * * \\
(0.024)\end{array}$ & $\begin{array}{c}0.118 * * * \\
(0.024)\end{array}$ & $\begin{array}{c}0.117 * * * \\
(0.024)\end{array}$ & $\begin{array}{c}0.119 * * * \\
(0.024)\end{array}$ & $\begin{array}{c}0.117 * * * \\
(0.024)\end{array}$ \\
\hline $0.073 * * *$ & $0.073 * * *$ & $0.072 * * *$ & $0.072 * * *$ & $0.073 * * *$ & $0.072 * * *$ & $0.071 * * *$ \\
\hline 0.036 & 0.036 & 0.036 & 0.037 & 0.035 & 0.036 & 0.034 \\
\hline $\begin{array}{c}(0.023) \\
-0.007 * * * \\
(0.002)\end{array}$ & $\begin{array}{c}(0.023) \\
-0.007 * * * \\
(0.002)\end{array}$ & $\begin{array}{c}(0.023) \\
-0.007 * * * \\
(0.002)\end{array}$ & $\begin{array}{c}(0.023) \\
-0.007 * * * \\
(0.002)\end{array}$ & $\begin{array}{c}(0.023) \\
-0.007 * * * \\
(0.002)\end{array}$ & $\begin{array}{c}(0.023) \\
-0.007 * * * \\
(0.002)\end{array}$ & $\begin{array}{c}(0.023) \\
-0.007 * * * \\
(0.002)\end{array}$ \\
\hline 8,772 & 8,772 & 8,772 & 8,772 & 8,772 & 8,772 & 8,772 \\
\hline
\end{tabular}

Observations

772

8,772

8,772

8,772

772

8,772

Notes: $* \mathrm{p}<0.10, * * \mathrm{p}<0.05, * * * \mathrm{p}<0.01$ OLS estimates of Table 6 with the addition of alternative quality measures. The dependent variable is our regressionbased inpatient price index that is risk-adjusted for DRG, age, and sex. Standard errors are clustered at the HRR-level and are in parentheses. Facilities prices are regression adjusted transaction prices for 2008-2011. All regressions include HRR and year fixed effects. All regressions also include same controls as Column (3) Table 6 Panel A. 


\section{Appendix Table 16: Cross-Sectional Relationships and Robustness to Sample Restrictions}

(1)

(2)

\begin{tabular}{cc}
\multicolumn{2}{c}{$\ln$ (Price) } \\
\hline & Excluding \\
Excluding & Hospitals in \\
Monopoly & Markets with \\
Hospitals & $\geq 6$ Hospitals \\
\hline
\end{tabular}

\section{Market Characteristics}

Monopoly

Duopoly

Triopoly

HCCI Market Share
$0.096 * * *$

$(0.024)$

$\begin{array}{cc}0.068 * * * & 0.071 * * * \\ (0.025) & (0.024)\end{array}$

0.031

0.035

(0.023)

$-0.007 * * *$

(0.002)

7,339

(0.023)

$-0.006 * * *$

(0.002)

5,727
(3)

(4)

(5)

(6)

Percent Paid Share of

\begin{tabular}{cc}
\multicolumn{2}{c}{ Charges } \\
\hline & Excluding \\
Excluding & Hospitals in \\
Monopoly & Markets with \\
Hospitals & $\geq 6$ Hospitals \\
\hline
\end{tabular}

$6.863 * * *$

$$
\text { (1.748) }
$$

$5.781 * * * \quad 3.385 *$

(1.638) (1.553)

$5.129 * *$

2.984

(1.567)

(1.671)

$-0.274^{*}$

$-0.475 * * *$

(0.125)

(0.136)

3,640

2,838

\begin{tabular}{cc} 
Percent Linked to Medicare \\
\hline & Excluding \\
Excluding & Hospitals in \\
Monopoly & Markets with \\
Hospitals & $\geq 6$ Hospitals \\
\hline
\end{tabular}

$-10.955 * * *$

(3.413)

$-3.530$

(2.589)

$-4.887$

(3.119)

(2.868)

$0.601 * * *$

$0.523 * * *$

(0.204)

(0.193)

Observations

Notes: $* \mathrm{p}<0.10, * * \mathrm{p}<0.05, * * * \mathrm{p}<0.01$. "Excluding monopolies" drops all monopoly hospitals and "Excluding Hospitals in Markets with $\geq 6$ Hospitals" drops all hospitals in markets with 6 or more hospitals. OLS estimates of Table 6 Panel A Column (3) with different sample restrictions. The dependent variable in Columns (1) and (2) is the log of our regression-based inpatient price index that is risk-adjusted for DRG, age, and sex. The dependent variable in Columns (3) and (4) is the share of cases paid as a percentage of hospital charges. The dependent variable in Columns (5) and (6) is the percent of prospective cases with prices set as a percentage of Medicare payments. Standard errors are clustered at the HRR-level and are in parentheses. Facilities prices are regression adjusted transaction prices for 2008-2011. All regressions include HRR and yearly fixed effects. All regressions also include insurance market controls, controls for beds, teaching status, government ownership, non-profit status, percent county uninsured and median income, Medicare payment rates, and share of hospitals' admits covered by Medicare and Medicaid. 


\section{Appendix Table 17: Inpatient Cross-Sectional Price Results with Alternative Sample Restrictions}

\begin{tabular}{|c|c|c|c|c|c|c|c|c|c|c|}
\hline & $(1)$ & (2) & (3) & (4) & (5) & (6) & (7) & $(8)$ & (9) & $(10)$ \\
\hline $\begin{array}{l}\text { Dependent } \\
\text { Variable }\end{array}$ & \multicolumn{10}{|c|}{$\ln$ (Price) } \\
\hline Monopoly & $\begin{array}{c}0.107 * * * \\
(0.024)\end{array}$ & $\begin{array}{c}0.109 * * * \\
(0.024)\end{array}$ & $\begin{array}{c}0.115 * * * \\
(0.024)\end{array}$ & $\begin{array}{c}0.115 * * * \\
(0.024)\end{array}$ & $\begin{array}{c}0.118^{* * *} \\
(0.024)\end{array}$ & $\begin{array}{c}0.119 * * * \\
(0.024)\end{array}$ & $\begin{array}{c}0.120 * * * \\
(0.025)\end{array}$ & $\begin{array}{c}0.123 * * * \\
(0.027)\end{array}$ & $\begin{array}{c}0.122 * * * \\
(0.028)\end{array}$ & $\begin{array}{c}0.127 * * * \\
(0.029)\end{array}$ \\
\hline Duopoly & $\begin{array}{c}0.069 * * * \\
(0.024)\end{array}$ & $\begin{array}{c}0.073 * * * \\
(0.024)\end{array}$ & $\begin{array}{c}0.076 * * * \\
(0.024)\end{array}$ & $\begin{array}{c}0.075^{* * *} \\
(0.024)\end{array}$ & $\begin{array}{c}0.073 * * * \\
(0.024)\end{array}$ & $\begin{array}{c}0.068 * * * \\
(0.023)\end{array}$ & $\begin{array}{c}0.068 * * * \\
(0.023)\end{array}$ & $\begin{array}{c}0.074 * * * \\
(0.023)\end{array}$ & $\begin{array}{c}0.074 * * * \\
(0.023)\end{array}$ & $\begin{array}{c}0.075^{* * * *} \\
(0.023)\end{array}$ \\
\hline Triopoly & $\begin{array}{c}0.029 \\
(0.023)\end{array}$ & $\begin{array}{c}0.027 \\
(0.024)\end{array}$ & $\begin{array}{c}0.033 \\
(0.024)\end{array}$ & $\begin{array}{c}0.036 \\
(0.023)\end{array}$ & $\begin{array}{c}0.036 \\
(0.023)\end{array}$ & $\begin{array}{l}0.037 * \\
(0.022)\end{array}$ & $\begin{array}{l}0.040 * \\
(0.023)\end{array}$ & $\begin{array}{l}0.041 * \\
(0.023)\end{array}$ & $\begin{array}{l}0.041^{*} \\
(0.022)\end{array}$ & $\begin{array}{l}0.042 * \\
(0.022)\end{array}$ \\
\hline $\begin{array}{l}\text { HCCI Market } \\
\text { Share }\end{array}$ & $\begin{array}{c}-0.007 * * * \\
(0.001)\end{array}$ & $\begin{array}{c}-0.007 * * * \\
(0.001)\end{array}$ & $\begin{array}{c}-0.007 * * * \\
(0.001)\end{array}$ & $\begin{array}{c}-0.007 * * * \\
(0.002)\end{array}$ & $\begin{array}{c}-0.007 * * * \\
(0.002)\end{array}$ & $\begin{array}{c}-0.008 * * * \\
(0.002)\end{array}$ & $\begin{array}{c}-0.008 * * * \\
(0.002)\end{array}$ & $\begin{array}{c}-0.008 * * * \\
(0.002)\end{array}$ & $\begin{array}{c}-0.007 * * * \\
(0.002)\end{array}$ & $\begin{array}{c}-0.007 * * * \\
(0.002)\end{array}$ \\
\hline $\begin{array}{l}\text { Minimum } \\
\text { Inpatient Case } \\
\text { Count }\end{array}$ & 10 & 20 & 30 & 40 & 50 & 60 & 70 & 80 & 90 & 100 \\
\hline $\begin{array}{l}\text { Number of } \\
\text { Hospitals } \\
\text { Observations }\end{array}$ & $\begin{array}{c}3,013 \\
11,374\end{array}$ & $\begin{array}{c}2,793 \\
10,488\end{array}$ & $\begin{array}{l}2,622 \\
9,789\end{array}$ & $\begin{array}{l}2,497 \\
9,269\end{array}$ & $\begin{array}{l}2,358 \\
8,772\end{array}$ & $\begin{array}{l}2,270 \\
8,380\end{array}$ & $\begin{array}{l}2,176 \\
8,000\end{array}$ & $\begin{array}{l}2,089 \\
7,689\end{array}$ & $\begin{array}{l}2,013 \\
7,389\end{array}$ & $\begin{array}{l}1,945 \\
7,133\end{array}$ \\
\hline
\end{tabular}


$\underline{\text { Appendix Table 18: Transactions and Targets by Distance }}$

\begin{tabular}{|c|c|c|c|c|c|c|c|c|}
\hline Distance: & & 5 Miles & 10 Miles & 15 Miles & 20 Miles & 30 Miles & 50 Miles & All \\
\hline \multirow[t]{3}{*}{2007} & Transactions & 6 & 14 & 18 & 25 & 31 & 37 & 69 \\
\hline & Target Hospitals & 7 & 17 & 21 & 29 & 38 & 51 & 119 \\
\hline & Acquirer Hospitals & 7 & 20 & 25 & 39 & 64 & 92 & 493 \\
\hline \multirow[t]{3}{*}{2008} & Transactions & 9 & 15 & 23 & 28 & 39 & 46 & 69 \\
\hline & Target Hospitals & 11 & 19 & 28 & 33 & 45 & 54 & 86 \\
\hline & Acquirer Hospitals & 13 & 30 & 43 & 58 & 89 & 136 & 693 \\
\hline \multirow[t]{3}{*}{2009} & Transactions & 9 & 15 & 17 & 21 & 32 & 44 & 70 \\
\hline & Target Hospitals & 9 & 15 & 17 & 22 & 33 & 48 & 85 \\
\hline & Acquirer Hospitals & 5 & 12 & 19 & 30 & 60 & 113 & 578 \\
\hline \multirow[t]{3}{*}{2010} & Transactions & 6 & 13 & 17 & 24 & 39 & 50 & 76 \\
\hline & Target Hospitals & 7 & 15 & 19 & 27 & 42 & 59 & 90 \\
\hline & Acquirer Hospitals & 7 & 19 & 33 & 45 & 68 & 120 & 753 \\
\hline \multirow[t]{3}{*}{2011} & Transactions & 11 & 21 & 32 & 38 & 49 & 64 & 82 \\
\hline & Target Hospitals & 11 & 21 & 33 & 40 & 55 & 75 & 106 \\
\hline & Acquirer Hospitals & 7 & 17 & 33 & 46 & 67 & 114 & 753 \\
\hline \multirow[t]{3}{*}{ All } & Transactions & 42 & 77 & 108 & 138 & 189 & 243 & 366 \\
\hline & Target Hospitals & 45 & 87 & 118 & 151 & 212 & 285 & 464 \\
\hline & Acquirer Hospitals & 39 & 97 & 146 & 204 & 320 & 494 & 1563 \\
\hline
\end{tabular}

Notes: This is based on data from the AHA, Irving-Levin Associates, Factset, and SDC Platinum databases. Data on hospital beds came from the AHA annual survey. 


\section{Appendix Table 19: Characteristics of Merging/Non-Merging Hospitals}

\begin{tabular}{|c|c|c|c|c|}
\hline & (1) & (2) & (3) & (4) \\
\hline Sample: & \multicolumn{4}{|c|}{ Any 5 Mile Merger } \\
\hline Column contents: & Treated & Controls & Treated & Controls \\
\hline Covariates: & Static & Static & Differenced & Differenced \\
\hline Price & 10880.8 & $13066.2 * * *$ & 656.4 & 663.5 \\
\hline $\ln ($ Price $)$ & 9.2 & $9.4 * *$ & 0.056 & 0.052 \\
\hline \multicolumn{5}{|l|}{ Market Structure } \\
\hline Monopoly & 0.0 & $48.6^{* * *}$ & 0.000 & $-0.050 *$ \\
\hline Duopoly & 40.3 & $25.0 *$ & 0.000 & 0.076 \\
\hline Triopoly & 23.4 & $9.9 *$ & 0.000 & 0.000 \\
\hline Hospital HHI & 0.419 & $0.719 * * *$ & -0.023 & -0.191 \\
\hline Insurer Market Share & 13.6 & $17.8 * * *$ & -0.001 & $<0.001$ \\
\hline \multicolumn{5}{|l|}{ Hospital Characteristics } \\
\hline Technologies & 64.5 & 59.6 & 3.4 & 1.5 \\
\hline Ranked in US News & 1.3 & $5.4 * * *$ & -1.4 & -0.5 \\
\hline Beds & 275.5 & 271.3 & -0.3 & 0.8 \\
\hline Teaching & 53.2 & $38.1 *$ & 0.0 & $0.4 * *$ \\
\hline Government & 14.3 & 12.2 & 0.0 & -0.2 \\
\hline Non-Profit & 70.1 & 69.7 & 0.0 & -0.1 \\
\hline \multicolumn{5}{|l|}{ Local Area Characteristics } \\
\hline Percent Uninsured & 14.8 & $17.1 * *$ & 0.3 & 0.2 \\
\hline Median Income & 50841.7 & 51537.3 & -757.1 & -533.2 \\
\hline \multicolumn{5}{|l|}{ Other Payers } \\
\hline PPS Payment Rate & 6547.4 & 6439.1 & 155.7 & 91.8 \\
\hline Medicare Share & 47.1 & 44.5 & -0.4 & $0.6^{*}$ \\
\hline Medicaid Share & 18.3 & 18.8 & 1.0 & 0.4 \\
\hline Observations & 77 & 8,415 & 70 & 7,944 \\
\hline Number of Hospitals & 37 & 2,241 & 35 & 2,153 \\
\hline
\end{tabular}

Notes: These are descriptive statistics for the inpatient sample used in estimating post-merger price differences. This table uses pre-merger data for each hospital. There are 8,492 hospital-year observations representing 2,278 unique hospitals. Hospital prices are hospital prices that are risk-adjusted for DRG, age, and sex. The static columns - (1) and (2) - display the average value of each covariate during our sample period across hospital years pre-merger. The differenced columns - (3) and (4) - capture the average first difference of each covariate pre-merger. 
Distance (miles):

Panel A: Baseline

Post-Merger

Observations

Panel B: Treatment Counts Estimated Log-Linearly Post-Merger

Observations

Panel C: Matching (Within State Mahalanobis Distance) Post-Merger

Observations

Panel D: Matched using Mahalanobis Distance

Post-Merger

Observations

Panel E: Matching (Dranove/Lindrooth Model)

Post-Merger

Observations

Panel F: Matched using K-Nearest Neighbor Method Post-Merger

\begin{tabular}{ccccccc}
$(1)$ & $(2)$ & $(3)$ & $(4)$ & $(5)$ & $(6)$ & $(7)$ \\
\hline \multicolumn{7}{c}{$\ln ($ price $)$} \\
5 & 10 & 15 & 20 & 25 & 30 & 50 \\
& & & & & & \\
& & & & & & \\
$0.060^{* *}$ & $0.039 * *$ & 0.021 & $0.023 *$ & $0.024 * *$ & 0.014 & 0.008 \\
$(0.025)$ & $(0.019)$ & $(0.013)$ & $(0.013)$ & $(0.011)$ & $(0.011)$ & $(0.009)$ \\
8655 & 8655 & 8655 & 8655 & 8655 & 8655 & 8655 \\
& & & & & & \\
$0.062 * *$ & $0.040^{* *}$ & 0.021 & $0.024 *$ & $0.024 * *$ & 0.014 & 0.008 \\
$(0.025)$ & $(0.019)$ & $(0.013)$ & $(0.013)$ & $(0.011)$ & $(0.010)$ & $(0.009)$ \\
8655 & 8655 & 8655 & 8655 & 8655 & 8655 & 8655 \\
& & & & & & \\
$0.100^{* * *}$ & 0.024 & 0.009 & 0.011 & 0.009 & 0.003 & -0.001 \\
$(0.028)$ & $(0.023)$ & $(0.016)$ & $(0.014)$ & $(0.012)$ & $(0.011)$ & $(0.009)$ \\
1286 & 2295 & 2993 & 3417 & 3954 & 4215 & 5120 \\
& & & & & & \\
$0.070^{* * *}$ & 0.023 & 0.007 & 0.014 & 0.014 & 0.004 & -0.000 \\
$(0.026)$ & $(0.021)$ & $(0.015)$ & $(0.013)$ & $(0.012)$ & $(0.011)$ & $(0.009)$ \\
1921 & 3124 & 4058 & 4745 & 5216 & 5509 & 6265 \\
& & & & & & \\
$0.075 * * *$ & 0.032 & 0.013 & 0.017 & 0.016 & 0.004 & 0.001 \\
$(0.026)$ & $(0.021)$ & $(0.015)$ & $(0.013)$ & $(0.011)$ & $(0.010)$ & $(0.009)$ \\
1918 & 3506 & 4522 & 5154 & 5636 & 5972 & 6786 \\
& & & & & & \\
$0.075 * * *$ & 0.024 & 0.010 & 0.016 & 0.018 & 0.006 & 0.001 \\
$(0.026)$ & $(0.021)$ & $(0.014)$ & $(0.013)$ & $(0.011)$ & $(0.011)$ & $(0.009)$ \\
& & & & & &
\end{tabular}


Observations

$\begin{array}{ccccccc}1912 & 3311 & 4239 & 4827 & 5496 & 5700 & 6544 \\ & & & & & & \\ 0.060 * * & 0.040^{* *} & 0.023 * & 0.023 * & 0.025 * * & 0.013 & 0.007 \\ (0.025) & (0.018) & (0.013) & (0.012) & (0.011) & (0.010) & (0.009) \\ 9086 & 9086 & 9086 & 9086 & 9086 & 9086 & 9086 \\ 0.076^{* * *} & 0.044 * * & 0.028 * * & 0.027 * * & 0.029 * * & 0.021 * * & 0.014 \\ (0.024) & (0.018) & (0.013) & (0.012) & (0.011) & (0.011) & (0.009) \\ 11157 & 11157 & 11157 & 11157 & 11157 & 11157 & 11157 \\ & & & & & & \\ 0.080 * * & 0.055^{*} & 0.034 & 0.033 & 0.031 & 0.019 & 0.010 \\ (0.040) & (0.031) & (0.026) & (0.023) & (0.020) & (0.019) & (0.017) \\ 0.039 * & 0.025 & 0.012 & 0.018 & 0.020 * & 0.011 & 0.007 \\ (0.023) & (0.018) & (0.011) & (0.012) & (0.011) & (0.011) & (0.009) \\ 8655 & 8655 & 8655 & 8655 & 8655 & 8655 & 8655\end{array}$

Notes: ***significant at 1 percent level; $* * 5$ percent level; $* 10$ percent level. Coefficients estimated by OLS with standard errors in parentheses (clustered by hospital). All regressions include hospital fixed effects and time dummies. The dependent variable is the log of our risk-adjusted inpatient price measure. Controls: Insurer HHI, percent privately insured covered by the HCCI insurers, quality scores from News \& World Report, technology index, hospital size, whether the hospital is a teaching facility, government-owned facility, or a not-for-profit; country median income and percent uninsured; the Medicare base payment rate, the share of hospitals' discharges that are Medicare and Medicaid patients. Unless otherwise specified, post-merger equals 1 in the year a hospital merges and in all years afterwards and zero otherwise. We match hospitals based on the covariates in described in Appendix E. 


\section{Appendix Table 21: Correlation between Private and Medicare Spending Per Beneficiaries}

Overall

High BCBS Share

Low BCBS Share
Total

\begin{tabular}{rr}
\hline Total Inpatient \\
\hline
\end{tabular}

0.044

0.172

0.011

0.156

0.063

Notes: Each cell presents the correlation between spending per beneficiary for private and Medicare patients across HRRs in 2011. High and low BCBS share are defined by HRRs which are above or below the median BCBS market share across HRRs (47 percent). 


\section{Appendix Table 22: Price/Quantity Decomposition for Cases in High/Low BCBS Market Share, 2011}

\begin{tabular}{|c|c|c|c|c|c|c|}
\hline \multirow[b]{4}{*}{ Overall } & \multicolumn{3}{|c|}{ Private } & \multicolumn{3}{|c|}{ Medicare } \\
\hline & (1) & (2) & (3) & (4) & (5) & (6) \\
\hline & Share Price & Share Quantity & $\begin{array}{c}\text { Share } \\
\text { Covariance }\end{array}$ & Share Price & Share Quantity & $\begin{array}{c}\text { Share } \\
\text { Covariance }\end{array}$ \\
\hline & 0.496 & 0.495 & 0.009 & 0.127 & 0.953 & -0.081 \\
\hline Low BCBS & 0.541 & 0.495 & -0.036 & 0.107 & 0.975 & -0.081 \\
\hline High BCBS & 0.496 & 0.488 & 0.016 & 0.149 & 0.921 & -0.070 \\
\hline
\end{tabular}


Appendix Table 23: Price Decomposition for Cases in High/Low BCBS Market Share

Panel A: Price Decomposition for High BCBS Market Share

\begin{tabular}{|c|c|c|c|c|c|c|c|c|}
\hline & $(1)$ & $(2)$ & (3) & (4) & $(5)$ & $(6)$ & $(7)$ & $(8)$ \\
\hline & & & $\mathrm{R}^{2}$ & & & $\begin{array}{l}\text { Unexplained } \\
\text { within hospital- } \\
\text { month variance }\end{array}$ & Observations & $\begin{array}{l}\text { Within } \\
\text { hospital- } \\
\text { month } \\
\text { coefficient of } \\
\text { variation }\end{array}$ \\
\hline Hip Replacement & 0.014 & 0.034 & 0.461 & 0.713 & 0.743 & $25.7 \%$ & 3,573 & 0.164 \\
\hline Knee Replacement & 0.010 & 0.028 & 0.464 & 0.702 & 0.747 & $25.3 \%$ & 8,344 & 0.190 \\
\hline Cesarean Section & 0.013 & 0.052 & 0.487 & 0.757 & 0.792 & $20.8 \%$ & 14,367 & 0.165 \\
\hline Vaginal Delivery & 0.014 & 0.036 & 0.380 & 0.612 & 0.670 & $33.0 \%$ & 22,834 & 0.187 \\
\hline PTCA & 0.006 & 0.037 & 0.585 & 0.739 & 0.768 & $23.2 \%$ & 3,455 & 0.223 \\
\hline Colonoscopy & 0.013 & 0.018 & 0.404 & 0.794 & 0.856 & $14.4 \%$ & 13,170 & 0.145 \\
\hline Lower Limb MRI & 0.003 & 0.016 & 0.370 & 0.775 & 0.789 & $21.1 \%$ & 29,018 & 0.139 \\
\hline Mean & & & & & & $23.4 \%$ & & 0.173 \\
\hline Patient Characteristics & Yes & Yes & Yes & Yes & Yes & & & \\
\hline Plan Characteristics & No & Yes & Yes & Yes & Yes & & & \\
\hline Control for Charges & No & No & No & No & Yes & & & \\
\hline HRR Fixed Effects & No & No & Yes & - & - & & & \\
\hline Hospital Fixed Effects & No & No & No & Yes & Yes & & & \\
\hline
\end{tabular}




\begin{tabular}{|c|c|c|c|c|c|c|c|c|}
\hline & $(1)$ & $(2)$ & $(3)$ & $(4)$ & $(5)$ & $(6)$ & $(7)$ & $(8)$ \\
\hline & & & $\mathrm{R}^{2}$ & & & $\begin{array}{l}\text { Unexplained } \\
\text { within hospital- } \\
\text { month variance }\end{array}$ & Observations & $\begin{array}{l}\text { Within } \\
\text { hospital- } \\
\text { month } \\
\text { coefficient of } \\
\text { variation }\end{array}$ \\
\hline Hip Replacement & 0.006 & 0.016 & 0.518 & 0.773 & 0.782 & $21.8 \%$ & 11,549 & 0.177 \\
\hline Knee Replacement & 0.006 & 0.017 & 0.418 & 0.734 & 0.758 & $24.2 \%$ & 28,813 & 0.211 \\
\hline Cesarean Section & 0.011 & 0.024 & 0.433 & 0.717 & 0.745 & $25.5 \%$ & 67,113 & 0.171 \\
\hline Vaginal Delivery & 0.011 & 0.028 & 0.395 & 0.653 & 0.707 & $29.3 \%$ & 85,956 & 0.194 \\
\hline PTCA & 0.006 & 0.021 & 0.460 & 0.718 & 0.756 & $24.4 \%$ & 13,181 & 0.244 \\
\hline Colonoscopy & 0.010 & 0.028 & 0.435 & 0.752 & 0.813 & $18.7 \%$ & 52,847 & 0.171 \\
\hline Lower Limb MRI & 0.001 & 0.008 & 0.365 & 0.773 & 0.782 & $21.8 \%$ & 84,896 & 0.164 \\
\hline Mean & & & & & & $23.7 \%$ & & 0.190 \\
\hline Patient Characteristics & Yes & Yes & Yes & Yes & Yes & & & \\
\hline Plan Characteristics & No & Yes & Yes & Yes & Yes & & & \\
\hline Control for Charges & No & No & No & No & Yes & & & \\
\hline HRR Fixed Effects & No & No & Yes & - & - & & & \\
\hline Hospital Fixed Effects & No & No & No & Yes & Yes & & & \\
\hline
\end{tabular}




\section{Appendix Table 24: Levels of Variation in High/Low BCBS Facilities}

\section{Panel A: Overall}

\begin{tabular}{|c|c|c|c|}
\hline & \multicolumn{3}{|c|}{ Coefficient of Variation } \\
\hline & (1) & (2) & (3) \\
\hline & Across HRR & Within HRR & Within Hospital \\
\hline Inpatient & 0.349 & 0.429 & 1.000 \\
\hline Hip Replacement & 0.348 & 0.218 & 0.189 \\
\hline Knee Replacement & 0.362 & 0.306 & 0.219 \\
\hline Cesarean Section & 0.350 & 0.245 & 0.178 \\
\hline Vaginal Delivery & 0.351 & 0.254 & 0.189 \\
\hline PTCA & 0.445 & 0.288 & 0.242 \\
\hline Colonoscopy & 0.383 & 0.311 & 0.170 \\
\hline Lower Limb MRI & 0.325 & 0.312 & 0.173 \\
\hline
\end{tabular}


Appendix Table 24, continued

Panel B: High BCBS (counties with over 51 percent market share)

\begin{tabular}{|c|c|c|c|}
\hline & \multicolumn{3}{|c|}{ Coefficient of Variation } \\
\hline & (1) & (2) & (3) \\
\hline & Across HRR & Within HRR & Within Hospital \\
\hline Inpatient & 0.414 & 0.422 & 0.907 \\
\hline Hip Replacement & 0.340 & 0.174 & 0.148 \\
\hline Knee Replacement & 0.375 & 0.237 & 0.189 \\
\hline Cesarean Section & 0.337 & 0.210 & 0.175 \\
\hline Vaginal Delivery & 0.393 & 0.243 & 0.190 \\
\hline PTCA & 0.475 & 0.188 & 0.183 \\
\hline Colonoscopy & 0.377 & 0.276 & 0.163 \\
\hline Lower Limb MRI & 0.317 & 0.299 & 0.157 \\
\hline
\end{tabular}


Appendix Table 24, continued

Panel C: Low BCBS (counties with under 51 percent market share)

\begin{tabular}{|c|c|c|c|}
\hline & \multicolumn{3}{|c|}{ Coefficient of Variation } \\
\hline & (1) & (2) & (3) \\
\hline & Across HRR & Within HRR & Within Hospital \\
\hline Inpatient & 0.385 & 0.429 & 1.042 \\
\hline Hip Replacement & 0.353 & 0.220 & 0.203 \\
\hline Knee Replacement & 0.351 & 0.324 & 0.229 \\
\hline Cesarean Section & 0.358 & 0.251 & 0.179 \\
\hline Vaginal Delivery & 0.324 & 0.258 & 0.189 \\
\hline PTCA & 0.461 & 0.283 & 0.256 \\
\hline Colonoscopy & 0.393 & 0.313 & 0.172 \\
\hline Lower Limb MRI & 0.348 & 0.312 & 0.179 \\
\hline
\end{tabular}


Appendix Table 25: Cross Sectional Analysis of Hospital Payments in High/Low BCBS Counties, 2008-2011 Panel A: Prices without HRR Fixed Effects, 2008-2011

\begin{tabular}{|c|c|c|c|c|}
\hline & $(1)$ & $(2)$ & (3) & (4) \\
\hline Dependent Variable: & \multicolumn{4}{|c|}{$\ln ($ Facilities Price $)$} \\
\hline \multirow[t]{2}{*}{ Monopoly } & $0.190 * * *$ & $0.190 * * *$ & $0.155 * * *$ & $0.225 * * *$ \\
\hline & $(0.024)$ & $(0.025)$ & $(0.031)$ & $(0.039)$ \\
\hline \multirow[t]{2}{*}{ Duopoly } & $0.130 * * *$ & $0.130 * * *$ & $0.108 * * *$ & $0.153 * * *$ \\
\hline & $(0.020)$ & $(0.020)$ & $(0.024)$ & $(0.038)$ \\
\hline \multirow[t]{2}{*}{ Triopoly } & $0.083 * * *$ & $0.083 * * *$ & $0.056 * *$ & $0.113 * * *$ \\
\hline & $(0.023)$ & $(0.023)$ & $(0.028)$ & $(0.041)$ \\
\hline \multirow[t]{2}{*}{ HCCI Market Share } & $-0.006 * * *$ & $-0.006 * * *$ & $-0.007 * * *$ & $-0.004 *$ \\
\hline & $(0.002)$ & $(0.002)$ & $(0.002)$ & $(0.002)$ \\
\hline \multirow[t]{2}{*}{ BCBS Market Share } & & $<0.001$ & & \\
\hline & & $(0.001)$ & & \\
\hline Sample & Overall & Overall & Low BCBS & High BCBS \\
\hline HRR FE & No & No & No & No \\
\hline Observations & 8,772 & 8,772 & 6,084 & 2,688 \\
\hline
\end{tabular}


Appendix Table 25, continued

Panel B: Prices with HRR Fixed Effects, 2008-2011

\begin{tabular}{|c|c|c|c|c|}
\hline & $(1)$ & $(2)$ & (3) & (4) \\
\hline Dependent Variable: & \multicolumn{4}{|c|}{$\ln ($ Facilities Price $)$} \\
\hline Monopoly & $\begin{array}{c}0.118^{* * *} * \\
(0.024)\end{array}$ & $\begin{array}{c}0.112 * * * \\
(0.023)\end{array}$ & $\begin{array}{c}0.126 * * * \\
(0.029)\end{array}$ & $\begin{array}{c}0.036 \\
(0.039)\end{array}$ \\
\hline Duopoly & $\begin{array}{c}0.073 * * * \\
(0.024)\end{array}$ & $\begin{array}{c}0.069 * * * \\
(0.023)\end{array}$ & $\begin{array}{c}0.073 * * * \\
(0.025)\end{array}$ & $\begin{array}{c}0.023 \\
(0.050)\end{array}$ \\
\hline Triopoly & $\begin{array}{c}0.036 \\
(0.023)\end{array}$ & $\begin{array}{c}0.036 \\
(0.023)\end{array}$ & $\begin{array}{c}0.042 \\
(0.026)\end{array}$ & $\begin{array}{l}-0.001 \\
(0.046)\end{array}$ \\
\hline HCCI Market Share & $\begin{array}{c}-0.007 * * * \\
(0.002)\end{array}$ & $\begin{array}{c}-0.007 * * * \\
(0.002)\end{array}$ & $\begin{array}{c}-0.006^{* * * *} \\
(0.002)\end{array}$ & $\begin{array}{c}-0.008 * * * \\
(0.002)\end{array}$ \\
\hline BCBS Market Share & & $\begin{array}{c}0.001 \\
(0.001)\end{array}$ & & \\
\hline Sample & Overall & Overall & Low BCBS & High BCBS \\
\hline HRR FE & Yes & Yes & Yes & Yes \\
\hline Observations & 8,772 & 8,772 & 6,084 & 2,688 \\
\hline
\end{tabular}


Panel C: Share of Chargemaster, 2010-2011

Appendix Table 25, continued

\begin{tabular}{|c|c|c|c|c|}
\hline & $(1)$ & $(2)$ & (3) & (4) \\
\hline Dependent Variable: & \multicolumn{4}{|c|}{ Percent of Cases Paid Share of Charges } \\
\hline \multirow[t]{2}{*}{ Monopoly } & $10.455^{* * *}$ & $10.215 * * *$ & $7.917 * * *$ & $11.924 * * *$ \\
\hline & $(1.778)$ & $(1.813)$ & $(2.064)$ & $(2.872)$ \\
\hline \multirow[t]{2}{*}{ Duopoly } & $5.702 * * *$ & $5.567 * * *$ & $4.080^{*}$ & $6.604^{*}$ \\
\hline & $(1.596)$ & $(1.624)$ & $(1.755)$ & $(2.788)$ \\
\hline \multirow[t]{2}{*}{ Triopoly } & $4.909 * *$ & $4.951 * *$ & 2.886 & 4.909 \\
\hline & $(1.608)$ & $(1.601)$ & $(1.859)$ & $(2.692)$ \\
\hline \multirow[t]{2}{*}{ HCCI Market Share } & $-0.403 * * *$ & $-0.367 * *$ & $-0.320 *$ & $-0.702 * *$ \\
\hline & $(0.120)$ & $(0.125)$ & $(0.128)$ & $(0.254)$ \\
\hline \multirow[t]{2}{*}{ BCBS Market Share } & & 0.077 & & \\
\hline & & $(0.051)$ & & \\
\hline Sample & Overall & Overall & Low BCBS & High BCBS \\
\hline HRR FE & Yes & Yes & Yes & Yes \\
\hline Observations & 4,344 & 4,344 & 2,980 & 1,364 \\
\hline
\end{tabular}


Panel D: Share Linked to Medicare, 2010-2011

\section{Appendix Table 25, continued}

\begin{tabular}{|c|c|c|c|c|}
\hline & $(1)$ & $(2)$ & (3) & (4) \\
\hline Dependent Variable: & \multicolumn{4}{|c|}{ Percent of Cases Tied to Medicare } \\
\hline \multirow[t]{2}{*}{ Monopoly } & $-11.293 * * *$ & $-11.342 * * *$ & $-14.721 * * *$ & -2.779 \\
\hline & $(3.160)$ & $(3.175)$ & $(3.666)$ & $(5.520)$ \\
\hline \multirow[t]{2}{*}{ Duopoly } & $-5.595 * *$ & $-5.634 * *$ & $-6.271 * *$ & -7.414 \\
\hline & $(2.316)$ & $(2.319)$ & $(2.770)$ & $(4.790)$ \\
\hline \multirow[t]{2}{*}{ Triopoly } & $-5.747 * *$ & $-5.744 * *$ & $-6.760 * *$ & -1.960 \\
\hline & $(2.790)$ & $(2.792)$ & $(3.361)$ & $(4.842)$ \\
\hline \multirow{2}{*}{ HCCI Market Share } & $0.616^{* * *}$ & $0.626 * * *$ & $0.470 * *$ & $1.590 * * *$ \\
\hline & $(0.174)$ & $(0.166)$ & $(0.188)$ & $(0.328)$ \\
\hline \multirow[t]{2}{*}{ BCBS Market Share } & & 0.024 & & \\
\hline & & $(0.091)$ & & \\
\hline Sample & Overall & Overall & Low BCBS & High BCBS \\
\hline HRR FE & Yes & Yes & Yes & Yes \\
\hline Observations & 3,669 & 3,669 & 2,620 & 1,049 \\
\hline
\end{tabular}




\begin{tabular}{|c|c|c|c|c|c|c|c|}
\hline & $(1)$ & $(2)$ & $(3)$ & $(4)$ & $(5)$ & $(6)$ & $(7)$ \\
\hline & \multicolumn{7}{|c|}{$\ln ($ price $)$} \\
\hline Distance (miles): & 5 & 10 & 15 & 20 & 25 & 30 & 50 \\
\hline \multicolumn{8}{|l|}{ Panel A: Full Sample } \\
\hline Post-Merger & $\begin{array}{c}0.060 * * \\
(0.025)\end{array}$ & $\begin{array}{c}0.039 * * \\
(0.019)\end{array}$ & $\begin{array}{c}0.021 \\
(0.013)\end{array}$ & $\begin{array}{l}0.023 * \\
(0.013)\end{array}$ & $\begin{array}{c}0.024 * * \\
(0.011)\end{array}$ & $\begin{array}{c}0.014 \\
(0.011)\end{array}$ & $\begin{array}{c}0.008 \\
(0.009)\end{array}$ \\
\hline Observations & 8,655 & 8,655 & 8,655 & 8,655 & 8,655 & 8,655 & 8,655 \\
\hline \multicolumn{8}{|c|}{ Panel B: Low BCBS Share } \\
\hline Post-Merger & $\begin{array}{c}0.074 * * * \\
(0.028)\end{array}$ & $\begin{array}{c}0.053 * * \\
(0.021)\end{array}$ & $\begin{array}{c}0.040 * * \\
(0.016)\end{array}$ & $\begin{array}{c}0.038 * * \\
(0.015)\end{array}$ & $\begin{array}{c}0.035 * * * \\
(0.013)\end{array}$ & $\begin{array}{c}0.027 * * \\
(0.013)\end{array}$ & $\begin{array}{c}0.022 * * \\
(0.011)\end{array}$ \\
\hline Observations & 5,831 & 5,831 & 5,831 & 5,831 & 5,831 & 5,831 & 5,831 \\
\hline \multicolumn{8}{|c|}{ Panel C: High BCBS Share } \\
\hline Post-Merger & $\begin{array}{c}0.021 \\
(0.050)\end{array}$ & $\begin{array}{c}0.015 \\
(0.033)\end{array}$ & $\begin{array}{l}-0.003 \\
(0.021)\end{array}$ & $\begin{array}{c}0.013 \\
(0.018)\end{array}$ & $\begin{array}{c}0.016 \\
(0.015)\end{array}$ & $\begin{array}{c}0.014 \\
(0.014)\end{array}$ & $\begin{array}{c}0.007 \\
(0.012)\end{array}$ \\
\hline Observations & 2,847 & 2,847 & 2,847 & 2,847 & 2,847 & 2,847 & 2,847 \\
\hline
\end{tabular}




\section{Appendix Figure 1: HCCI Data Coverage Rates by State}

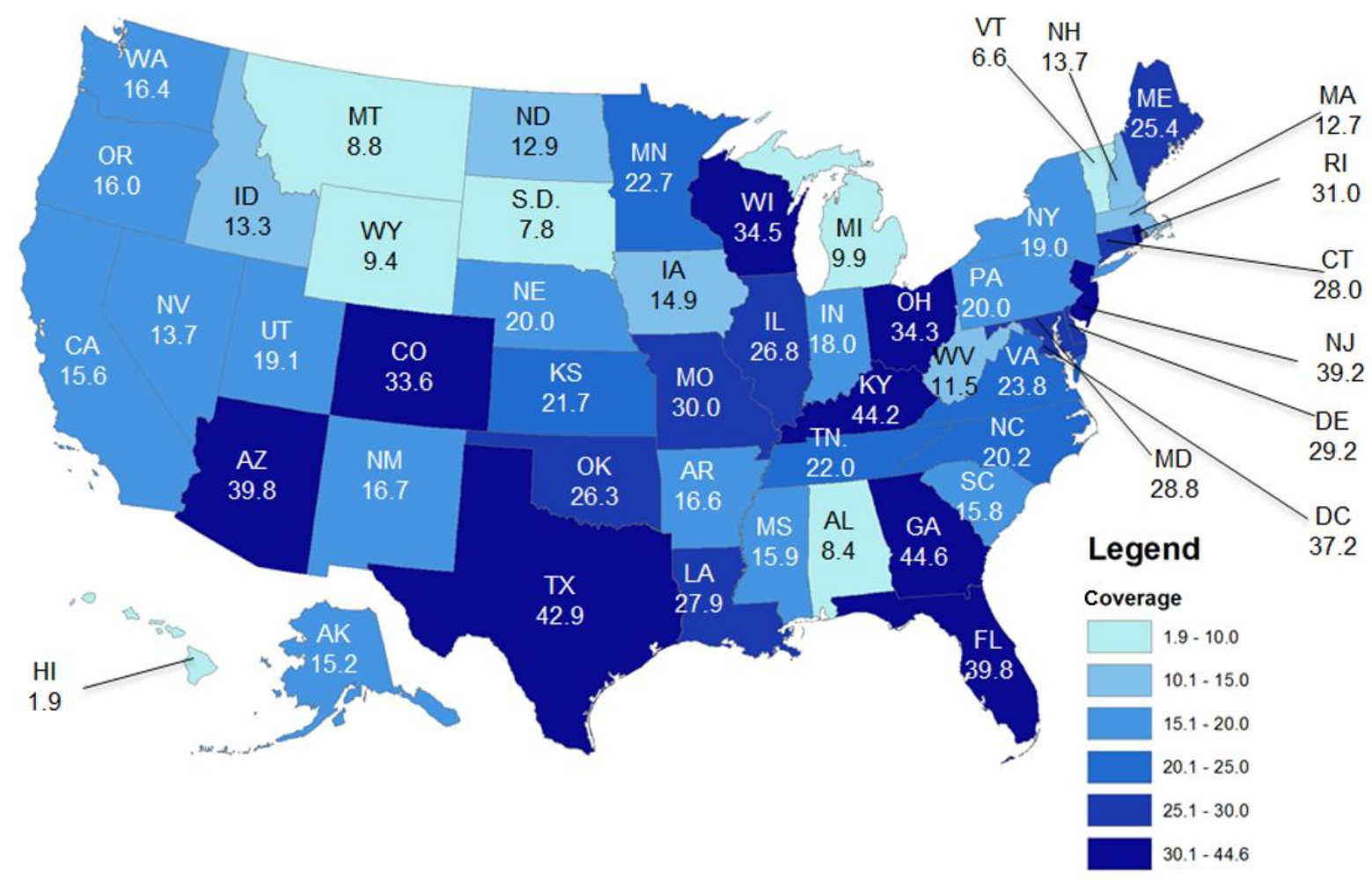

Notes: Coverage rates $=$ number of HCCI lives enrolled divided by total number of beneficiaries. Coverage rates were calculated using $2011 \mathrm{HCCI}$ enrollment data. Statewide insurance coverage totals were derived from the American Community Survey for 2011. All numbers in percentages. 


\section{Appendix Figure 2: Correlations between Negotiated Prices and Charges for All}

Procedures, 2011

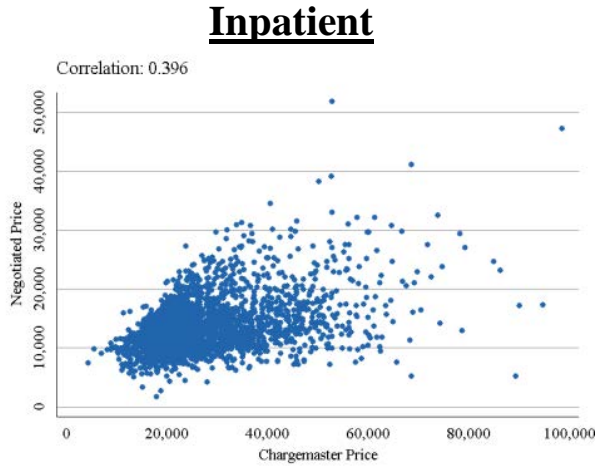

$\underline{\text { Knee Replacement }}$

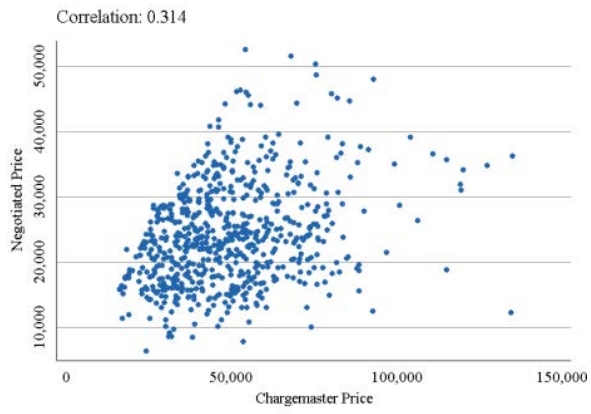

Vaginal Delivery

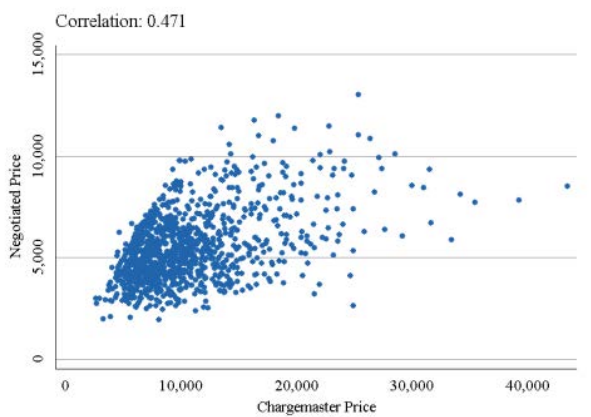

Colonoscopy

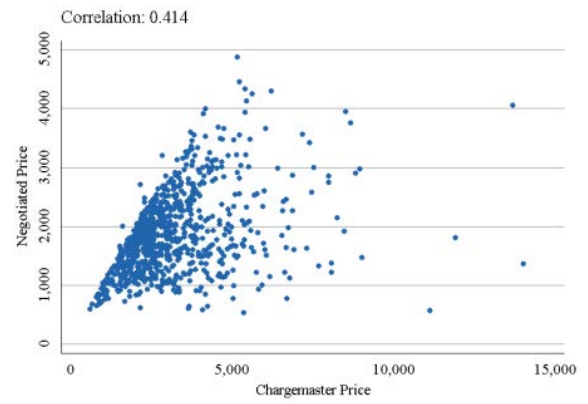

\section{Hip Replacement}

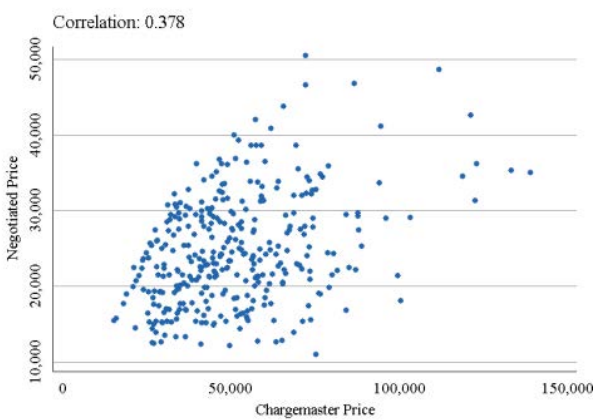

Cesarean Section

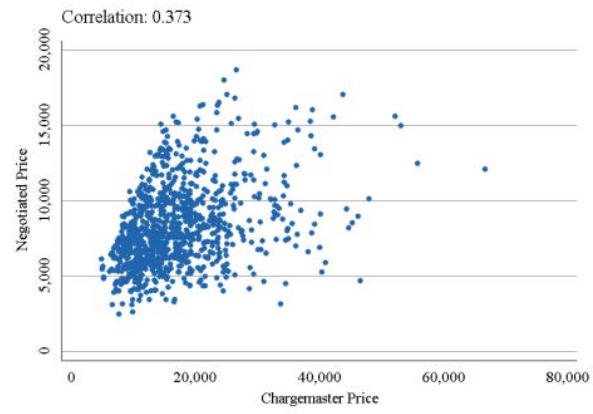

PTCA

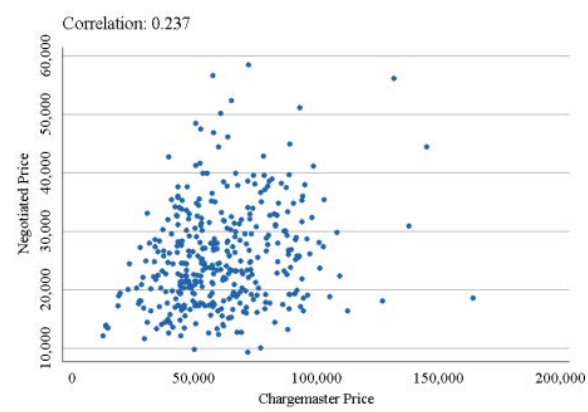

\section{Lower Limb MRI}

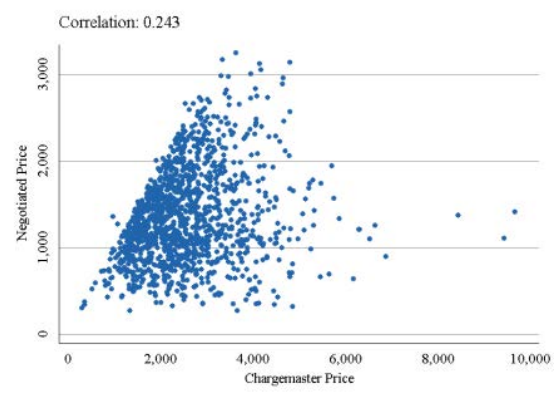

Notes: These are scatter plots of hospital charges for our main procedures and regression-adjusted transaction prices ("negotiated prices"). We include providers who deliver 10 or more of the specific procedure per year (50 for inpatient). We include prices from 2011. The figures contain the correlation between charges and transaction prices. 


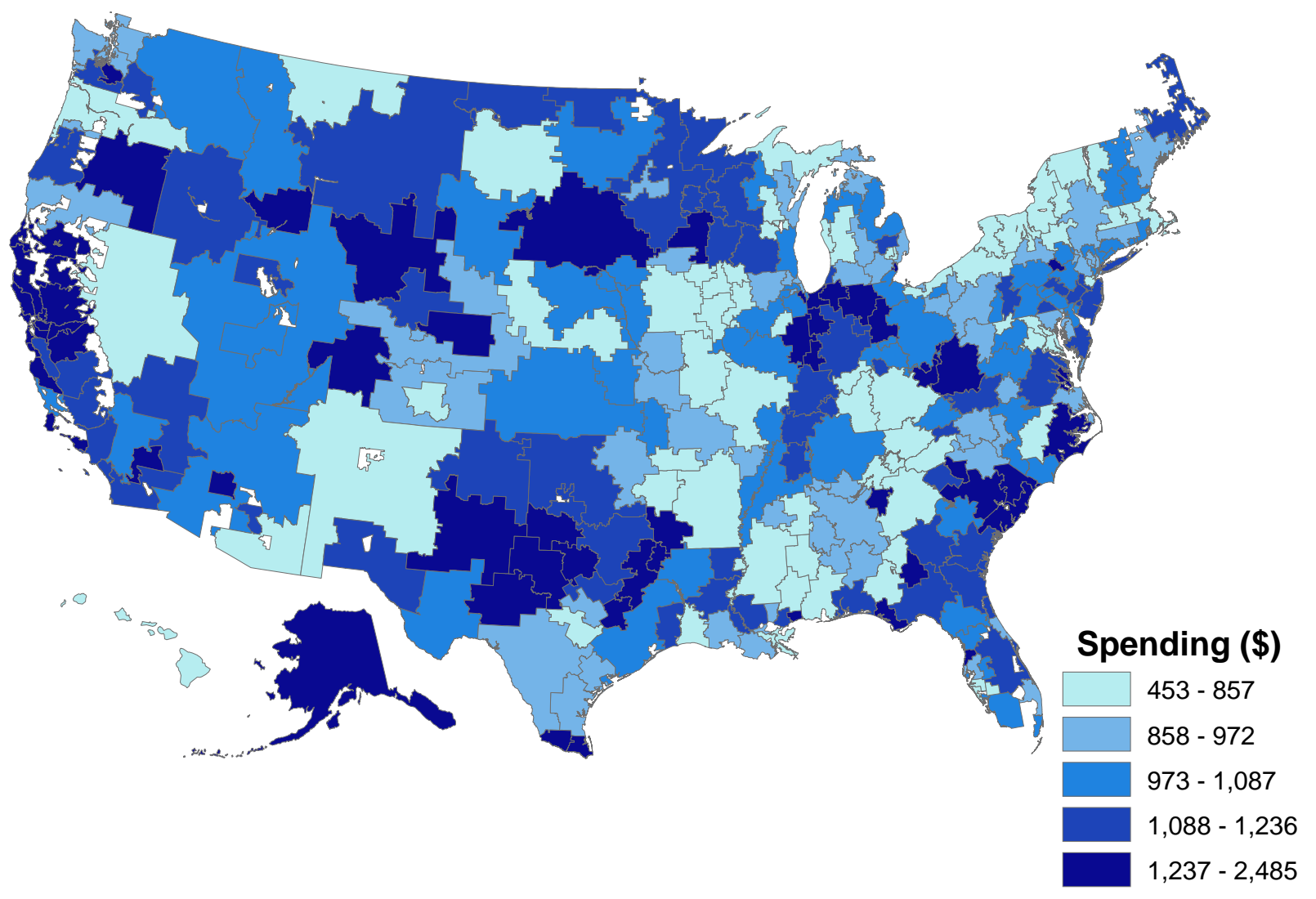

\begin{tabular}{cccc}
\hline \hline Mean & SD & Min & Max \\
$\$ 1,059$ & $\$ 258$ & $\$ 453$ & $\$ 2,485$ \\
\hline \hline
\end{tabular}

Notes: This figure captures risk-adjusted inpatient spending per beneficiary by HRR using data from 2011. Each bin captures a quintile of spending per beneficiary. 


\section{Panel A: Total Medicare Spending per Beneficiary, 2011}

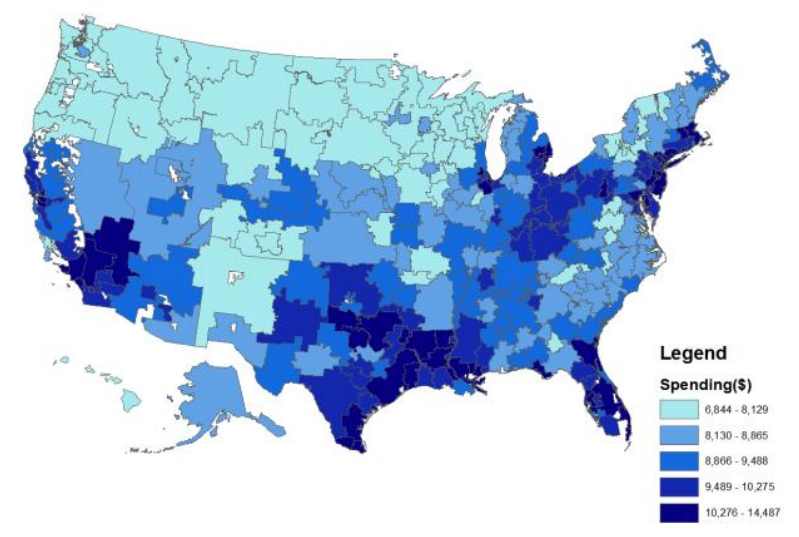

\begin{tabular}{cccc}
\hline \hline Mean & SD & Min & Max \\
$\$ 9,316$ & $\$ 1,315$ & $\$ 6,843$ & $\$ 14,487$ \\
\hline \hline
\end{tabular}

Panel B: Medicare Inpatient Spending Per Beneficiary, 2011

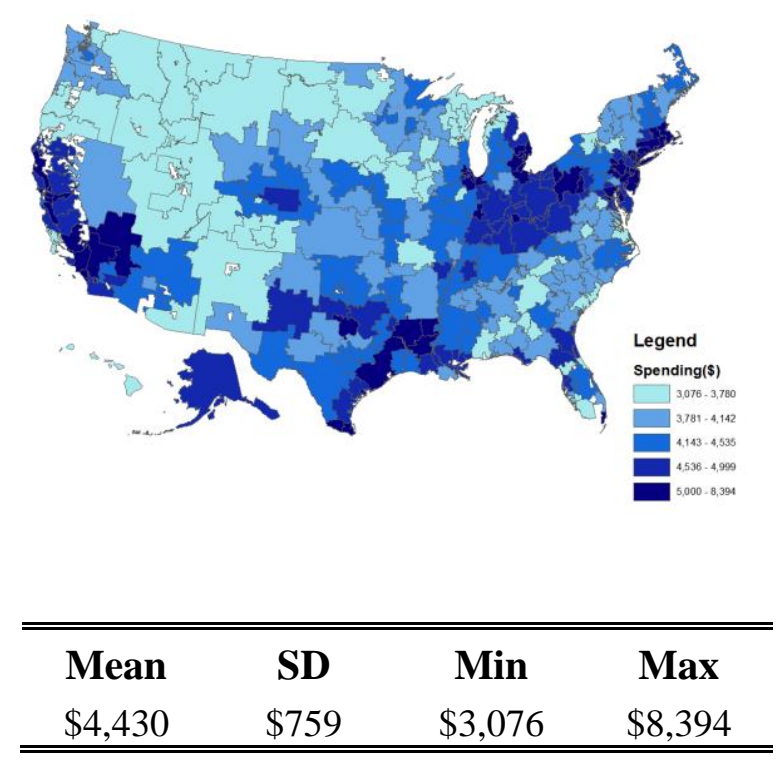

Notes: Medicare data are drawn from the Dartmouth Atlas (dartmouthatlas.org). Private data are risk-adjusted for age and sex using indirect standardization. Spending data do not include prescription drug spending. 
Appendix Figure 5: National Variation in Hospital Prices for All Procedures, 2011

$\underline{\text { Panel A: Hip Replacement Prices }}$

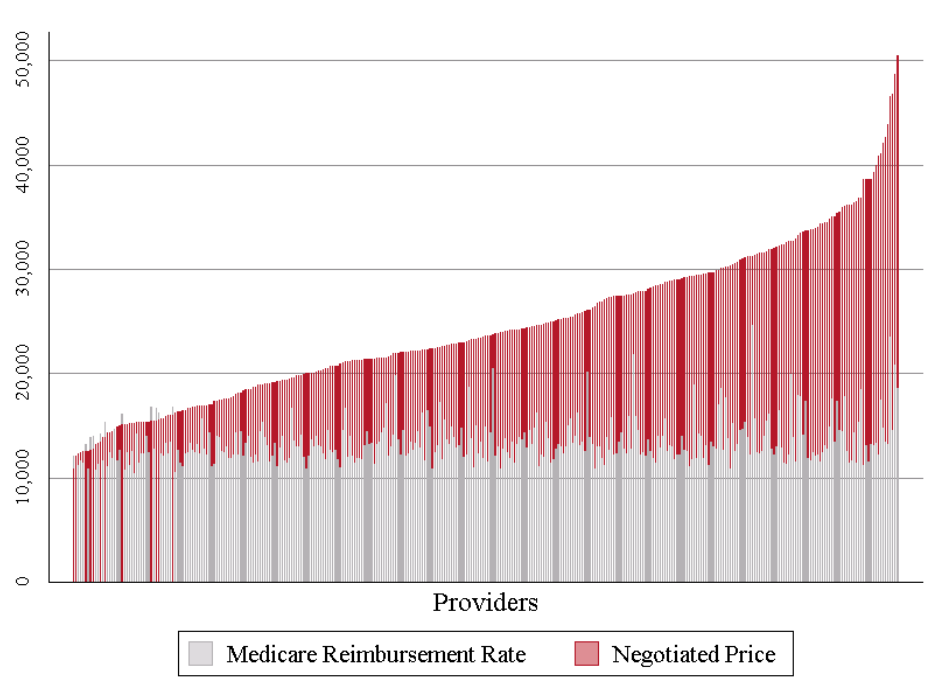

$\$ 10,894-\$ 50,476$

$\$ 15,501-\$ 33,933$

$\$ 19,231-\$ 29,319$

2.19

0.29

0.16

341

\author{
Mean \\ Min - Max \\ p10 - p90 \\ IQR \\ p90/10 ratio \\ Coefficient of Variation \\ Gini Coefficient \\ Number of Hospitals
}

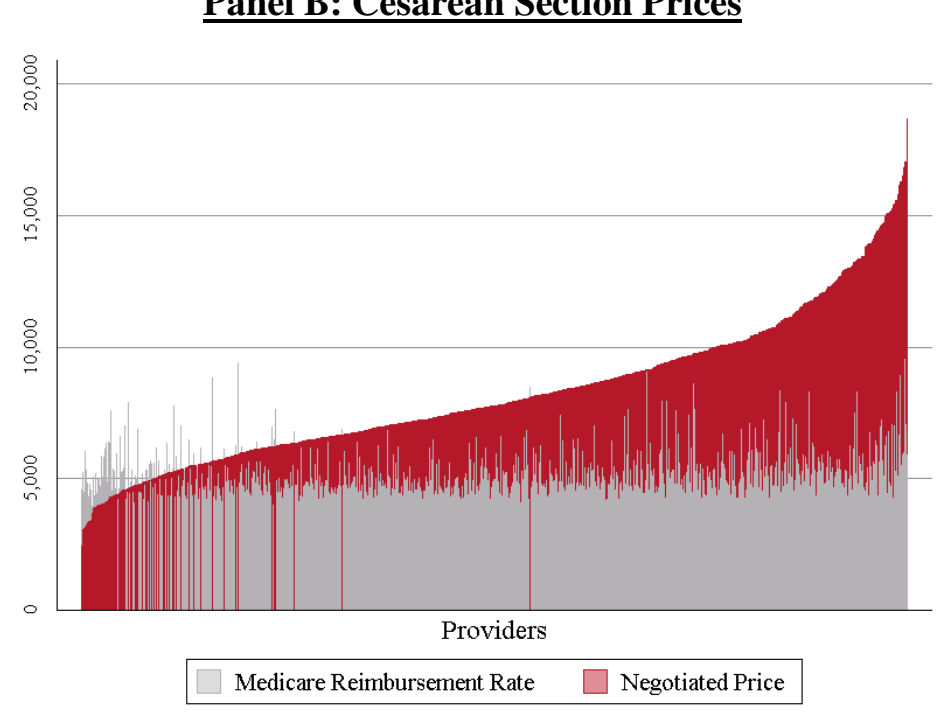

Panel B: Cesarean Section Prices
$\$ 8,258$

$\$ 2,424-\$ 18,679$

$\$ 5,154-\$ 12,109$

$\$ 6,317-\$ 9,815$

2.35

0.33

0.18

926 


\section{Appendix Figure 5: National Variation in Hospital Prices for All Procedures, continued}
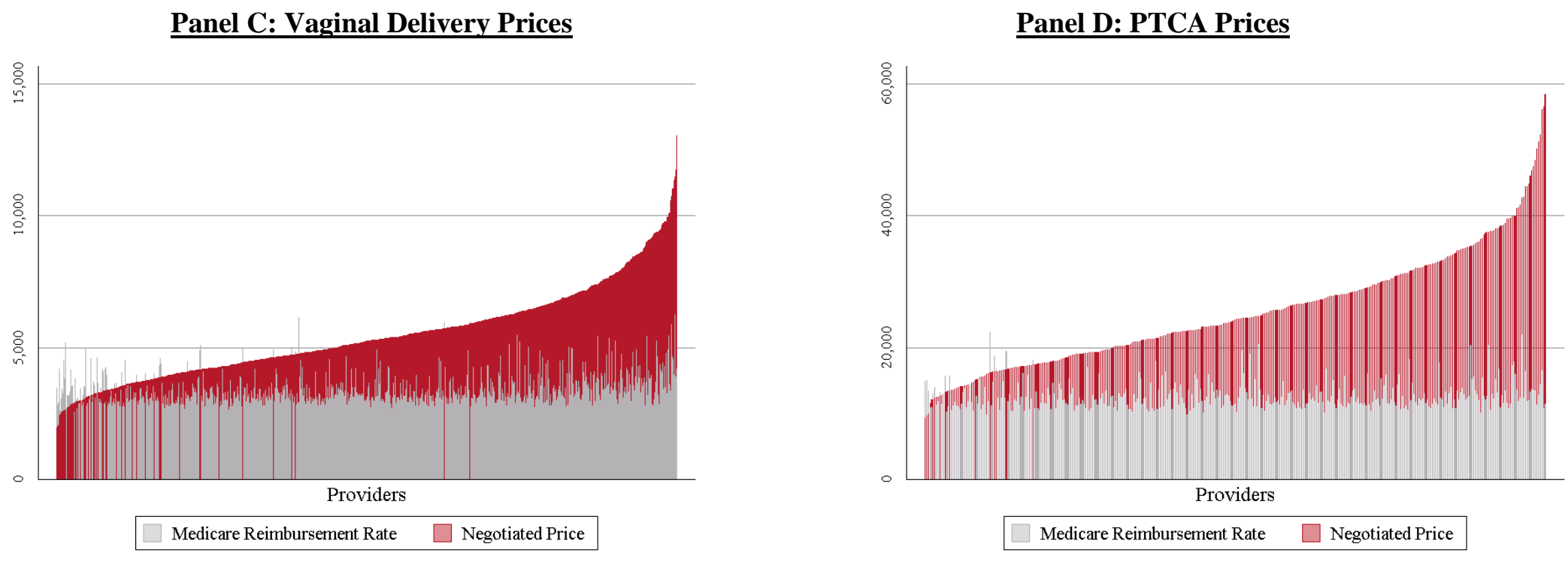

$\$ 5,465$
$\$ 1,944-\$ 13,039$
$\$ 3,486-\$ 7,814$
$\$ 4,218-\$ 6,387$
2.24
0.32
0.17
1,022

Mean
Min - Max
p10 - p90
IQR
p90/10 ratio
Coefficient of Variation
Gini Coefficient
Number of Hospitals

$\$ 25,395$

$\$ 9,293-\$ 58,433$

$\$ 15,965-\$ 37,097$

$\$ 19,034-\$ 30,528$

2.32

0.34

0.19

375 


\section{Appendix Figure 5: National Variation in Hospital Prices for All Procedures, continued}

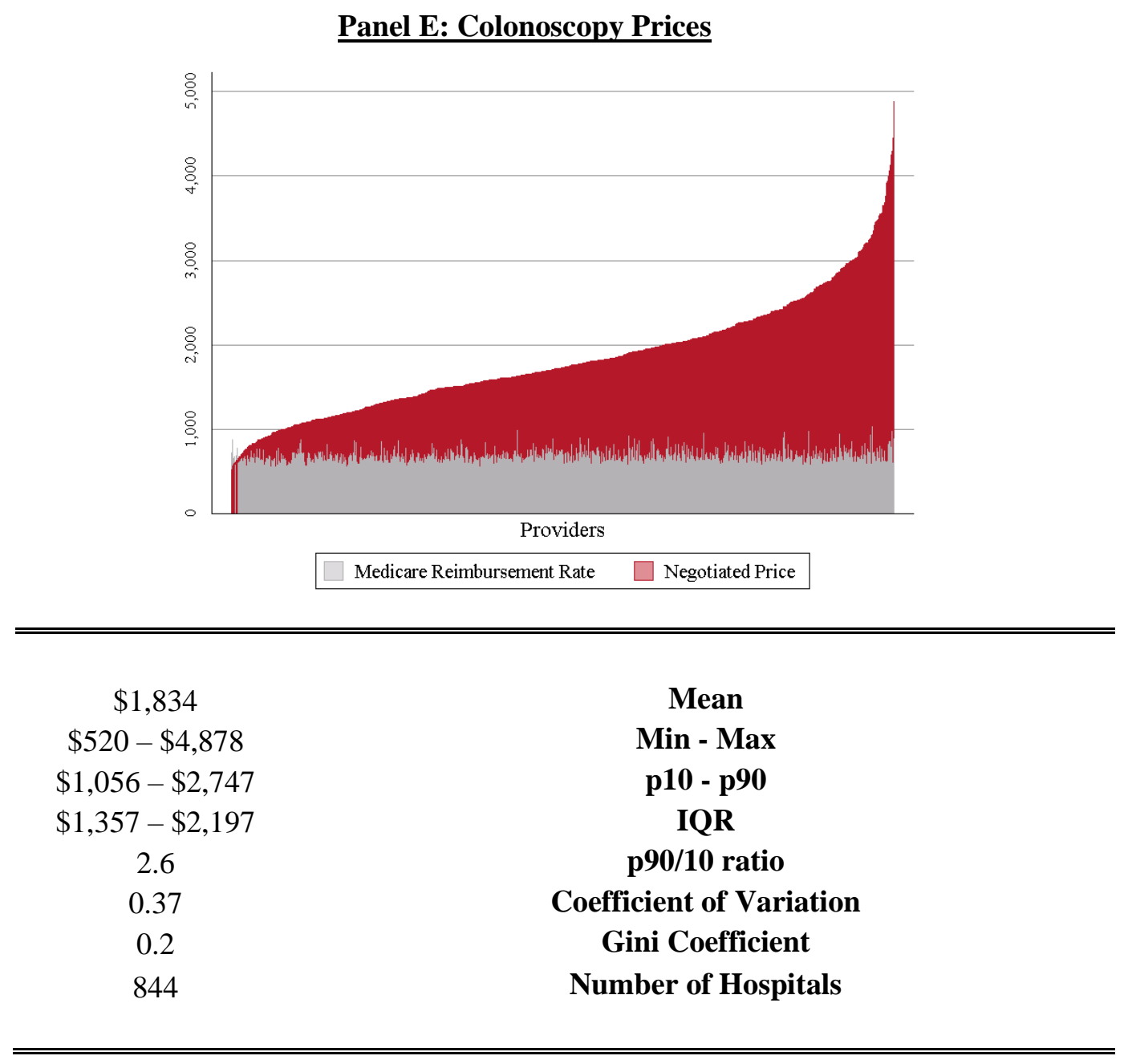

Notes: Each bar represents a single hospital's regression-adjusted transaction price based on hospital cases from 2011. The Medicare payment is based on the PPS fee schedule described in Appendix B4 and excludes outlier adjustments. The bars are ordered by private price. 


\section{Appendix Figure 6: Regression Adjusted HRR-Level Inpatient Hospital Prices Normalized Using the Medicare Wage Index}

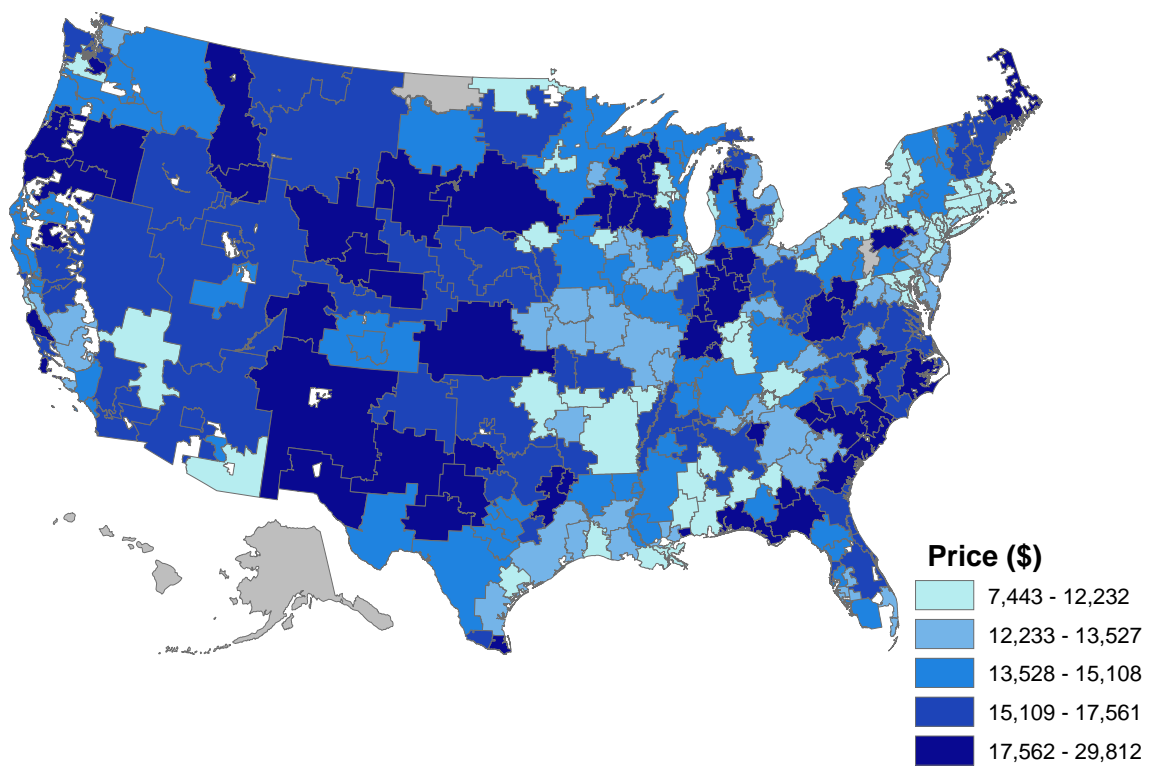

Notes: This figure presents coverage hospital regression adjusted inpatient prices per HRR, weighted by hospital activity, using data from 2011 and normalized prices using the Medicare 2011 wage index. This therefore captures price after adjusting for the cost of care in each HRR. Prices are risk-adjusted for DRG, age, and sex. 


\section{Appendix Figure 7: Contract Classification Rates by Minimum Case Count}

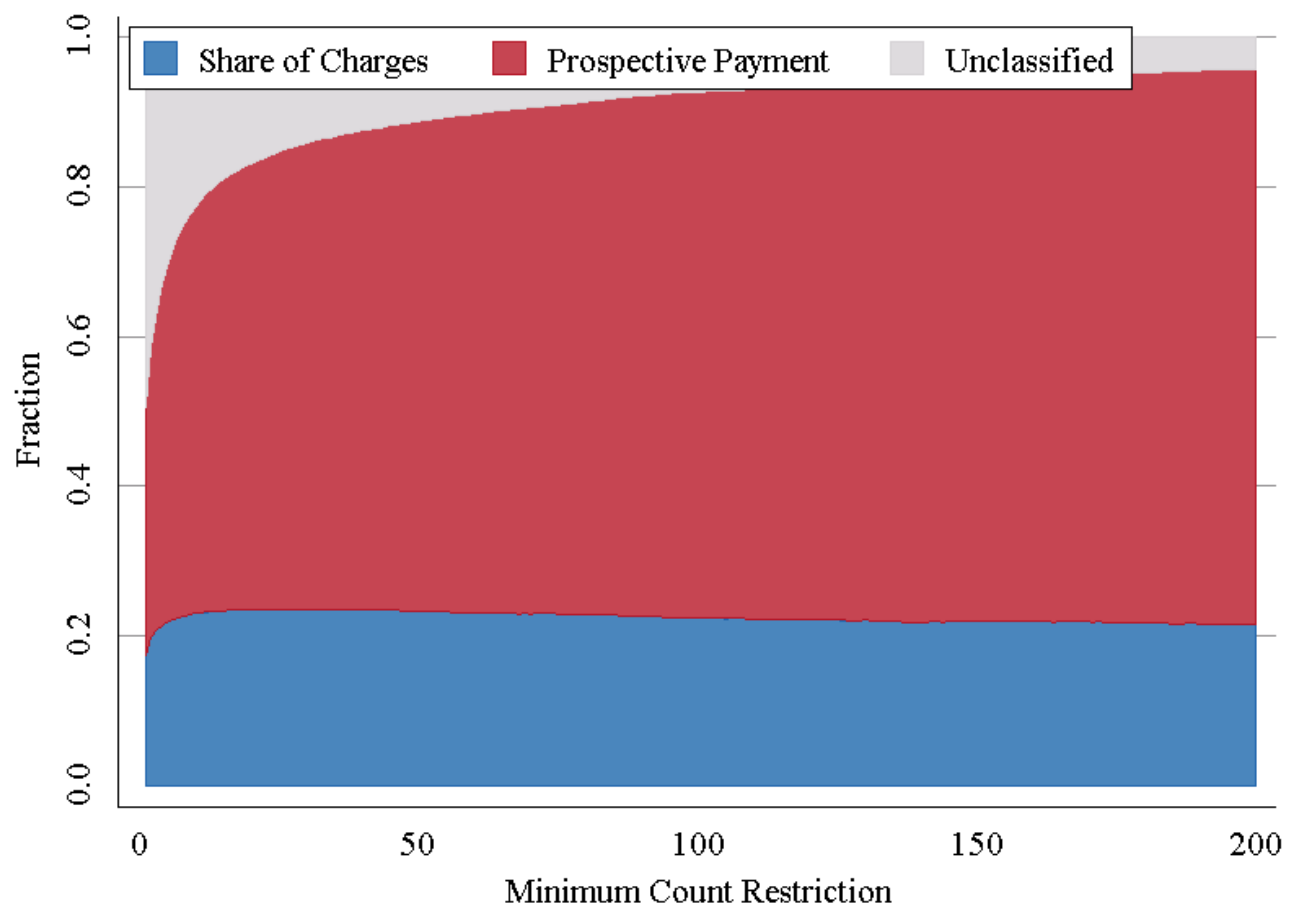

Notes: This figure presents fraction of cases classified as either prospective payment or paid as a percent markup over Medicare. Data is at the case level in the Inpatient sample in 2010 and 2011. The data include all hospital-DRG combinations for which there are at least $\mathrm{x}$-observations (the value on the $\mathrm{x}$-axis). 


\section{Appendix Figure 8: Percent of Hospital Cases Paid as Share of Charges, 2011}

\section{Inpatient}

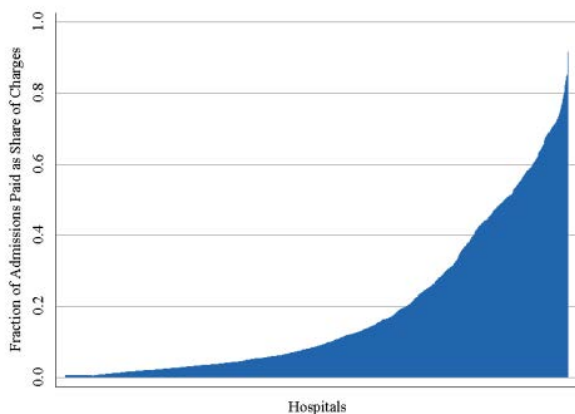

Knee Replacement

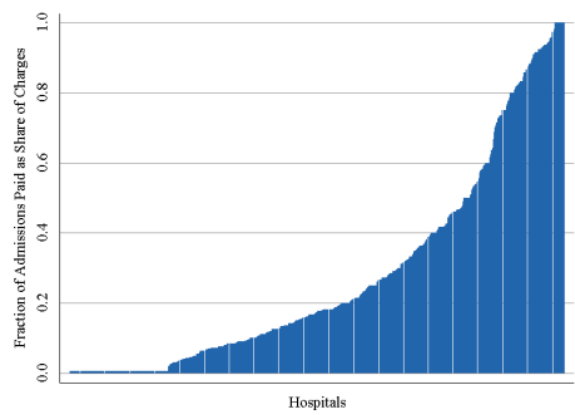

Vaginal Delivery

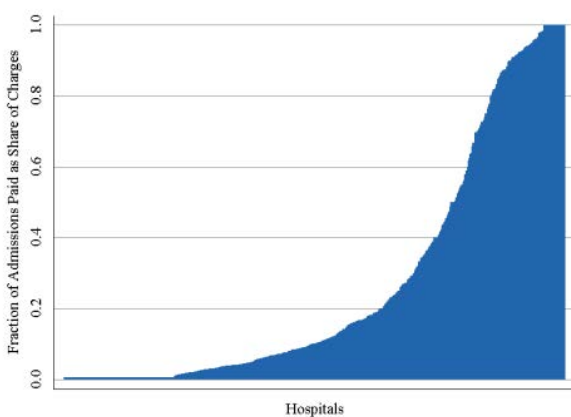

Colonoscopy

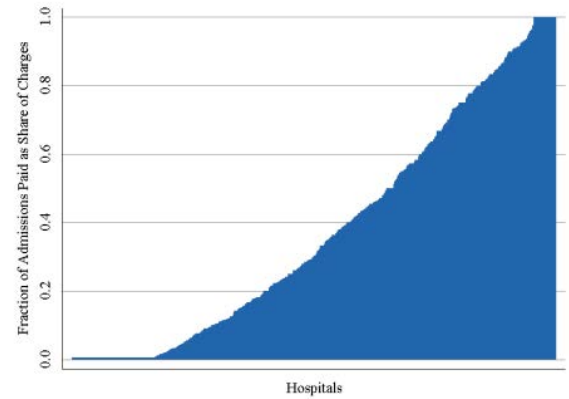

$\underline{\text { Hip Replacement }}$

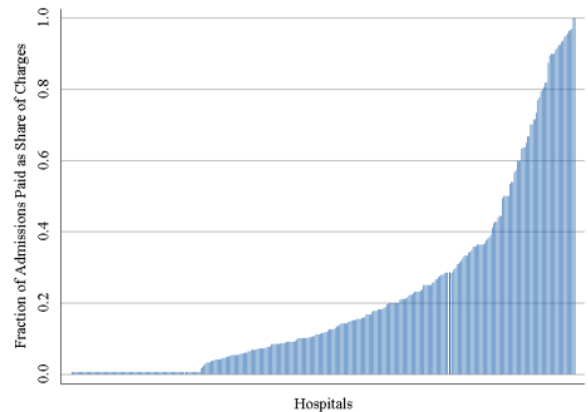

Cesarean Section

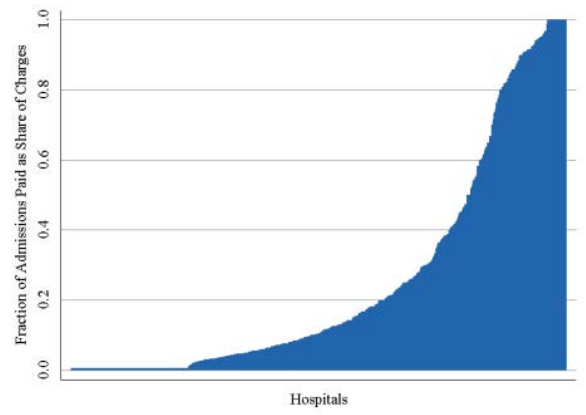

$\underline{\text { PTCA }}$

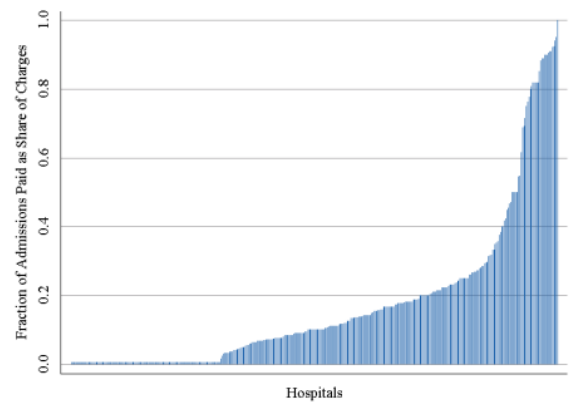

Notes: These are bar graphs of the percent of a hospital's cases paid as a share of charges for our main procedures. We include providers who deliver ten or more of the specific procedure per year ( 50 for inpatient). We include prices from 2011. The figures contain bars for each unique hospital, where the height indicates the percent of that hospital's cases that were paid as share of charges. For more detail on how we identify method of payment, see Appendix B3. 
Appendix Figure 9: Correlation between Prices Paid as Share of Charges and Charges across DRGs at a High Volume Hospital, 2011

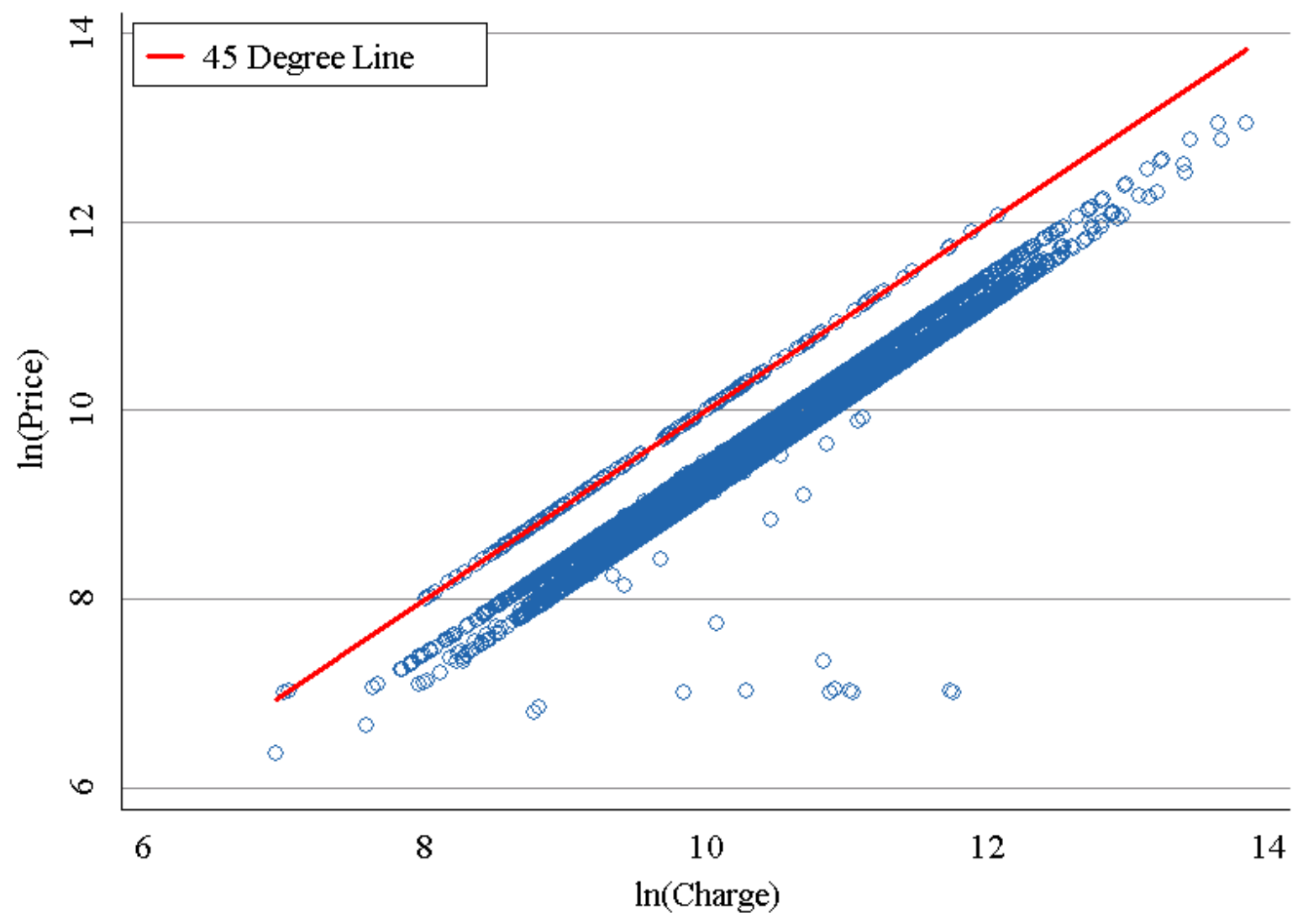

Notes: The y-axis presents logged, DRG-level prices and the x-axis presents logged, DRG-level charges within a high volume hospital for inpatient cases which occurred in 2011. 


\section{Appendix Figure 10: Bivariate Correlations of Hospital HHI with Observable Factors, 2008-2011}

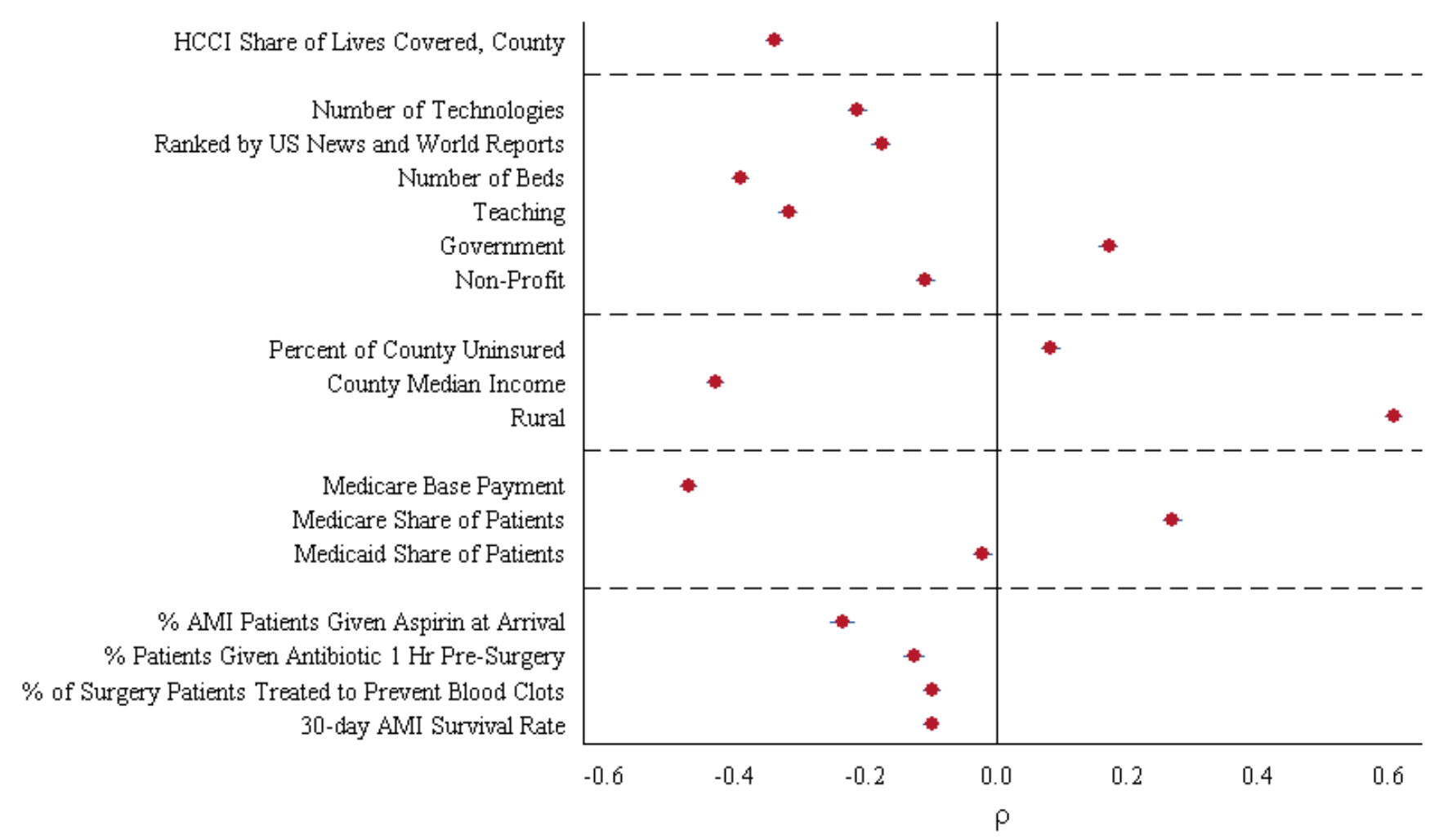

Notes: The X-axis captures the bivariate correlations between key variables featured in our regressions and our HHI. The bars capture the 95 percent confidence intervals surrounding the correlations. For government and non-profit, the omitted category is private for-profit hospital. 


\section{Appendix Figure 11: Bivariate Correlations of Hospital Percent Paid as Share of Charges with Observable Factors, 2010-2011}

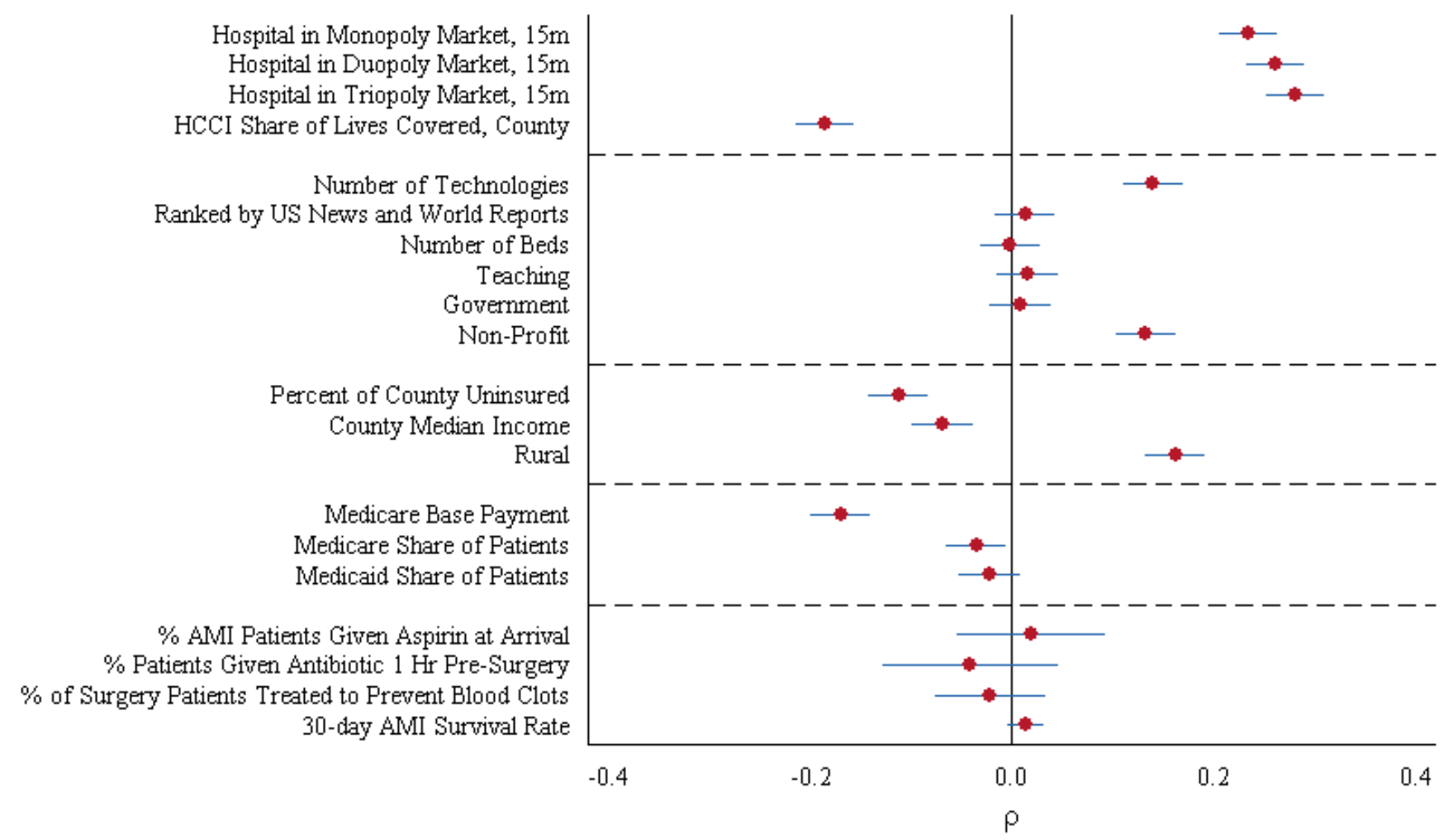

Notes: The x-axis captures the bivariate correlations between key variables featured in our regressions and our hospitals' share of cases at a hospital paid as a fraction of a hospitals' charges. The bars capture the 95 percent confidence intervals surrounding the correlations. Since these are bivariate correlations "Duopoly" is duopoly or monopoly and the implicit omitted category is triopoly or greater. "Triopoly" is triopoly, duopoly or monopoly. For government and non-profit, the omitted category is private for-profit hospital. 


\section{Appendix Figure 12: Bivariate Correlations of Percent of Prospective Payment Paid as a Share of Medicare with Observable Factors,}

\section{$\underline{2010-2011}$}

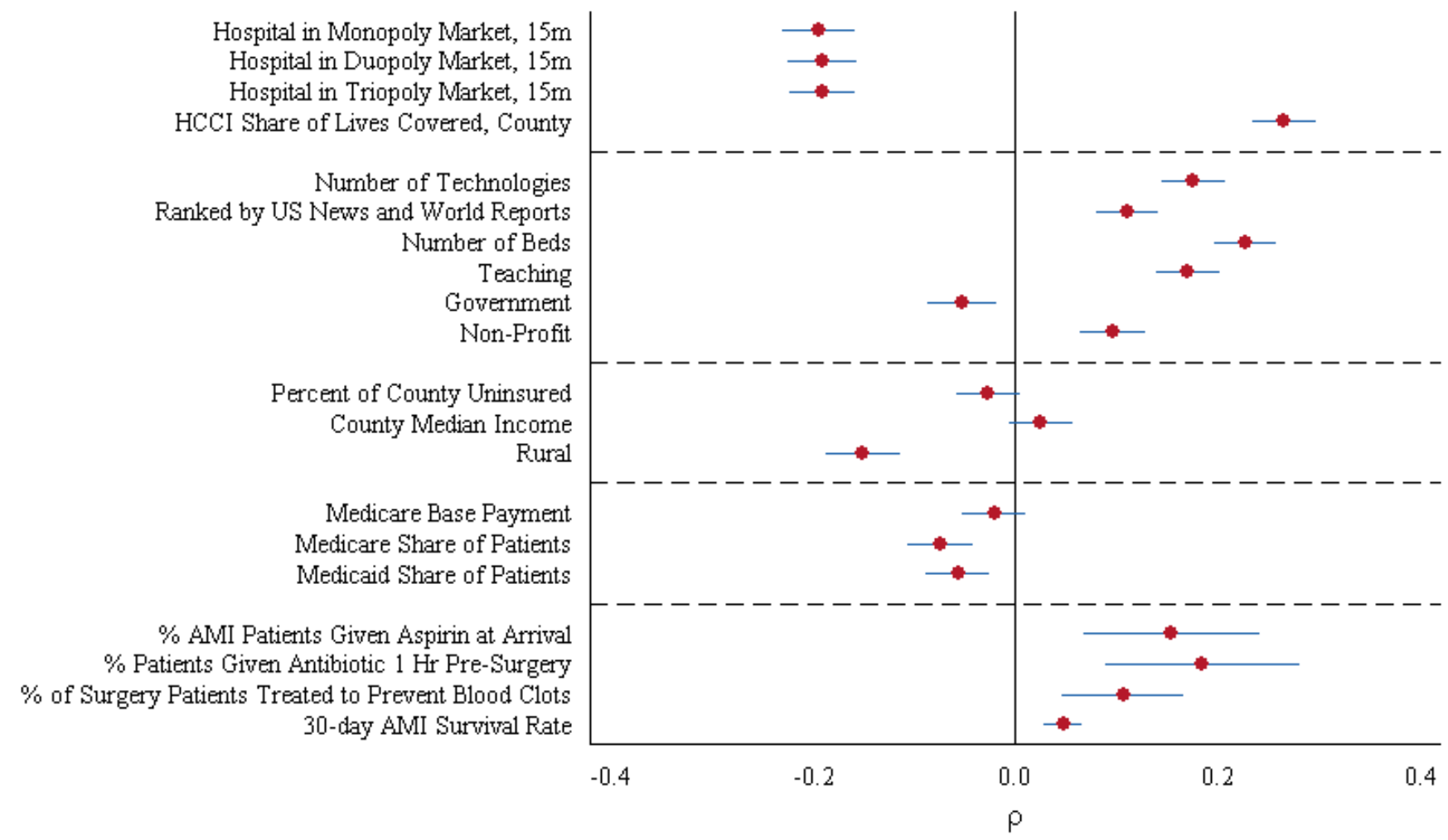

Notes: The x-axis captures the bivariate correlations between key variables featured in our regressions and our hospitals' share of fixed-price cases linked to the Medicare payment rate. The bars capture the 95 percent confidence intervals surrounding the correlations. Since these are bivariate correlations "Duopoly" is duopoly or monopoly and the implicit omitted category is triopoly or greater. "Triopoly" is triopoly, duopoly or monopoly. For government and non-profit, the omitted category is private for-profit hospital. 


\section{Appendix Figure 13: BCBS Market Share}

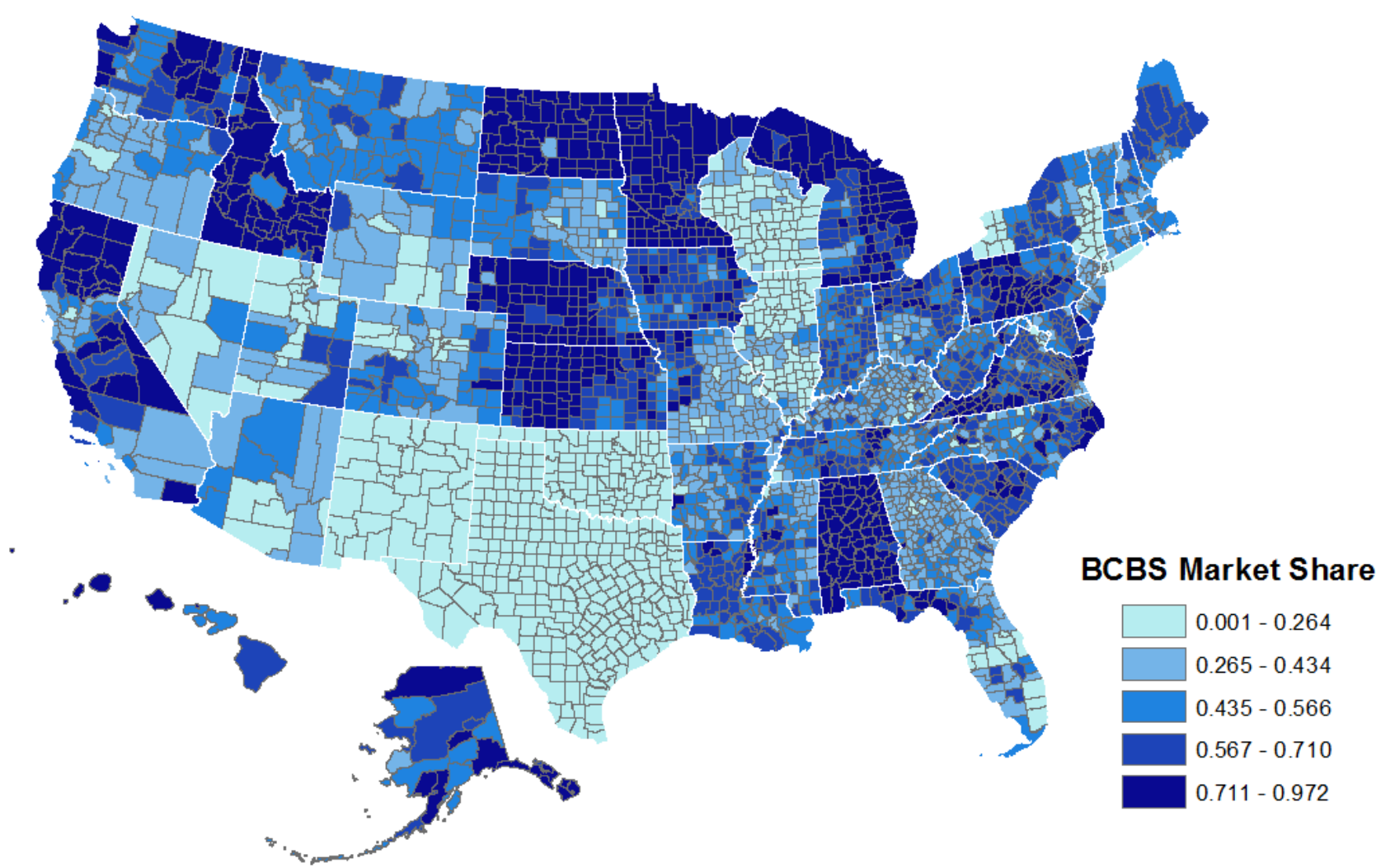

Notes: These are estimates of the share of covered lives by county covered by BCBS using HealthLeaders Interstudy coupled with Census data. 